\author{
Universidade de São Paulo \\ Instituto de Física
}

\title{
Preparação e estudo de nanotubos luminescentes de hidróxidos duplos lamelares (LDH) contendo íons terras raras
}

\author{
Alysson Ferreira Morais
}

Orientador: Prof. Dr. Danilo Mustafa

Tese de doutorado apresentada ao Instituto de Física como requisito parcial para obtenção do título de Doutor em Ciências.

Banca Examinadora:

Prof. Dr. Danilo Mustafa (IFUSP)

Prof. Dr. Antônio Domingues dos Santos (IFUSP)

Prof. ${ }^{a}$ Dr. ${ }^{a}$ Vera Regina Leopoldo Constantino (IQUSP)

Prof. ${ }^{a}$ Dr. ${ }^{a}$ Ana Valéria Lourenço (UNIFESP)

Prof. Dr. Gustavo Silva Wiederhecker (IFGW-UNICAMP) 


\section{FICHA CATALOGRÁFICA \\ Preparada pelo Serviço de Biblioteca e Informação do Instituto de Física da Universidade de São Paulo}

Morais, Alysson Ferreira

Preparação e estudo de nanotubos luminescentes de hidróxidos duplos lamelares (LDH) contendo íons terras raras São Paulo, 2018.

Tese (Doutorado) - Universidade de São Paulo. Instituto de Física. Depto. de Física dos Materiais e Mecânica.

Orientador: Prof. Dr. Danilo Mustafa

Área de Concentração: Física.

Unitermos: 1. Nanotubos; 2. Nanopartículas; 3. Luminescência; 4. Materiais porosos; 5 . Lantanídeos.

USP/IF/SBI-058/2018 


\author{
University of São Paulo \\ Physics Institute
}

\title{
Preparation and study of luminescent layered double hydroxide (LDH) nanotubes containing rare earth ions
}

\author{
Alysson Ferreira Morais
}

Supervisor: Prof. Dr. Danilo Mustafa

Thesis submitted to the Physics Institute of the University of São Paulo in partial fulfillment of the requirements for the degree of Doctor of Science.

Examining Committee:

Prof. Dr. Danilo Mustafa (IFUSP)

Prof. Dr. Antônio Domingues dos Santos (IFUSP)

Prof. ${ }^{a}$ Dr. ${ }^{\text {a }}$ Vera Regina Leopoldo Constantino (IQUSP)

Prof. a Dr. a Ana Valéria Lourenço (UNIFESP)

Prof. Dr. Gustavo Silva Wiederhecker (IFGW-UNICAMP)

São Paulo 



\section{Agradecimentos}

Sem dúvida, meu primeiro agradecimento merece ir para meus pais Paulo C. F. Morais e Roseane Ap. X. Morais e meu irmão Daniel F. Morais. Eles sempre me incentivaram, me apoiaram e são aqueles que estão comigo em todas as ocasiões. Sei que muitas vezes eles postergaram ou abdicaram dos seus sonhos para que eu pudesse viver o meu. Agradeço muito a toda minha família, em especial aos meus avós Alvina, Maria, Lupércia e José. Minha família em São Paulo, minha companheira, Débora Linhares, e Dolores, também merecem um agradecimento especial por terem me dado apoio durante todo o período desse trabalho.

Certamente, meu orientador, Prof. Danilo Mustafa, teve um papel fundamental na minha formação e gostaria de fazer um agradecimento especial a ele pelo seu exemplo de trabalho e espírito de colaboração. Sou testemunha do seu esforço de trabalho na pesquisa e sua preocupação com a formação dos alunos. Espero que seu exemplo se propague e se espalhe pelo IFUSP.

Como todo trabalho multidisciplinar, o desenvolvimento mostrado nesta tese teve a colaboração muito próxima de muitas pessoas, de diferentes áreas da ciência. Meus colegas Ivan G. N. Silva (IFUSP e IQUSP), Eric Breynaert (KULeuven), Sreeprasanth P. Sree (KULeuven) e Karl Lawers (KULeuven) contribuíram ativamente para a obtenção de alguns dos resultados mostrados nesta tese. Gostaria de fazer menção especial à Prof. ${ }^{\text {a }}$ Márcia Fantini, que abriu as portas de seu laboratório e gastou parte do seu tempo em algumas discussões aqui mostradas. Gostaria de fazer um agradecimento especial a Alfredo Duarte. Sou testemunha da sua incrível habilidade na operação dos microscópios eletrônicos da Central Analítica (CA) do IQUSP. Espero que a sua habilidade seja reconhecida pela CA e por seus usuários. Muitos dos resultados mais importantes dessa tese dependeram das medidas feitas pelo Alfredo.

Agradeço ao Laboratório de Cristalografia (LCr-IFUSP) por suporte nas medidas de difração e, em especial, aos seus técnicos, Antônio Carlos e Tarsis; ao Laboratório de Elementos do Bloco-f (LEB-f), em especial ao Prof. Hermi Felinto; ao Center for Surface Chemistry and Catalysis (COK) da KULeuven, ao qual adiciono meu obrigado a Sambhu Radhakrishnan, Sam Smet, Heleen Van Den Noortgate, Lieve Pollentier e aos professores 
Johan Martens e Christine Kirschhock; ao Laboratório de Química Supramolecular e Nanotecnologia (LQSN) do IQUSP, ao Prof. Henrique Toma e aos seus integrantes, Júlio Rocha, Jorge Shinoha e, em especial, ao Fernando Menegatti de Melo, que contribuiu bastante para o artigo que publicamos juntos. Agradeço ao Laboratório de Cristais Iônicos, Filmes Finos e Datação (LACIFID) do IFUSP, em especial ao Prof. José Chubaci, por disponibilizar o equipamento do grupo para nossas medidas de fotoluminescência.

Agradeço aos secretários e às secretárias da Comissão de Pós-Graduação do IFUSP, em especial ao Éber, à Andrea, à Paula e à Cláudia. Agradeço ao Eron, técnico do Departamento de Física dos Materiais e Mecânica do IFUSP, por auxiliar na manutenção das instalações do Laboratório de Nanomateriais e Aplicações (LNA).

Agradeço ao banco Santander por ter financiado minha visita à Universidade de Leuven (KULeuven, Bélgica) em 2016.

Agradeço ao Laboratório Nacional de Nanotecnologia (LNNano) pelo treinamento que realizei na operação de microscópios eletrônicos de transmissão.

Agradeço o suporte financeiro recebido da Fundação de Amparo à Pesquisa do Estado de São Paulo (FAPESP, projeto 2015/19210-0) na forma de diárias; da Coordenação de Aperfeiçoamento de Pessoal de Nível Superior (CAPES) na forma de passagem aérea por intermédio da Comissão de Pós-Graduação do IFUSP; e, do Conselho Nacional de Desenvolvimento Científico e Tecnológico $(\mathrm{CNPq})$ na forma de bolsa de pós-graduação. Agradeço o suporte financeiro fornecido pelo banco Santander para a realização de estágio no exterior. 


\section{Resumo}

Hidróxidos duplos lamelares (LDHs) são uma classe de materiais com fórmula química $\left[\mathrm{M}_{1-\mathrm{x}}^{\mathrm{II}} \mathrm{M}_{\mathrm{x}}^{\mathrm{III}}(\mathrm{OH})_{2}\right]\left[\mathrm{A}^{\mathrm{n}-}\right]_{\mathrm{x} / \mathrm{n}} \cdot \mathrm{yH}_{2} \mathrm{O}$ (onde $\mathrm{M}^{\mathrm{II}}$ e $\mathrm{M}^{\mathrm{III}}$ são metais di e trivalentes, respectivamente) formados pelo empilhamento de camadas positivamente carregadas de hidróxidos metálicos intercaladas por espécies aniônicas $\mathrm{A}^{\mathrm{n}-}$. Este trabalho descreve uma estratégia inédita para a produção de nanotubos de LDHs autossuportados $(\varnothing 20 \mathrm{~nm}$ e comprimentos $\gtrsim 100 \mathrm{~nm}$ ) através da coprecipitação de $\mathrm{Zn}^{2+}, \mathrm{Al}^{3+} \mathrm{e} \mathrm{Eu}^{3+} \mathrm{em} \mathrm{pH}$ controlado e sua auto-organização sobre micelas cilíndricas do surfactante Plurônico® P-123. A subsequente extração destes agentes estruturantes através de lavagem com metanol resultou em uma rede de nanotubos cilíndricos, ocos e interconectados, formados pela deposição de multicamadas de hidróxidos duplos intercalados pela molécula sensibilizadora ácido benzeno-1,3,5-tricarboxílico (ácido trimésico, BTC). A combinação de $\mathrm{Eu}^{3+}$ nas camadas de hidróxidos e BTC no meio interlamelar resultou em nanotubos com propriedades luminescentes, demonstrando de maneira notável como modificações químicas e morfológicas nos LDHs podem levar ao remodelamento das suas propriedades físicoquímicas e, consequentemente, direcionar suas aplicações de maneira desejável.

Palavras-chave: hidróxidos duplos lamelares; nanotubos; luminescência; nanomateriais; materiais porosos 


\begin{abstract}
Layered double hydroxides are a class of lamellar compounds with chemical formula $\left[\mathrm{M}_{1-\mathrm{x}}^{\mathrm{II}} \mathrm{M}^{\mathrm{III}}(\mathrm{OH})_{2}\right]^{\mathrm{x}+}\left[\mathrm{A}^{\mathrm{n}-}{ }_{\mathrm{n} / \mathrm{x}}\right]^{\mathrm{x}-}$ (with $\mathrm{M}^{\mathrm{II}}$ and $\mathrm{M}^{\mathrm{III}}$ being di and trivalent metals, respectively) that are formed by the stacking of positively charged mixed-valence metal hydroxide sheets intercalated by anionic species $\left(\mathrm{A}^{\mathrm{n}-}\right)$. This work describes a new strategy for the synthesis of self-supported mesoporous LDH nanotubes ( $\varnothing 20 \mathrm{~nm}$ and length $\gtrsim 100 \mathrm{~nm}$ ) by coprecipitation of $\mathrm{Zn}^{2+}, \mathrm{Al}^{3+}$ and $\mathrm{Eu}^{3+}$ around non-ionic worm-like micelles of Pluronic $®$ P-123 in controlled pH. Subsequent extraction of the structure-directing agent with methanol resulted in a network of interconnected, well-defined, multi-walled and hollow cylindrical LDH nanotubes intercalated by the sensitizing ligand BTC (1,3,5benzenetricarboxilate). The combination of $\mathrm{Eu}^{3+}$ in the hydroxide layers and BTC in the interlayers resulted in nanotubes with luminescent properties in a notable demonstration on how chemical and morphological changes in LDHs can lead to materials with tuned physico-chemical properties that can be tailored towards a wide range of applications.
\end{abstract}

Keywords: layered double hydroxides; nanotubes; luminescence; nanomaterials; porous materials 


\section{Sumário}

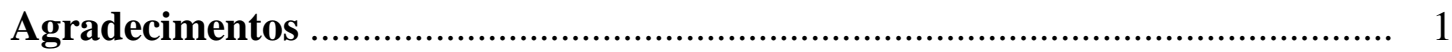

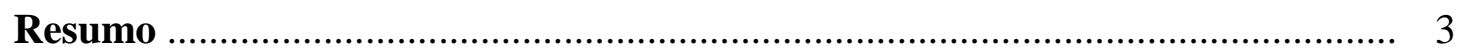

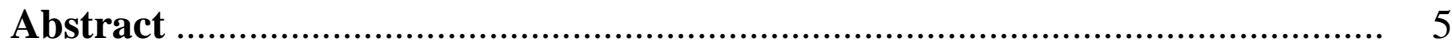

Capítulo 1. Introdução, motivação e objetivos ...................................................... 9

Capítulo 2. Discussão teórica .............................................................................. 17

2.1. Micelas surfactantes ....................................................................... 17

2.2. Íons terras raras ............................................................................... 23

2.3. Eficiência quântica de um nível emissor ................................................. 24

2.4. Rendimento quântico .......................................................................... 25

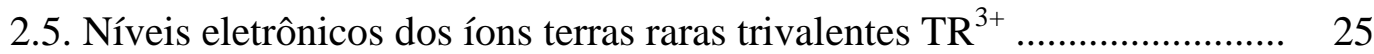

2.6. Transições eletrônicas $4 \mathrm{f}-4 \mathrm{f}$ nos íons terras raras trivalentes $\mathrm{TR}^{3+} \ldots \ldots \ldots \ldots . .31$

2.7. Teoria de Judd-Ofelt ...................................................................... 32

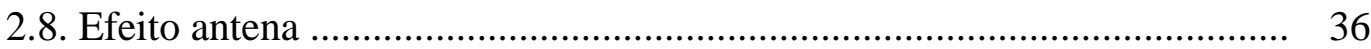

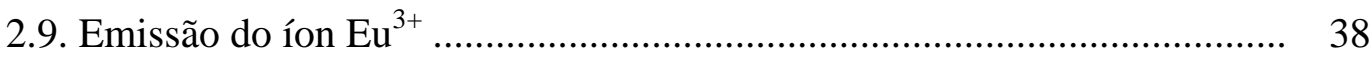

Capítulo 3. Técnicas experimentais ................................................................... 41

3.1. Difração de raios X ............................................................................. 41

3.2. Microscopia eletrônica de varredura (MEV) …………………………...... 43

3.3. Microscopia eletrônica de transmissão (TEM) ......................................... 45

3.4. Espectroscopia de raios X por dispersão de energia (EDX) ..................... 46

3.5. Espectrometria de emissão atômica com plasma acoplado (ICP-OES) .... 47

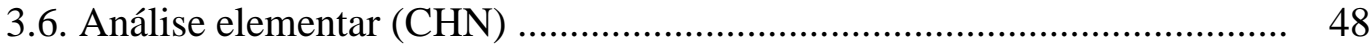

3.7. Adsorçãa-dessorção de Nitrogênio ........................................................... 49

3.8. Fotoluminescência (PL) ………………………………………….... 51

3.9. Termogravimetria (TG) ………………………………………….... 52

Capítulo 4. Materiais e métodos ..................................................................... 53

4.1. Materiais utilizados ....................................................................... 53

4.2. Síntese de hidróxidos duplos lamelares de morfologia plana .................... 53

4.3. Síntese de micelas cilíndricas de P-123 .................................................. 57

4.4. Síntese de nanotubos de LDHs sobre a superfície das micelas ................. 58 
Capítulo 5. Resultados e discussão

5.1. Caracterização estrutural dos LDHs de morfologia plana: $\mathrm{Zn}_{2} \mathrm{Al}_{1}-\mathrm{NO}_{3} . . \quad 61$

5.2. Caracterização química dos LDHs de morfologia plana: $\mathrm{Zn}_{2} \mathrm{Al}_{1}-\mathrm{NO}_{3} \ldots . \quad 67$

5.3. Micrografias eletrônicas dos LDHs de morfologia plana: $\mathrm{Zn}_{2} \mathrm{Al}_{1}-\mathrm{NO}_{3} . . \quad 68$

5.4. Efeitos estruturais da intercalação de BTC: $\mathrm{Zn}_{2} \mathrm{Al}_{1}-\mathrm{BTC}$........................ 69

5.5. Propriedades estruturais dos $\mathrm{LDHs}$ com $\mathrm{Eu}^{3+}: \mathrm{Zn}_{2} \mathrm{Al}_{0.95} \mathrm{Eu}_{0.05}-\mathrm{NO}_{3}$ e $\mathrm{Zn}_{2} \mathrm{Al}_{0.95} \mathrm{Eu}_{0.05}-\mathrm{BTC}$

5.6. Propriedades luminescentes dos $\mathrm{LDHs}$ com $\mathrm{Eu}^{3+}: \mathrm{Zn}_{2} \mathrm{Al}_{0.95} \mathrm{Eu}_{0.05}-\mathrm{NO}_{3} \mathrm{e}$ $\mathrm{Zn}_{2} \mathrm{Al}_{0.95} \mathrm{Eu}_{0.05}$-BTC 73

5.7. Formação de nanotubos de LDHs: $\mathrm{Zn}_{2} \mathrm{AlEu}_{\mathrm{x} \%}$-BTC-P123 .................... 79

5.8. Extração das micelas dos dutos dos nanotubos ........................................ 89

5.9. Caracterização da porosidade das amostras sintetizadas com $\mathrm{P}-123 \ldots \ldots . . . \quad 90$

5.10. Tentativa de síntese de nanotubos com substituição de BTC ................ 93

5.11. O papel do $\mathrm{Eu}^{3+}$ e do BTC na estruturação dos LDHs ........................... 94

5.12. Propriedades luminescentes dos nanotubos de LDHs ............................ 97

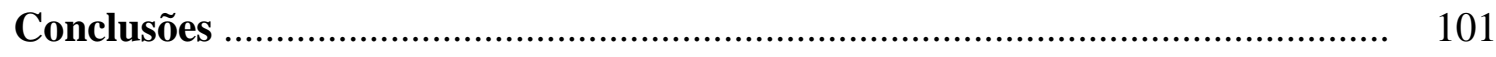

Referências Bibliográficas ............................................................................ 104 


\section{Capítulo 1}

\section{Introdução, motivação e objetivos}

Os materiais porosos estão presentes no nosso dia-a-dia. Nas casas brasileiras, é comum encontrarmos velas de barro e carvão ativado, utilizados na filtração e purificação da água. No corpo humano, o parênquima pulmonar (Figura 1.1) é um meio poroso que permite a troca de gases entre a atmosfera e o sangue. Para que essa troca ocorra de maneira eficiente, o pulmão conta com cerca de 400 milhões de macroporos (os alvéolos) de diâmetros de 75 a $300 \mu \mathrm{m}$ [1], que somam uma área superficial da ordem de $75 \mathrm{~m}^{2}$ através da qual o $\mathrm{O}_{2}$ penetra no sangue enquanto o $\mathrm{CO}_{2}$ resultante do processo metabólico é liberado [2].

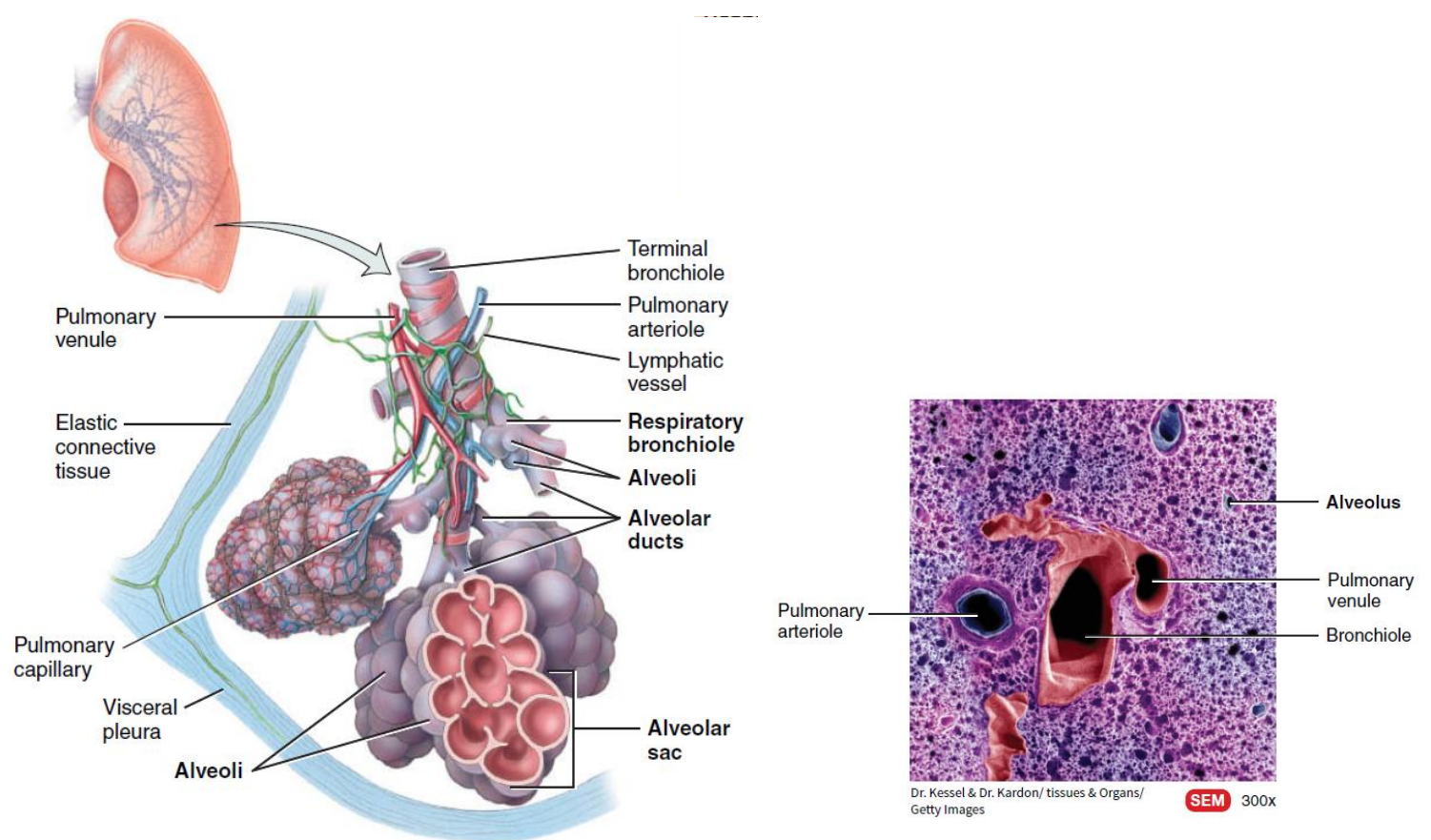

Figura 1.1. Diagrama do parênquima pulmonar ilustrando a estrutura porosa do pulmão (esquerda) e imagem de microscopia eletrônica de varredura com detalhes dos alvéolos (direita) [2].

As propriedades e a aplicabilidade dos materiais porosos são definidas principalmente pelo tamanho dos seus poros e pelas características físico-químicas das suas paredes. Nos filtros de água potável, o tamanho diminuto dos poros não permite a passagem de poeira, 
particulados e bactérias ${ }^{1}$. No processo conhecido como filtração em gel $^{2}$, a coexistência de diferentes tamanhos de poros na fase estacionária causa uma diferença no tempo de eluição de moléculas com tamanhos diferentes. Nesta técnica, moléculas grandes percolam rapidamente pela coluna de filtração enquanto moléculas pequenas, capazes de penetrar nos poros do gel filtrante, percorrem um longo caminho, sendo eluídas tardiamente, permitindo a sua separação.

Algumas classes de materiais porosos possuem poros com propriedades especiais. As zeólitas, por exemplo, possuem paredes carregadas negativamente. Para contrabalançar essa carga elétrica, os poros desses materiais acomodam cátions lábeis, que podem ser facilmente trocados por outros num processo conhecido como "troca iônica". A engenharia conjunta da composição química, tamanho dos poros e das propriedades das zeólitas como trocador de cátions causou uma revolução nessa área de pesquisa e em sua aplicação industrial. Atualmente, elas são utilizadas como aditivos em detergentes e são os principais catalisadores no processo de craqueamento do petróleo. Outras aplicações incluem seu uso como aditivos para o solo, catalisadores da conversão de biomassa, removedores de isótopos radioativos e redutores de odores em liteiras de gatos [3-7].

Similarmente às zeólitas os materiais conhecidos como hidróxidos duplos lamelares (HDLs ou, na sigla em inglês, $\mathrm{LDHs}^{3}$ ) também possuem propriedades de troca iônica. A partir de modificações da sua composição química e da sua morfologia, uma vasta gama de funcionalidades já foi demonstrada para esses materiais, incluindo aplicações como catalisadores na quebra da água para a produção de combustíveis [8], eletrodo em baterias de íons de Lítio [9], eletrólito sólido (condutor iônico) em células combustíveis [10], supercapacitores [11] e sensibilizadores em dispositivos fotovoltaicos $[12,13]$.

Apesar das várias funcionalidades demonstradas, o uso industrial dos LDHs permanece incipiente devido a dois fatores principais: (i) sua área superficial ainda é baixa se comparada a de outros materiais porosos comercializados e (ii) diferentemente do que acontece com as zeólitas, uma morfologia de poros tridimensionais interconectados não havia sido demonstrada, até recentemente, para os LDHs, limitando suas aplicações. Essas

\footnotetext{
${ }^{1}$ Por exemplo, com as tecnologias de microfiltração e "hollow fiber", esta última capaz de retirar até vírus.

${ }^{2}$ Em inglês: Gel-filtration chromatography. Também conhecida como size-exclusion chromatography ou molecular-sieve chromatography.

${ }^{3}$ LDHs: Layered Double Hydroxides.
} 
limitações serviram com inspiração e motivação para escolha do tema deste trabalho, que tem como objetivo o desenvolvimento de LDHs com morfologia porosa tridimensional e com área superficial aumentada com relação aos hidróxidos lamelares comumente encontrados na literatura. A partir desse trabalho, espera-se expandir consideravelmente as possibilidades de aproveitamento para esses materiais, na direção de obter materiais com propriedades adequadas capazes de ser aplicados como gel filtrante em colunas de cromatografia e colunas de troca iônica, catalizadores heterogêneos de alto desempenho ou carregadores de moléculas bioativas para o interior de células vivas.

Hidróxidos duplos lamelares (LDHs) são materiais formados pelo empilhamento alternado de camadas metálicas e camadas contendo ânions, conforme esquematizado na Figura 1.2 [14]. Com fórmula química geral $\left[\mathrm{M}_{1-\mathrm{x}}^{\mathrm{II}} \mathrm{M}_{\mathrm{x}}^{\mathrm{III}}(\mathrm{OH})_{2}\right]^{\mathrm{x}+}$, as camadas metálicas dos LDHs são formadas por metais di e trivalentes $\mathrm{M}^{\mathrm{II}}$ e $\mathrm{M}^{\mathrm{III}}$, respectivamente, podendo ser produzidas a partir de hidróxidos da forma $\mathrm{M}^{\mathrm{II}}(\mathrm{OH})_{2}$, nos quais a substituição parcial dos cátions divalentes por cátions metálicos trivalentes forma camadas com excesso de cargas positivas. Essas cargas, devendo ser compensadas, induzem o posicionamento de ânions na superfície das camadas, próximos aos cátions trivalentes. A alternância entre camadas metálicas e ânions $\left(\mathrm{A}^{\mathrm{n}}{ }^{-}\right)$forma estruturas lamelares de fórmula química geral $\left[\mathrm{M}_{1-\mathrm{x}}^{\mathrm{II}} \mathrm{M}_{\mathrm{x}}^{\mathrm{III}}(\mathrm{OH})_{2}\right]\left[\mathrm{A}^{\mathrm{n}-}\right]_{\mathrm{x} / \mathrm{n}} \cdot \mathrm{yH}_{2} \mathrm{O}$, os hidróxidos duplos lamelares.

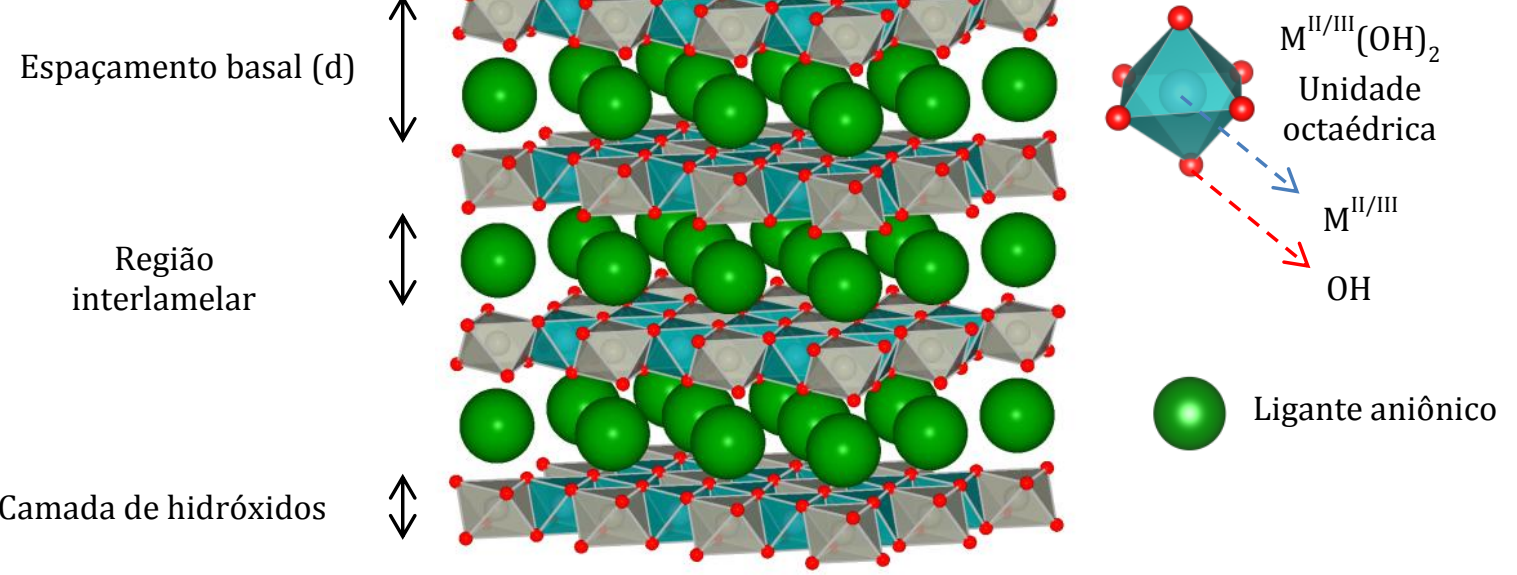

Figura 1.2. Estrutura dos hidróxidos duplos lamelares com suas camadas metálicas e regiões interlamelares acomodando ânions e água. 
LDHs sintéticos de diversas composições foram relatados na literatura científica, sendo $\mathrm{M}^{\mathrm{II}}=\mathrm{Zn}, \mathrm{Mg}, \mathrm{Ni}, \mathrm{Fe}$ e $\mathrm{M}^{\mathrm{III}}=\mathrm{Al}, \mathrm{Fe}, \mathrm{Mn}$, Ni os metais mais frequentemente encontrados $[15,16]$. Uma grande variedade de ânions também podem ser intercalados no meio interlamelar: $\mathrm{A}^{\mathrm{n}-}=\mathrm{NO}_{3}{ }^{-}, \mathrm{CO}_{3}{ }^{2-}, \mathrm{OH}^{-}, \mathrm{Cl}^{-}, \mathrm{SO}_{4}{ }^{2-}$, dentre outros [15, 17].

A interação fraca entre as camadas metálicas dos LDHs permite uma flexibilidade importante no espaçamento interlamelar destes compostos, sendo possível modificar quase que livremente os ânions intercalados. Como consequência dessa versatilidade, suas propriedades físico-químicas podem ser extensivamente modificadas, alterando-se tanto a composição das camadas de hidróxidos quanto o conteúdo interlamelar. Como um exemplo dessa estratégia, a introdução de elementos terras raras trivalentes $\left(\mathrm{TR}^{3+}=\mathrm{La}^{3+}, \mathrm{Eu}^{3+}, \mathrm{Tb}^{3+}\right.$, $\mathrm{Yb}^{3+}, \mathrm{Tm}^{3+}, \mathrm{Er}^{3+}$, dentre outros) em LDHs resulta em fases com propriedades luminescentes [18, 19]. Enquanto os cátions $\mathrm{TR}^{3+}$ podem ser homogeneamente incorporados nas camadas de hidróxidos, produzindo cargas elétricas residuais, sensibilizadores aniônicos podem ser dispostos na sua vizinhança, promovendo não só a neutralidade de cargas no material, mas também permitindo a transferência eficiente de energia entre esses dois sistemas, melhorando suas propriedades luminescentes. Esse fenômeno é conhecido como efeito antena [19].

A preparação de LDHs luminescentes contendo íons terras raras tem sido reportada na última década utilizando-se dos métodos de coprecipitação e de troca iônica para intercalar sensibilizadores aniônicos entre as camadas de hidróxidos. Gunawan et al. [19] mostraram que 4-bifenilacetato intercalado em $\mathrm{LDHs}$ de $\mathrm{Mg}^{2+}, \mathrm{Al}^{3+} \mathrm{e} \mathrm{Tb}^{3+}$ pode transferir energia eficientemente para os níveis eletrônicos do $\mathrm{Tb}^{3+}$, produzindo materiais com rendimento quântico ${ }^{4} \Phi=14$ - 22\%. Materiais similares intercalados com $\mathrm{NO}_{3}{ }^{-}$, inadequado para a promoção do efeito antena, possuem rendimentos quânticos bastante inferiores, com $\Phi=0.2$ - 4\% [19, 20]. Zhuravleva et al. [21] sintetizaram uma série de LDHs de $\mathrm{Mg}^{2+}$ e $\mathrm{Al}^{3+}$ intercalados com complexos de $\mathrm{Tb}^{3+}$-picolinato que, para o nosso conhecimento, possuem o maior rendimento quântico já reportado para LDHs contendo íons $\operatorname{TR}^{3+}(\Phi=32-45 \%)$. Outras espécies aniônicas já foram intercaladas nos LDHs a fim de atuar como absorvedoras de energia eletromagnética e transferi-la para os íons terras raras, tais como molibdatos [22], complexos de [Tb(EDTA)] [23], complexos de $\mathrm{Eu}^{3+}$ [24],

\footnotetext{
${ }^{4}$ Para uma definição de "rendimento quântico", vide seção 2.4.
} 
sulfonatos e carboxilatos [25]. Gago et. al. [26] imobilizaram $\mathrm{Eu}^{3+}$ no meio interlamelar de LDHs de $\mathrm{Zn}^{2+}$ e $\mathrm{Al}^{3+}$ intercalados com ânions 2,2'-bipiridina-5,5'-dicarboxilato (BDC), produzindo materiais com eficiência quântica ${ }^{5} \eta=7.7 \%$. Mais recentemente, nosso grupo também demonstrou ${ }^{6}$ que a intercalação de uma série de ligantes orgânicos (benzeno-1,3,5tricarboxilato, acetil-acetonato e tenoil-trifluor-acetonato) em $\mathrm{LDHs}$ de $\mathrm{Zn}^{2+}, \mathrm{Al}^{3+}$ e $\mathrm{Eu}^{3+}$, produz uma série de materiais com alta luminescência, com eficiência quântica $\eta=15$ $18 \%$.

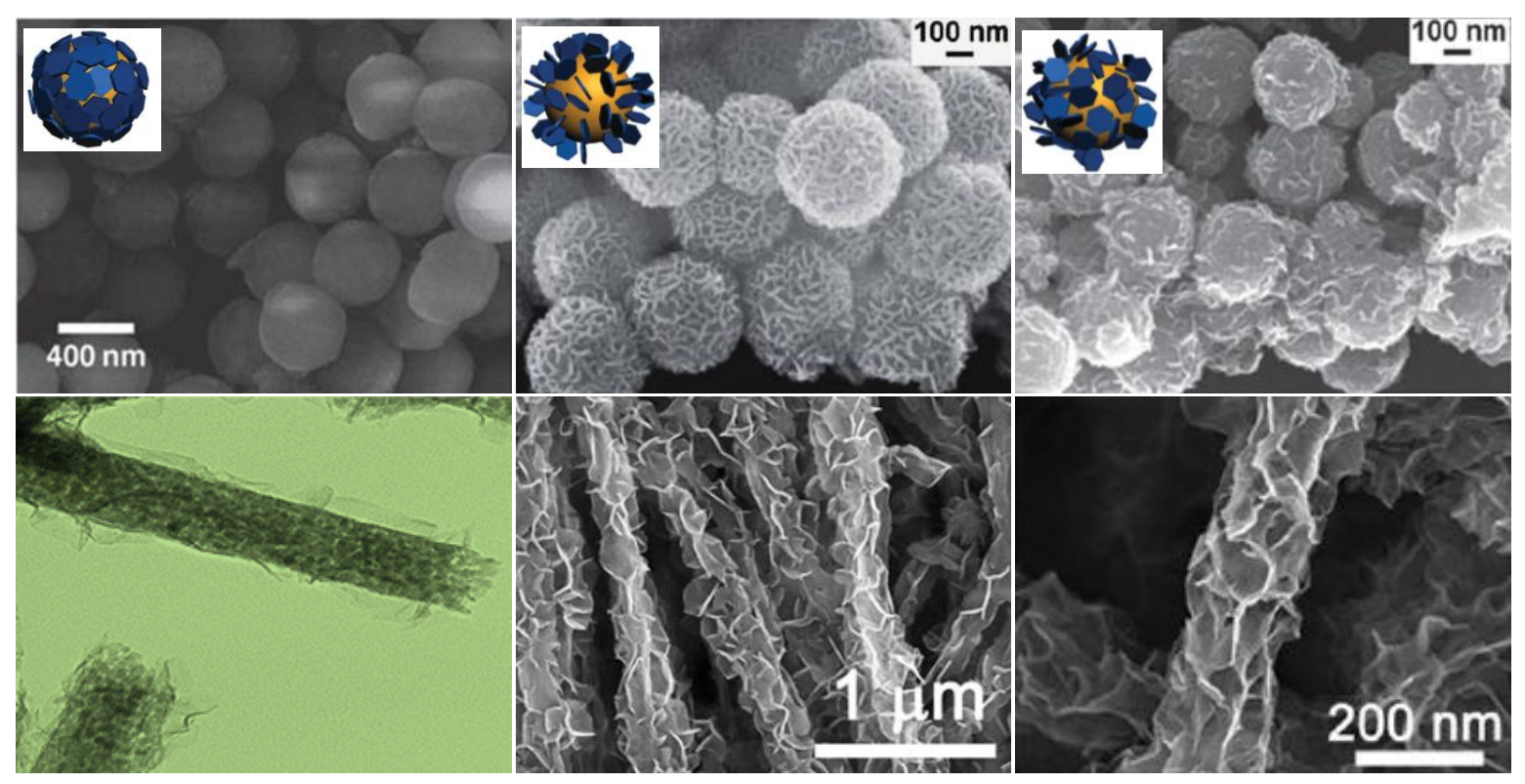

Figura 1.3. Diferentes hierarquias tridimensionais impostas aos LDHs. Acima: deposição de LDHs horizontalmente (esquerda), verticalmente (centro) e aleatoriamente (direita) sobre a superfície de partículas esféricas. Adaptadas de [27-29]. Abaixo: Nanofios de $\mathrm{NiCo}_{2} \mathrm{O}_{4}$ (esquerda) e nanotubos de carbono (centro e direita) encobertos com LDHs. Adaptados de [30, 31].

Apesar de muitas aplicações terem sido demonstradas explorando a flexibilidade de composições químicas dos LDHs, uma quantidade limitada de estudos tem sido publicada explorando diferentes morfologias para esses materiais. Surpreendentemente, as primeiras tentativas de se impor uma hierarquia tridimensional aos hidróxidos lamelares foram publicadas apenas recentemente utilizando outras partículas como suporte para estruturar esses materiais. Esses trabalhos deram origem a microesferas encobertas por camadas de LDHs [27, 28, 32], nanofios de $\mathrm{NiCo}_{2} \mathrm{O}_{4}$ encobertos por hidróxidos duplos [30], nanotubos

\footnotetext{
${ }_{6}^{5}$ Para uma definição de "eficiência quântica", vide seção 2.3 .

${ }^{6}$ Trabalho submetido para publicação.
} 
de carbono encobertos por LDHs [31], dentre outros [11, 33-35], conforme ilustrado na Figura 1.3. Ainda menos exploradas, estratégias de produção de LDHs com poros tridimensionais autossustentados também foram relatadas, com a produção de nanocones [11], nanoesferas [36], microesferas [32] e nanoenrolamentos de LDHs [37] como ilustrados na Figura 1.4.

Este trabalho de doutorado descreve uma estratégia inédita para a produção de nanotubos de hidróxidos duplos lamelares autossuportados ( coprecipitação de $\mathrm{Zn}^{2+}, \mathrm{Al}^{3+}$ e $\mathrm{Eu}^{3+}$ em pH controlado e sua auto-organização sobre micelas cilíndricas de Plurônico® P-123 (Poloxâmero 4037). A subsequente extração destes agentes estruturantes através de lavagem com metanol resultou em uma rede de nanotubos cilíndricos, ocos e interconectados, formados pela deposição de multicamadas de hidróxidos duplos intercalados pela molécula sensibilizadora ácido benzeno-1,3,5tricarboxílico (ácido trimésico, BTC). A combinação de $\mathrm{Eu}^{3+}$ (nas camadas de hidróxidos) e BTC no meio interlamelar resultou em nanotubos [38] com propriedades luminescentes, demonstrando de maneira notável como modificações químicas e morfológicas nos LDHs podem levar ao remodelamento das suas propriedades físico-químicas e, consequentemente, direcionar suas aplicações de maneira desejável.
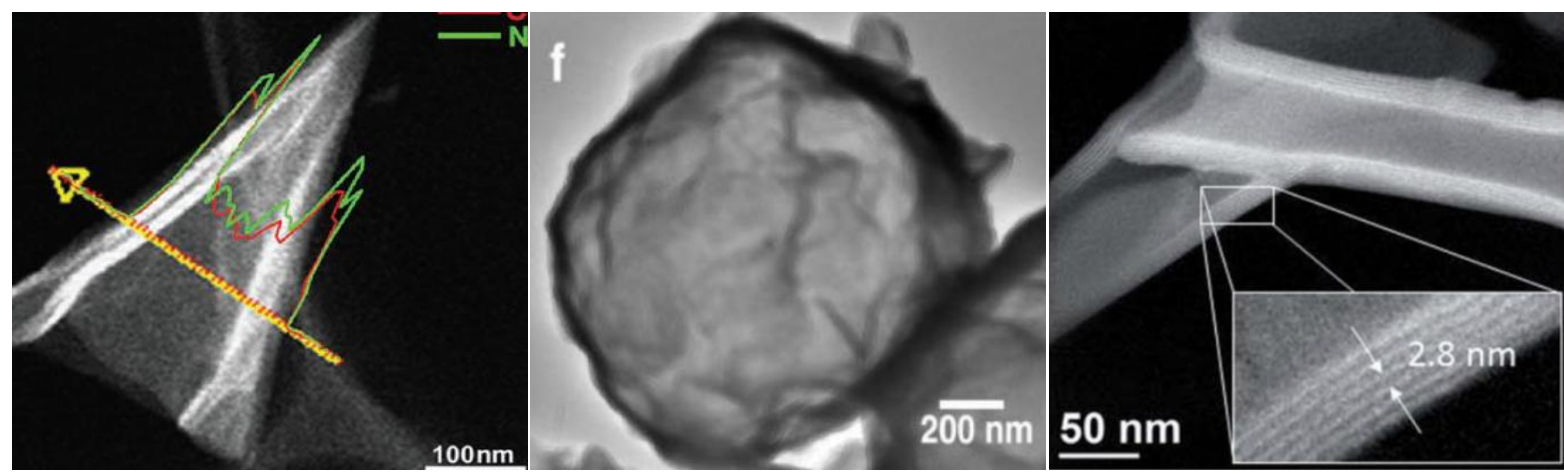

Figura 1.4. Morfologias tridimensionais autossustentadas impostas aos LDHs: nanocone (esquerda), nanoesfera oca (centro) e nanoenrolamento (direita). Adaptadas de [11, 36, 37].

A estratégia adotada para a nanoestruturação dos LDHs apresentada neste trabalho é baseada na utilização de micelas surfactantes como molde (template) para a formação dos hidróxidos sobre a sua superfície. Além da morfologia nanotubular obtida, micelas de

\footnotetext{
${ }^{7}$ Em inglês: Poloxamer 403 ou Pluronic ${ }^{\circledR}$ P-123.
} 
diferentes formatos podem ser sintetizadas, como esquematizado na Figura 1.5 [39], de modo que novas perspectivas para formatos inovadores podem ser exploradas para os LDHs.

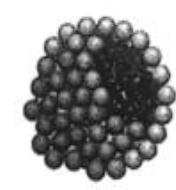

A

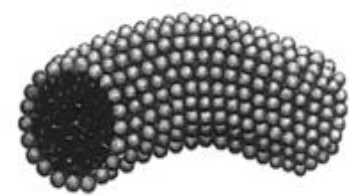

B

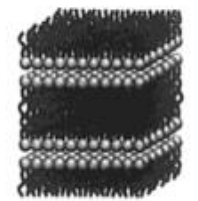

C

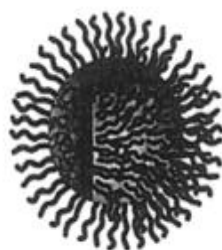

D

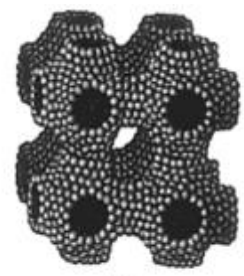

E

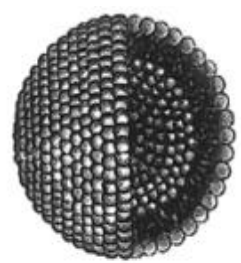

F

Figura 1.5. Estruturas micelares $(\mathrm{A}=$ esfera, $\mathrm{B}=$ cilindro, $\mathrm{C}=$ dupla camada planar, $\mathrm{D}=$ micela reversa, $\mathrm{E}=$ fase bi-contínua, $\mathrm{F}=$ lipossomo) $[39,40]$.

A íntegra deste trabalho será apresentada em detalhes nos quatro capítulos a seguir. Para dar suporte às interpretações e aos resultados obtidos, o Capítulo 2 será dedicado a uma revisão dos conceitos teóricos envolvidos (i) na formação de micelas surfactantes, (ii) na formação de LDHs e (iii) na luminescência dos íons terras raras trivalentes.

Diversas técnicas experimentais utilizadas nesse trabalho são bastante comuns na ciência de materiais, mas para que este texto seja legível para um público amplo, o Capítulo 3 traz um resumo básico das técnicas e os detalhes experimentais de como foram utilizadas para alcançar os objetivos propostos. Para a caracterização da estrutura cristalográfica dos materiais, utilizamos o método de pó para a obtenção de difratogramas de raios $\mathrm{X}$. Detalhes da morfologia das amostras foram obtidos por meio de microscopia eletrônica de varredura (MEV) e de transmissão (TEM). Estudos quantitativos da composição metálica dos materiais foram realizados por meio da técnica de espectrometria de emissão ótica com plasma acoplado (ICP-OES). Enquanto a composição de Carbono, Hidrogênio e Nitrogênio foi acessada pela técnica de análise elementar, também conhecida pela sigla $\mathrm{CHN}$, a estabilidade térmica dos materiais foi investigada através da técnica de análise termogravimétrica (TG). O comportamento fotoluminescente dos materiais foi estudado com base em seus espectros de excitação e emissão, obtidos por meio de experimentos de fotoluminescência (PL).

No Capítulo 4 são apresentados os métodos de síntese utilizados na preparação dos materiais estudados. Este capítulo foi escrito cuidadosamente para que o leitor tenha todos os detalhes dos métodos de preparação e assim possa reproduzi-los. Por fim, os resultados 
experimentais, em conjunto com as discussões e interpretações deles decorrentes, estão organizados no Capítulo 5. 


\section{Capítulo 2}

\section{Discussão teórica}

$\mathrm{O}$ desenvolvimento deste trabalho exigiu uma ampla pesquisa multidisciplinar envolvendo duas grandes áreas da ciência moderna: a Física e a Química. Para tornar o leitor familiar com os assuntos tratados nos capítulos a seguir, este capítulo traz uma discussão teórica de temas como a formação de micelas surfactantes, a luminescência dos íons terras raras $\left(\mathrm{TR}^{3+}\right)$, efeito antena e alguns conceitos quânticos sobre eficiência de emissão dos cátions $\mathrm{TR}^{3+}$. As discussões foram feitas de modo a trazer esses temas para o contexto deste trabalho.

\subsection{Micelas surfactantes}

Surfactantes são compostos capazes de alterar a tensão superficial entre duas interfaces. Tipicamente, são moléculas orgânicas formadas por grandes cadeias apolares de Carbono ligadas a um grupo polar, resultando em uma parte hidrofóbica e uma parte hidrofílica, como ilustrado na Figura 2.1. Essa característica anfifílica dessa classe de moléculas é responsável por sua riqueza de propriedades e sua variedade de aplicações, sendo usadas como detergentes, emulsificantes, estabilizantes e dispersantes.

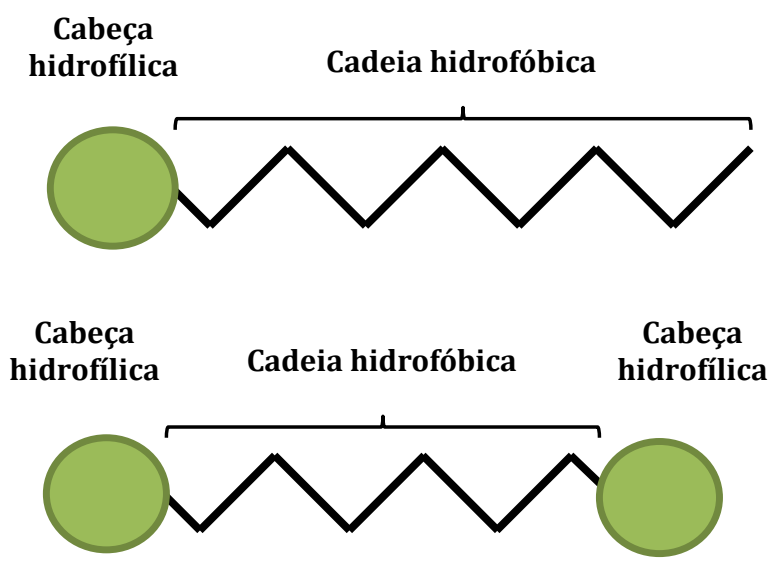

Figura 2.1. Ilustração de dois tipos possíveis de surfactantes. Acima: um surfactante formado por uma parte hidrofóbica (apolar) e uma cabeça polar hidrofílica. Abaixo: uma molécula de três blocos formada por uma cadeia apolar entre duas cabeças polares. 
Devido à existência de um grupo polar em sua estrutura, os surfactantes são capazes de formar ligações de hidrogênio com moléculas de água, sendo solúveis em soluções aquosas. Na interface com sua cadeia apolar, no entanto, ligações de hidrogênio não podem ser formadas, fazendo com que moléculas de água nessa região encontrem-se em um estado mais energético do que as outras moléculas do solvente. Esse aumento de energia (U) faz com que, em certas regiões do diagrama de concentração do surfactante versus temperatura (T), sua parte hidrofóbica seja segregada no interior de estruturas chamadas micelas, impedindo o contato entre o bloco hidrofóbico e as moléculas de água, como ilustrado na Figura 2.2. Nessa estratégia, a formação de micelas (em sistemas fechados ${ }^{8}$ ) garante ao sistema a diminuição de sua energia livre de Helmholtz (F) [41], segundo a equação

$$
F=U-T S
$$

apesar da diminuição da entropia (S).

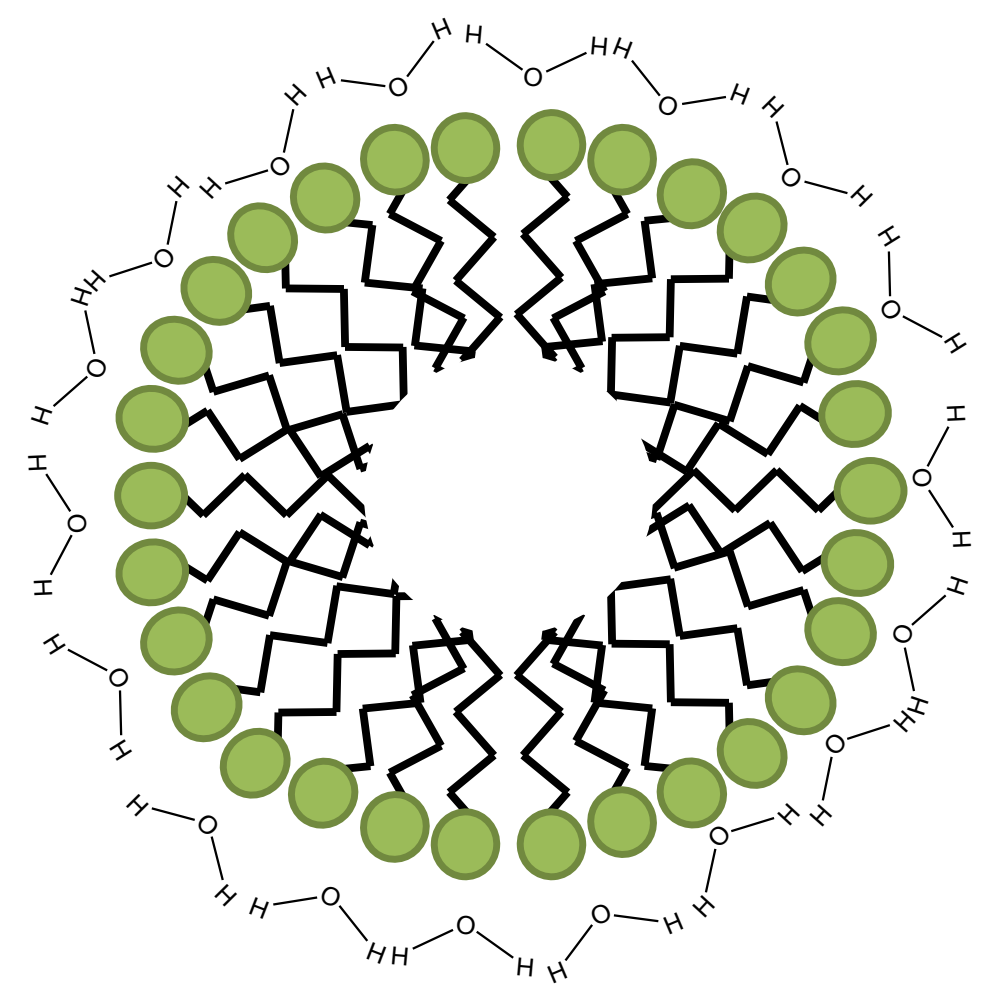

Figura 2.2. Esquema de uma micela em que as cadeias apolares ficam segregadas em seu interior enquanto as cabeças polares, externamente, ficam solvatadas por moléculas de água, que podem assim satisfazer seu dipolo elétrico realizando ligações de hidrogênio com os grupos hidrofílicos.

\footnotetext{
${ }^{8}$ Em sistemas abertos, é a energia livre de Gibbs $(\mathrm{G})$ que é minimizada: $\mathrm{G}=\mathrm{H}-\mathrm{TS}$, onde $\mathrm{H}$ é a entalpia do sistema.
} 
Para a estruturação dos LDHs na forma de nanotubos, utilizamos micelas do surfactante Plurônico® P-123. A classe de surfactantes Plurônico®, que são copolímeros de três blocos formados por longas cadeias laterais de poli-(etileno glicol) (PEG) e uma cadeia central de poli-(propileno glicol) (PPG) (Figura 2.3), está listada na Farmacopeia dos Estados Unidos e também na Britânica. Eles são excipientes farmacêuticos conhecidos e que, segundo dados de 2002 da Food and Drug Administration?, possuíam 141 usos reportados até aquele ano. Não tóxicos, são utilizados em cosméticos, xampus, desodorantes e loções, com concentrações que variam de $0.005 \%$ a $20 \%$ em massa [42-44].

A abundância de dados sobre os polímeros da classe Plurônico®, aliada à sua atoxidade, faz com que essas moléculas sejam bastante adequadas para manipulação em laboratório. Além disso, devido à sua característica anfifílica, suas propriedades surfactantes têm sido constantemente utilizadas em pesquisas científicas.

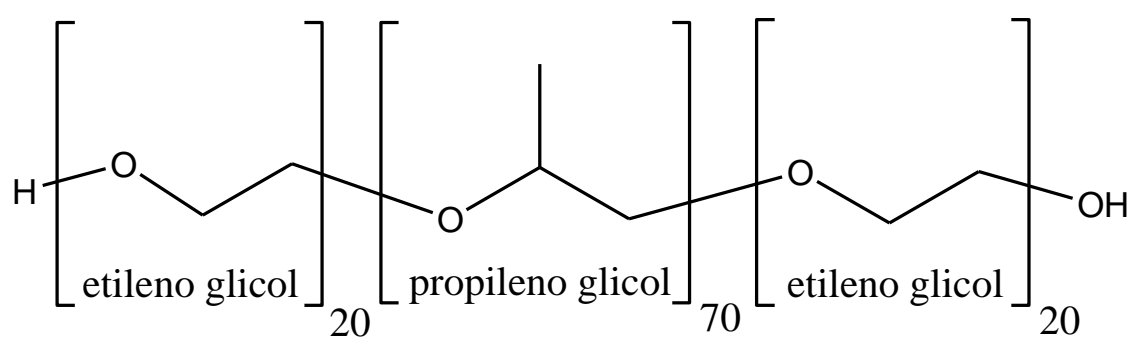

Figura 2.3. Plurônico® P-123 e suas cadeias centrais de PPG e laterais de PEG.

Para temperaturas abaixo de $15{ }^{\circ} \mathrm{C}$, ambas as cadeias PEG e PPG dos surfactantes Pluronic® são solúveis em água [43]. Para temperaturas mais altas, a cadeia PPG tem seu caráter hidrofóbico cada vez mais acentuado e, a partir de certa concentração crítica, é segregada pelas moléculas de água do solvente, formando micelas poliméricas de diferentes tamanhos e formatos. As concentrações críticas e os diagramas de fase de alguns polímeros da classe Plurônico®, incluindo o P-123, podem ser encontradas nas referências [44, 45]. Na Figura 2.4 é mostrado um diagrama de fases micelares típico em que as micelas passam de um formato esférico para cilíndrico em concentrações crescentes do surfactante.

Os diagramas de fases de sistemas micelares em geral podem variar consideravelmente quando solutos e cossolventes são adicionados ao sistema. Especificamente para os surfactantes da classe Plurônico®, um grande número de estudos

\footnotetext{
${ }^{9}$ FDA, órgão regulatório dos EUA.
} 
foram realizados demonstrando essa variabilidade [46-58]. Sais inorgânicos como KCl, $\mathrm{NaCl}$ e KF, competem com esses surfactantes por solvatação e desidratam suas cadeias de poli-(etileno glicol), diminuindo sua solubilidade e consequentemente a concentração crítica a partir da qual micelas são formadas, chamada de concentração micelar crítica (CMC). Na mesma linha, solventes altamente polares, como o glicerol, segregam ainda mais facilmente as cadeias apolares de poli-(propileno glicol) [55-58], facilitando a formação das micelas. Por outro lado, solventes menos polares como etanol e metanol são bons solventes para ambas as cadeias PEG e PPG, dificultando ou até proibindo a formação de micelas nesses meios.

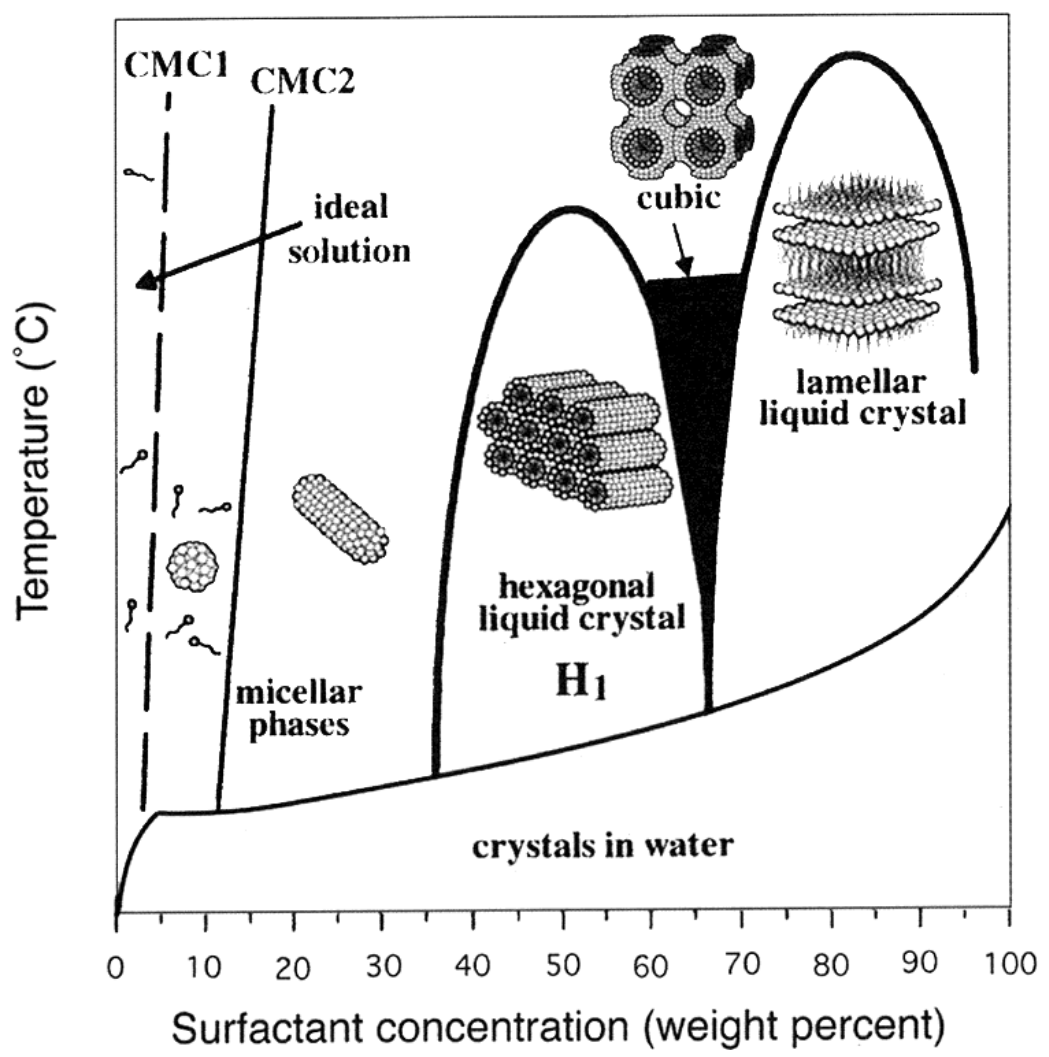

Figura 2.4. Diagrama de fases do surfactante brometo de cetiltrimetilamônio (CTAB) [59, 60], típico de sistemas micelares com formação de micelas esféricas (CMC1), cilíndricas (CMC2) e sistemas liquidocristalinos como o surfactante Plurônico® P-123.

Para sistemas aquosos de P-123 em concentrações abaixo da $\mathrm{CMC}=0.025 \%(\% \mathrm{em}$ massa a $25^{\circ} \mathrm{C}$ ) $[45,46]$, as moléculas do polímero se encontram dissolvidas, sem a formação de micelas. Para concentrações levemente acima desta, algumas moléculas iniciam um processo de agregação formando micelas esféricas como ilustrado na Figura 
2.5. Como suas cadeias orgânicas são flexíveis graças à natureza não direcional das ligações simples em cadeias de Carbono, o diâmetro dessas micelas esféricas pode variar dependendo do número $N_{a g r}$ de moléculas agregadas em cada micela em solução. Com o aumento da concentração de polímeros no meio e a consequente elevação do número de agregação, as cadeias poliméricas se estendem até o limite máximo de cerca de $19 \mathrm{~nm}$, sendo este o diâmetro máximo que a seção transversal de uma micela de P-123 pode alcançar [43, 61]. A partir desse ponto, um aumento da concentração de moléculas na solução leva a um crescimento longitudinal das micelas, que sofrem uma transição para o formato cilíndrico. Esses cilindros podem crescer longitudinalmente, mas mantém seu diâmetro fixo em cerca de 19 nm, como ilustrado na Figura 2.5.

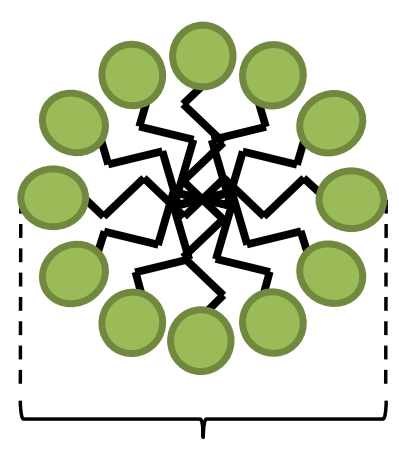

$\sim 19 \mathrm{~nm}$

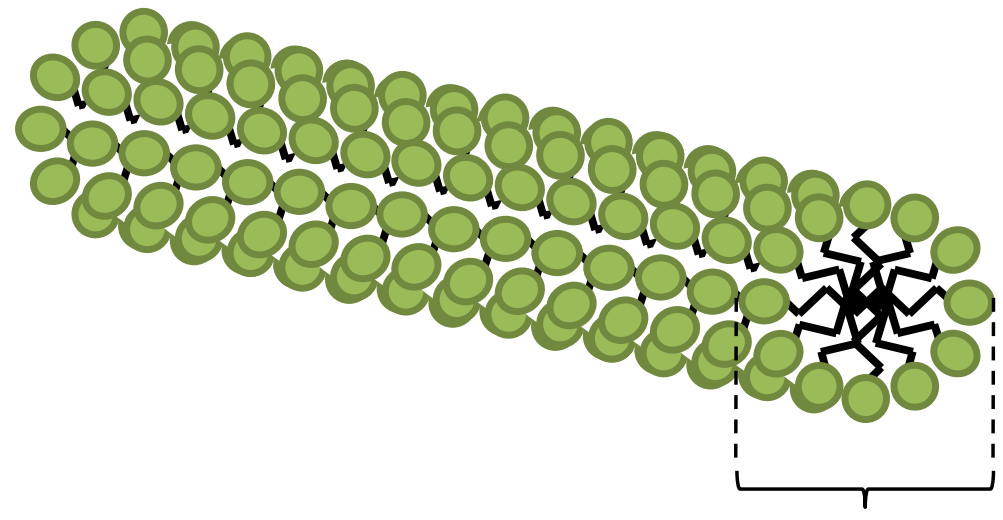

$\sim 19 \mathrm{~nm}$

Figura 2.5. Um esquema das micelas esféricas (esquerda) e cilíndricas (direita) de P-123.

Diante dos diversos estudos demonstrando a variabilidade dos diagramas de fase micelares em função da adição de solutos, substâncias específicas podem ser adicionadas a esses sistemas de modo a conferir-lhes propriedades extras, além de eventualmente facilitarem a formação das micelas ou promoverem a sua formação em diferentes topologias. Uma aplicação interessante dessa variabilidade foi demonstrada por Petrov et al. [43] em um estudo no qual a adição de tetraacrilato de pentaeritritol (PETA $\left.{ }^{10}\right)$ induzia a transição da morfologia esférica para a cilíndrica em micelas de P-123. Nesse estudo, as moléculas de PETA, insolúveis em água, eram solubilizadas pelas cadeias de PPG no interior das micelas e então polimerizadas por iluminação com radiação ultravioleta. Essa polimerização criava um esqueleto rígido que fixava a morfologia das micelas, que assim

\footnotetext{
${ }^{10}$ Em inglês: pentaerythritol tetraacrylate (PETA).
} 
puderam ser observadas por técnicas de microscopia. Algumas das imagens obtidas por Petrov et al. foram adaptadas e estão mostradas na Figura 2.6. Apesar de serem chamadas por alguns autores por micelas cilíndricas, essas imagens mostram claramente que tratam-se de formatos mais flexíveis e tortuosos e, por isso, são também referidos pelo termo wormlike $e^{11}$. O diâmetro da seção transversal dessas micelas também pode ser estimado através da Figura 2.6 e é da ordem de 20 nm, compatível com a extensão máxima das cadeias de P123 , como discutido anteriormente.
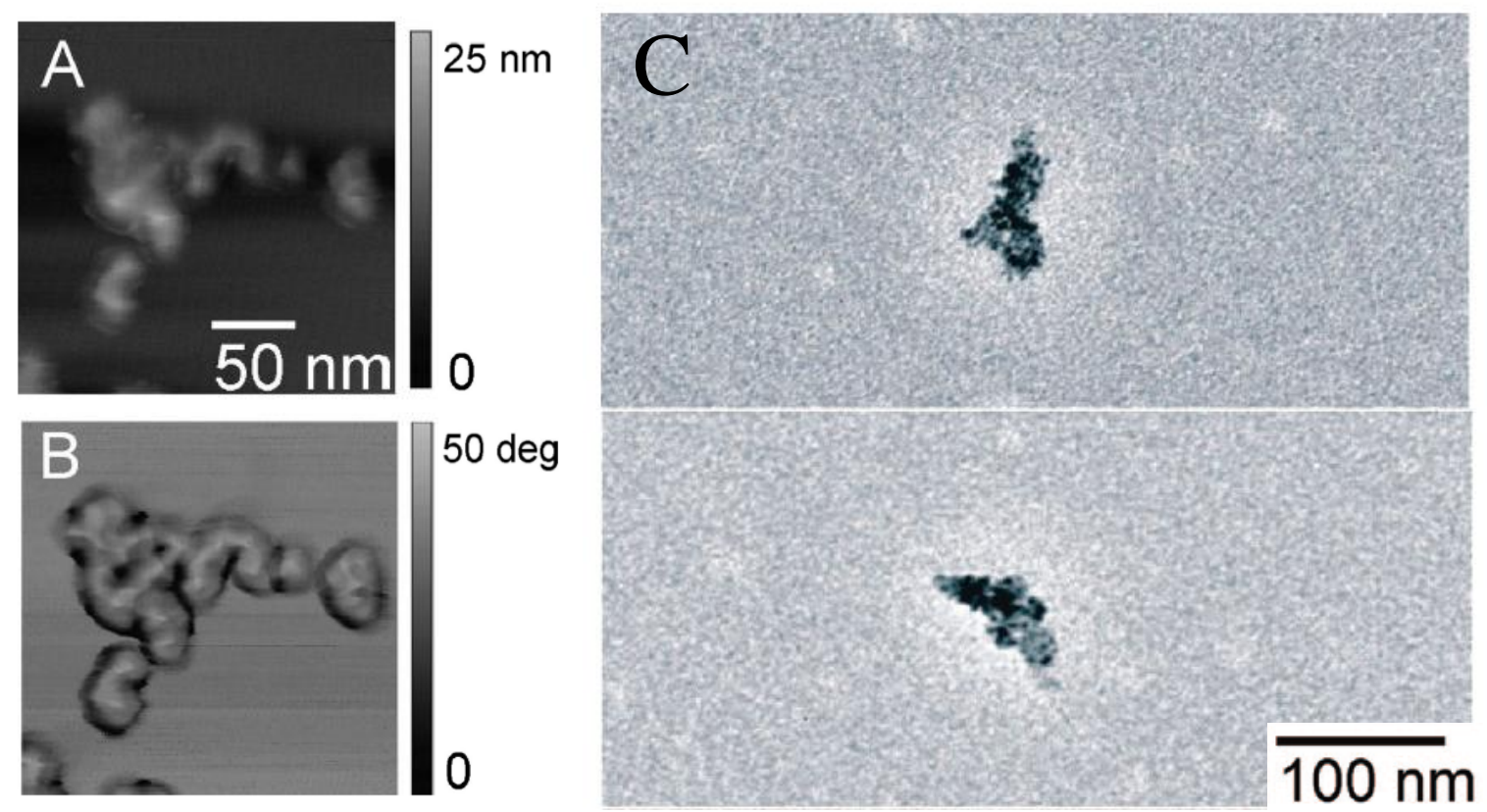

Figura 2.6. Imagens de microscopia de tunelamento (STM) em contraste de profundidade (A) e de fase (B) e microscopia eletrônica de transmissão (C) de micelas cilíndricas de P-123. Adaptadas da Ref. [43].

Outro estudo interessante sobre a formação de micelas cilíndricas de P-123 foi feito por Ganguly et al [62], que demonstraram que a adição de alguns sais nesses sistemas micelares é capaz de promover uma transição entre as morfologias esférica e cilíndrica. Nesse caso, a facilidade com que esses sais promovem essa transição aumenta com a sua capacidade de desidratar as cadeias de PEG e PPG, competindo por solvatação, seguindo o que se chama de série de Hofmeister: $\left(\mathrm{PO}_{4}\right)^{3-}>\mathrm{F}^{-}>\mathrm{Cl}^{-}$. A partir do seu estudo da evolução temporal dessas micelas ficou claro que a transição citada não ocorria instantaneamente, mas poderia demorar horas ou até dias para que o sistema encontrasse o equilíbrio. Mais

\footnotetext{
${ }^{11}$ Do inglês: formato de minhoca.
} 
uma vez, a velocidade da transição seguia a série de Hofmeister. Complementarmente a esses resultados, Kadam et al [61] demonstraram que o aquecimento de soluções contendo P-123 e sais até seu ponto de separação de fase (cloud point) e seu posterior resfriamento até a temperatura ambiente acelerava o processo de formação de micelas cilíndricas assim como também as tornava estáveis mesmo sob diluição de até dez vezes, o que foi o primeiro processo demonstrado de estabilização de sistemas micelares de surfactantes da classe Plurônico®.

\section{2. Íons terras raras}

São designados como terras raras alguns elementos do grupo III da tabela periódica, sendo eles: Sc, Y e os elementos da série do Lantânio (do La ao Lu).

Nos elementos da série do Lantânio, os orbitais $5 \mathrm{~s}, 5 \mathrm{p}, 5 \mathrm{~d}$ e $6 \mathrm{~s}$ são os orbitais mais externos [63]. Em sua configuração trivalente $\left(\mathrm{TR}^{3+}\right)$, esses elementos perdem os elétrons das camadas $5 \mathrm{~d}$ e $6 \mathrm{~s}$, fazendo com que os orbitais $5 \mathrm{~s}$ e $5 \mathrm{p}$, totalmente preenchidos, se tornem os mais externos. Nesses íons, a internalidade dos orbitais $4 \mathrm{f}$ os mantem blindados de campos de força externos e seus níveis energéticos permanecem praticamente inalterados independentemente da matriz em que estão inseridos [64, 65]. Diferentemente dos metais de transição, que apresentam bandas de emissão largas (largura 20 $000 \mathrm{~cm}^{-1}$ ) devido ao desdobramento dos seus subníveis eletrônicos pelo campo ligante, os $\mathrm{TR}^{3+}$ possuem linhas de emissão finas e características.

Devido às suas emissões características e à riqueza de transições eletrônicas entre seus níveis $4 \mathrm{f}$, os elementos $\mathrm{TR}^{3+}$ têm sido muito utilizados em aplicações envolvendo luminescência [66-70]. No entanto, devido à proibição das transições eletrônicas 4f-4f, como discutiremos a seguir, esses elementos possuem sérias restrições na absorção de radiação eletromagnética, possuindo baixa absortividade molar. Sendo assim, sua utilização em aplicações fotoluminescentes depende da sua associação com matrizes ou moléculas (ligantes) capazes de absorver radiação eletromagnética e transferi-la ao $\mathrm{TR}^{3+}$.

A associação dos terras raras com ligantes orgânicos tem sido bastante explorada. Nesse contexto, ligantes específicos são escolhidos de forma que seus níveis eletrônicos sejam ressonantes com níveis eletrônicos dos $\mathrm{TR}^{3+}$. Isso permite a transferência eficiente de energia entre esses sistemas, aumentando a emissão luminescente do material. Para 
quantificar a luminescência dos materiais, duas quantidades podem ser definidas: a eficiência quântica de um nível emissor e o rendimento quântico.

\subsection{Eficiência quântica de um nível emissor}

Consideremos que um certo centro emissor de um material seja excitado e que existam rotas radiativas e não-radiativas para que seu decaimento ocorra, conforme ilustrado na Figura 2.7. Sejam $A_{\text {rad }}$ e $A_{\text {nrad }}$ as taxas de decaimento radiativo e não-radiativo do nível excitado deste centro, respectivamente. A eficiência quântica ( $\eta$ ) deste nível emissor é definida pela fração dos decaimentos que ocorre através da emissão de fótons:

$$
\eta=\frac{A_{\text {rad }}}{A_{\text {nrad }}+A_{\text {rad }}}
$$

Observe que a eficiência quântica não depende diretamente da população inicial do estado excitado do sistema, já que as taxas de decaimento apenas dependem de mecanismos intrínsecos de transição definidos pelo seu Hamiltoniano. No caso da luminescência dos íons $\mathrm{TR}^{3+}$, por exemplo, sua eficiência quântica está relacionada apenas à composição e à simetria do ambiente químico no qual eles estão imersos. Isso significa dizer também que não é possível melhorá-la através do fenômeno da luminescência sensibilizada por meio da associação entre $\mathrm{TR}^{3+}$ e ligantes fotossensibilizadores [71]. O uso dessa estratégia aumentaria a população do estado excitado, mas a fração $\eta$ de decaimentos radiativos continuaria a ser aquela determinada pelas probabilidades ditadas pelo Hamiltoniano.

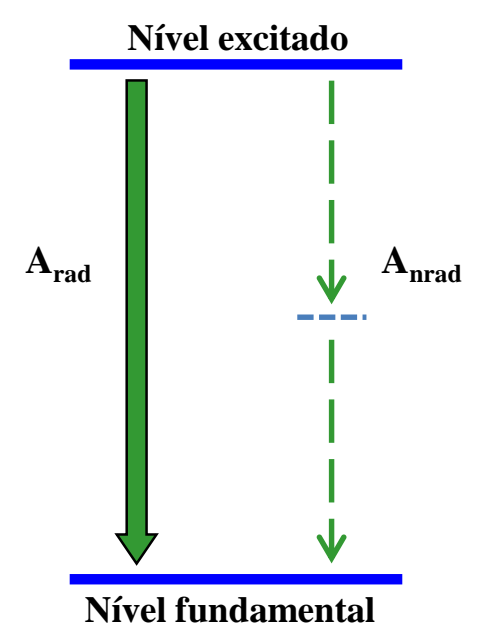

Figura 2.7. Ilustração do decaimento de um nível excitado, que pode ocorrer pela rota radiativa (taxa $A_{\text {rad}}$ ), com a emissão fótons, ou pela rota não-radiativa (taxa $\mathrm{A}_{\text {nrad }}$ ), com a emissão de fônons. 


\subsection{Rendimento quântico}

Diferentemente da eficiência quântica, o rendimento quântico $(\Phi)$ mede a fração do espectro absorvido pela amostra que foi realmente aproveitado pelo material para originar sua fotoluminescência. Ele é a fração do número de fótons produzidos pelo fenômeno da luminescência $\left(\mathrm{N}_{\mathrm{lum}}\right)$ sobre o número de fótons absorvidos $\left(\mathrm{N}_{\mathrm{abs}}\right)$ :

$$
\Phi=\frac{N_{l u m}}{N_{a b s}}
$$

Da forma como é definido, o rendimento quântico de matrizes contendo cátions $\mathrm{TR}^{3+}$ depende da eficiência (E) de transferência de energia entre a matriz e o terra rara e da eficiência quântica ( $\eta$ ) desse íon [71]:

$$
\Phi=\mathrm{E} \eta
$$

Esse parâmetro leva em conta, portanto, o efeito da sensibilização do $\mathrm{TR}^{3+}$ através da sua associação com matrizes ou moléculas antenas. Na estratégia do efeito antena, boa parte do espectro que, de outra maneira, não seria absorvido pelo $\mathrm{TR}^{3+}$ pode agora ser aproveitado, melhorando o que identificamos visualmente como o brilho do material. Apesar disso, deve ser observado também que o rendimento quântico é sempre menor que a eficiência quântica $(\Phi<\eta)$, ou seja, $\eta$ é um limite superior para $\Phi$ que só pode ser alcançado em sistemas com propriedades excelentes de absorção e transferência de energia para o centro emissor. Em outras palavras, mesmo que todo espectro incidente seja absorvido pela matriz e a energia transferida para o $\mathrm{TR}^{3+}(\mathrm{E}=1)$, a luminescência do material ainda estará restrita pela eficiência quântica do terra rara no material.

\subsection{Níveis eletrônicos dos íons terras raras trivalentes $\mathbf{T R}^{3+}$}

Em sua configuração trivalente $\left(\mathrm{TR}^{3+}\right)$, os elementos da série do Lantânio possuem configuração eletrônica [Xe] $4 \mathrm{f}^{\mathrm{n}}$, onde, variando $n$ de 0 a 14 varre-se do $\mathrm{La}^{3+}$ ao $\mathrm{Lu}^{3+}$ [72], conforme mostrado na Tabela 1. 
Tabela 1. Configurações eletrônicas dos elementos TR [73] e seu raio iônico.

\begin{tabular}{|c|c|c|c|}
\hline Elemento & $\begin{array}{c}\text { Configuração do } \\
\text { elemento } \mathbf{T R}^{*}\end{array}$ & $\begin{array}{c}\text { Configuração do } \\
\text { cátion } \mathbf{T R}^{3+*}\end{array}$ & $\begin{array}{c}\text { Raio iônico } \\
\text { (pm) }\end{array}$ \\
\hline La & {$[\mathrm{Xe}] 5 \mathrm{~d}^{1} 6 \mathrm{~s}^{2}$} & {$[\mathrm{Xe}] 4 \mathrm{f}^{0}$} & 116,0 \\
\hline $\mathrm{Ce}$ & {$[\mathrm{Xe}] 4 \mathrm{f}^{1} 5 \mathrm{~d}^{1} 6 \mathrm{~s}^{2}$} & {$[\mathrm{Xe}] 4 \mathrm{f}^{1}$} & 114,3 \\
\hline $\mathbf{P r}$ & {$[\mathrm{Xe}] 4 \mathrm{f}^{3} 6 \mathrm{~s}^{2}$} & {$[\mathrm{Xe}] 4 \mathrm{f}^{2}$} & 112,6 \\
\hline Nd & {$[\mathrm{Xe}] 4 \mathrm{f}^{4} 6 \mathrm{~s}^{2}$} & {$[\mathrm{Xe}] 4 \mathrm{f}^{3}$} & 110,9 \\
\hline Pm & {$[\mathrm{Xe}] 4 \mathrm{f}^{5} 6 \mathrm{~s}^{2}$} & {$[\mathrm{Xe}] 4 \mathrm{f}^{4}$} & 109,3 \\
\hline Sm & {$[\mathrm{Xe}] 4 \mathrm{f}^{6} 6 \mathrm{~s}^{2}$} & {$[\mathrm{Xe}] 4 \mathrm{f}^{5}$} & 107,9 \\
\hline $\mathbf{E u}$ & {$[\mathrm{Xe}] 4 \mathrm{f}^{7} 6 \mathrm{~s}^{2}$} & {$[\mathrm{Xe}] 4 \mathrm{f}^{6}$} & 106,6 \\
\hline Gd & {$[\mathrm{Xe}] 4 \mathrm{f}^{7} 5 \mathrm{~d}^{1} 6 \mathrm{~s}^{2}$} & {$[\mathrm{Xe}] 4 \mathrm{f}^{7}$} & 105,3 \\
\hline $\mathbf{T b}$ & {$[\mathrm{Xe}] 4 \mathrm{f}^{9} 6 \mathrm{~s}^{2}$} & {$[\mathrm{Xe}] 4 \mathrm{f}^{8}$} & 104,0 \\
\hline Dy & {$[\mathrm{Xe}] 4 \mathrm{f}^{10} 6 \mathrm{~s}^{2}$} & {$[\mathrm{Xe}] 4 \mathrm{f}^{9}$} & 102,7 \\
\hline Ho & {$[\mathrm{Xe}] 4 \mathrm{f}^{11} 6 \mathrm{~s}^{2}$} & {$[\mathrm{Xe}] 4 \mathrm{f}^{10}$} & 101,5 \\
\hline Er & {$[\mathrm{Xe}] 4 \mathrm{f}^{12} 6 \mathrm{~s}^{2}$} & {$[\mathrm{Xe}] 4 \mathrm{f}^{11}$} & 100,4 \\
\hline $\mathbf{T m}$ & {$[\mathrm{Xe}] 4 \mathrm{f}^{13} 6 \mathrm{~s}^{2}$} & {$[\mathrm{Xe}] 4 \mathrm{f}^{12}$} & 99,4 \\
\hline $\mathbf{Y b}$ & {$[\mathrm{Xe}] 4 \mathrm{f}^{14} 6 \mathrm{~s}^{2}$} & {$[\mathrm{Xe}] 4 \mathrm{f}^{13}$} & 98,5 \\
\hline $\mathbf{L u}$ & {$[\mathrm{Xe}] 4 \mathrm{f}^{14} 5 \mathrm{~d}^{1} 6 \mathrm{~s}^{2}$} & {$[\mathrm{Xe}] 4 \mathrm{f}^{14}$} & 97,7 \\
\hline
\end{tabular}

Com $n$ elétrons em sua subcamada $4 \mathrm{f}$, os elementos $\mathrm{TR}^{3+}$ possuem um número $\frac{14 !}{n !(14-n) !}$ de configurações eletrônicas possíveis associadas às diferentes formas de seus elétrons ocuparem os quatorze orbitais 4 f disponíveis. Cada uma dessas configurações pode ser classificada de acordo com uma série de parâmetros que servem também para nomeálas, segundo o que é conhecido como notação espectroscópica. São eles: o momento angular orbital $L$, o spin total $S$ e o momento angular total $J$ da configuração. Conhecidas essas características, cada configuração recebe a notação

$$
{ }^{2 S+1} L_{J}
$$

que inclui a multiplicidade de spin $2 S+1$. Nessa notação, cada valor de $L$ é representado por uma letra maiúscula do alfabeto latino de acordo com a regra: 


\begin{tabular}{cccccccccccccccccc}
$L=$ & 0 & 1 & 2 & 3 & 4 & 5 & 6 & 7 & 8 & 9 & 10 & 11 & 12 & 13 & 14 & 15 & $\ldots$ \\
\hline Notação & S & P & D & F & G & H & I & K & L & M & N & O & Q & R & T & U & $\ldots$
\end{tabular}

Assim, por exemplo, uma configuração com $L=2$ e $S=1$ pode possuir os valores $J \leq \mathrm{S}+\mathrm{L}, J=3,2$ e 1 . Cada uma dessas possibilidades é designada pela notação ${ }^{3} D_{3},{ }^{3} D_{2}$ e ${ }^{3} D_{1}$, respectivamente.

No contexto das várias interações envolvidas na definição dos níveis energéticos de um átomo, cada configuração ${ }^{2 S+1} L_{J}$ pode possuir uma energia diferente, conforme ilustrado na Figura 2.8. A interação eletrostática entre o núcleo e os elétrons, por exemplo, é capaz de definir energias diferentes para cada camada eletrônica, não distinguindo, no entanto, entre as diferentes configurações de spin e momento angular orbital. Todas as configurações com mesmo número quântico orbital são, portanto, degeneradas com relação à interação eletrostática entre os elétrons e os prótons.

Em elementos químicos que possuem mais de um elétron, no entanto, é necessário também considerar as interações entre todos os seus elétrons, que, devido à sua natureza repulsiva, tendem a deformar as órbitas eletrônicas no sentido de manter os elétrons o mais afastado possível um do outro. Essa deformação dos orbitais altera a energia de cada órbita eletrônica de acordo com o seu momento angular orbital e de spin associados, causando a separação dos seus níveis energéticos de acordo com o que é conhecido como regras de Hund [71]. Sendo assim: (primeira regra) a configuração com maior spin é a com menor energia; (segunda regra) para configurações de mesmo spin, aquela com maior momento angular orbital é a de menor energia. Em outras palavras, em ordem crescente de energia as configurações são arranjadas em ordem decrescente de spin e momento angular orbital, respectivamente.

Para cada spin $S$ e momento angular orbital $L$ estão associadas possibilidades de momento angular total $J$ variando de $|L-S|$ até $|L+S|$. Dentro dessas possibilidades, a cada configuração ${ }^{2 S+1} L_{J}$ está associado um nível energético. Após a ordenação desses níveis de acordo com a primeira e segunda regra de Hund, a configuração com menor energia é aquela com menor momento angular total $J$ (terceira regra de Hund).

Todas as regras de Hund estão ilustradas na Figura 2.8 para o caso concreto do íon $\mathrm{Eu}^{3+}$. Está ilustrado, também, um efeito adicional capaz de desdobrar os níveis de energia 
em subníveis de acordo com o ambiente químico no qual o elemento está inserido. Esse ambiente químico pode ser sentido como o efeito de um campo efetivo atuando naquele átomo e costuma ser denominado por campo cristalino ou campo ligante, podendo ordenar os subníveis do elemento de acordo com a projeção $M_{J}$ do seu momento angular total: (terceira regra) para $4 f^{n<7}\left(4 f^{n>7}\right)$ o subnível com menor (maior) projeção do momento angular total é o menos energético.

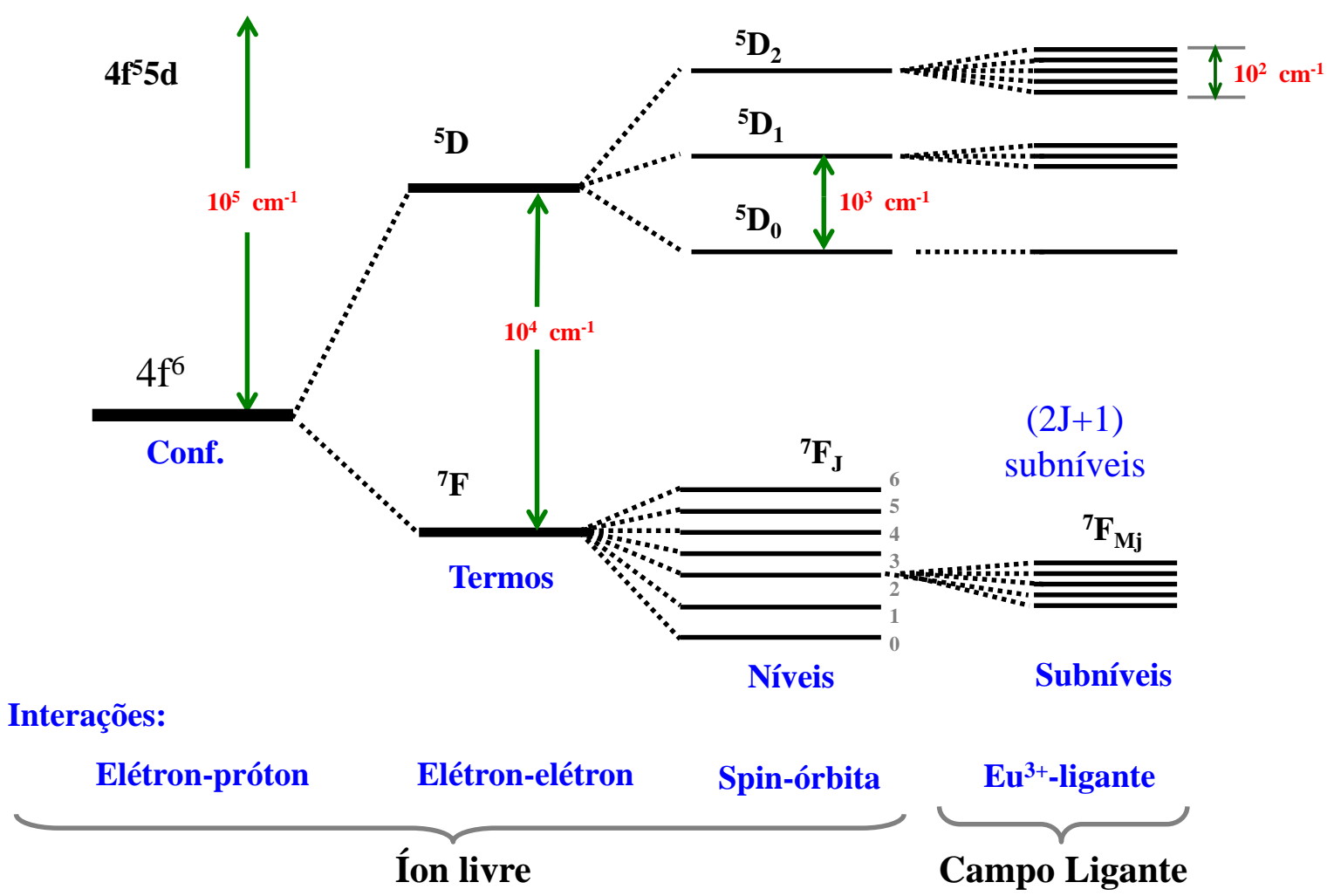

Figura 2.8. Diagrama parcial dos níveis de energia do terra rara trivalente $\mathrm{Eu}^{3+}$. Adaptado de [71].

Quando os elementos da série do Lantânio realizam ligações químicas, os orbitais preferencialmente envolvidos são aqueles mais externos: 5d e 6s. Como mostrado na Figura 2.9, a presença de camadas eletrônicas mais externas $(5 \mathrm{~s}, 5 \mathrm{p})$ aos seus orbitais $4 \mathrm{f}$ faz com que esses orbitais sejam praticamente insensíveis a campos eletrostáticos externos, num efeito de blindagem eletrostática propiciado pela deformação dos orbitais mais externos [64, 65]. Essas distorções atuam no sentido de compensar o efeito do campo cristalino nas camadas mais internas, diminuindo a sua influência sobre os níveis eletrônicos dos orbitais 4f, o que é refletido na proximidade energética entre os subníveis 
${ }^{2 S+1} L_{J\left(M_{J}\right)}$ dos elementos $\mathrm{TR}^{3+}$. Esse efeito também está ilustrado na Figura 2.8, que mostra um deslocamento total da ordem de apenas $10^{2} \mathrm{~cm}^{-1}\left(\sim 10^{-2} \mathrm{eV}\right)$ entre os subníveis do nível ${ }^{5} \mathrm{D}_{2}$ do cátion $\mathrm{Eu}^{3+}$.

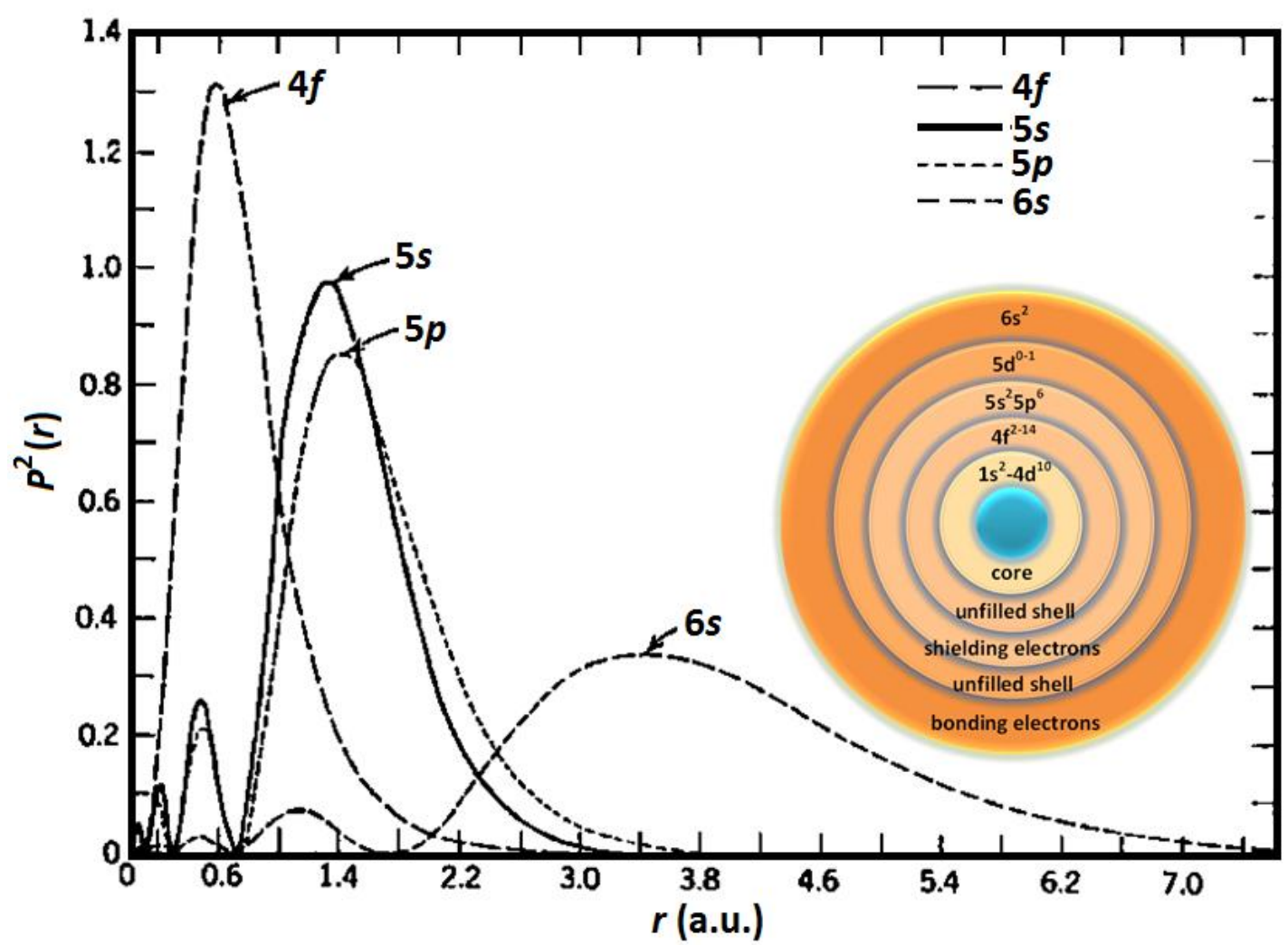

Figura 2.9. Densidade radial de carga de alguns dos orbitais mais externos do elemento Gadolínio (Gd), representativo da série do Lantânio [63, 74].

Devido ao efeito de blindagem eletrostática, os níveis eletrônicos dos íons $\mathrm{TR}^{3+}$ praticamente não se deslocam em função dos vários ambientes químicos em que esses íons podem estar submetidos. Os níveis energéticos das suas configurações eletrônicas são, portanto, muito próximos daqueles encontrados para os íons livres e são descritos pelo diagrama de Dieke mostrado na Figura 2.10. 


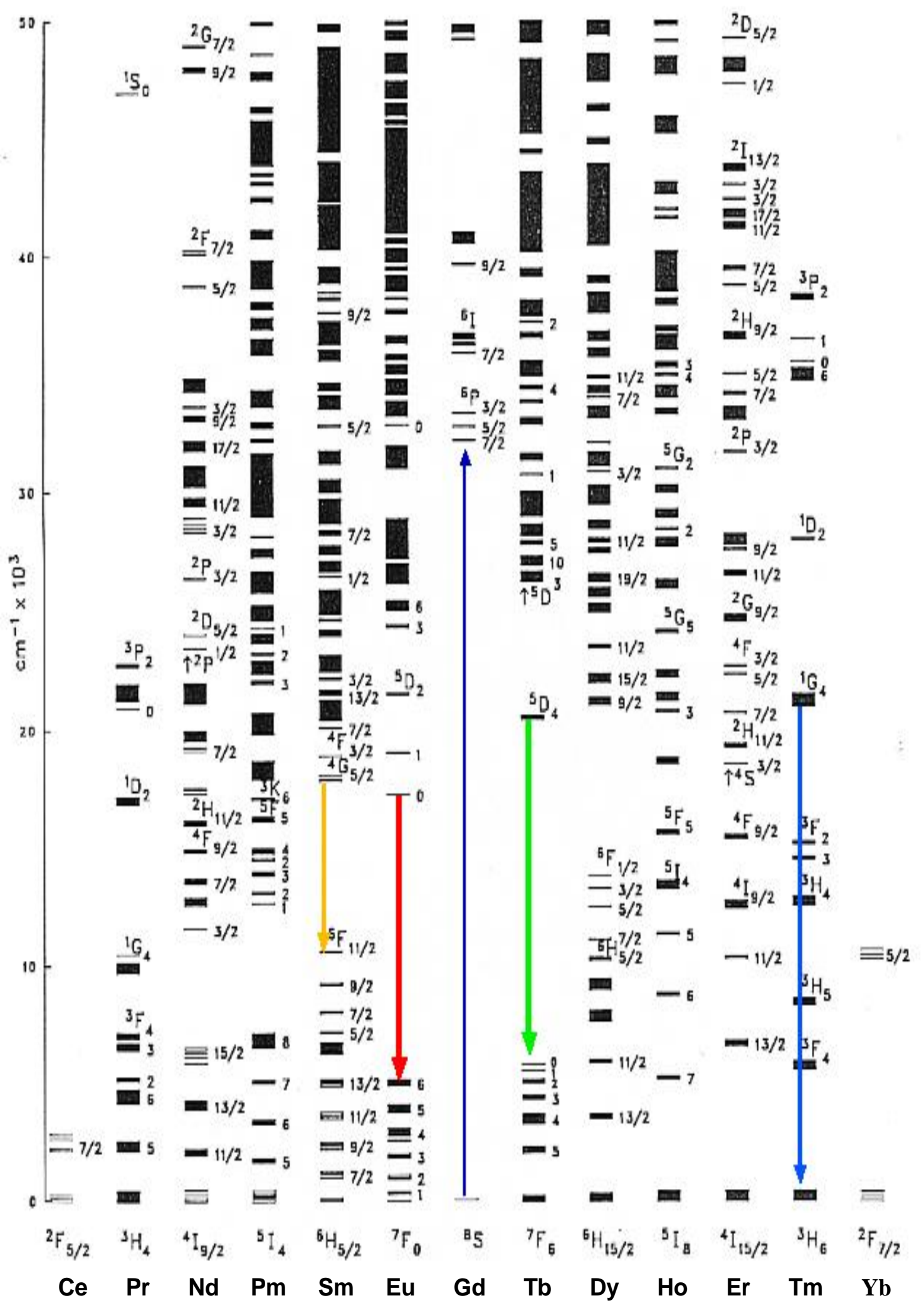

Figura 2.10. Diagrama dos níveis de energia $4 \mathrm{f}$ dos elementos $\mathrm{TR}^{3+}$. As setas coloridas representam as cores emitidas nas transições eletrônicas. Adaptado de [75, 76]. 


\subsection{Transições eletrônicas $4 f-4 f$ nos íons terras raras trivalentes $T^{3+}$}

Apesar da riqueza de níveis eletrônicos dos elementos $\mathrm{TR}^{3+}$, quando esses íons encontram-se no vácuo, todas as transições radiativas entre seus níveis 4f são proibidas por dipolo elétrico. Esse tipo de transição é geralmente responsável pela alta absortividade molar dos metais de transição, mas exige que os estados quânticos inicial e final possuam paridade oposta (regra de Laporte), o que não ocorre para estados dentro de uma mesma subcamada eletrônica. De fato, a paridade $(P)$ de uma configuração ${ }^{2 S+1} L_{J}$ em um elemento $\mathrm{TR}^{3+}$ com $n$ elétrons em sua subcamada $4 \mathrm{f}$ é dada por:

$$
P=(-1)^{n l}
$$

e pode assumir dois valores distintos, $P=1$ (função de onda par) e $P=-1$ (função de onda ímpar). $l=3$ é o momento angular de cada elétron individual em um orbital $\mathrm{f}$. Para um mesmo elemento $\mathrm{TR}^{3+}$ ( $n$ fixo), todas as configurações possuem a mesma paridade, o que faz com que transições $4 \mathrm{f}-4 \mathrm{f}$ não possam ser estimuladas por campos de dipolo elétrico.

Apesar da proibição das transições por dipolo elétrico entre níveis 4f, o acoplamento das órbitas eletrônicas com o momento de dipolo magnético ainda permite a ocorrência de transições entre certos níveis dos elementos $\mathrm{TR}^{3+}$, mesmo quando esses elementos estão no vácuo. Tais transições dão origem, no entanto, a linhas de luminescência de intensidade bastante reduzida. Para interpretar os espectros de emissão dos íons terras raras, é sempre bom ter em mente as regras de seleção para transições eletrônicas entre seus níveis. Para transições induzidas por dipolo magnético, devem ser satisfeitas as condições:

(i) $\Delta J=0, \pm 1$. Exceção: a transição $J=0 \rightarrow J=0$ não é permitida;

(ii) $\Delta M_{J}=0, \pm 1$;

(iii) $\Delta P=0$ (transições sem mudança de paridade).

Diferentemente do que é esperado para os íons terras raras no vácuo (longe da atuação de forças externas), quando eles estão imersos na matéria, seus orbitais eletrônicos são distorcidos e seus níveis de energia são, mesmo que ligeiramente, modificados. Isso é suficiente para fazer com que algumas transições $4 \mathrm{f}-4 \mathrm{f}$ possam ser observadas, aparentemente contrariando sua proibição pela regra de Laporte. A explicação para esse fenômeno ficou em aberto durante algumas décadas, mas no ano de 1962 Brian R. Judd [77] e George S. Ofelt [78] propuseram, independentemente, uma maneira de entendê-lo. A 
teoria desenvolvida por eles é conhecida hoje em dia por "teoria de Judd-Ofelt" e é a base moderna do estudo das propriedades espectroscópicas dos elementos terras raras.

\subsection{Teoria de Judd-Ofelt}

Quando um átomo está imerso em uma rede cristalina, uma série de campos externos atuam em seus elétrons, distorcendo suas órbitas. Esses campos formam o que chamamos de campo cristalino e se originam das cargas e dipolos elétricos dos átomos ao seu redor, diminuindo sua intensidade à medida que nos distanciamos do átomo em questão. Como já discutido nas seções anteriores, os orbitais $4 \mathrm{f}$ dos elementos terras raras são, grande parte, blindados dos campos externos pelos orbitais preenchidos $5 \mathrm{~s}^{2}$ e $5 \mathrm{p}^{6}$, que formam uma espécie de "gaiola de Faraday", impedindo que campos elétricos e magnéticos alcancem os orbitais 4f. Essa blindagem não é, no entanto, perfeita, e a existência do potencial $\mathrm{V}_{\mathrm{CF}}$ do campo cristalino atuante nesses orbitais tem implicações profundas nas linhas de emissão dos íons terras raras.

Judd e Ofelt consideraram o efeito perturbativo do campo cristalino sobre os orbitais eletrônicos nos terras raras trivalentes. Como previsto pela teoria de perturbação independente do tempo na mecânica quântica, sob o efeito de um potencial perturbativo $\mathrm{V}_{\mathrm{CF}}$, os orbitais $\left|\psi_{n L J}\right\rangle$,

$$
\left|\psi_{n L J}\right\rangle=\left|\varphi_{n L J}\right\rangle+\sum_{\beta L^{\prime} J^{\prime}} \frac{\left\langle\varphi_{\beta L^{\prime} J^{\prime}}\left|V_{C F}\right| \varphi_{n L J}\right\rangle}{E_{n L^{\prime}}-E_{\beta L^{\prime} J^{\prime}}}\left|\varphi_{\beta J^{\prime} M^{\prime}}\right\rangle,
$$

são autoestados, em primeira ordem de perturbação, do Hamiltoniano perturbado do sistema. Os índices $\beta, L^{\prime}$ (momento angular orbital) e $J^{\prime}$ (momento angular total) correm

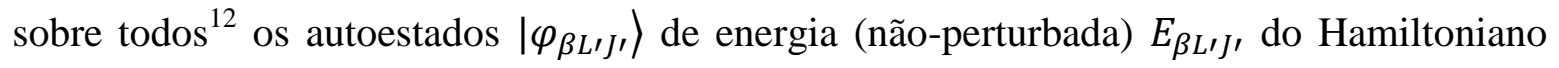
não-perturbado $\mathrm{H}_{0}$ e é neste fato que reside a núcleo da teoria de Judd-Ofelt: dentre os autoestados de $\mathrm{H}_{0}$, encontram-se estados com simetria ímpar, mas também estados com simetria par. No caso de campos cristalinos sem simetria de inversão, o termo de matriz $\left\langle\varphi_{\beta L^{\prime} J^{\prime}}\left|V_{C F}\right| \varphi_{n L J}\right\rangle$ produzirá autoestados $\left|\psi_{n L J}\right\rangle$ com simetria mista e as transições entre níveis energéticos do Hamiltoniano perturbado não mais estarão proibidas por dipolo elétrico (ao menos em ordem perturbativa em $\mathrm{V}_{\mathrm{CF}}$ ). Os íons terras raras em sítios cristalinos

\footnotetext{
${ }^{12}$ Aqui queremos dizer realmente que a soma se estende por todos os orbitais de $\mathrm{H}_{0}$, incluindo outras camadas eletrônicas e não somente os subníveis da camada 4f.
} 
sem simetria de inversão poderão, portanto, realizar transições entre seus níveis $4 \mathrm{f}$ (perturbados). Por outro lado, em caso de campos cristalinos com simetria de inversão, o termo de matriz $\left\langle\varphi_{\beta L^{\prime} J^{\prime}}\left|V_{C F}\right| \varphi_{n L J}\right\rangle$ só será não nulo para estados $\left|\varphi_{\beta L^{\prime} J^{\prime}}\right\rangle$ com mesma simetria que $\left|\varphi_{n L J}\right\rangle$, fazendo que $\left|\psi_{n L J}\right\rangle$ continue tendo simetria bem definida. Nesse caso, as transições entre os níveis 4f dos terras raras trivalentes continuarão restritas pela regra de Laporte.

Dentro do contexto descrito, Judd e Ofelt seguiram seus cálculos de modo a obter a taxa de transição entre estados perturbados $\left|\psi_{(4 f) L J}\right\rangle$ sob a influência de um segundo termo de perturbação causado pela interação dos elétrons com campos de dipolo elétrico externos ao sistema, o que corresponderia aos fenômenos de emissão ou absorção de ondas eletromagnéticas ${ }^{13}$. Novamente em primeira ordem de perturbação, o número de transições por segundo $\left(\mathrm{A}_{i \rightarrow f}\right)^{14}$ entre um estado inicial $(i)\left|\psi_{(4 f) L J}\right\rangle$ e outro estado final $(f)\left|\psi_{(4 f) L^{\prime} J \prime}\right\rangle$ depende do elemento de matriz $\left\langle\psi_{(4 f) L^{\prime} J^{\prime}}|D| \psi_{(4 f) L J}\right\rangle$ do operador dipolo elétrico $D=$ $-e \sum_{i} r_{i}$, em que a soma se estende sobre todos os elétrons do sistema:

$$
\mathrm{A}_{i \rightarrow f}=\frac{16 \pi^{3}}{\epsilon_{0} h \lambda^{3}} n^{3}\left(\frac{n^{2}+2}{3 n}\right)^{2} \sum_{M M^{\prime}}\left\langle\psi_{(4 f) L^{\prime} J^{\prime}}|D| \psi_{(4 f) L J}\right\rangle^{2},
$$

onde $n$ é o índice de refração do material, $\lambda$ é o comprimento de onda da emissão, $\epsilon_{0}$ é a constante de permissividade do vácuo e a soma se estende sobre os momentos angulares azimutais dentro de cada multipleto ${ }^{15}$ LJ e L'J' dos estados considerados. Como já discutido, caso $\mathrm{V}_{\mathrm{CF}}$ possua simetria de inversão, os termos $\left\langle\psi_{(4 f) L^{\prime} J}|D| \psi_{(4 f) L J}\right\rangle$ se anulam para transições $4 \mathrm{f}-4 \mathrm{f}$.

A equação anterior é o ponto de início da teoria de Judd-Ofelt. Para calcular os estados perturbados $\left|\psi_{(4 f) L J}\right\rangle$, Judd e Ofelt expandiram os graus de liberdade angular do potencial cristalino em termos dos harmônicos esféricos $Y_{k}^{q}$ e a parte radial em uma série de Taylor:

\footnotetext{
${ }^{13}$ Transições de dipolo magnético também podem ser consideradas, mas suas intensidades não são alteradas significativamente pelo campo cristalino e, portanto, podem ser calculadas utilizando o modelo de átomo no vácuo.

${ }^{14}$ Uma notação mais completa seria escrever $\mathrm{A}^{D E}{ }_{i \rightarrow f}$, evidenciando que se trata da taxa de transição por dipolo elétrico.

${ }_{15}^{15}$ Multipleto: conjunto dos estados com mesmo momento angular $\mathrm{J}$ contendo as diversas possibilidades de projeções azimutais $\mathrm{M}_{\mathrm{J}}$.
} 


$$
V_{C F}=\sum_{q, k} A_{k q} \sum_{i} r_{i}^{k} Y_{k}^{q}\left(\theta_{i}, \varphi_{i}\right)
$$

no qual a soma em $i$ se estende a todos os elétrons do terra rara e $k$ e $q$ são os índices dos harmônicos esféricos. Os cálculos que se seguem até a obtenção de $\left|\psi_{(4 f) L J}\right\rangle$ e a posterior obtenção de $A_{i \rightarrow f}$ são bastante complexos e envolvem uma série de aproximações sem as quais uma fórmula simples e fechada não seria possível. Para uma discussão mais completa, mas ainda sim simplificada, indicamos a leitura da referência [79].

Os resultados de Judd e Ofelt podem ser usados para demonstrar que:

$$
\mathrm{A}_{i \rightarrow f}=\frac{16}{3} \frac{\pi^{3} e^{2}}{\epsilon_{0} h \lambda^{3}\left(2 J_{i}+1\right)} n^{3}\left(\frac{n^{2}+2}{3 n}\right)^{2} \sum_{t=2,4,6} \Omega_{t}\left|U_{t}^{i \rightarrow f}\right|^{2}
$$

onde os termos $\left|U_{t}^{i \rightarrow f}\right|^{2}$ são independentes do campo cristalino e são tabelados na literatura [80-84]. A dependência do campo cristalino está toda embutida nos três parâmetros $\Omega_{2}, \Omega_{4}$ e $\Omega_{6}$, conhecidos como parâmetros de intensidade de Judd-Ofelt. Eles são diretamente proporcionais ao quadrado dos coeficientes de ordem ímpar ( $A_{k q}^{2} \operatorname{com} k$ ímpar) da expansão em harmônicos esféricos do potencial $\mathrm{V}_{\mathrm{CF}}$. Os coeficientes de ordem par, como era esperado, mantêm a simetria de inversão do Hamiltoniano e, por isso, não alteram as regras de transição do sistema, mantendo nulas as taxas de transição 4f-4f.

Como os parâmetros de intensidade de Judd-Ofelt são exclusivamente dependentes do campo cristalino, é possível, conhecendo a simetria e o ambiente químico ao redor do íon terra rara, calculá-los de maneira $a b$ initio usando a teoria de Judd-Ofelt. O procedimento oposto é mais comumente utilizado, no entanto: a determinação experimental de $\Omega_{2}, \Omega_{4}$ e $\Omega_{6}$ fornece informações sobre a simetria ao redor do $\mathrm{TR}^{3+}$. Em ambientes perfeitamente simétricos, baixas taxas de transições são esperadas, o que se reflete nos valores de $\Omega_{t}(t=2,4,6)$, como é o caso do íon $\mathrm{Eu}^{3+}{ }_{\text {(aq) }}$ (em solução aquosa), onde [85] $\Omega_{2}$ $=1.62 \times 10^{-20} \mathrm{~cm}^{2}, \Omega_{4}=5.65 \times 10^{-20} \mathrm{~cm}^{2}$ e $\Omega_{6}=5.02 \times 10^{-20} \mathrm{~cm}^{2}$. Por outro lado, em ambientes com simetria de inversão prejudicada, como no sistema [Eu(dbm) $3(\mathrm{dbso})][75]$, $\Omega_{2}=34 \times 10^{-20} \mathrm{~cm}^{2}, \Omega_{4}=11 \times 10^{-20} \mathrm{~cm}^{2}$. Enquanto $\Omega_{2}$ é mais sensível a mudanças angulares na geometria de coordenação do íon terra rara, $\Omega_{4}$ varia mais significativamente sob mudanças na distância e polarizabilidade dos átomos ligantes ao redor do $\mathrm{TR}^{3+}$ [86]. 
O método de determinação experimental de $\Omega_{t}(t=2,4,6)$ passa pela obtenção do valor experimental de $\mathrm{A}_{i \rightarrow f}$ para, no mínimo três transições $4 \mathrm{f}-4 \mathrm{f}$ do elemento $\mathrm{TR}^{3+}$ no material de interesse. Em um espectro de emissão, no entanto, a intensidade $S_{i \rightarrow f}(\lambda)$ observada é, em geral, a potência ótica por intervalo de comprimento de onda, sendo apenas proporcional a $\mathrm{A}_{i \rightarrow f}[87,88]$ :

$$
\mathrm{A}_{i \rightarrow f}=N 8 \pi n^{2} c \bar{\lambda} \int S_{i \rightarrow f}(\lambda) d \lambda
$$

onde $\bar{\lambda}=\int \lambda S_{i \rightarrow f}(\lambda) d \lambda / \int S_{i \rightarrow f}(\lambda) d \lambda$ é o valor médio de $\lambda$ referente à transição $i \rightarrow f$ e $N$ é uma constante desconhecida, dependente de detalhes arranjo experimental, como o tempo de integração do espectro e as aberturas das fendas de excitação e emissão, dentre outros.

No caso do íon $\mathrm{Eu}^{3+}$, um artifício pode ser utilizado para a determinação das taxas de transição $\mathrm{A}_{i \rightarrow f}$ : a transição ${ }^{5} \mathrm{D}_{0} \rightarrow{ }^{7} \mathrm{~F}_{1}$ desse cátion é proibida por dipolo elétrico mesmo no contexto perturbativo que descrevemos. Ela é, porém, permitida por dipolo magnético e, por isso, possui uma taxa de transição $A_{M D}=14.73 \mathrm{n}^{3} \mathrm{~s}^{-1}$, dependente apenas do índice de refração do material e independente do campo cristalino, podendo ser usada como calibração para os espectros de emissão do íon $\mathrm{Eu}^{3+}$. Sendo assim, podemos calcular [89]:

$$
\frac{\mathrm{A}_{i \rightarrow f}}{\mathrm{~A}_{M D}}=\frac{\bar{\lambda}_{i \rightarrow f}}{\bar{\lambda}_{M D}} \frac{\int S_{i \rightarrow f}(\lambda) d \lambda}{\int S_{M D}(\lambda) d \lambda}
$$

Além disso, para o íon $\mathrm{Eu}^{3+}$, podemos facilmente analisar as transições ${ }^{5} D_{0} \rightarrow{ }^{7} F_{t}$ $(t=2,4,6)$, já que [84]:

(i) para a transição ${ }^{5} D_{0} \rightarrow{ }^{7} F_{2}:\left|U_{2}\right|^{2}=0.0032,\left|U_{4}\right|^{2}=0$ e $\quad\left|U_{6}\right|^{2}=0$;

(ii) para a transição ${ }^{5} D_{0} \rightarrow{ }^{7} F_{4}:\left|U_{2}\right|^{2}=0, \quad\left|U_{4}\right|^{2}=0.0023$ e $\left|U_{6}\right|^{2}=0$;

(iii) para a transição ${ }^{5} D_{0} \rightarrow{ }^{7} F_{6}:\left|U_{2}\right|^{2}=0, \quad\left|U_{4}\right|^{2}=0$ e $\quad\left|U_{6}\right|^{2}=0.0002$.

Esses valores facilitam a análise dos espectros, desacoplando as equações para $\Omega_{t}$, que podem ser calculados a partir das transições ${ }^{5} D_{0} \rightarrow{ }^{7} F_{t}(t=2,4,6)$ :

$$
\Omega_{t}=\frac{3}{16} \frac{\lambda^{3}{ }_{t}}{\left|U_{t}\right|^{2}} \frac{\epsilon_{0} h}{\pi^{3} e^{2}}\left(\frac{3 n}{n^{2}+2}\right)^{2} \frac{\bar{\lambda}_{t}}{\bar{\lambda}_{M D}} \frac{\mathrm{A}_{M D}}{n^{3}} \frac{\int S_{i \rightarrow f}(\lambda) d \lambda}{\int S_{M D}(\lambda) d \lambda} .
$$




\subsection{Efeito antena}

Mesmo com a atuação do campo cristalino, que, como tratado pela teoria de JuddOfelt, flexibiliza as regras de transição $4 \mathrm{f}-4 \mathrm{f}$ dos íons terras raras trivalentes, esses elementos possuem coeficientes de absortividade molar bastante reduzidos, ordens de grandeza menores que os encontrados nos metais de transição. Isso causa uma dificuldade intrínseca para popular seus níveis excitados e, mesmo que eficiências quânticas de emissão em torno de $100 \%$ possam ser obtidas, a fotoluminescência desses materiais será limitada pela absorção. Esse problema, no entanto, pode ser em grande parte resolvido com a associação dos terras raras com outras moléculas absorvedoras de luz. Essas moléculas devem ser escolhidas de forma a absorver energia eletromagnética e transferi-la não radiativamente aos terras raras, o que é chamado de efeito antena. Explorar o efeito antena é fundamental para que o material projetado tenha boas propriedades luminescentes.

No efeito antena, uma molécula orgânica - ligante - com boas propriedades de absorção de radiação eletromagnética é posicionada nas proximidades de um íon terra rara, como ilustrado na Figura 2.11. Para cada elemento $\mathrm{TR}^{3+}$, moléculas específicas devem ser escolhidas de acordo com a existência de níveis ressonantes entre o terra rara e o ligante. Nessa geometria molecular, a energia absorvida pela molécula antena pode ser transferida eficientemente para os íons, com eficiência de transferência que pode ser, em alguns casos, próxima de 100\% [90]. Sendo assim, ao excitarmos a molécula antena estamos indiretamente excitando o terra rara de maneira mais eficiente que sua excitação direta e, portanto, obteremos uma luminescência mais intensa.

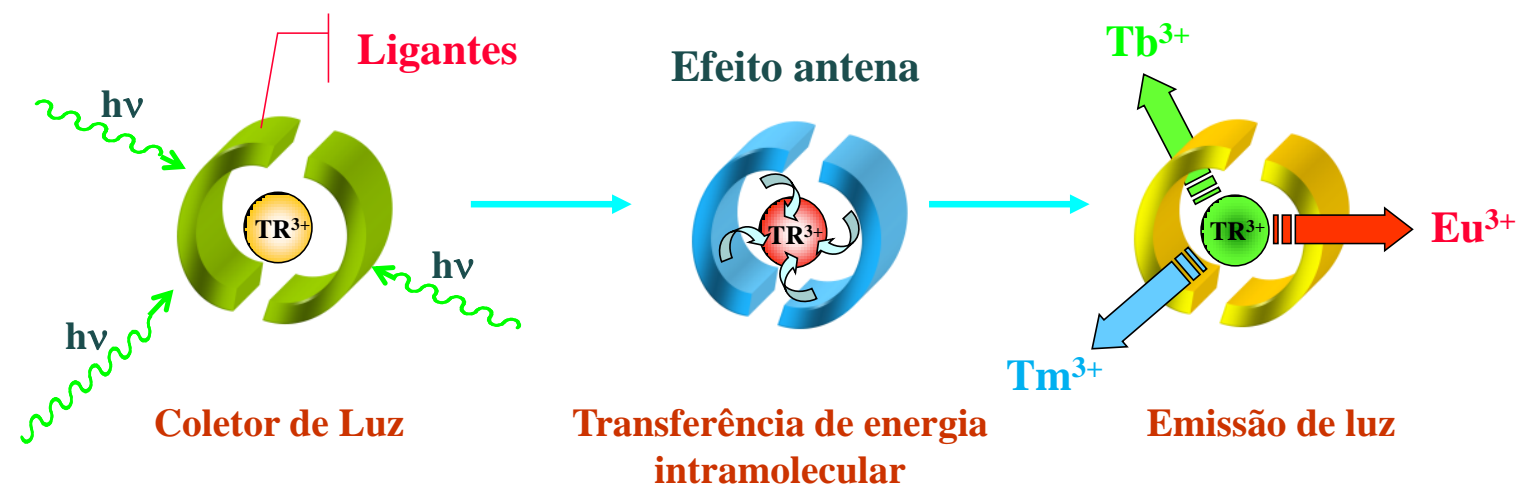

Figura 2.11. No efeito antena, os ligantes absorvem energia eletromagnética e transferem-na para os íons $\mathrm{TR}^{3+}$ na sua redondeza, tornando a luminescência desse íon mais eficiente. Adaptado de [75, 91]. 
Diversos mecanismos são propostos para descrever o processo de absorção e transferência de energia no efeito antena [92-97]. Todos eles possuem estágios iniciais de absorção de energia promovendo transições eletrônicas entre estados de mesmo spin do ligante, mas com diferentes momentos angulares orbitais. Justamente porque transições desse tipo são permitidas por dipolo elétrico, os ligantes possuem coeficientes de absortividade tipicamente três ordens de grandeza maiores que os dos elementos terras raras.

Após a ocupação dos estados singletos mais energéticos do ligante, a transferência de energia para o íon terra rara pode ocorrer diretamente destes estados singletos ou, alternativamente, a partir de um estado tripleto menos energético, após a relaxação do ligante pela emissão de fônons. Este último, ilustrado na Figura 2.12, é geralmente o caso quando os íons envolvidos são o $\mathrm{Eu}^{3+}$ ou o $\mathrm{Tb}^{3+}$. Quando estados eletrônicos tripletos $\mathrm{T}_{1}$ $(S=1, L=0)$ estão populados, a sua desexcitação para estados singletos $\mathrm{S}_{0}(S=0$, $L=0$ ) não é permitida de modo radiativo devido à proibição desse tipo transição entre estados de mesmo momento angular orbital. Dessa forma, a desexcitação desse estado é forçada ocorrer de forma não-radiativa para um estado de nível energético o mais próximo possível. Esse mecanismo torna a existência de níveis ressonantes entre o ligante e o terra rara bastante conveniente, dando origem a transições com probabilidades bastante elevadas.

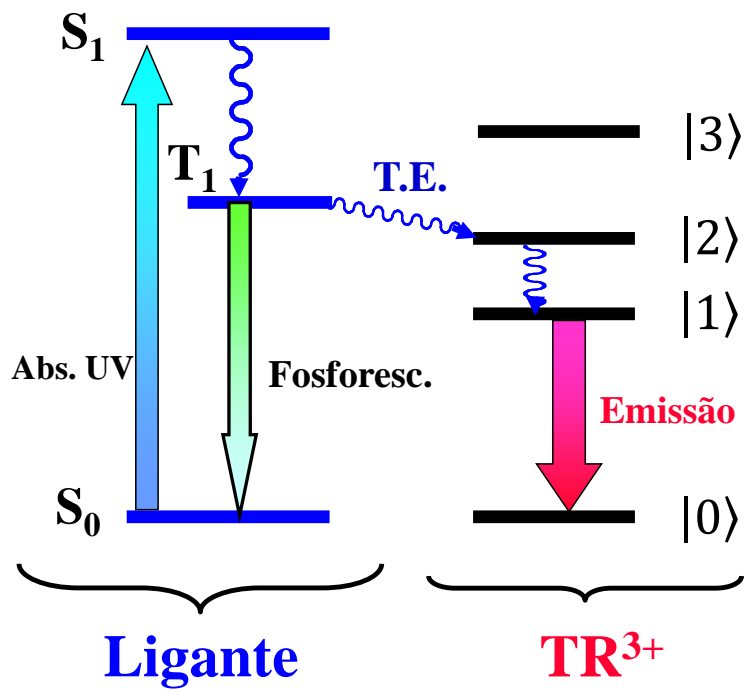

Figura 2.12. Mecanismo simplificado de transferência de energia $\mathrm{TR}^{3+}$-ligante mais comum nos compostos de $\mathrm{Eu}^{3+}$ e $\mathrm{Tb}^{3+}[92,98]$. A excitação do ligante entre os estados singletos $S_{0}$ e $S_{1}$ ocorre, com a posterior relaxação para o estado tripleto $\mathrm{T}_{1}$, que transfere para um nível ressonante do terra rara. 
A partir da excitação não radiativa do íon terra rara, a luminescência se torna muito mais intensa, com rendimentos quânticos que podem chegar a 90\% [66, 99].

\subsection{Emissão do íon $\mathrm{Eu}^{3+}$}

Utilizando a associação de íons $\mathrm{Eu}^{3+}$ com ligantes orgânicos, diversos materiais foram descritos na literatura aproveitando a emissão visível desses íons em diferentes aplicações [66, 100-103]. Algumas características das bandas de emissão do $\mathrm{Eu}^{3+}$ são [71]:

(i) A transição ${ }^{5} D_{0} \rightarrow{ }^{7} F_{0}$ é proibida por dipolo magnético por ser do tipo $J=0 \rightarrow$ $J=0$ (cf. seção 2.6) e é proibida por dipolo elétrico mesmo em sistemas sem simetria de inversão, produzindo emissões de intensidade baixíssima.

(ii) A transição ${ }^{5} D_{0} \rightarrow{ }^{7} F_{1}$ é permitida por dipolo magnético, mas proibida por dipolo elétrico mesmo em sistemas sem simetria de inversão, possuindo intensidade de emissão que varia pouco com diferenças no ambiente químico.

(iii) A transição ${ }^{5} D_{0} \rightarrow{ }^{7} F_{2}$ é proibida por dipolo magnético por possuir $\Delta J=2$, mas costuma-se dizer que é hipersensível à simetria do campo ligante, podendo tornar-se 200 vezes mais intensa caso o sítio do íon não seja um centro de inversão do sistema, como no caso do espectro mostrado na Figura 2.13.

(iv) A transição ${ }^{5} D_{0} \rightarrow{ }^{7} F_{3}$ é proibida por dipolo magnético por possuir $\Delta J=3$ e é proibida por dipolo elétrico mesmo em sistemas sem simetria de inversão, produzindo linhas de emissão de baixa intensidade.

(v) A transição ${ }^{5} D_{0} \rightarrow{ }^{7} F_{4}$ é proibida por dipolo magnético por possuir $\Delta J=4$, porém, como ocorre na transição ${ }^{5} D_{0} \rightarrow{ }^{7} F_{2}$, é sensível à quebra da simetria de inversão pelo campo ligante, podendo ter sua proibição relaxada e sua intensidade de emissão aumentada.

(vi) Em temperaturas baixas, tipicamente na temperatura do nitrogênio liquido, os desdobramentos do espectro referentes às transições entre diferentes projeções $M_{J}$ do momento angular total se tornam visíveis. 


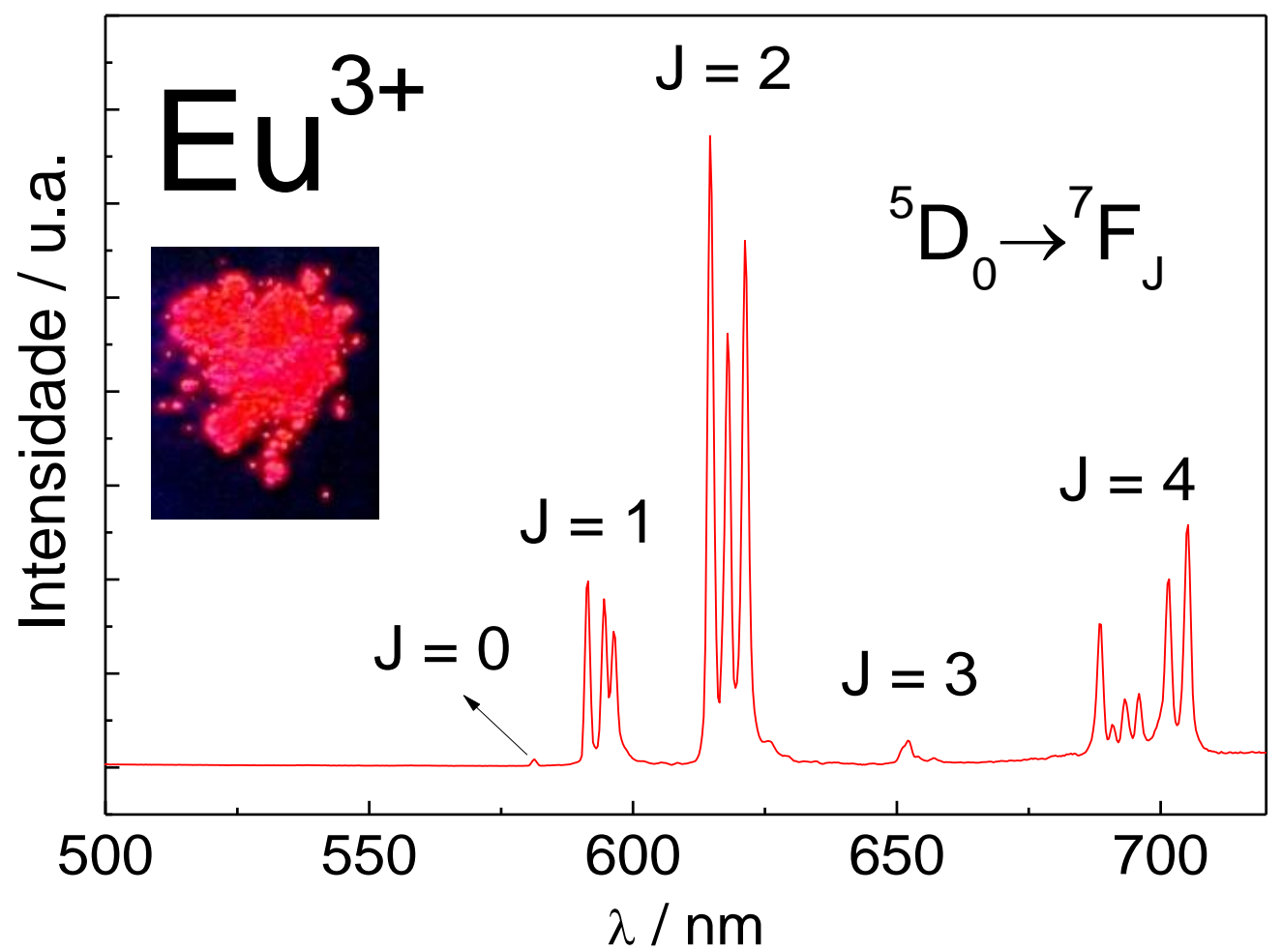

Figura 2.13. Espectro de emissão (medido a $77 \mathrm{~K}$ ) de um complexo de $\mathrm{Eu}^{3+}$ cujo sítio ocupado pelo íon terra rara não é um centro de inversão do sistema. No detalhe, imagem do material quando iluminado com luz ultravioleta. 


\section{Capítulo 3}

\section{Técnicas de caracterização.}

Diversas técnicas experimentais utilizadas nesse trabalho são bastante comuns na área da ciência de materiais. Neste capítulo, fazemos uma breve descrição dessas técnicas e detalhamos as condições experimentais utilizadas. Fazemos também uma pequena introdução teórica de cada técnica a fim de guiar a interpretação dos resultados mostrados nos capítulos adiante.

\subsection{Difração de raios $X$}

Exatamente como a luz visível, os raios $\mathrm{X}$ são ondas eletromagnéticas, compreendendo a faixa do espectro com comprimentos de onda entre $0.01 \mathrm{~nm}$ e $10 \mathrm{~nm}$. Quando duas ou mais ondas eletromagnéticas interferem, um padrão de interferência é formado como o resultado da soma das duas ondas.

Quando um feixe de raios X incide em uma amostra, como esquematizado na Figura 3.1, os elétrons presentes no material espalham essas ondas eletromagnéticas por todas as direções. A soma dessas ondas espalhadas produz um padrão de interferência que pode ser observado utilizando um detector de ondas eletromagnéticas. No caso da luz visível, esse detector poderia ser, por exemplo, o olho humano. Já no caso dos raios X, é necessário utilizar um detector de raios $\mathrm{X}$.

O padrão de interferência, também chamado de padrão de difração, detectado em um experimento de difração de raios $X$ traz muitas informações sobre a disposição dos átomos na amostra analisada. Para cada tipo de arranjo cristalográfico, um tipo de padrão de interferência é detectado. Para cada tipo de informação desejada, um tipo de experimento deve ser realizado.

Diversas geometrias foram desenvolvidas para possibilitar a obtenção do maior número de informações possíveis sobre o arranjo cristalográfico das amostras utilizando difração de raios X. Na Figura 3.1, está esquematizado um arranjo experimental conhecido como $\theta-2 \theta$ (teta, dois teta) e também chamada de geometria de Bragg-Brentano. Nessa 
geometria, os ângulos de incidência e de detecção são mantidos iguais. As distâncias do tubo de produção de raios X (X-Ray Tube) e do detector até a amostra são mantidas fixas, enquanto o ângulo $\theta$ é variado.

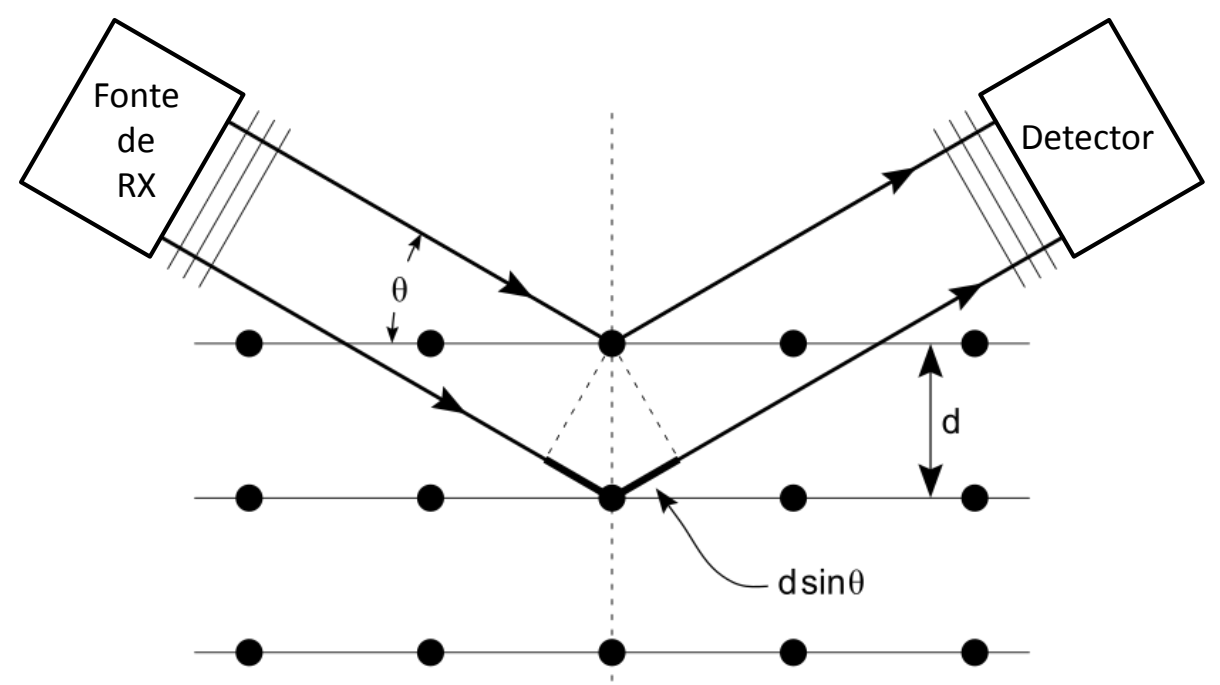

Figura 3.1. Esquema de um experimento de difração de raios $X$ na geometria de Bragg-Brentano na qual a fonte e o detector de raios $\mathrm{X}$ de deslocam simetricamente. Os planos atômicos da amostra espalhando os feixes de raios X, que, na condição de Bragg, interferem construtivamente..

Na geometria $\theta-2 \theta$, a intensidade do feixe na posição do detector é resultado da interferência entre os feixes espalhados pela a amostra. Em uma situação simplificada em que cada átomo da amostra está separado por uma distância $d$ um do outro (veja Figura 3.1), é possível entender o padrão de intensidade que será medido no detector. Seguindo o esquema mostrado na Figura 3.1, observa-se que feixes espalhados por átomos separados por uma distância vertical $d$ emergem da amostra com uma diferença de caminho ótico $\Delta x=2 d \sin \theta$. Interferência construtiva desses feixes será observada quando $\Delta x$ for um número inteiro de comprimentos de onda $(\lambda)$, levando à equação que é conhecida como equação de Bragg:

$$
\sin \theta=\frac{n \lambda}{2 d} \quad(n=1,2,3, \ldots) .
$$

Ângulos que satisfazem essa equação para algum $n$ são ditos satisfazer a condição de Bragg e são muito importantes para a interpretação de padrões de interferência em experimentos 
de difração de raios X. Com esses ângulos é possível determinar a distância entre os planos atômicos equivalentes do material que está sendo analisado.

Neste trabalho, o método de difração de pó foi utilizado na obtenção de todos os padrões de difração de raios $\mathrm{X}$ apresentados (também chamados de difratogramas). Essas medidas foram realizadas no Laboratório de Cristalografia do IFUSP (LC-IFUSP) e no Center for Surface Chemistry and Catalysis (COK) da Universidade de Leuven (KULeuven). No LC-IFUSP utilizamos a geometria de Bragg-Brentano nos difratômetros D8 Discover (Bruker) com fonte de radiação $\mathrm{CuK} \alpha(\lambda=1.5418 \AA$, $40 \mathrm{kV}$ e $30 \mathrm{~mA})$ e detector Lynxeye com 193 canais de detecção simultânea e Rigaku Ultima Plus também com fonte de radiação $\mathrm{CuK} \alpha(\lambda=1.5418 \AA$ A, $40 \mathrm{kV}$ e $30 \mathrm{~mA})$ e detector pontual. O ângulo $2 \theta$ de detecção foi de $4^{\circ}$ to $70^{\circ}$ em passos de $0.05^{\circ}$ com tempos de integração tipicamente entre 1 e 3s. Para a medição, as amostras eram trituradas em almofariz até a obtenção de um pó com a granulação mais fina possível a fim de garantir uma boa distribuição aleatória de orientações dos cristalitos. No equipamento da marca Bruker a amostra era disposta nos sulcos circulares de um porta amostra de acrílico e sua superfície era aplainada com uma lâmina de vidro. No equipamento da marca Rigaku, a amostra era fixada com graxa em uma lâmina de vidro e prensada contra outra lâmina para obter uma superfície plana e regular. Em ambos os equipamentos as amostras eram rodadas tipicamente a velocidades de 20 a 30 rpm dependendo do tempo de integração utilizado e da estabilidade da amostra no porta amostra.

No COK-KULeuven, as medidas foram realizadas utilizando uma geometria de transmissão com o equipamento STADI P (STOE \& Cie GmbH, Darmstadt, Alemanha) com fonte de radiação $\mathrm{CuK} \alpha$ e detector em linha para detecção simultânea de ângulos $2 \theta$ de $-60^{\circ}$ a $60^{\circ}$. O tempo de medição variou de 5 a 20 min dependendo da intensidade difratada por cada amostra. Para a medida, as amostras eram trituradas em almofariz e dispostas sobre um filme plástico, sem a necessidade de prensagem da superfície.

\subsection{Microscopia eletrônica de varredura (MEV)}

Um microscópio, em geral, é um equipamento que utiliza lentes para ampliar imagens. Em um microscópio ótico, por exemplo, a luz captada de uma amostra passa por um conjunto de lentes óticas antes de ser projetada em uma tela. O conjunto de lentes é 
escolhido de forma a produzir uma boa imagem ampliada. A resolução dessa imagem, porém, está limitada pelo comprimento de onda da luz visível, que é da ordem de $1 \mu \mathrm{m}$.

Um microscópio eletrônico, como o esquematizado na Figura 3.2, tem um funcionamento similar ao de um microscópio ótico, mas utiliza um feixe de elétrons em vez de um feixe luminoso. As lentes utilizadas são lentes magnéticas, nas quais um campo magnético deflete a trajetória dos elétrons. Estes, por conseguinte, possuem comprimento de onda da ordem de $10^{-5} \mu \mathrm{m}$, muito menor que o da luz, permitindo imagens muito mais detalhadas das amostras de interesse.

A detecção dos elétrons em um microscópio eletrônico de varredura e, portanto, a formação da imagem, pode ser feita por diferentes métodos. Se a amostra não é totalmente opaca aos elétrons incidentes, a fração dessas partículas que é transmitida pode ser detectada por um cintilador ou um detector semicondutor posicionado abaixo do portaamostra.

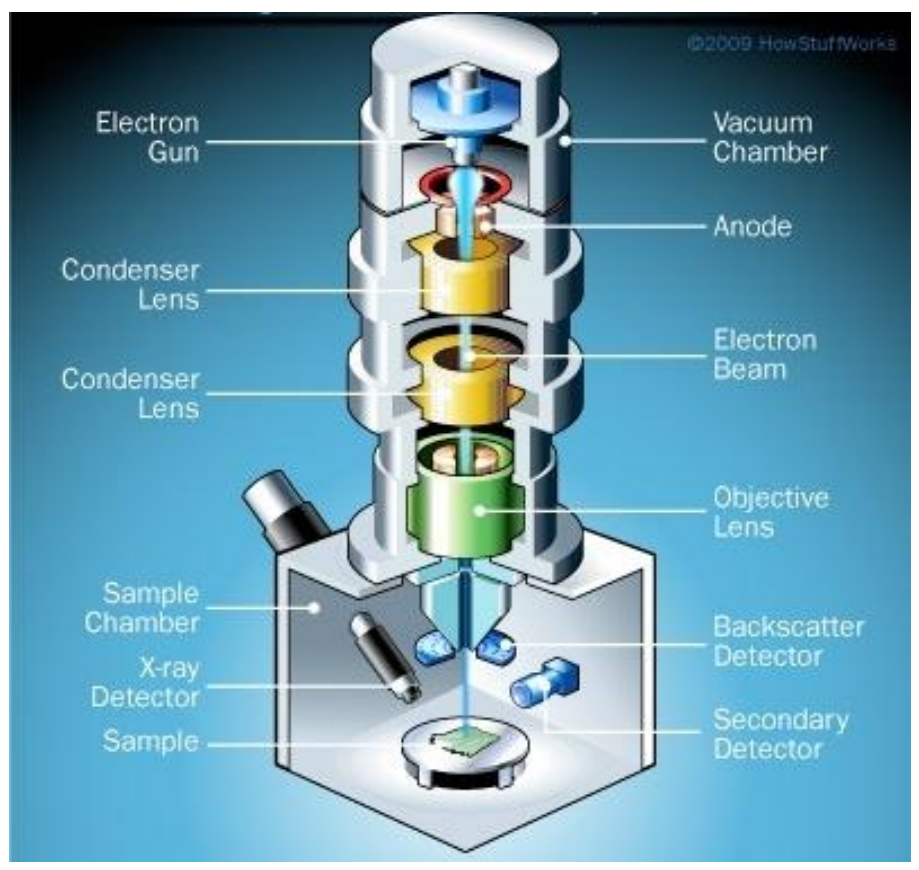

Figura 3.2. Esquema de um microscópio eletrônico de varredura (MEV) [104].

Elétrons ejetados da amostra por ionização podem ser coletados por um detector (“detector de elétrons secundários”) posicionado ao lado da amostra, produzindo as imagens mais detalhadas da sua superfície. Nessas imagens, com resoluções de $5-20 \mathrm{~nm}$, 
regiões com maior densidade de elétrons, ou seja, com maior intensidade de elétrons ejetados, são mostradas mais claras que as regiões de baixa densidade eletrônica [105].

Elétrons retroespalhados também podem ser detectados, mas produzem imagens com menor resolução se comparadas àquelas produzidas pelos elétrons secundários.

As imagens de microscopia eletrônica de varredura mostradas neste trabalho foram obtidas utilizando os equipamentos FESEM JEOL JSM-7401F na Central Analítica do IQUSP e Nova NanoSEM450 FEI no Center for Surface Chemistry and Catalysis da KULeuven, na Bélgica. Energias típicas dos elétrons utilizados foram de $2-3 \mathrm{keV}$. Para a medida, as amostras em pó eram dispersas em etanol em um banho ultrassom por cerca de 15 min. A dispersão obtida era gotejada em cima de um suporte de grafite $(s t u b)$ que era introduzido no microscópio após a secagem do etanol. A dispersão ideal das amostras para a medida era obtida quando apenas uma camada de pó bem fina podia ser vagamente vista em cima do suporte de grafite.

\subsection{Microscopia eletrônica de transmissão (TEM)}

Como uma técnica de microscopia eletrônica, a microscopia eletrônica de transmissão utiliza elétrons para formar imagens. Na TEM, um feixe de elétrons é incidido na amostra de interesse e sua parte transmitida é ampliada por um conjunto de lentes magnéticas antes de colidir contra uma tela fluorescente produzindo a imagem. Devido à alta energia dos elétrons utilizados nessa técnica, que é da ordem de $200 \mathrm{keV}$, a resolução conseguida pode chegar a $0.2 \mathrm{~nm}$, até 100 vezes maior que a dos microscópios eletrônicos de varredura [106].

As imagens de microscopia eletrônica de varredura mostradas neste trabalho foram obtidas na Central Analítica do IQ-USP com um equipamento Jeol JEM 2100 com tensão de aceleração máxima de $200 \mathrm{kV}$. Para a medida, as amostras em pó eram também dispersas em etanol em um banho ultrassom por cerca de $15 \mathrm{~min}$. Tipicamente, as dispersões obtidas eram diluídas várias vezes até se obter um líquido quase transparente. Após as diluições, concentrações típicas de $0.1 \mathrm{mg} / \mathrm{mL}$ ou menores eram obtidas e cerca de $3 \mu \mathrm{L}$ dessas soluções eram gotejados sobre o lado com Formvar de uma grade de cobre para TEM com uma malha de 200 poços (formvar/Carbon 200 mesh copper TEM grid, Electron Microscopy Sciences, USA). 


\subsection{Espectroscopia de raios $X$ por dispersão de energia (EDX)}

A técnica de EDX é geralmente utilizada em conjunto com as microscopias eletrônicas de varredura e de transmissão e é capaz de detectar a composição química das amostras analisadas.

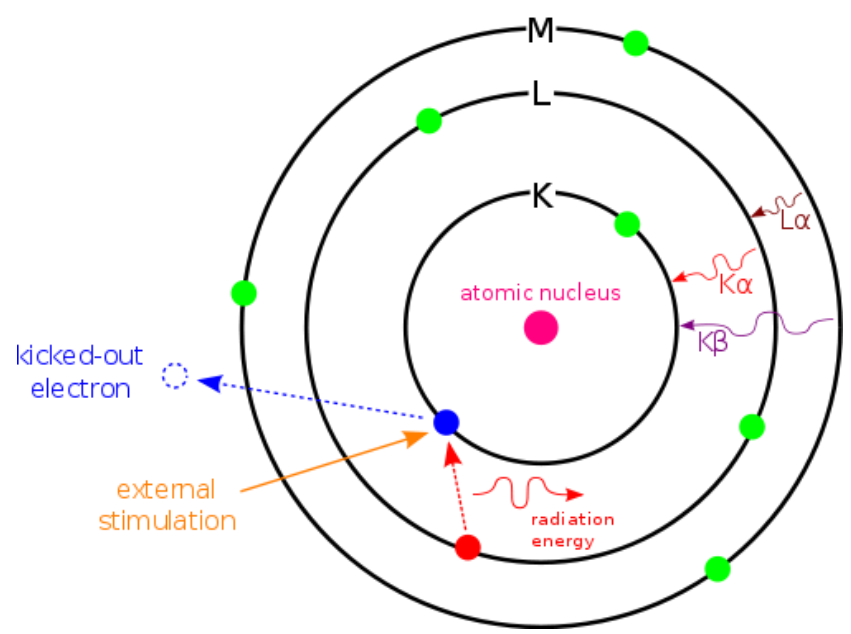

Figura 3.3. Princípios da técnica de espectroscopia de raios $X$ por dispersão de energia (EDX).

Nessa técnica, um feixe de elétrons com energia de $10 \mathrm{keV}$ a $20 \mathrm{keV}$ incide na amostra, arrancando elétrons das camadas mais internas de seus átomos, como mostrado na Figura 3.3. O rearranjo dos elétrons a fim de preencher a vacância deixada causa a emissão de fótons de alta energia, na região dos raios X. Esses fótons são coletados por um detector e seu espectro (dispersão) de energia é comparado com uma base de dados. Nessa comparação, as diversas linhas de emissão características das diferentes espécies de átomos podem ser identificadas.

Devido ao fato de que os fótons gerados por essa técnica são frequentemente reabsorvidos pela amostra, gerando uma nova cascata de excitação dos elétrons do material, as medidas da intensidade luminosa detectada dificilmente podem ser convertidas na quantidade de elementos contidos na amostra. Isso torna a técnica de EDX uma ferramenta apenas qualitativa de análise da composição do material, não sendo possível obter dados quantitativos confiáveis.

Os espectros de EDX mostrados neste trabalho foram obtidos na Central Analítica do IQ-USP com um MET Jeol JEM 2100 com tensão de aceleração máxima de 200 kV. 


\subsection{Espectrometria de emissão atômica com plasma acoplado (ICP-OES)}

A espectrometria de emissão atômica com plasma acoplado é uma técnica capaz de quantificar metais e semimetais. Nessa técnica, a amostra passa por um processo de preparação prévia onde é reagida com ácidos a fim de remover compostos orgânicos presentes.

Em equipamentos de ICP-OES um gerador de plasma é acoplado a um espectrômetro óptico, como mostrado na Figura 3.4. Enquanto o plasma, geralmente de argônio, induz transições eletrônicas nos elementos a serem quantificados, o espectrômetro acoplado detecta os comprimentos de onda emitidos durante a desexcitação.
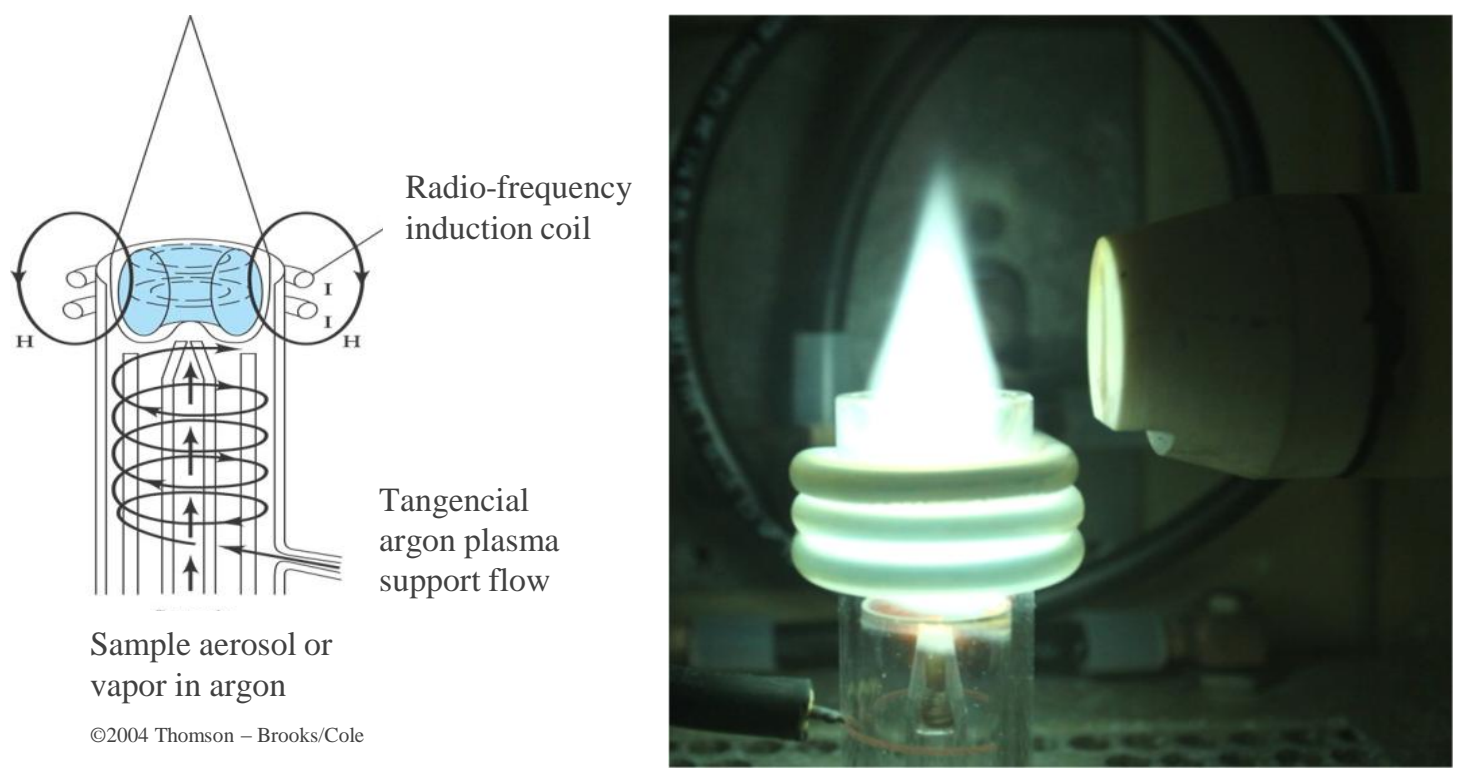

Figura 3.4. Sistema de plasma acoplado em um equipamento de ICP-OES [107-110].

Para a geração do plasma em um equipamento de ICP-OES, uma bobina é percorrida por uma corrente alternada em radiofrequência, tipicamente $27 \mathrm{MHz}$ ou $40 \mathrm{MHz}$. A passagem dessa corrente cria um campo elétrico circulando a bobina, enquanto uma centelha inicial ioniza o gás, geralmente Argônio, que passa a girar ao redor da bobina. A aceleração causada pelo campo elétrico no gás ionizado e o choque entre partículas carregadas e não carregadas são responsáveis por aquecer o plasma até temperaturas que podem variar de $7000 \mathrm{~K}$ a $10000 \mathrm{~K}$. A essas temperaturas, a amostra, injetada no plasma por um nebulizador, passa a emitir luz nos diversos comprimentos de onda característicos 
dos átomos em sua composição. A intensidade das emissões é posteriormente convertida na concentração dos elementos desejados.

Neste trabalho, as medidas de ICP-OES foram realizadas na Central Analítica do IQUSP com um equipamento da marca SPECTRO, modelo Arcos com visão radial (SOP), capaz de medir comprimentos de onda de $130 \mathrm{~nm}$ a $770 \mathrm{~nm}$.

\subsection{Análise elementar (CHN)}

Análise elementar é uma técnica capaz de quantificar os elementos Carbono, Hidrogênio e Nitrogênio em uma amostra. Seus princípios básicos estão ilustrados na Figura 3.5 [111].

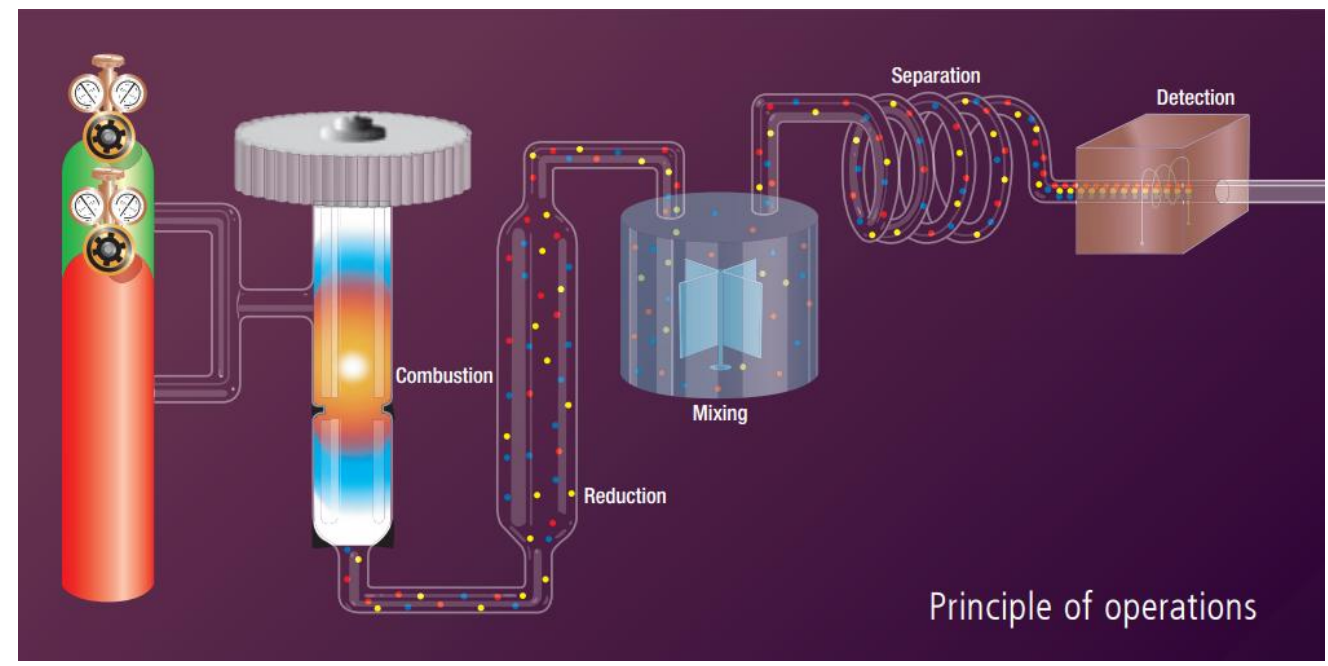

Figura 3.5. Princípios básicos de operação da técnica de análise elementar (CHN) [111].

Na técnica de análise elementar, a amostra passa por uma etapa de combustão a temperaturas em torno de $1000^{\circ} \mathrm{C}$ em atmosfera de oxigênio $\left(\mathrm{O}_{2}\right)$ puro. Os gases produzidos durante essa queima são guiados a uma câmara de oxidação e redução, onde sua reação com $\mathrm{O}_{2}$ produz dióxido de carbono $\left(\mathrm{CO}_{2}\right)$, água $\left(\mathrm{H}_{2} \mathrm{O}\right)$ e compostos nitrogenados (NO e $\mathrm{NO}_{2}$ ), dentre outros gases. Após uma etapa de filtragem de resíduos e homogeneização, os gases são separados por espécie e a concentração de cada um deles é separadamente inferida por medidas de condutividade térmica [112].

As medidas de análise elementar apresentadas neste trabalho foram realizadas na Central Analítica do IQ-USP com o equipamento Perkin Elmer 2400 series ii capaz de 
analisar amostras sólidas e liquidas com precisão de $0.2 \%$ e um tempo médio menor que 10 minutos [113].

\subsection{Adsorção-dessorção de Nitrogênio}

Adsorção é o fenômeno através do qual moléculas de gases ou líquidos se aderem a superfícies sólidas, ficando retidas. Quanto menor o grau de agitação das moléculas (temperatura), mais facilmente ocorrerá sua adsorção. Esse processo cria um filme formado por uma monocamada de moléculas adsorvidas na superfície do adsorvente e foi inicialmente descrito pela teoria de Langmuir, com sua posterior modificação por Stephen Brunauer, Paul Emmett, e Edward Teller (BET), que incluíram em seu modelo o fenômeno da adsorção de multicamadas. Essa teoria ficou conhecida como o "método BET".

O método BET é amplamente utilizado para a caracterização da porosidade contida em amostras sólidas através das suas isotermas de adsorção-dessorção. Uma isoterma desse tipo é uma curva da quantidade de gás adsorvida na amostra em função da pressão de gás imposta por um equipamento chamado de porosímetro. O gás normalmente utilizado nessas análises é o $\mathrm{N}_{2}$ e as medidas são realizadas na temperatura constante de $77 \mathrm{~K}$, na qual, sob pressão atmosférica $\left(\mathrm{P}_{0}\right)$, pode-se encontrar ambas as fases líquidas e gasosas do $\mathrm{N}_{2}$. A adsorção das moléculas na superfície das amostras diminui sua energia livre, fazendo que sua condensação para o estado líquido aconteça para pressões $\mathrm{P}<\mathrm{P}_{0}$. Após a condensação, há uma estabilização das moléculas sob a superfície do material. Elas resistem, portanto, a sair dos poros no momento do abaixamento da pressão (dessorção), causando um formato de histerese na isoterma do sistema.

$\mathrm{O}$ formato das isotermas de adsorção-dessorção de $\mathrm{N}_{2}$ pode ser organizado em seis classes, de acordo com a classificação da IUPAC [114]. Subdivisões dessas classes também têm sido propostas ao longo do tempo, conforme discutido na referência [114] e ilustrado na Figura 3.6. Isotermas do tipo I são características de sistemas com microporos de dimensões moleculares, nos quais a grande afinidade das moléculas de $\mathrm{N}_{2}$ pela superfície do material faz com que elas sejam adsorvidas mesmo em pressões extremamente baixas. O longo patamar desse tipo de isoterma é indicativo da baixa área superficial do material analisado. Isotermas do tipo IIa são características dos sistemas macroporosos (> $50 \mathrm{~nm}$ ) ou não porosos, com adsorção ocorrendo na superfície externa do material, enquanto isotermas do tipo IIb são características de sistemas lamelares ou com poros do tipo fenda. A 
condensação do gás ocorre a pressões altas, levando a isoterma a apresentar histerese. Isotermas do tipo III são raras e encontradas em sistemas com baixa afinidade para as moléculas do gás a ser adsorvido. As moléculas são adsorvidas em regiões esparsas do material, não levando a deposições de camadas monocamadas completas. Isotermas do tipo IVa, IVb, IVc e V, com um patamar na região de pressões elevadas, são características de sistemas de mesoporos bem definidos, com o preenchimento total dos poros, limitando a quantidade de moléculas adsorvidas na amostra. Isotermas do tipo VI são característicos de sistemas com superfície extremamente regular (como o grafite) e sob a adsorção de gases nobres. Seu formato de degrau é indicativo da adsorção camada a camada das moléculas do adsorvato.

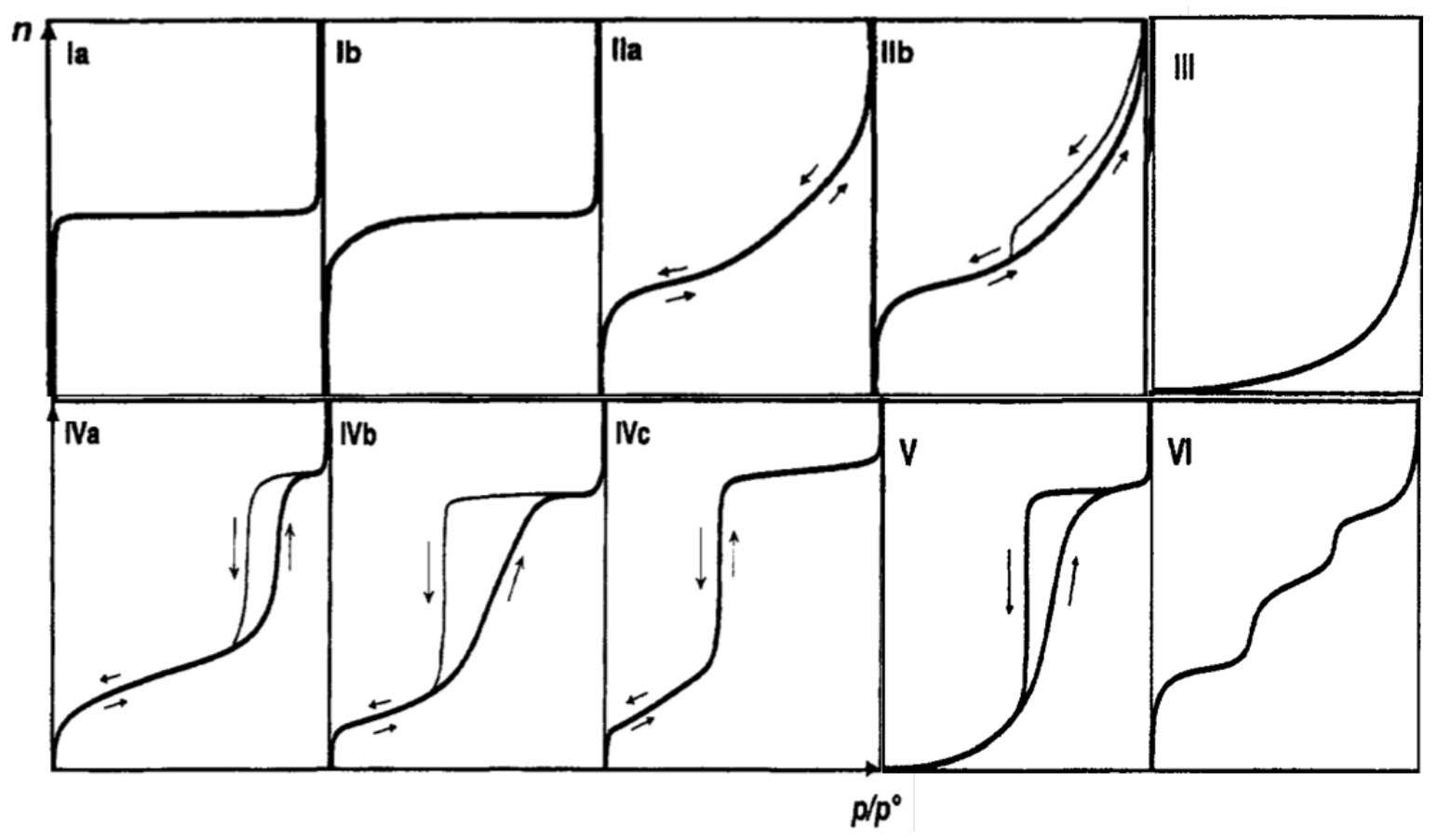

Figura 3.6. Classificação das isotermas de adsorção-dessorção de $\mathrm{N}_{2}$. Adaptado de [114].

As isotermas de adsorção-dessorção mostradas nesse trabalho foram medidas no Laboratório de Cristalografia do IFUSP utilizando o equipamento ASAP 2020 da companhia Micrometrics. As amostras foram submetidas a um pré-tratamento a $150^{\circ} \mathrm{C}$ em tubo evacuado por períodos superiores a $10 \mathrm{~h}$ a fim de retirar moléculas que possam estar bloqueando a superfície do material. As medidas foram realizadas a $77 \mathrm{~K}$ em banho de $\mathrm{N}_{2}$ líquido. 


\subsection{Fotoluminescência (PL)}

Através do fenômeno de fotoluminescência, a estrutura eletrônica dos materiais pode ser investigada. Nesse tipo de experimento, como esquematizado na Figura 3.7, uma amostra é irradiada com radiação eletromagnética de certo comprimento de onda. Em decorrência das diversas transições eletrônicas causadas pela absorção dessa radiação, fótons de diferentes energias são emitidos e seu espectro é monitorado por um detector.

Espectros de excitação e emissão podem ser medidos em um experimento de fotoluminescência. Em um espectro de excitação, o comprimento de onda de excitação é variado enquanto um detector monitora a emissão da amostra em um comprimento de onda específico $\lambda_{e m}$. Já no caso de um espectro de emissão, a amostra é excitada com radiação monocromática de comprimento de onda fixo $\lambda_{\text {exc }}$, enquanto o espectro emitido pela amostra é monitorado.

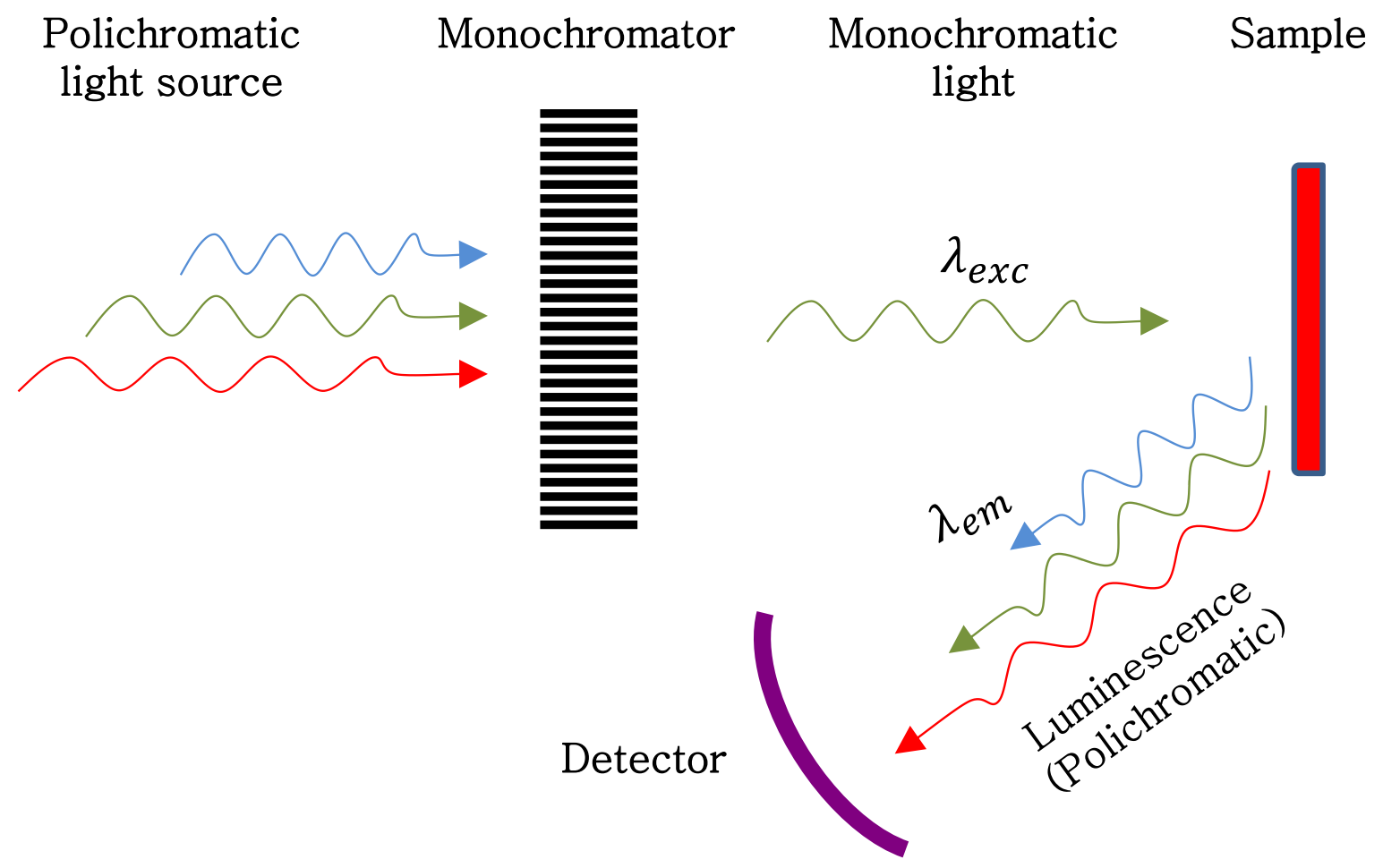

Figura 3.7. Esquema de um experimento de fotoluminescência [115].

Os espectros de fotoluminescência mostrados neste trabalho foram medidos no Laboratório dos Elementos do Bloco-f no IQ-USP com um equipamento da marca Horiba, modelo Spex® Fluorolog® 3 com detector frontal $\left(22.5^{\circ}\right)$, na qual a fonte de iluminação é 
uma lâmpada de Xenônio de 450 W. Para as medidas, as amostras em pó eram prensadas nos sulcos de um porta amostra de cobre que então era inserido na câmara do equipamento.

\subsection{Termogravimetria (TG)}

$\mathrm{Na}$ análise termogravimétrica, ou termogravimetria, a amostra é disposta em uma balança dentro de um forno sob atmosfera controlada, como mostrado na Figura 3.8. Enquanto a temperatura do forno é elevada, a massa da amostra é monitorada em função da temperatura e do tempo.

A velocidade de aquecimento pode ser ajustada, sendo $5^{\circ} \mathrm{C} / \mathrm{min}$ ou $10^{\circ} \mathrm{C} / \mathrm{min}$ alguns valores típicos. A temperatura do forno é comumente elevada desde a temperatura ambiente até cerca de $900^{\circ} \mathrm{C}$. Durante esse processo, reações químicas de queima e pirólise ocorrem nas amostras, liberando gases que carregam seu conteúdo de carbono, água, nitrogênio e etc. Esses eventos de perda de massa podem então fornecer um modelo para a composição química do material analisado e também dão informação sobre sua estabilidade térmica.

O equipamento utilizado para as análises termogravimétricas realizadas neste trabalho foi um TGA Q500 da TA Instruments na Central Analítica do IQ-USP e também no Center for Surface Chemistry and Catalysis da KULeuven. A velocidade de aquecimento adotada para todas as análises mostradas nesta tese foi de $5^{\circ} \mathrm{C} / \mathrm{min}$.

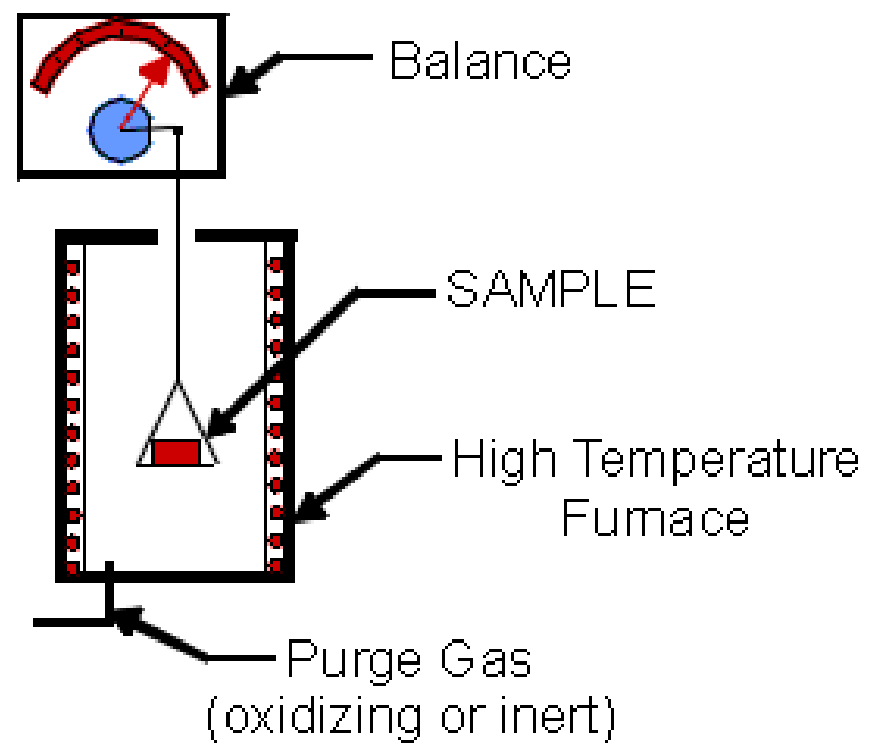

Figura 3.8. Esquema experimental para análise termogravimétrica [116]. 


\section{Capítulo 4}

\section{Síntese dos materiais}

\subsection{Materiais utilizados}

Para a síntese dos LDHs foram utilizados os sais precursores dos cátions metálicos $\mathrm{Zn}^{2+}, \mathrm{Al}^{3+}$ e $\mathrm{Eu}^{3+}: \mathrm{Zn}\left(\mathrm{NO}_{3}\right)_{2} \cdot 6 \mathrm{H}_{2} \mathrm{O}$ (98 mol\%, Vetec), $\mathrm{Al}\left(\mathrm{NO}_{3}\right)_{3} \cdot 9 \mathrm{H}_{2} \mathrm{O}$ (98 mol\%, LabSynth) e $\mathrm{Eu}\left(\mathrm{NO}_{3}\right)_{3} \cdot 6 \mathrm{H}_{2} \mathrm{O}$ (99.9 mol\%, Sigma-Aldrich), respectivamente. Nitrato de Európio também foi preparado a partir de uma suspensão de $\mathrm{Eu}_{2} \mathrm{O}_{3}$ (CSTARM, 99,99 mol\%) pela adição de ácido nítrico concentrado. O ligante ácido benzeno-1,3,5tricarboxílico (BTC ou ácido trimésico, Sigma-Aldrich) foi utilizado na sua forma protonada (vide Figura 4.1) e em pó. Hidróxido de Sódio $(\mathrm{NaOH})$ foi utilizado na forma de soluções aquosas preparadas a partir de suas lentilhas $(\mathrm{NaOH} 97 \mathrm{~mol} \%$, Vetec). Para a síntese das micelas foi utilizado o surfactante Plurônico® P-123 (Sigma Aldrich)

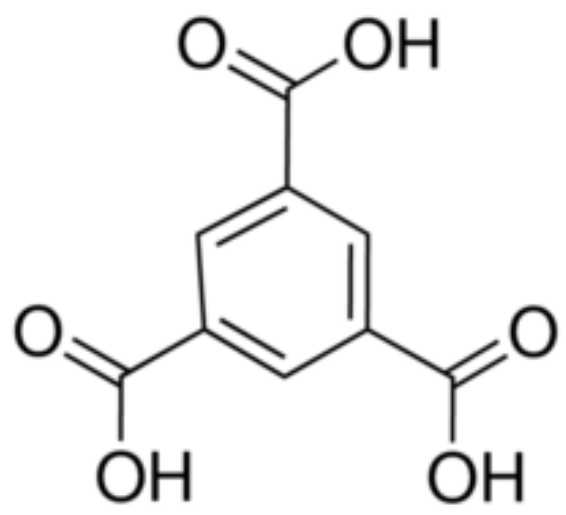

Figura 4.1. Estrutura molecular do BTC (ácido benzeno-1-3-5-tricarboxílico). Seus pKas são 3.12, 3.89 e 4.70. Em soluções aquosas com $\mathrm{pH}$ acima dos pKas a maioria das moléculas de BTC encontram-se negativamente carregadas, com a ionização dos seus grupos carboxilas.

\subsection{Síntese de hidróxidos duplos lamelares de morfologia plana}

Neste trabalho, foram sintetizados LDHs contendo os cátions di- e trivalentes $\mathrm{M}^{\mathrm{II}}=$ $\mathrm{Zn}^{2+} \mathrm{e} \mathrm{M}^{\mathrm{III}}=\mathrm{Al}^{3+}$ na proporção $\mathrm{Zn}: \mathrm{Al}=2: 1$. No caso de $\mathrm{LDHs}$ contendo $\mathrm{Eu}^{3+}$, uma fração de $\mathrm{Al}^{3+}$ é substituída de forma que $\mathrm{Zn}:(\mathrm{Al}+\mathrm{Eu})=2: 1$. Com uma porcentagem $\mathrm{x}$ de $\mathrm{Eu}^{3+}$ 
em substituição aos cátions $\mathrm{Al}^{3+}$ a fórmula geral dos materiais sintetizados pode ser escrita como: $\left[\mathrm{Zn}_{2} \mathrm{Al}_{1-\mathrm{x}} \mathrm{Eu}_{\mathrm{x}}(\mathrm{OH})_{6}\right]^{1+}\left[\left(\mathrm{A}^{\mathrm{n}-}\right)_{1 / \mathrm{n}} \cdot \mathrm{yH}_{2} \mathrm{O}\right]^{1-}$. Apesar de diversas composições serem permitidas para essas estruturas e já terem sido relatadas na literatura [117], os metais Zn e Al são relativamente abundantes na crosta terrestre e foram escolhidos para serem a matriz padrão dos LDHs sintetizados para este trabalho.

A proporção 2:1 dos cátions $\mathrm{M}^{\mathrm{II}}$ e $\mathrm{M}^{\mathrm{III}}$ impõe às camadas metálicas o maior excesso de cargas positivas possível antes que os cátions trivalentes comecem a ocupar sítios metálicos adjacentes formando ligações do tipo $\mathrm{M}^{\mathrm{III}}-\mathrm{O}-\mathrm{M}^{\mathrm{III}}$, como ilustrado na Figura 4.2. Dessa forma, cada cátion $\mathrm{M}^{\mathrm{III}}$ possui apenas cátions $\mathrm{M}^{\mathrm{II}}$ em sua redondeza. Nessa configuração, apenas um ordenamento é possível para os cátions nas camadas de hidróxidos e alguns autores têm inclusive observado picos de difração de baixa intensidade relacionados a esse ordenamento [118]. Medidas de ressonância magnética nuclear também têm, mais recentemente, comprovado esse ordenamento $[119,120]$, assim como experimentos de espectroscopia de absorção de raios X (XAS) [121].

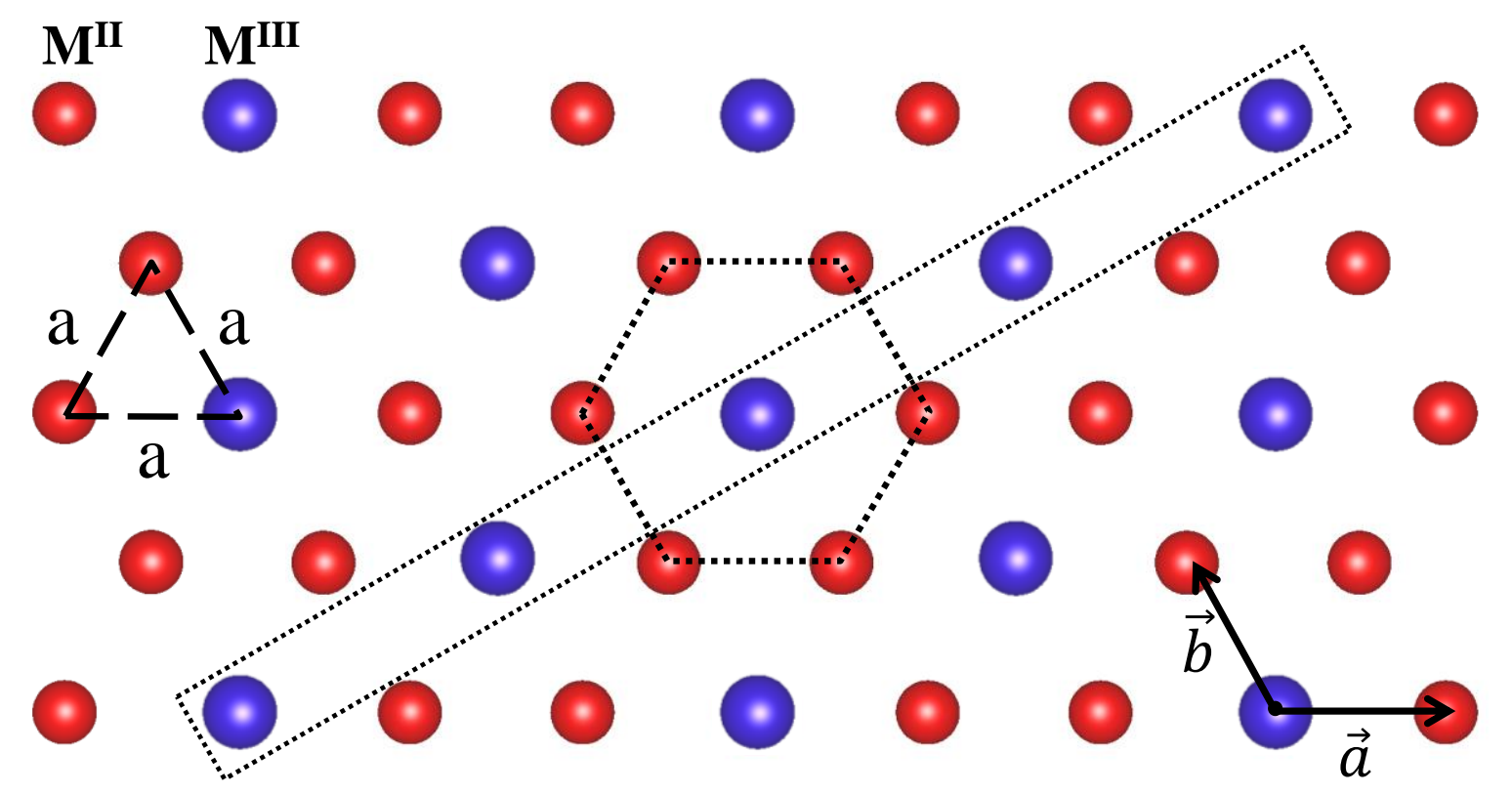

Figura 4.2. Estrutura de repetição nas lamelas dos LDHs com fração molar $\mathrm{M}^{\mathrm{II}}: \mathrm{M}^{\mathrm{III}}=2: 1$ e disposição dos metais $\mathrm{Zn}$ e Al.

Alguns autores afirmam que configurações com $\mathrm{M}^{\mathrm{II}}: \mathrm{M}^{\mathrm{III}}<2: 1$ são desfavoráveis devido à repulsão entre os cátions trivalentes que, a essas proporções, seriam forçados à 
ocupar sítios metálicos vizinhos [122-124]. De fato, para certos cátions, LDHs com $\mathrm{M}^{\mathrm{II}}: \mathrm{M}^{\mathrm{III}}<2: 1$ apenas puderam ser produzidos em temperaturas e pressões mais elevadas que as ambientes. Nessas condições, a formação dos LDHs é forçada pela diminuição da solubilidade dos metais e pelo aumento da sua capacidade de hidrólise. Por esse motivo, a proporção $\mathrm{M}^{\mathrm{II}}: \mathrm{M}^{\mathrm{III}}=2: 1$ utilizada neste trabalho é bastante conveniente. Nesta configuração, não somente a síntese dos LDHs em sistema aberto à temperatura ambiente é possível, como ao mesmo tempo, também produz uma densidade de carga relativamente alta nas lamelas, melhorando a cristalinidade do material, como já relatado por Miyata na ref. [125]. No estudo citado verificou-se um aumento da cristalinidade dos LDHs para densidades de carga crescentes em suas camadas metálicas até o limite em que os cátions trivalentes não ocupam sítios metálicos adjacentes. A partir desse limite e mesmo com a síntese acontecendo em pressões e temperaturas elevadas (entre $150{ }^{\circ} \mathrm{C}$ e $250{ }^{\circ} \mathrm{C}$ ), o tamanho dos cristalitos passa a diminuir.

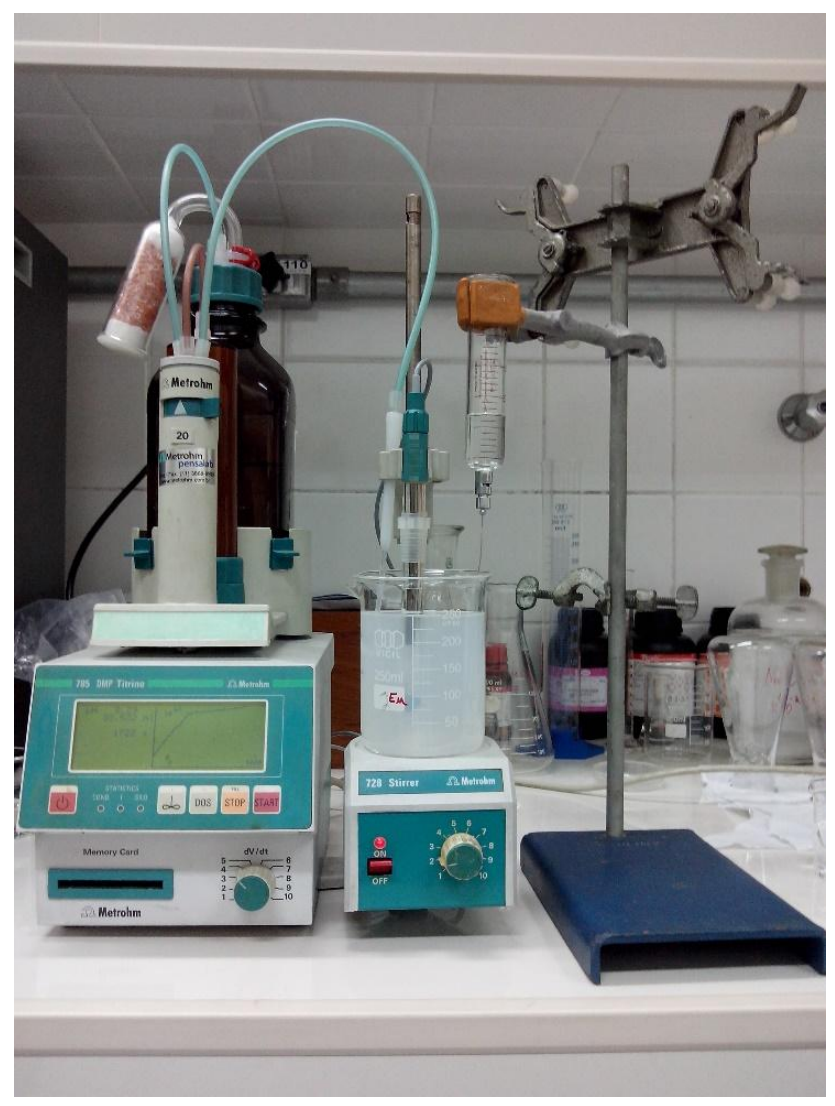

Figura 4.3. Arranjo experimental montado no Laboratório de Nanomateriais e Aplicações (LNA-IFUSP) para preparação de LDHs. Síntese em andamento: titulador automático, seringa para gotejamento e solução de LDHs em síntese. 
A síntese dos LDHs de morfologia plana foi feita pelo método de coprecipitação dos cátions $\mathrm{Zn}^{2+}, \mathrm{Al}^{3+}$ e $\mathrm{Eu}^{3+}$ na presença dos ânions a serem intercalados em sua estrutura. Os sais precursores $\mathrm{Zn}\left(\mathrm{NO}_{3}\right)_{2} \cdot 6 \mathrm{H}_{2} \mathrm{O}, \mathrm{Al}\left(\mathrm{NO}_{3}\right)_{3} \cdot 9 \mathrm{H}_{2} \mathrm{O}$ e $\mathrm{Eu}\left(\mathrm{NO}_{3}\right)_{3} \cdot 6 \mathrm{H}_{2} \mathrm{O}$ foram dissolvidos em água deionizada até a concentração de $1 \mathrm{~mol} / \mathrm{L}$ na proporção 2:1-x:x, respectivamente (vide exemplo na Tabela 2 para LDHs com $5 \mathrm{~mol} \%$ de $\mathrm{Eu}^{3+}$ ). Essa solução foi transferida para uma seringa e lentamente gotejada com velocidade aproximada de $10 \mathrm{~mL} / \mathrm{h}$ em $200 \mathrm{~mL}$ de água deionizada contendo o ligante a ser intercalado. $\mathrm{O}$ pH desta solução foi mantido fixo em 8 durante toda a síntese com o auxílio do titulador automático Titrino 702 SM $\Omega$ Metrohm carregado com solução aquosa de $\mathrm{NaOH} 1 \mathrm{~mol} / \mathrm{L}$. Em alguns casos de interesse, a solução de síntese era continuamente purgada com gás $\mathrm{N}_{2}$ para impedir a entrada de ar. $\mathrm{O}$ arranjo experimental utilizado está mostrado na Figura 4.3. A síntese foi deixada ocorrer sob agitação constante e à temperatura ambiente até que o conteúdo da seringa se esgotasse. Para otimizar o processo de cristalização do material, a mistura resultante foi deixada descansar por dois dias em estufa a $60^{\circ} \mathrm{C}$. O gel resultante, decantado após esse descanso, foi separado, centrifugado, lavado com água deionizada para a retirada de íons que não participaram da reação e deixado secar em estufa novamente a $60{ }^{\circ} \mathrm{C}$. A amostra foi macerada e o pó resultante submetido às caracterizações necessárias. Um esquema do processo de síntese até a produção da amostra em pó está mostrado na Figura 4.4.

\begin{tabular}{|c|c|c|}
\hline \multicolumn{3}{|c|}{$\begin{array}{l}\text { Tabela 2. Sais utilizados para a preparação de LDHs com } 5 \text { mol\% } \\
\qquad \text { de } \mathrm{Eu}^{3+} \text { em substituição ao cátion } \mathrm{Al}^{3+}\end{array}$} \\
\hline & $\mathrm{N}^{\circ}$ de mols & Massa (g) \\
\hline $\mathrm{Zn}\left(\mathrm{NO}_{3}\right)_{2} \cdot 6 \mathrm{H}_{2} \mathrm{O}$ & $6.6 \times 10^{-3}$ & 1.9832 \\
\hline $\mathrm{Al}\left(\mathrm{NO}_{3}\right)_{3} \cdot 9 \mathrm{H}_{2} \mathrm{O}$ & $3.2 \times 10^{-3}$ & 1.1867 \\
\hline $\mathrm{Eu}\left(\mathrm{NO}_{3}\right)_{3} \cdot 6 \mathrm{H}_{2} \mathrm{O}$ & $1.7 \times 10^{-4}$ & 0.0713 \\
\hline BTC* & $2.3 \times 10^{-3}$ & 0.4896 \\
\hline
\end{tabular}

* Apenas para LDHs intercalados com BTC.

Para a dissolução do BTC, $0.4896 \mathrm{~g}\left(2.3 \times 10^{-3} \mathrm{~mol}\right)$ desse ligante foram dispensadas na solução de síntese, que era constantemente agitada e teve seu pH corrigido para pH 5 pela adição de uma solução de $\mathrm{NaOH}(1 \mathrm{~mol} / \mathrm{L})$ a fim de desprotonar suas carboxilas $(\mathrm{pH}>$ pKa) e permitir a intercalação desse ligante nos LDHs. A quantidade de BTC foi calculada 
de forma que a carga elétrica total dos ligantes em solução excedesse por um fator dois a quantidade de sítios positivamente carregados nas camadas de hidróxidos, ou seja: carga do ligante: $\mathrm{Al}^{3+} \sim 2: 1$.

Para a síntese de $\mathrm{LDHs}$ intercalados com $\mathrm{NO}_{3}{ }^{-}$nenhuma fonte extra desse ânion foi adicionada, sendo que todo o nitrato intercalado é proveniente dos sais precursores dos metais.
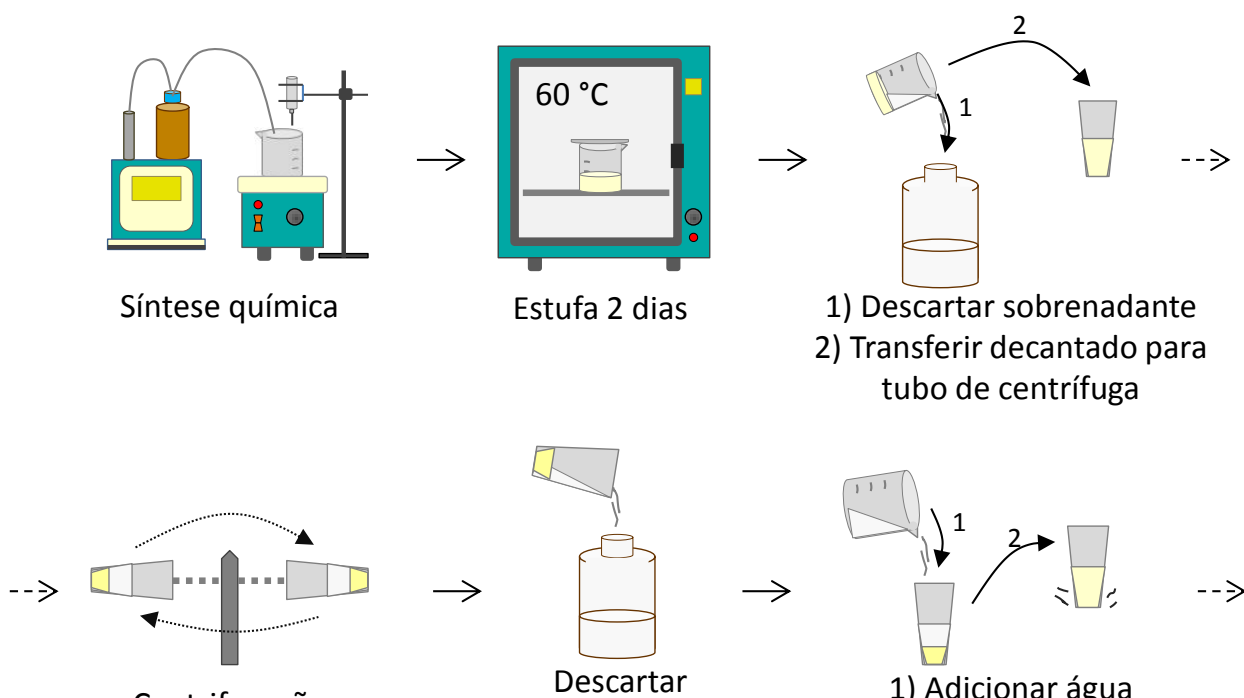

Centrifugação
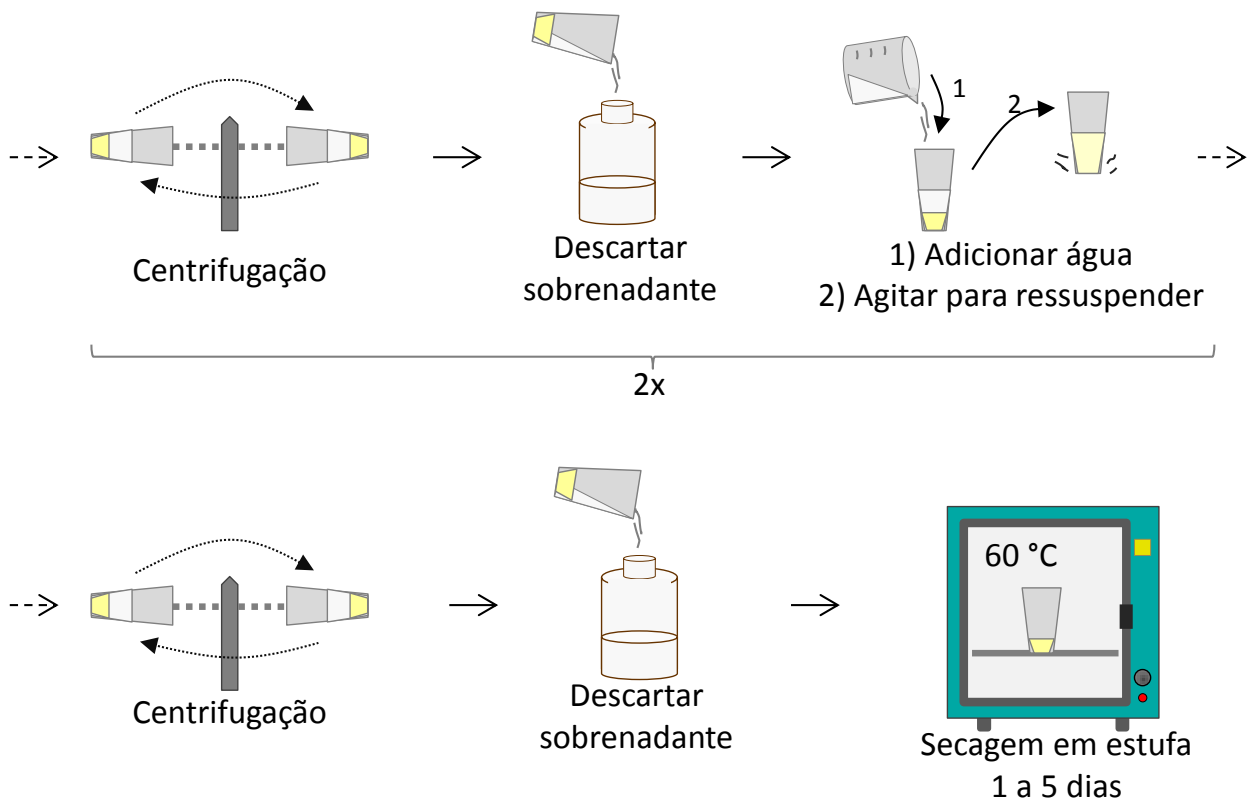

Figura 4.4. Esquema dos passos utilizados para a síntese dos LDHs até a produção da amostra em pó.

\subsection{Síntese de micelas cilíndricas de $\mathbf{P}-\mathbf{1 2 3}$}

A síntese dos LDHs estruturados na forma de nanotubos foi realizada pela decoração de micelas do surfactante Plurônico® ${ }^{\circledR}$ P-123. Inicialmente, as micelas foram obtidas utilizando $200 \mathrm{~mL}$ de solução aquosa de $\mathrm{NaOH} 10^{-4} \mathrm{~mol} / \mathrm{L}$ contendo $0.3 \mathrm{~g}$ do surfactante polimérico. A dissolução do surfactante foi feita sob agitação da solução em $60^{\circ} \mathrm{C}$. Após a 
dissolução, $0.4896 \mathrm{~g}\left(2.3 \times 10^{-3} \mathrm{~mol}\right)$ de BTC foram adicionadas à solução. A dissolução desse ácido foi feita ainda a quente e assistida pela adição de $\mathrm{NaOH}$ até que o $\mathrm{pH}$ da solução fosse elevado para pH 5, ou seja, acima do pKa do BTC. Após a dissolução completa desse ácido, submeteu-se a solução resultante a um ciclo térmico, esfriando-a até a temperatura ambiente e aquecendo-a novamente até a temperatura de $60^{\circ} \mathrm{C}$. Como já discutido anteriormente, a adição de determinadas quantidades de sais em sistemas micelares de P-123 é capaz de induzir a formação de micelas cilíndricas enquanto também as torna estáveis mesmo após o esfriamento da solução. Apesar de estudos nessa direção não terem ainda sido reportados na literatura utilizando adição de BTC especificamente, os resultados do presente trabalho indicam que a adição desse soluto produz resultados similares aos já reportados com a utilização de outros sais.

\subsection{Síntese de nanotubos de LDHs sobre a superfície das micelas}

A síntese dos LDHs nanoestruturados foi realizada seguindo o mesmo procedimento para a síntese de LDHs de morfologia plana como descrito anteriormente, sendo que, para a nanoestruturação, a solução base para a síntese continha as micelas de P-123 recémsintetizadas (cf. fluxograma da Figura 4.5). Uma solução aquosa com concentração 1 mol/L dos precursores $\mathrm{Zn}\left(\mathrm{NO}_{3}\right)_{2} \cdot 6 \mathrm{H}_{2} \mathrm{O}, \mathrm{Al}\left(\mathrm{NO}_{3}\right)_{3} \cdot 9 \mathrm{H}_{2} \mathrm{O}$ e $\mathrm{Eu}\left(\mathrm{NO}_{3}\right)_{3} \cdot 6 \mathrm{H}_{2} \mathrm{O}$ em proporções molares Zn: Al: $\mathrm{Eu}=2:(1-\mathrm{x}): \mathrm{x}$ foi gotejada lentamente com uma seringa $(\sim 10 \mathrm{~mL} / \mathrm{h})$ na solução contendo as micelas. $\mathrm{O}$ pH desta solução de síntese foi mantido fixo durante todo o tempo com o auxílio do titulador automático Titrino 702 SM $\Omega$ Metrohm em um arranjo experimental idêntico ao mostrado na Figura 4.3. A crescente turbidez da solução indicava a formação dos LDHs. A síntese foi deixada ocorrer sob agitação constante e à temperatura ambiente até o consumo total da solução da seringa. Para otimizar o processo de cristalização do material, a mistura resultante também foi deixada agindo por dois dias em estufa a $60^{\circ} \mathrm{C}$. Após essa etapa, a solução gelatinosa decantada foi separada por centrifugação e lavada com água deionizada para garantir a retirada de sais e íons residuais que não participam da estrutura dos LDHs. Para a retirada das micelas do interior dos dutos dos nanotubos, as amostras foram então lavadas duas vezes com cerca de $15 \mathrm{~mL}$ de metanol e tratadas em banho ultrassom por 15 minutos após cada lavagem. Após cada etapa de lavagem, a solução era centrifugada. Ao final, o gel resultante foi deixado secar em estufa a $60{ }^{\circ} \mathrm{C}$ por um período de aproximadamente cinco dias, resultando em um bloco macio e 
poroso em formato de giz. Esse material foi macerado e o pó resultante estava pronto para caracterização.

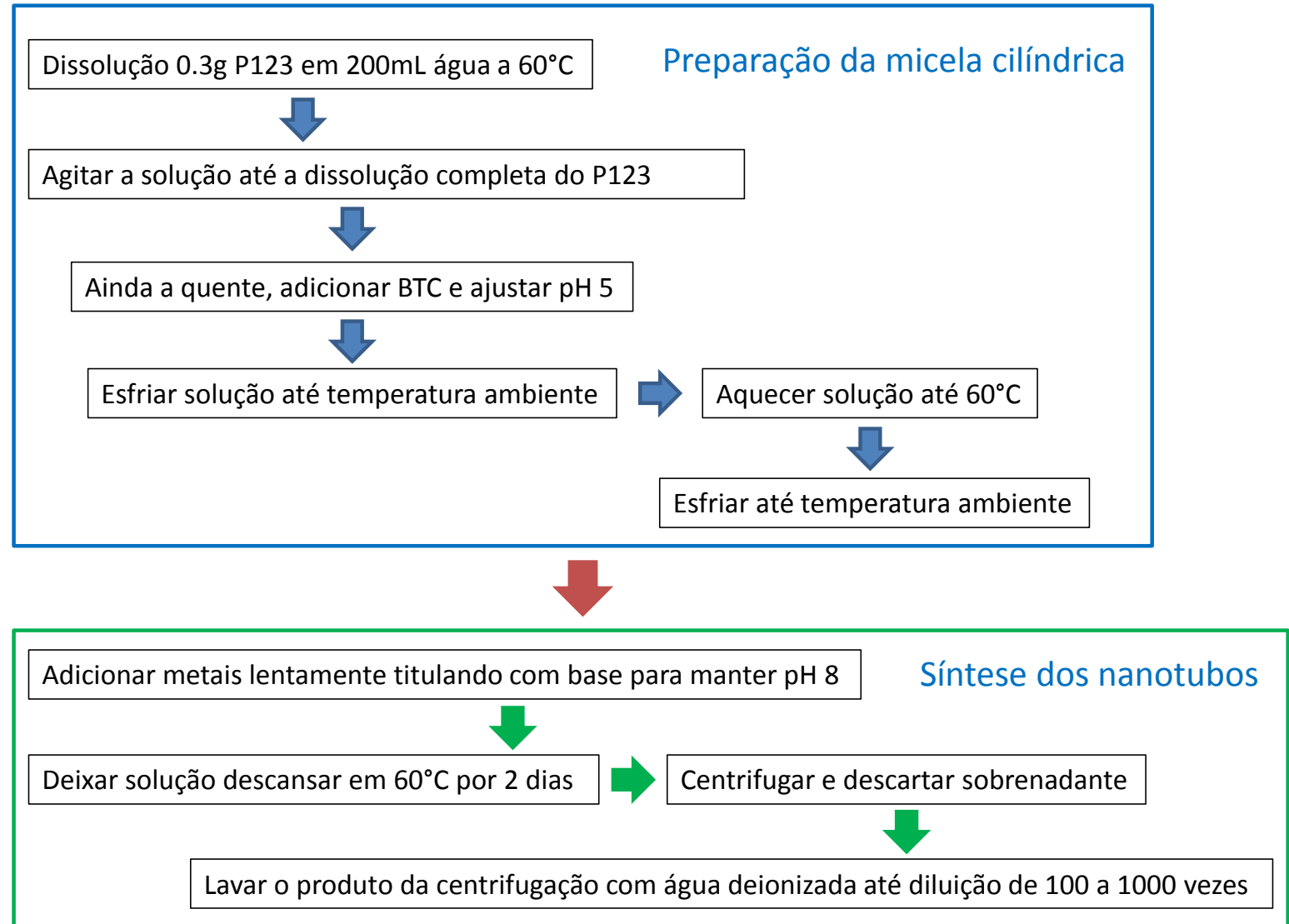

Figura 4.5. Fluxograma do processo de preparação dos nanotubos de LDHs. A combinação de BTC, Eu ${ }^{3+}$ e micelas cilíndricas de Plurônico® P-123 levaram à formação dos nanotubos de LDHs. 


\section{Capítulo 5}

\section{Resultados e discussão}

Neste capítulo serão mostrados e discutidos os resultados experimentais obtidos neste trabalho. A sequência dos tópicos a seguir não necessariamente corresponde à sequência temporal das medidas realizadas, mas sim a uma tentativa de racionalizar os resultados de forma que os primeiros resultados indiquem um caminho para a interpretação dos resultados que os seguem. Sendo assim, optamos por mostrar primeiro as caracterizações que fizemos para LDHs com morfologia plana. Em sequência, mostramos que modificações na composição química destes materiais, como a intercalação com BTC e inserção de $\mathrm{Eu}^{3+}$, levam à modificação das suas propriedades fisico-químicas, culminando com a modificação de sua morfologia quando os ingredientes (i) BTC, (ii) $\mathrm{Eu}^{3+}$ e (iii) micelas de P-123 são utilizados conjuntamente na síntese dos LDHs.

\subsection{Caracterização estrutural dos $\mathrm{LDHs}$ de morfologia plana: $\mathrm{Zn}_{2} \mathrm{Al}_{1}-\mathrm{NO}_{3}$}

A síntese dos LDHs de morfologia plana foi realizada conforme discutido na seção 4.2. Inicialmente, foram sintetizados $\mathrm{LDHs}$ intercalados com nitrato $\left(\mathrm{NO}_{3}{ }^{-}\right)$proveniente dos sais precursores dos metais $\mathrm{Zn}^{2+} \mathrm{e} \mathrm{Al}^{3+}$, utilizados na proporção $\mathrm{Zn}: \mathrm{Al}=2: 1$. A síntese foi realizada com e sem purga de $\mathrm{N}_{2}$ e as amostras foram denominadas $\mathrm{Zn}_{2} \mathrm{Al}_{1}-\mathrm{NO}_{3}-\mathrm{N}_{2} \mathrm{e}$ $\mathrm{Zn}_{2} \mathrm{Al}_{1}-\mathrm{NO}_{3}$-Ar, respectivamente. A purga com $\mathrm{N}_{2}$ diminui o contato da solução com o $\mathrm{CO}_{2}$ proveniente do ar. A captura deste por soluções aquosas induz sua acidificação com a formação de ânions carbonato $\left(\mathrm{CO}_{3}{ }^{2-}\right)$ segundo a reação:

$$
\mathrm{H}_{2} \mathrm{O}_{(l)}+\mathrm{CO}_{2}(g) \rightleftarrows \mathrm{H}_{2} \mathrm{CO}_{3}(a q) \leftrightarrows 2 \mathrm{H}^{+}{ }_{(a q)}+\mathrm{CO}_{3}^{2-}{ }_{(a q)}
$$

Os ânions $\mathrm{CO}_{3}{ }^{2-}$ possuem afinidade alta com as camadas dos LDHs e deslocam facilmente os ânions $\mathrm{NO}_{3}^{-}$do meio interlamelar, formando materiais com espaçamento basal levemente diferentes. Esse tipo de contaminação já é bem conhecida e relatada na literatura [126-128]. 
As primeiras caracterizações realizadas foram para confirmar o sucesso da síntese, ou seja, a formação dos LDHs. A caracterização e identificação das fases presentes nas amostras foi feita pela análise do difratograma de raios $\mathrm{X}$ obtido através do método de pó (Figura 5.1).

Nas camadas de hidróxidos, os sítios metálicos dos LDHs formam arranjos hexagonais. Neste plano, a rede pode ser inteiramente coberta a partir de deslocamentos realizados com composições dos vetores $\vec{a}$ e $\vec{b}$ como mostrados na Figura 4.2. Com o empilhamento das camadas dos LDHs, um novo vetor de repetição $\vec{c} \perp \vec{a}$, $\vec{b}$ pode ser definido. $\vec{a}, \vec{b}$ e $\vec{c}$ formam a célula unitária hexagonal que é convencional nos sistemas de LDHs e a partir da qual as suas reflexões de Bragg são comumente indexadas.

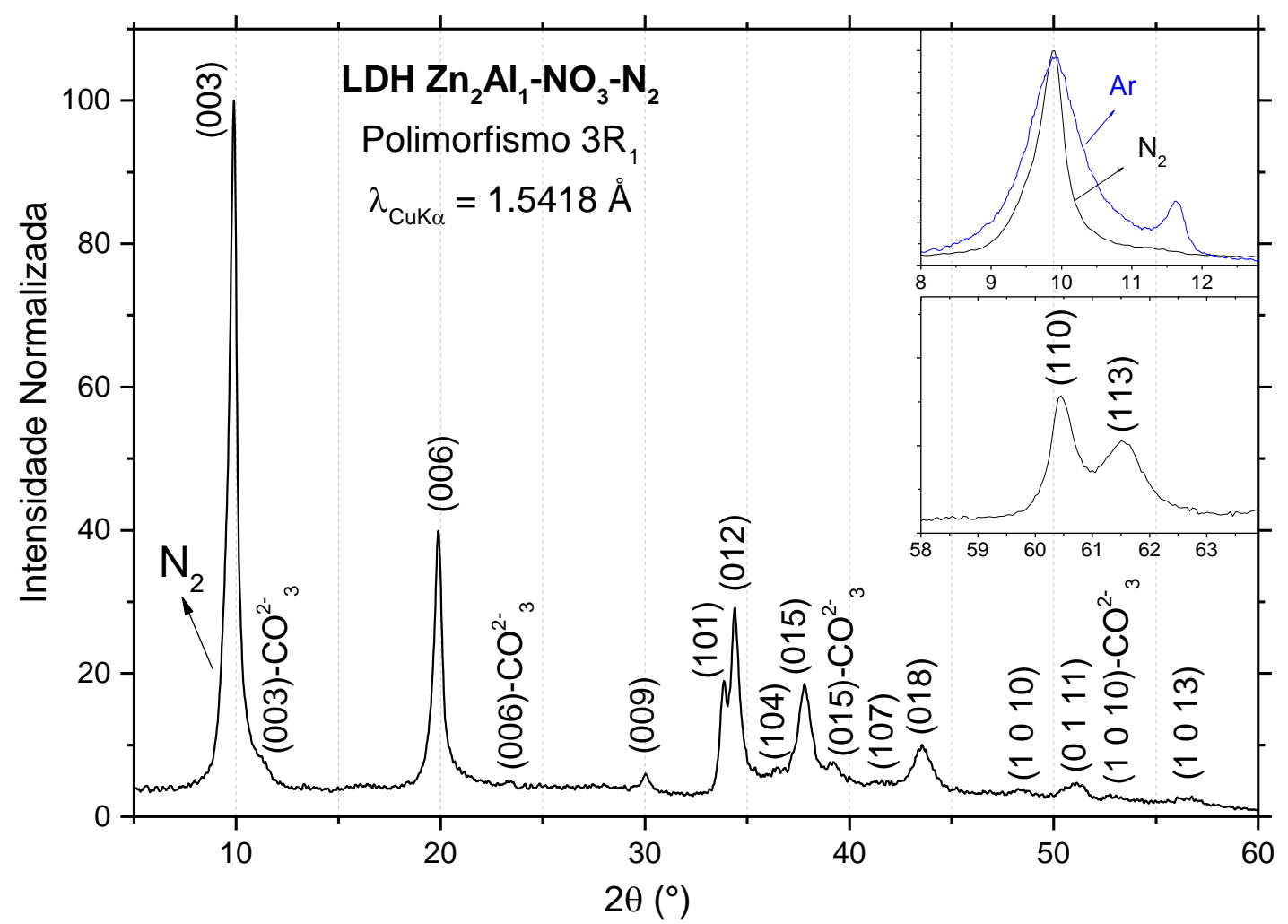

Figura 5.1. Padrão de difração de pó (radiação $\mathrm{CuK} \alpha$ ) da amostra $\mathrm{Zn}_{2} \mathrm{Al}_{1}-\mathrm{NO}_{3}-\mathrm{N}_{2}$. No detalhe do canto superior direito, comparação com LDHs sintetizados em atmosfera aberta (azul) mostrando um pico mais pronunciado relacionado com a formação de LDHs intercalados com carbonato. No detalhe no centro à direita, aumento de 5 vezes na região de $2 \theta$ compreendendo as reflexões (110) e (113) dos LDHs.

O empilhamento das camadas dos LDHs pode ocorrer de várias maneiras diferentes, de forma que a perfeita repetição do cristal na direção normal $\vec{c}$ ocorra apenas após o 
empilhamento de um número $N$ de camadas. Na Figura 5.2, é mostrado o exemplo de um polimorfismo onde cada camada é deslocada de $\vec{a}+\frac{1}{3} \vec{b}+\frac{1}{3} \vec{c}$ com relação à camada anterior, levando a uma sequência de empilhamento que denotamos por ABCA. Após três camadas, um octaedro centrado numa posição $\vec{Q}$ é levado para a posição $\vec{Q}+3 \vec{a}+\vec{b}+\vec{c}$, equivalente à posição inicial, e a rede passa a se repetir. Essa característica tem implicações importantes na simetria dos sistemas de LDHs e portanto terão implicações diretas em seus difratogramas de raios $X$. De fato, no caso do exemplo de empilhamento mostrado na Figura 5.2, a célula unitária hexagonal dos LDHs não é primitiva, pois possui um total de três sítios em seu interior, como ilustrado na Figura 5.3. A célula hexagonal é, na verdade, romboedricamente centrada (grupo espacial $\mathrm{R} \underline{3} \mathrm{~m}$ ), o que faz com que a rede de Bravais do sistema possua simetria reduzida, não possuindo um eixo de rotação de ordem 6 , como é o caso para redes hexagonais primitivas, mas sim um eixo de rotação de ordem 3. A rede de Bravais desse sistema é, portanto, romboédrica. Polimorfismos $\operatorname{com} c=N c_{o}$ e simetria romboédrica são comumente denominados na literatura de LDHs como sendo do tipo NR. Subdivisões desta classe são indicadas pela adição de um índice numérico: $\mathrm{NR}_{\mathrm{i}}$. A estrutura mostrada na Figura 5.2 é do tipo $3 \mathrm{R}_{1}$, como descrito na referência [124]. Também existem polimorfismos com simetria hexagonal, denominados por $\mathrm{NH}_{\mathrm{i}}$.

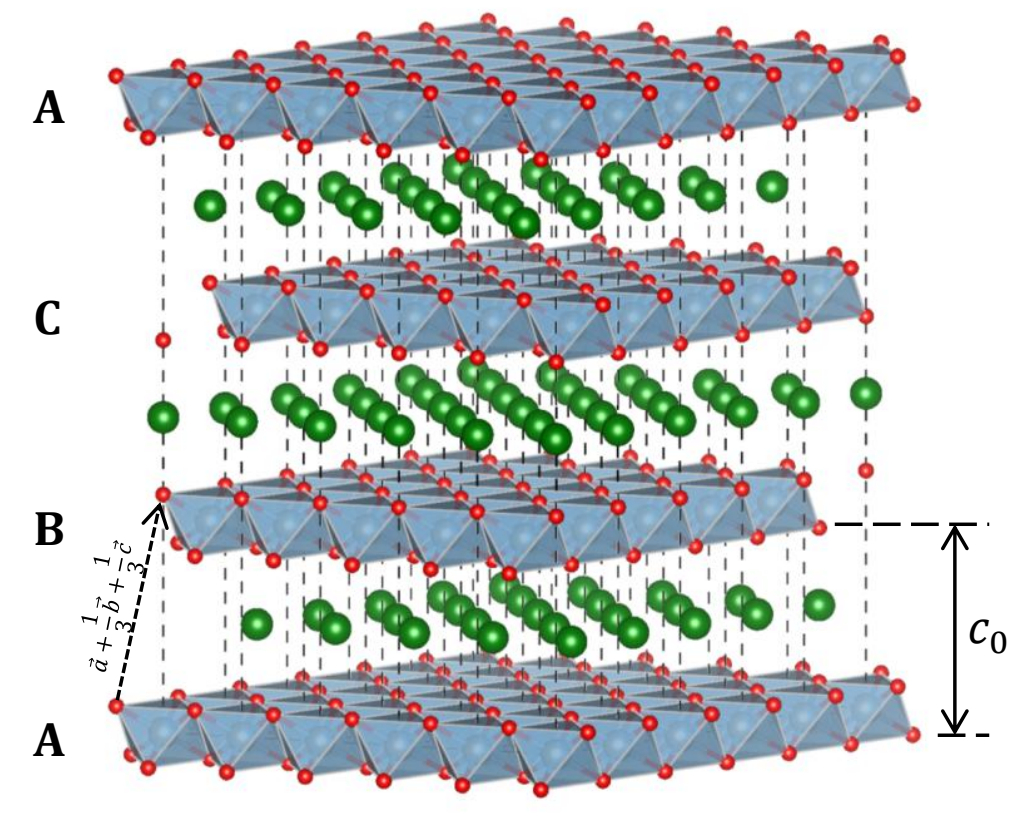

Figura 5.2. Ilustração de um $\mathrm{LDH}$ com polimorfismo do tipo $3 \mathrm{R}_{1}$. Na direção $\vec{c}$, a perfeita repetição dos octaedros centrados nos sítios metálicos acontece apenas após o empilhamento de três camadas de hidróxidos. 

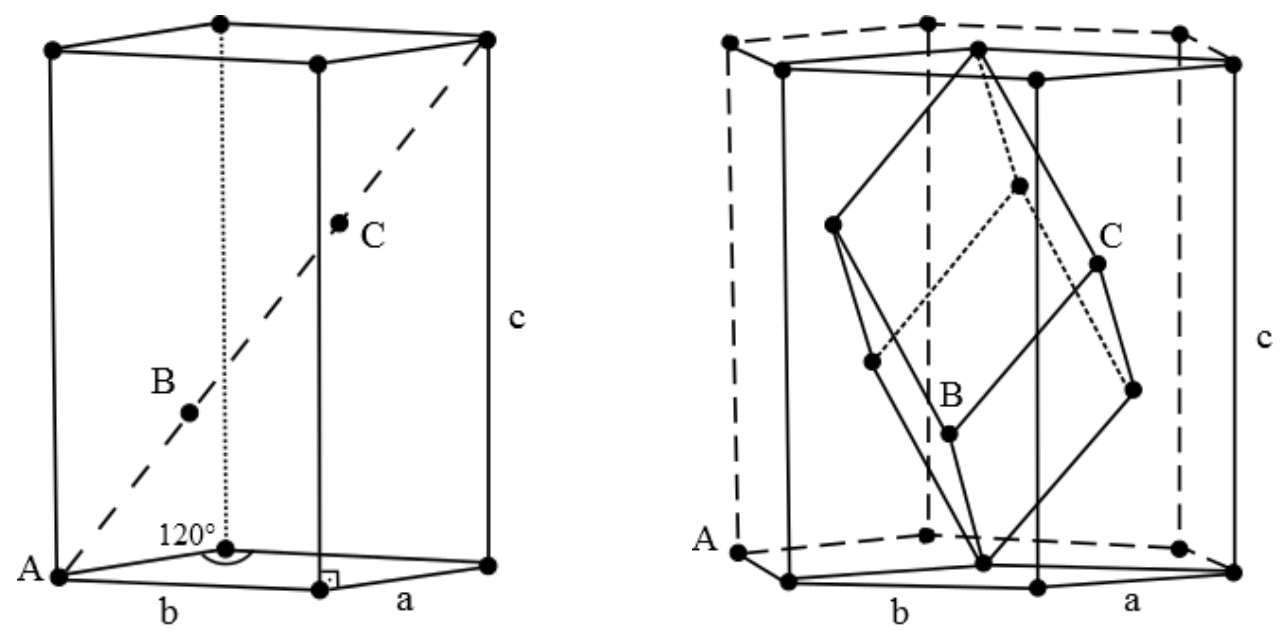

Figura 5.3.(Esquerda) célula unitária hexagonal romboedricamente centrada dos LDHs com polimorfismo $3 \mathrm{R}_{1}$ e (direita) sua célula romboédrica primitiva.

No geral, os difratogramas de pó dos LDHs apresentam três regiões distintas que podem ser utilizadas para obter informações sobre (i) o espaçamento basal $c_{o}$ do sistema, (ii) a distância $a$ entre os metais nas camadas de hidróxidos e (iii) o polimorfismo do sistema. Essas características podem ser observadas no difratograma da amostra $\mathrm{Zn}_{2} \mathrm{Al}_{1}$ $\mathrm{NO}_{3}-\mathrm{N}_{2}$, mostrado na Figura 5.1, onde o primeiro pico, na região de baixo ângulo, com $2 \theta=9.88^{\circ}$, corresponde à reflexão $(00 N)$ e fornece, a partir da lei de Bragg, a distância basal $c_{o}=8.95 \AA$ típica dos LDHs intercalados com nitrato [128]. O pico em torno de $2 \theta=60.43^{\circ}$ corresponde à reflexão (110) com distância interplanar $d_{(110)}=1.53 \AA$ fornece a metade da distância intermetálica $a=2 d_{(110)}=3.06 \AA$ (Tabela 3).

A identificação do tipo de polimorfismo presente em uma amostra de LDH pode ser feita a partir dos picos presentes na região de ângulos intermediários, com $30^{\circ}<2 \theta<50^{\circ}$. Eles correspondem à reflexões de Bragg $(01 l)$ e $(10 l)$ e suas posições exatas podem ser calculadas a partir dos valores de $a, c_{o}$ e $N$, já que, para células unitárias hexagonais, como é o caso dos LDHs:

$$
\frac{1}{d_{(h k l)}^{2}}=\frac{4}{3}\left(\frac{h^{2}+h k+k^{2}}{a^{2}}\right)+\frac{l^{2}}{N^{2} c_{o}^{2}} .
$$


Comparando esse resultado com os valores experimentais obtidos a partir da posição $2 \theta$ dos picos do difratograma de pó, pode-se determinar $N$. Além disso, para polimorfismos com simetria romboédrica, apenas reflexões com $-h+k+l=3 n$ para algum número inteiro $n$ são observáveis. Devido à simetria reduzida da rede romboédrica, todas as outras reflexões são faltantes. Por último, para sistemas com $N=3$ e quando as reflexões $(01(3 n+1))$ são mais intensas que as respectivas $(10(3 n+1))$ para $0 \leq n \leq 4$, tem-se que o polimorfismo da amostra é do tipo $3 \mathrm{R}_{1}$, como o mostrado na Figura 5.2 [124, 129].

\begin{tabular}{lc}
\hline \multicolumn{2}{c}{ Tabela 3. Parâmetros estruturais do $\mathrm{LDH}$ de $\mathrm{Zn}_{2} \mathrm{Al}_{\mathbf{1}}-\mathrm{NO}_{3}-\mathrm{N}_{\mathbf{2}}$} \\
\hline Espaçamento basal $-\mathrm{NO}_{\mathbf{3}}^{-}-\left(c_{o}\right)$ & $8.95 \AA$ \\
Distância intermetálica $(\boldsymbol{a})$ & $3.06 \AA$ \\
\hline
\end{tabular}

Para realizar uma identificação completa da fase presente na amostra $\mathrm{Zn}_{2} \mathrm{Al}_{1}-\mathrm{NO}_{3}-\mathrm{N}_{2}$ e indexar suas reflexões de Bragg visíveis no difratograma mostrado na Figura 5.1, seguimos o procedimento descrito para a determinação de $N$. A presença das reflexões (101) em $2 \theta=33.85^{\circ},(012)$ em $2 \theta=34.40^{\circ}$ e (015) em $2 \theta=37.76^{\circ}$ é suficiente para identificarmos que $N=3$. O conjunto dos picos de difração observados são perfeitamente consistentes com a formação de LDHs com polimorfismo do tipo $3 \mathrm{R}_{1}$, com a presença de um número considerável de extinções consistentes com redes de Bravais de simetria romboédrica e intensidades seguindo as relações $I(101)<I(012), I(104)<I(015)$,

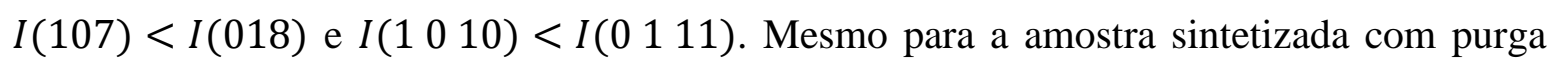
de $\mathrm{N}_{2}$, houve a formação de uma pequena quantidade de LDHs intercalados com carbonato provenientes do processo de acidificação da água, como já discutido. Essa fase residual é caracterizada pela existência de uma reflexão basal $(003)-\mathrm{CO}_{3}{ }^{2-}$ ao redor de $2 \theta=11.70^{\circ}$ como é possível observar no detalhe da Figura 5.1. A existência das reflexões denominadas (015)- $\mathrm{CO}_{3}{ }^{2-} \mathrm{e}\left(\begin{array}{lll}1 & 0 & 10\end{array}\right)-\mathrm{CO}_{3}{ }^{2-} \mathrm{e}$ inexistência das reflexões (104)- $\mathrm{CO}_{3}{ }^{2-} \mathrm{e}$ (l $\left.\begin{array}{lll}0 & 1 & 11\end{array}\right)-\mathrm{CO}_{3}{ }^{2-}$ é suficiente para determinar que estes LDHs também possuem polimorfismo $3 \mathrm{R}_{1}$. Na Tabela 4 são mostrados todos os picos de Bragg encontradas para a amostra $\mathrm{Zn}_{2} \mathrm{Al}_{1}-\mathrm{NO}_{3}-\mathrm{N}_{2}$, juntamente com seus índices de Miller e seus valores de $2 \theta$ e distâncias interplanares calculadas. A partir da análise do difratograma da Figura 5.1 e indexação de 
todos os picos encontrados, não resta dúvidas de que os hidróxidos duplos lamelares formam a única fase cristalina presente na amostra $\mathrm{Zn}_{2} \mathrm{Al}_{1}-\mathrm{NO}_{3}-\mathrm{N}_{2}$.

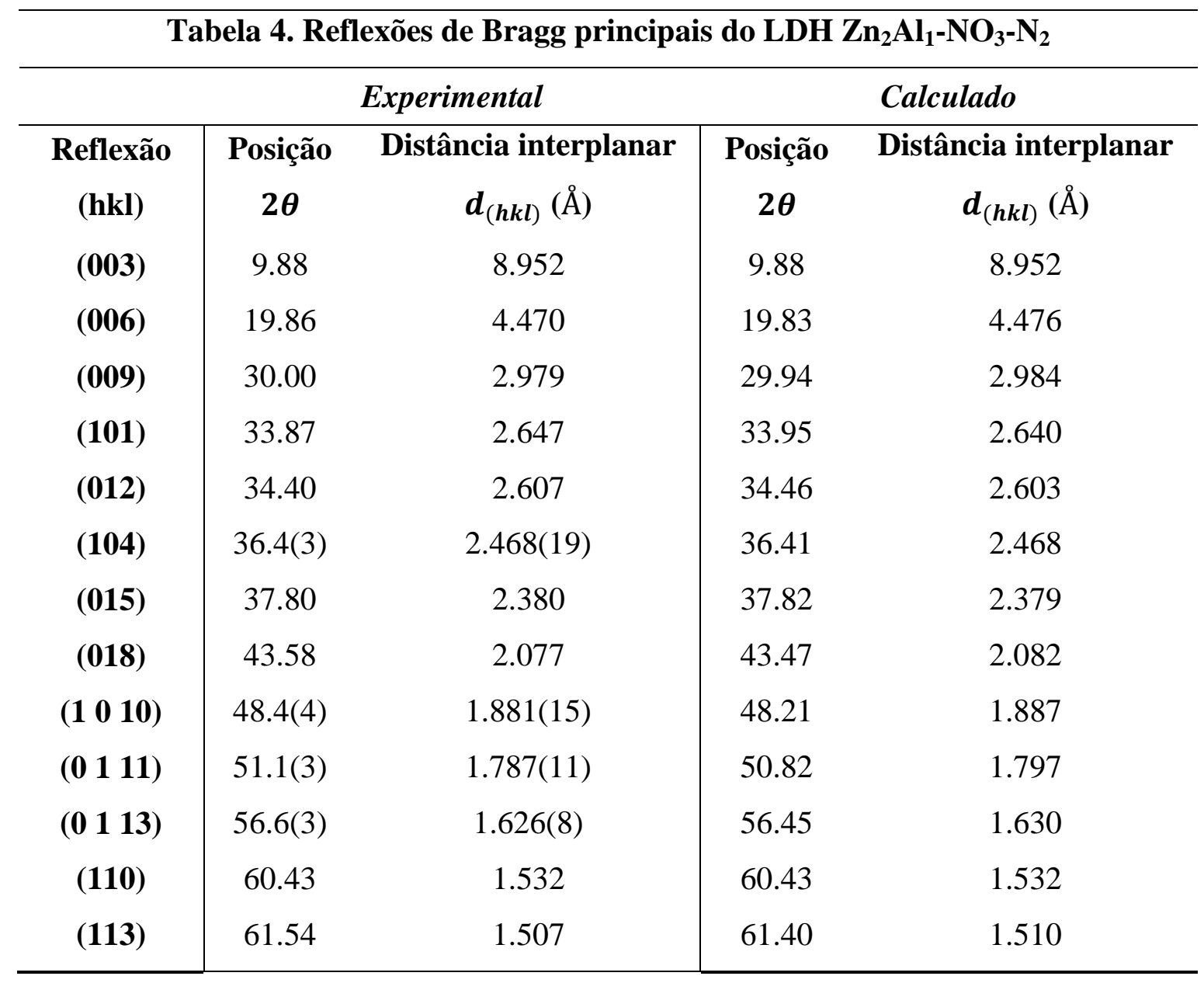

Além da análise da posição dos picos em um difratograma de raios $\mathrm{X}$, podemos também interpretar sua largura a meia altura $\delta(2 \theta)$. A partir da equação de Scherrer para picos de formato gaussiano, podemos estimar um limite inferior para o tamanho do cristalito $(D)$ :

$$
D=\frac{k \lambda}{\sqrt{\delta(2 \theta)^{2}+\delta^{2}} \cos \theta}
$$

onde $\lambda=1.5418 \AA$ é o comprimento de onda da radiação CuKa utilizada nos experimentos, $\delta=0.14^{\circ}$ é a largura a meia altura intrínseca adicionada pelo equipamento e $k$ é uma constante dependente do formato tridimensional dos cristalitos. Pequenas 
variações de $k$ entre 0.9 e 1.1 são esperadas para diferentes formatos, mas seu valor exato não é de grande importância para a nossa análise. Sendo assim, para as estimativas que fizemos, tomamos $k=0.9$, que é o valor esperado para um conjunto unidimensional de planos cristalinos ou para cristalitos de formato esféricos. Para a amostra $\mathrm{Zn}_{2} \mathrm{Al}_{1}-\mathrm{NO}_{3}-\mathrm{N}_{2}$, a largura a meia altura da reflexão $(003)$ é $\delta\left(2 \theta_{003}\right)=0.48(1)^{\circ}$ e, portanto, a dimensão dos cristalitos na direção $\vec{c}$ é estimada em $D=18 \mathrm{~nm}$, correspondendo ao empilhamento de cerca de 20 camadas de hidróxidos, em média, para cada cristalito da amostra.

\subsection{Caracterização química dos $\mathrm{LDHs}$ de morfologia plana: $\mathrm{Zn}_{2} \mathrm{Al}_{1}-\mathrm{NO}_{3}$}

Após confirmar a formação de hidróxidos duplos lamelares na amostra $\mathrm{Zn}_{2} \mathrm{Al}_{1}-\mathrm{NO}_{3}$ $\mathrm{N}_{2}$, determinamos sua composição química pela medição do seu teor de Nitrogênio e Carbono pelo método de análise elementar $(\mathrm{CHN})$ e de Sódio, Alumínio e Zinco pelo método de ICP-OES (Tabela 5). Também foi realizada a medição do teor de Cloro para determinar possíveis contaminações por $\mathrm{Cl}^{-}$proveniente da água.

\begin{tabular}{ccccccc}
\hline \multicolumn{6}{c}{ Tabela 5. Composição química dos LDHs da amostra } & $\mathbf{Z n}_{\mathbf{2}} \mathbf{A l}_{\mathbf{1}}-\mathbf{N O}_{3}-\mathbf{N}_{\mathbf{2}}$ \\
\hline & $\mathbf{Z n}$ & $\mathbf{A l}$ & $\mathbf{N}$ & $\mathbf{C}$ & $\mathbf{C l}$ & $\mathbf{N a}$ \\
Teor $(\mathbf{m o l} / \mathbf{k g})$ & 5.87 & 2.73 & 2.53 & 0.28 & 0.048 & 0.44 \\
\hline
\end{tabular}

A fração $\mathrm{Zn} / \mathrm{Al}=2.15$ encontrada é próxima da proporção $\mathrm{Zn}: \mathrm{Al}=2: 1$ utilizada para a síntese do material. Grande quantidade de nitrogênio foi encontrada, associada à presença de ânions nitrato do meio interlamelar dos LDHs. A fração de Carbono está relacionada à formação residual de LDHs intercalados com $\mathrm{CO}_{3}{ }^{2-}$, resultante do processo de acidificação da água em consonância com a identificação dessa fase a partir do difratograma de raios X da amostra em questão. É possível calcular que íons $\mathrm{CO}_{3}{ }^{2-}$ compõe cerca de $10 \%$ dos ânions intercalados nos $\mathrm{LDHs}$ da amostra $\mathrm{Zn}_{2} \mathrm{Al}_{1}-\mathrm{NO}_{3}-\mathrm{N}_{2}$. Também é possível observar que há uma fração considerável de Sódio que não foi extraída da amostra mesmo após o processo de lavagem.

A partir dos dados de análise elementar e ICP-OES é possível propor que os LDHs da amostra $\mathrm{Zn}_{2} \mathrm{Al}_{1}-\mathrm{NO}_{3}-\mathrm{N}_{2}$ devem possuir fórmula química $\left[\mathrm{Zn}_{2.05} \mathrm{Al}_{0.95}(\mathrm{OH})_{6}\right]^{0.95+}\left[\left(\mathrm{NO}_{3}{ }^{-}\right.\right.$ )$\left._{0.88}\left(\mathrm{CO}_{3}{ }^{2-}\right)_{0.10}\left(\mathrm{Cl}^{-}\right)_{0.02}\left(\mathrm{Na}^{+}\right)_{0.15}\right]^{0.95-}$, de forma que a carga elétrica total do material é neutralizada. 


\subsection{Micrografias eletrônicas dos $\mathrm{LDHs}$ de morfologia plana: $\mathrm{Zn}_{2} \mathrm{Al}_{1}-\mathrm{NO}_{3}$}

Microscopia eletrônica foi realizada como forma de caracterizar a morfologia dos LDHs na amostra $\mathrm{Zn}_{2} \mathrm{Al}_{1}-\mathrm{NO}_{3}-\mathrm{N}_{2}$. Observamos que a amostra é composta por flocos microscópicos de comprimento longitudinal típico da ordem de $1 \mu \mathrm{m}$ e com aparência de folhas finas que se sobrepõe, como é comumente observado nos sistemas de hidróxidos duplos lamelares. Como é possível observarmos nas micrografias eletrônicas de varredura da Figura 5.4, esses flocos possuem morfologia planar e rígida, não acomodando torções ou curvaturas notáveis. Como discutido por Evans e Slade em seu capítulo de revisão sobre LDHs [124] e por Solin et al. [130], a rigidez dos materiais lamelares está diretamente relacionada com a quantidade de planos atômicos existentes em cada lamela. Nos LDHs, a interconectividade dos três planos atômicos das camadas de hidróxidos dificulta sua curvatura. Por isso, esses materiais possuem rigidez muito maior do que o grafite, que facilmente forma enrolamentos de monocamadas e nanotubos.

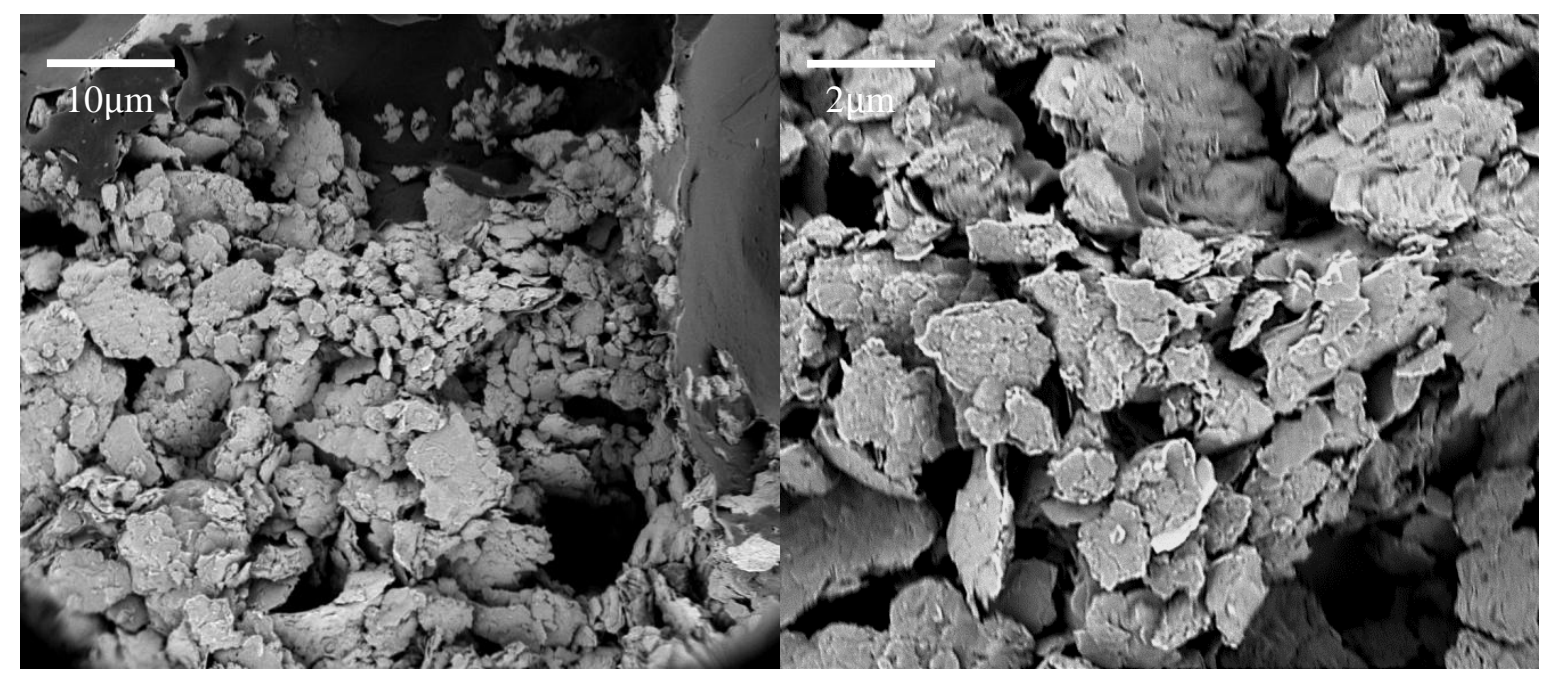

Figura 5.4. Imagens de Microscopia Eletrônica de Varredura (MEV) mostrando os flocos de hidróxidos duplos lamelares na amostra $\mathrm{Zn}_{2} \mathrm{Al}_{1}-\mathrm{NO}_{3}-\mathrm{N}_{2}$.

$\mathrm{Na}$ Figura 5.5, é mostrada uma micrografia eletrônica de transmissão da amostra $\mathrm{Zn}_{2} \mathrm{Al}_{1}-\mathrm{NO}_{3}-\mathrm{N}_{2}$ e um espectro de EDX coletado com o feixe de elétrons do microscópio focalizado na região mostrada na figura. Esse último dado mostra a presença dos elementos Zinco e Alumínio nas partículas observadas. A presença de um pico identificado como Cobre, está relacionado à composição do material do porta-amostras. A imagem mostrada 
apresenta uma partícula de formato aproximadamente hexagonal, seguindo o formato da célula unitária dos LDHs.
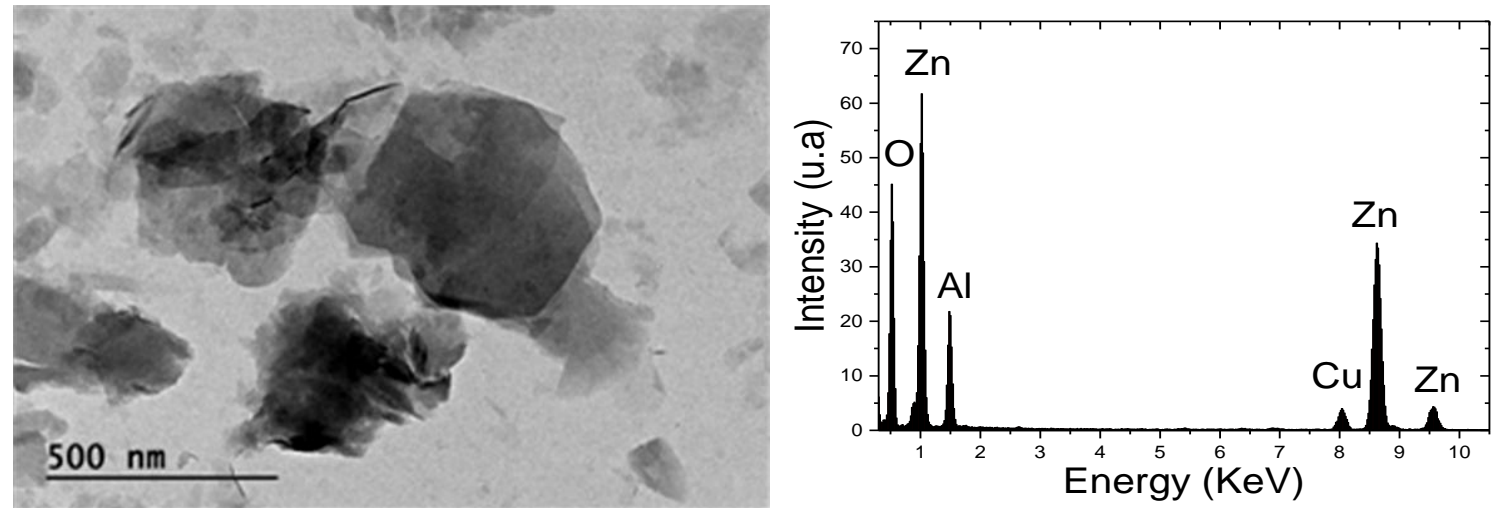

Figura 5.5. (Esquerda) Imagem de Microscopia Eletrônica de Transmissão (MEV) mostrando os flocos de hidróxidos duplos lamelares e (direita) espectro de EDX mostrando a composição química local da amostra. O pico de cobre $(\mathrm{Cu})$ é devido à composição do porta-amostra.

\subsection{Efeitos estruturais da intercalação de BTC: $\mathrm{Zn}_{2} \mathrm{Al}_{1}-\mathrm{BTC}$}

A síntese de $\mathrm{LDHs}$ de $\mathrm{Zn}^{2+}$ e $\mathrm{Al}^{3+}$ intercalados com BTC foi realizada conforme discutido na seção 4.2 e a amostra foi denominada $\mathrm{Zn}_{2} \mathrm{Al}_{1}$-BTC. A intercalação de BTC aumenta o espaçamento basal desses materiais, levando a um deslocamento do primeiro pico de difração, como mostrado na Figura 5.6. A reflexão basal desses LDHs, presente em torno de $2 \theta=6.61^{\circ}$, indica um espaçamento $c_{o}=13.4 \AA$. Descontando a espessura da camada de hidróxidos (4.8 ̊ [124]), essa distância é da ordem do tamanho das moléculas de BTC e consistente com o seu posicionamento transversal entre as camadas dos LDHs, em contraste com o posicionamento longitudinal dos ânions carbonatos [131] e inclinado dos ânions nitrato [132], como ilustrado na Figura 5.7.

Comparando os difratogramas das amostras $\mathrm{Zn}_{2} \mathrm{Al}_{1}-\mathrm{NO}_{3}$ (Figura 5.1) e $\mathrm{Zn}_{2} \mathrm{Al}_{1}-\mathrm{BTC}$ (Figura 5.6), observamos que a intercalação de BTC induz o alargamento dos picos de difração dos LDHs, o que pode ser interpretado como reflexo da diminuição do número de camadas de hidróxidos empilhadas em cada cristalito da amostra ou a desordens estruturais causadas pelo ânion intercalado. A largura a meia altura da reflexão basal em torno de $2 \theta=6.61^{\circ}$ é de $\delta\left(2 \theta_{003}\right)=0.99^{\circ}$, o que, pela equação de Scherrer, corresponde a uma espessura $D=8.5 \mathrm{~nm}$. O número de camadas empilhadas em cada cristalito é, portanto, da ordem de 6 camadas de hidróxidos para cada cristalito. 


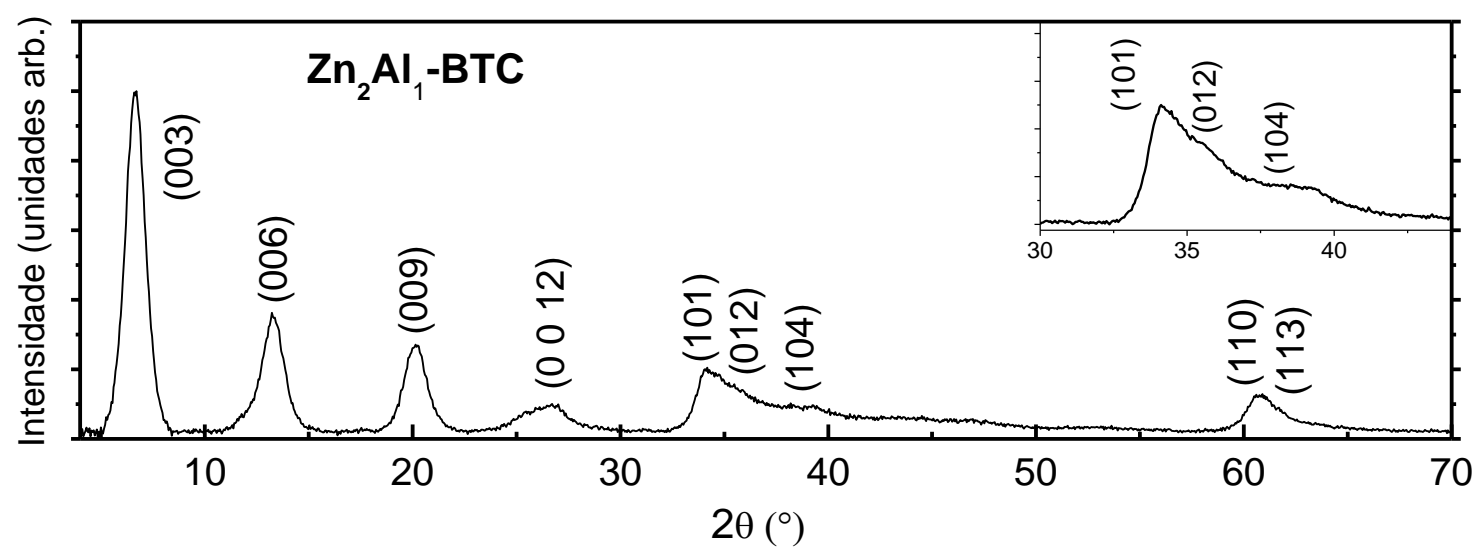

Figura 5.6. Difratograma de raios $\mathrm{X}$ da amostra $\mathrm{Zn}_{2} \mathrm{Al}_{1}-\mathrm{BTC}$ de $\mathrm{LDHs}$ intercalados com BTC.

Além do alargamento simétrico das reflexões basais da amostra $\mathrm{Zn}_{2} \mathrm{Al}_{1}-\mathrm{BTC}$ (Figura 5.6), chama atenção o alargamento assimétrico das reflexões ao redor de $2 \theta=35^{\circ}$. Devido a isto, as posições exatas das reflexões (101), (012) e (015) não podem ser determinadas e, portanto, não é possível determinar o tipo de polimorfismo da amostra nem a dimensão $c=N c_{o}$ da célula unitária do cristal. Para facilitar a comparação com os difratogramas das demais amostras, no entanto, continuamos indexando todas as reflexões com base em uma célula unitária $\operatorname{com} N=3$.

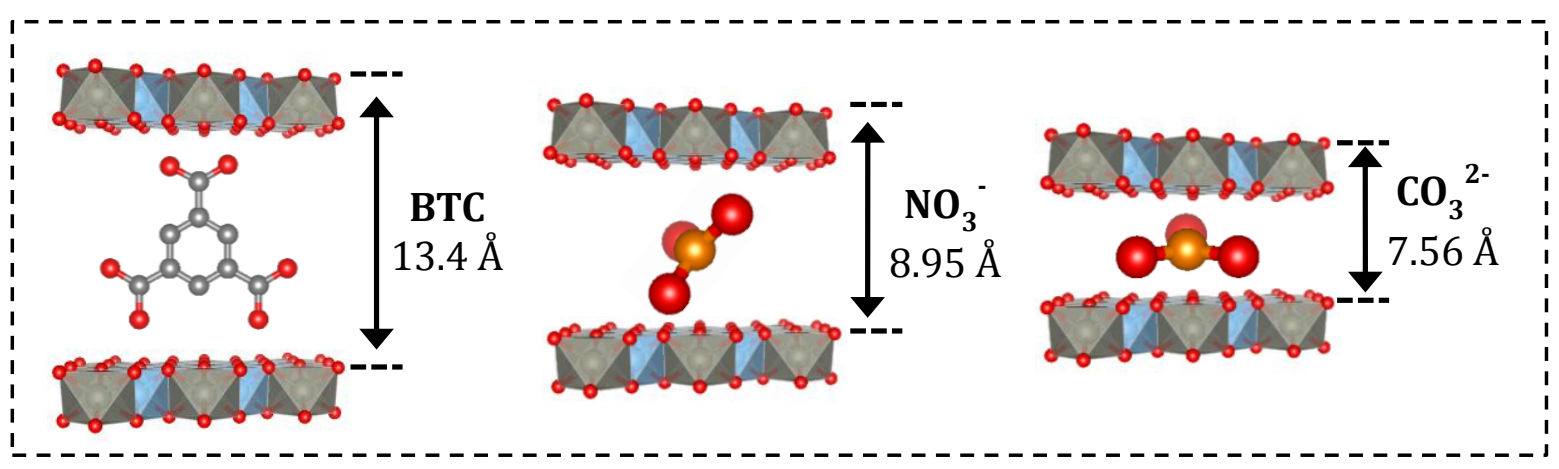

Figura 5.7. Orientação dos ligantes intercalados entre as camadas dos LDHs.

O formato de "barbatana de tubarão" do pico ao redor de $2 \theta=35^{\circ}$ observado no difratograma da amostra $\mathrm{Zn}_{2} \mathrm{Al}_{1}$-BTC (Figura 5.6), com o alargamento assimétrico da região de ângulos altos, tem sido descrito na literatura como sendo associado a desordens na periodicidade dos planos $(10 l)$ e $(01 l)$ causadas por incompatibilidades geométricas entre a posição dos cátions nas camadas de hidróxidos e a posição das cargas negativas dos ânions intercalados [133]. Essa incompatibilidade seria responsável por forçar o 
empilhamento turbostrático das camadas dos LDHs, com deslocamentos e rotações (torções) entre camadas adjacentes, causando uma diminuição do ordenamento da posição dos cátions em camadas adjacentes. Segundo essa interpretação, o aumento do grau de aleatoriedade do empilhamento faz com que diversas reflexões $(10 l)$ e $(01 l)$ apareçam em posições ligeiramente diferentes, formando um contínuo (ou envelope) de vários picos relativos às diversas sequencias locais de empilhamento das camadas de hidróxidos. Esse tipo de empilhamento turbostrático também ocorre em outras estruturas lamelares, como no caso do grafeno [134, 135], conforme ilustrado na Figura 5.8. Podemos dizer então que a intercalação de BTC nos LDHs permite a flexibilização da sequência de empilhamento das camadas deste material.

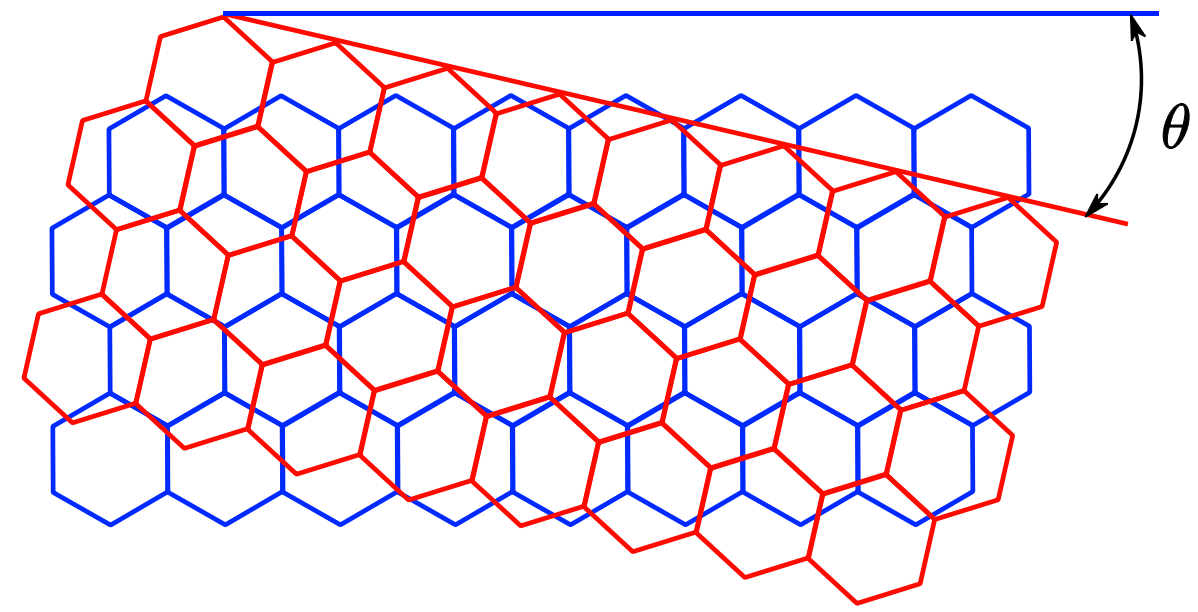

Figura 5.8. Ilustração do empilhamento turbostrático de duas camadas de grafeno. Adaptado da ref. [136].

\subsection{Propriedades estruturais dos $\mathrm{LDHs}$ com $\mathrm{Eu}^{3+}: \mathrm{Zn}_{2} \mathrm{Al}_{0.95} \mathrm{Eu}_{0.05}-\mathrm{NO}_{3}$ e $\mathrm{Zn}_{2} \mathrm{Al}_{0.95} \mathbf{E u}_{0.05}-\mathrm{BTC}$}

A síntese de LDHs contendo Európio foi realizada conforme discutido na seção 4.2, com a substituição de uma fração $x=0.05(5 \mathrm{~mol} \%)$ de $\mathrm{Al}^{3+}$ por $\mathrm{Eu}^{3+}$. Esses LDHs foram intercalados com $\mathrm{NO}_{3}{ }^{-}$e BTC, sendo denominados por $\mathrm{Zn}_{2} \mathrm{Al}_{0.95} \mathrm{Eu}_{0.05}-\mathrm{NO}_{3}$ e $\mathrm{Zn}_{2} \mathrm{Al}_{0.95} \mathrm{Eu}_{0.05}$-BTC, respectivamente. Como será discutido mais adiante, o BTC é um ligante orgânico com boas características de transferência de energia para o íon $\mathrm{Eu}^{3+}$, melhorando as propriedades luminescentes do material.

A inserção de $5 \mathrm{~mol} \%$ de $\mathrm{Eu}^{3+}$ na estrutura dos LDHs de Zinco e Alumínio não alterou o polimorfismo da amostra, como observado a partir do difratograma de raios $\mathrm{X}$ da amostra $\mathrm{Zn}_{2} \mathrm{Al}_{0.95} \mathrm{Eu}_{0.05}-\mathrm{NO}_{3}$ (Figura 5.9). Como a amostra foi sintetizada sem realização 
de purga com $\mathrm{N}_{2}$, é possível identificar reflexões bastante pronunciadas relativas à formação de LDHs intercalados com carbonato. Não foram identificados picos extras que indicassem a segregação do íon terra rara em outras fases cristalinas.

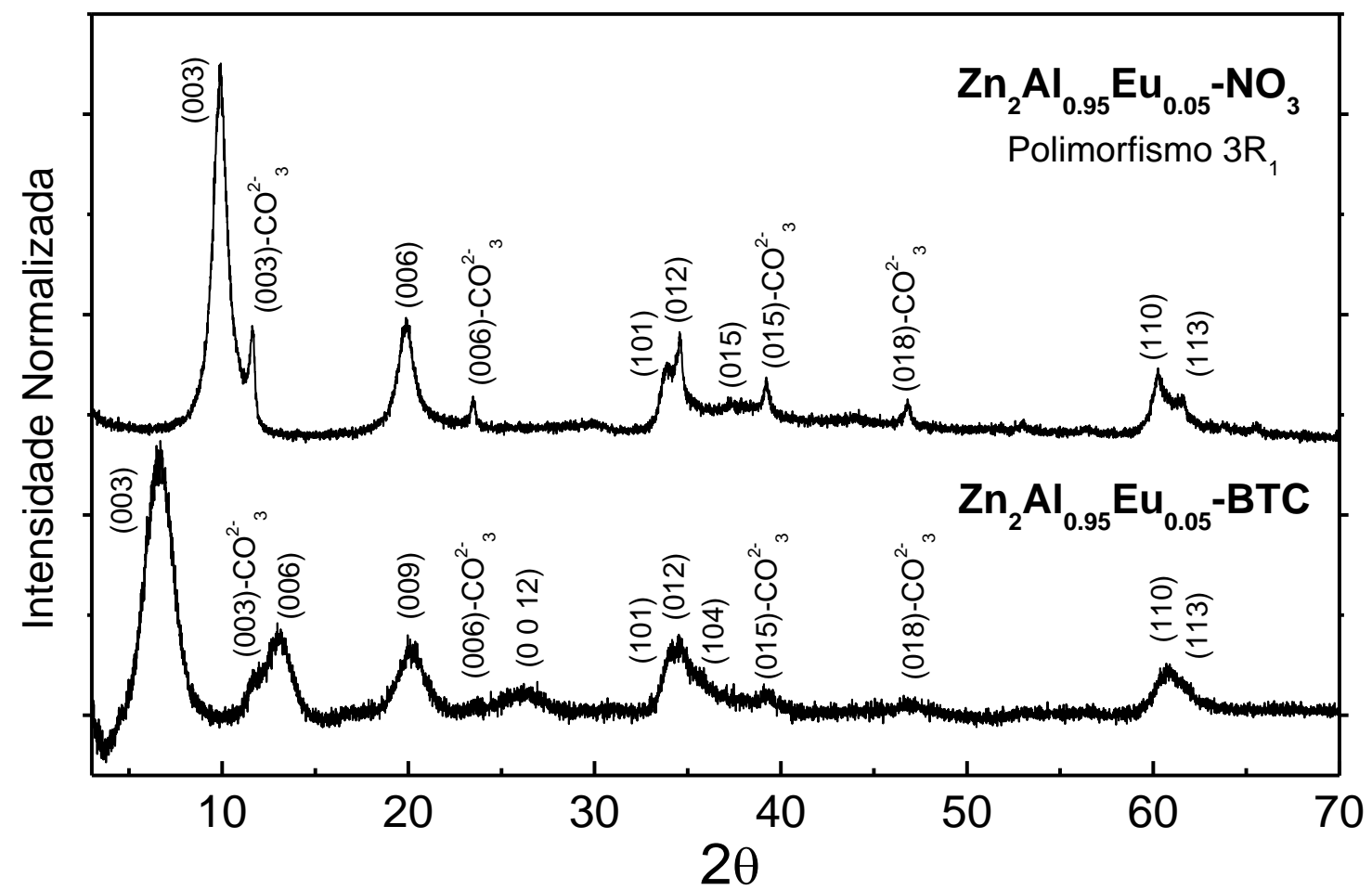

Figura 5.9. Padrão de difração de raios $X$ das amostras de LDHs planos dopados com $5 \%$ de $\mathrm{Eu}^{3+}$ intercalados com $\mathrm{NO}_{3}$ e $\mathrm{BTC}\left(\mathrm{Zn}_{2} \mathrm{Al}_{0.95} \mathrm{Eu}_{0.05}-\mathrm{NO}_{3}\right.$ e $\mathrm{Zn}_{2} \mathrm{Al}_{0.95} \mathrm{Eu}_{0.05}-\mathrm{BTC}$, respectivamente).

A partir da comparação dos difratogramas das amostras $\mathrm{Zn}_{2} \mathrm{Al}_{1}-\mathrm{NO}_{3}$ (Figura 5.1) e $\mathrm{Zn}_{2} \mathrm{Al}_{0.95} \mathrm{Eu}_{0.05}-\mathrm{NO}_{3}$ (Figura 5.9), observamos que a inserção de $\mathrm{Eu}^{3+}$ na estrutura dos LDHs induz um alargamento dos seus picos de difração. Musumeci et al. [20] mostraram que a inclusão de Térbio trivalente $\left(\mathrm{Tb}^{3+}\right)$ em LDHs de Magnésio e Alumínio leva à diminuição da espessura e do comprimento longitudinal dos cristais de LDH, o que deve se repetir para inserção de os outros elementos da série do Lantânio. Esse efeito leva a uma diminuição no número de planos cristalinos capazes de espalhar raios $\mathrm{X}$ coerentemente, alargando os picos de difração. Além desse efeito, devido ao fato de os elementos da série do Lantânio possuírem raios iônicos entre 0.977 e $1.160 \AA$ A , bastante superiores ao raio iônico do Alumínio em sua geometria octaédrica (0.675 Å), sua inserção nos LDHs deve distorcer sua rede cristalina, sendo outra fonte de alargamento para os picos de difração. A 
largura da reflexão (003) da amostra $\mathrm{Zn}_{2} \mathrm{Al}_{0.95} \mathrm{Eu}_{0.05}-\mathrm{NO}_{3}$ é calculada como sendo de $\delta\left(2 \theta_{003}\right)=0.93(1)^{\circ}$, o que, pela fórmula de Scherrer, corresponde a uma espessura de $9 \mathrm{~nm}$, ou seja, um empilhamento de cerca de 10 camadas de hidróxidos, em média, para cada cristalito da amostra. Esse valor é aproximadamente a metade do que foi determinado na seção 5.1 para a amostra $\mathrm{Zn}_{2} \mathrm{Al}_{1}-\mathrm{NO}_{3}-\mathrm{N}_{2}$, sem a inserção de $\mathrm{Eu}^{3+}$.

A intercalação de BTC nos LDHs da amostra $\mathrm{Zn}_{2} \mathrm{Al}_{0.95} \mathrm{Eu}_{0.05}$-BTC é comprovada pelo aumento do espaçamento basal desses materiais, similarmente ao que foi discutido seção 5.4. Comparando os difratogramas das amostras $\mathrm{Zn}_{2} \mathrm{Al}_{0.95} \mathrm{Eu}_{0.05}-\mathrm{NO}_{3}$ e $\mathrm{Zn}_{2} \mathrm{Al}_{0.95} \mathrm{Eu}_{0.05}-\mathrm{BTC}$ (Figura 5.9), fica claro que a intercalação do BTC introduz um alargamento adicional aos picos de difração dos $\mathrm{LDHs}$ com $\mathrm{Eu}^{3+}$. A largura a meia altura da sua reflexão basal em torno de $2 \theta=6.61^{\circ}$ é de $\delta\left(2 \theta_{003}\right)=1.72(2)^{\circ}$, o que, pela equação de Scherrer, corresponde a uma espessura $D=5 \mathrm{~nm}$. O número de camadas empilhadas em cada cristalito é, portanto, em média, cerca de 4 camadas de hidróxidos para cada cristalito.

\subsection{Propriedades luminescentes dos $\mathrm{LDHs} \operatorname{com} \mathrm{Eu}^{3+}: \mathrm{Zn}_{2} \mathrm{Al}_{0.95} \mathrm{Eu}_{0.05}-\mathrm{NO}_{3}$ e $\mathrm{Zn}_{2} \mathrm{Al}_{0.95} \mathbf{E u}_{0.05}-\mathrm{BTC}$}

Como discutido na seção 2.8, o posicionamento de uma molécula antena na vizinhança dos íons terras raras é capaz de melhorar significativamente a emissão desses elementos. Na estrutura lamelar dos LDHs, enquanto cátions $\mathrm{TR}^{3+}$ podem ser incorporados nas camadas de hidróxidos, sensibilizadores aniônicos podem ser hospedados no meio interlamelar. Adsorvidos na vizinhança dos metais, esses ligantes podem servir como antenas, absorvendo energia eletromagnética e transferindo-a não radiativamente para os terras raras. Com a população mais eficiente dos seus níveis de energia, a emissão desses elementos aumenta significativamente, melhorando a luminescência total do material. 


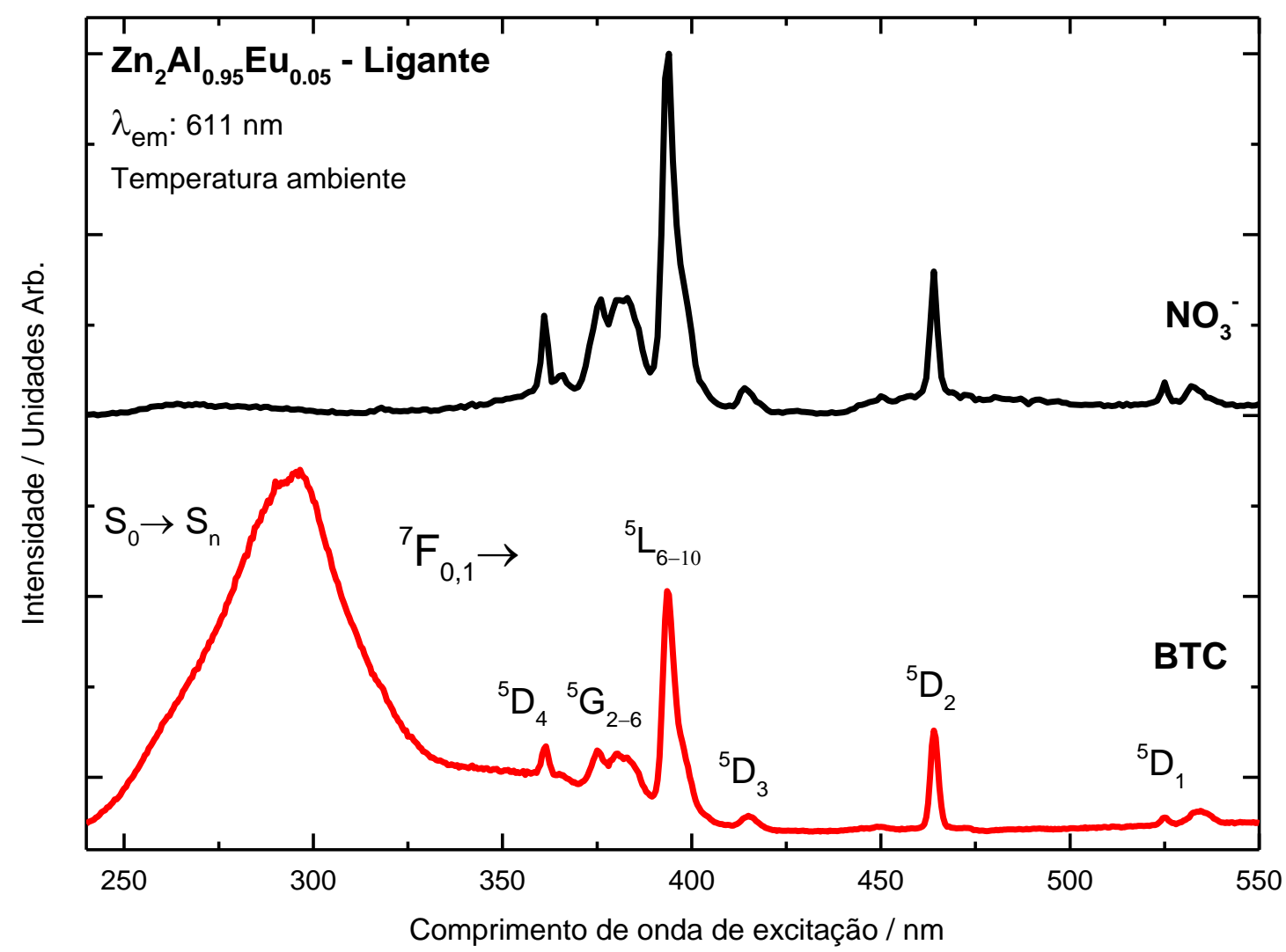

Figura 5.10. Espectro de excitação das amostras de LDHs de topologia plana dopados com $5 \%$ de $\mathrm{Eu}^{3+} \mathrm{e}$ intercalados com NO3- e BTC: $\mathrm{Zn}_{2} \mathrm{Al}_{0.95} \mathrm{Eu}_{0.05}-\mathrm{NO}_{3}$ e $\mathrm{Zn}_{2} \mathrm{Al}_{0.95} \mathrm{Eu}_{0.05}$ - $\mathrm{BTC}$, respectivamente.

Para caracterizar as propriedades luminescentes dos LDHs dopados com $\mathrm{Eu}^{3+}$, os espectros de excitação em temperatura ambiente das amostras $\mathrm{Zn}_{2} \mathrm{Al}_{0.95} \mathrm{Eu}_{0.05}-\mathrm{NO}_{3} \mathrm{e}$ $\mathrm{Zn}_{2} \mathrm{Al}_{0.95} \mathrm{Eu}_{0.05}$-BTC foram medidos monitorando a transição hipersensível $\left(\mathrm{Eu}^{3+}\right)^{5} \mathrm{D}_{0} \rightarrow{ }^{7} \mathrm{~F}_{2}$ $(611 \mathrm{~nm})$ do íon $\mathrm{Eu}^{3+}$ (Figura 5.10). O conjunto de bandas finas entre 350 e $550 \mathrm{~nm}$ corresponde às transições intraconfiguracionais $4 \mathrm{f}-4 \mathrm{f}$ do íon $\mathrm{Eu}^{3+}$ partindo do nível fundamental ${ }^{7} \mathrm{~F}_{0}$ e de seu nível mais próximo ${ }^{7} \mathrm{~F}_{1}$, que em $300 \mathrm{~K}$ está populado devido à energia térmica do sistema. Após a excitação do íon, sua desexcitação pode ocorrer em vários passos, passando por seus níveis menos energéticos até alcançar o nível emissor ${ }^{5} \mathrm{D}_{0}$, que, ao decair radiativamente para o nível fundamental, emite um fóton que é detectado pelo experimento. No espectro de excitação da amostra intercalada com BTC, é possível observar uma banda larga na região de energia mais alta $(250-325 \mathrm{~nm})$, correspondendo à excitação do ligante com a subsequente transferência de energia para o íon $\mathrm{Eu}^{3+}$. A excitação do íon BTC acontece de maneira bastante eficiente, já que a transição entre seus 
níveis singletos $S_{0}$ e $S_{n}$ é permitida por dipolo elétrico. Após a excitação ocorre a relaxação não radiativa do sistema para o nível tripleto $\mathrm{T}_{1}$, sendo seu retorno ao nível $\mathrm{S}_{0}$ proibido por dipolo elétrico por envolver uma mudança do spin do sistema. A energia então é transferida para os níveis ressonantes do íon $\mathrm{Eu}^{3+}$, como esquematizado na Figura 5.11.

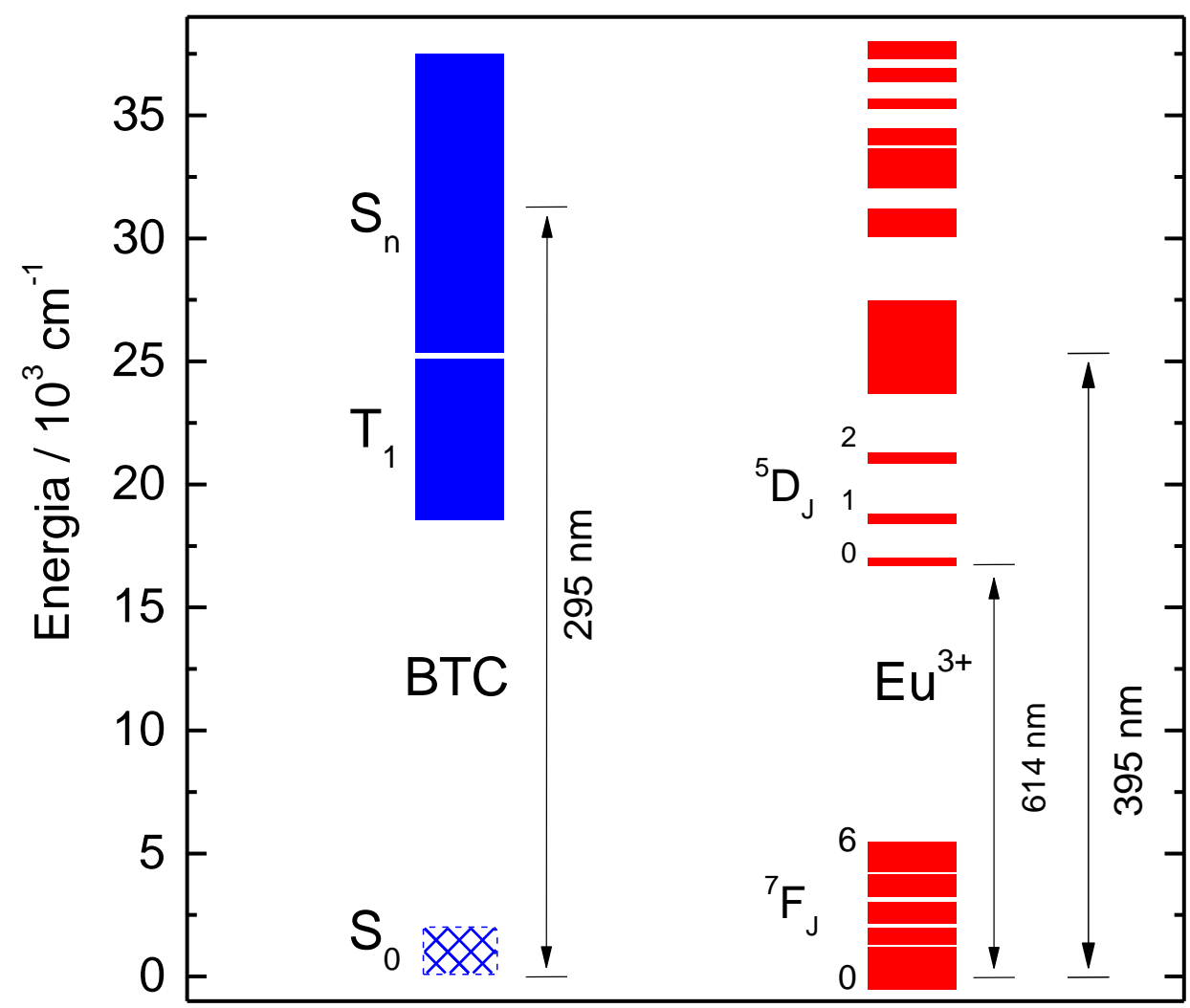

Figura 5.11. Diagrama parcial de energia mostrando os estados singletos $\left(S_{0}\right.$ e $\left.S_{n}\right)$ e tripleto $\left(T_{1}\right)$ do BTC [137], os níveis eletrônicos 4f do íon $\mathrm{Eu}^{3+}$ [138] e o comprimento de onda de algumas transições. A largura do nível $\mathrm{S}_{0}$ do BTC é desconhecida e por isso é mostrada como uma área hachurada no diagrama.

A fim de monitorar a transferência de energia ligante-metal, o espectro de emissão (Figura 5.12) das amostras $\mathrm{Zn}_{2} \mathrm{Al}_{0.95} \mathrm{Eu}_{0.05}-\mathrm{NO}_{3}$ e $\mathrm{Zn}_{2} \mathrm{Al}_{0.95} \mathrm{Eu}_{0.05}-\mathrm{BTC}$ foi obtido sob excitação direta da transição $\left(\mathrm{Eu}^{3+}\right)^{7} \mathrm{~F}_{0,1} \rightarrow{ }^{5} \mathrm{~L}_{6-10}$ em $395 \mathrm{~nm}$ na amostra intercalada com $\mathrm{NO}_{3}{ }^{-}$e sob excitação no centro da banda do BTC $(295 \mathrm{~nm})$ na amostra intercalada com esse ligante. As bandas finas de emissão observadas correspondem às transições intraconfiguracionais $\left(\mathrm{Eu}^{3+}\right)^{5} \mathrm{D}_{0} \rightarrow{ }^{7} \mathrm{~F}_{\mathrm{J}}(\mathrm{J}=0-4)$ do íon $\mathrm{Eu}^{3+}$ [71]. A inexistência de emissão do ligante na amostra $\mathrm{Zn}_{2} \mathrm{Al}_{0.95} \mathrm{Eu}_{0.05}$-BTC revela que o processo de transferência de energia ligante-metal nessa amostra é bastante eficiente, com probabilidade reduzida de desexcitação direta do ligante e com pouco efeito do processo de retrotransferência do íon 
$\mathrm{Eu}^{3+}$ para o BTC, visto que seu nível $\mathrm{T}_{1}$ é ligeiramente mais energético que os níveis do terra rara.

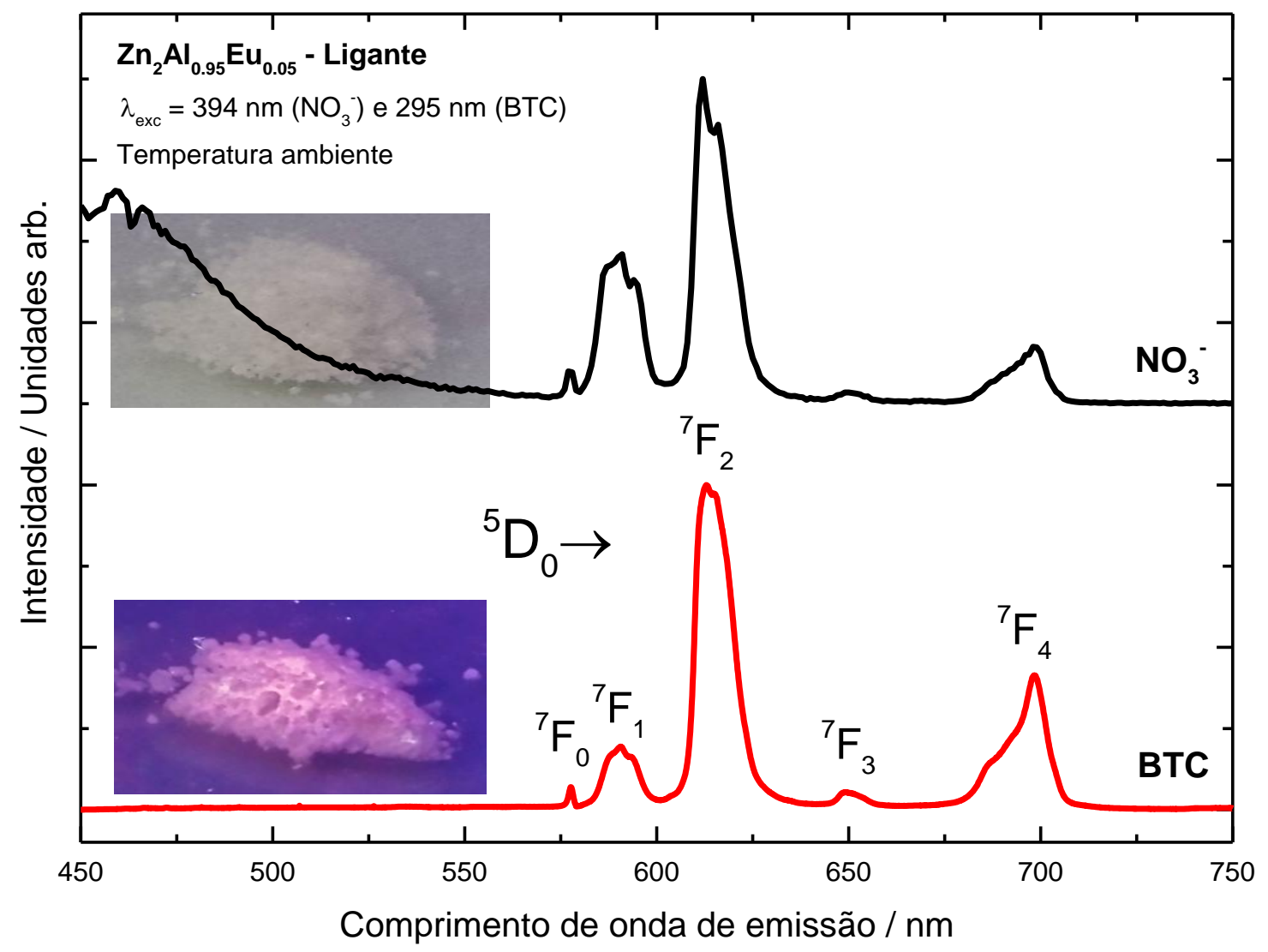

Figura 5.12. Espectro de emissão das amostras $\mathrm{Zn}_{2} \mathrm{Al}_{0.95} \mathrm{Eu}_{0.05}-\mathrm{NO}_{3}$ e $\mathrm{Zn}_{2} \mathrm{Al}_{0.95} \mathrm{Eu}_{0.05}-\mathrm{BTC}$ sob excitação da transição $\left(\mathrm{Eu}^{3+}\right)^{7} \mathrm{~F}_{0,1} \rightarrow{ }^{5} \mathrm{~L}_{6-10}$ em $394 \mathrm{~nm} \mathrm{e} \mathrm{S}_{0} \rightarrow \mathrm{S}_{\mathrm{n}}$ em $295 \mathrm{~nm}$ nas amostras intercaladas com $\mathrm{NO}_{3}{ }^{-}$e BTC, respectivamente. As fotografias mostram o comportamento luminescente das amostras sob iluminação por lâmpada UVA com espectro centrado em $365 \mathrm{~nm}$. Os espectros foram normalizados pelo máximo da banda $\left(\mathrm{Eu}^{3+}\right)^{5} D_{0} \rightarrow{ }^{7} F_{2}$.

No espectro de emissão mostrado na Figura $\mathbf{5 . 1 2}$ alguns detalhes revelam informações sobre a estrutura dos LDHs dopados. Como discutido na seção 2.9, transições do nível ${ }^{5} \mathrm{D}_{0}$ para o nível ${ }^{7} \mathrm{~F}_{1}$ são proibidas por dipolo elétrico, mas permitidas por dipolo magnético e, por isso, têm sua intensidade de emissão quase inalterada pela simetria do campo ligante provocado pelo ambiente químico ao redor do íon $\mathrm{Eu}^{3+}$. No entanto, as transições de ${ }^{5} \mathrm{D}_{0}$ para ${ }^{7} \mathrm{~F}_{2}$ e ${ }^{7} \mathrm{~F}_{4}$ são proibidas tanto por dipolo magnético quanto por dipolo elétrico, devendo, portanto, apresentar baixíssimas intensidades quando o sítio do íon emissor é um centro de inversão do sistema. Na falta de um centro de inversão, no entanto, 
essas regras de transição são relaxadas devido às misturas de funções de onda com paridades opostas como o resultado da existência de componentes esfericamente assimétricas do campo ligante. No caso dos espectros de emissão das amostras $\mathrm{Zn}_{2} \mathrm{Al}_{0.95} \mathrm{Eu}_{0.05}-\mathrm{NO}_{3}$ e $\mathrm{Zn}_{2} \mathrm{Al}_{0.95} \mathrm{Eu}_{0.05}$-BTC, a transição $\left(\mathrm{Eu}^{3+}\right)^{5} \mathrm{D}_{0} \rightarrow{ }^{7} \mathrm{~F}_{2}$ é a mais intensa, indicando que o sítio ocupado pelos íons $\mathrm{Eu}^{3+}$ nos LDHs dopados não pode ser o usual sítio de simetria octaédrica característico dos sítios metálicos nos LDHs em geral.

Mais detalhes da simetria ao redor do íon $\mathrm{Eu}^{3+}$ foram obtidos a partir da análise dos parâmetros de intensidade de Judd-Ofelt das amostras intercaladas com $\mathrm{NO}_{3}{ }^{-}$e BTC. Enquanto $\Omega_{2}$ é mais sensível a mudanças angulares na geometria de coordenação do íon terra rara, $\Omega_{4}$ varia mais significativamente sob mudanças na distância e polarizabilidade dos átomos ligantes ao redor do $\mathrm{TR}^{3+}$ [86]. Em termos do espectro de emissão do íon $\mathrm{Eu}^{3+}$, cada $\Omega_{\lambda}$ é proporcional a intensidade da transição ${ }^{5} \mathrm{D}_{0} \rightarrow{ }^{7} \mathrm{~F}_{\lambda}$. Em um ambiente perfeitamente simétrico, intensidades bastante reduzidas das transições $4 \mathrm{f}-4 \mathrm{f}$ dos terras raras são esperadas, como é o caso do íon $\mathrm{Eu}^{3+}{ }_{(\mathrm{aq})}\left(\mathrm{em}\right.$ solução aquosa), onde [85] $\Omega_{2}=1.62$ $\times 10^{-20} \mathrm{~cm}^{2}, \Omega_{4}=5.65 \times 10^{-20} \mathrm{~cm}^{2}$ e $\Omega_{6}=5.02 \times 10^{-20} \mathrm{~cm}^{2}$.

Os parâmetros $\Omega_{2,4}$ das amostras $\mathrm{Zn}_{2} \mathrm{Al}_{0.95} \mathrm{Eu}_{0.05}-\mathrm{NO}_{3}$ e $\mathrm{Zn}_{2} \mathrm{Al}_{0.95} \mathrm{Eu}_{0.05}$ - $\mathrm{BTC}$ estão apresentados na Tabela 6. Tanto $\Omega_{2}$ quanto $\Omega_{4}$ aumentam significativamente com a intercalação de BTC nos LDHs, sugerindo que a presença deste ligante orgânico causa a diminuição da simetria ao redor dos íons $\mathrm{Eu}^{3+}$. Supomos que a presença dos grupos carboxílicos desloca (atrai) os sítios metálicos nas camadas de hidróxidos, enquanto repele os grupos hidroxilas ao seu redor. Estas mudanças angulares na esfera de coordenação do cátion $\mathrm{Eu}^{3+}$ seriam responsáveis pela diferença de $\Omega_{2}$ entre os $\mathrm{LDHs}$ intercalados com $\mathrm{NO}_{3}{ }^{-}$ e BTC. Por outro lado, as moléculas de BTC, voltando seus grupos carboxílicos na direção dos metais trivalentes dos LDHs, conforme proposto na Figura 5.7, providenciam uma esfera de coordenação bastante polarizável ao redor do íon $\mathrm{Eu}^{3+}$, aumentando $\Omega_{4}$.

Tabela 6. Parâmetros óticos dos LDHs $\mathrm{Zn}_{2} \mathrm{Al}_{0.95} \mathrm{Eu}_{0.05}$ intercaladas com BTC ou $\mathrm{NO}_{3}^{-}$

\begin{tabular}{|c|c|c|c|c|c|c|c|c|c|}
\hline & $\begin{array}{c}\Omega_{2} \\
\left(10^{-20} \mathrm{~cm}^{2}\right)\end{array}$ & $\begin{array}{c}\Omega_{4} \\
\left(10^{-20} \mathrm{~cm}^{2}\right)\end{array}$ & $\begin{array}{l}A_{\text {rad }} \\
\left(s^{-1}\right)\end{array}$ & $\begin{array}{c}A_{\text {nrad }} \\
\left(\mathbf{s}^{-1}\right)\end{array}$ & $\begin{array}{l}\mathbf{A}_{\text {tot }} \\
\left(\mathbf{s}^{-1}\right)\end{array}$ & $\begin{array}{l}\tau_{\text {rad }} \\
(\mathbf{m s})\end{array}$ & $\begin{array}{c}\tau_{\text {nrad }} \\
(\mathrm{ms})\end{array}$ & $\begin{array}{c}\tau \\
(\mathbf{m s})\end{array}$ & $\begin{array}{c}\eta \\
(\%)\end{array}$ \\
\hline BTC & 11.9 & 11.6 & 583 & 2643 & 3226 & 1.71 & 0.38 & 0.31 & 18.9 \\
\hline $\mathrm{NO}_{3}^{-}$ & 3.9 & 1.8 & 194 & 3254 & 3448 & 5.15 & 0.31 & 0.29 & 5.6 \\
\hline
\end{tabular}




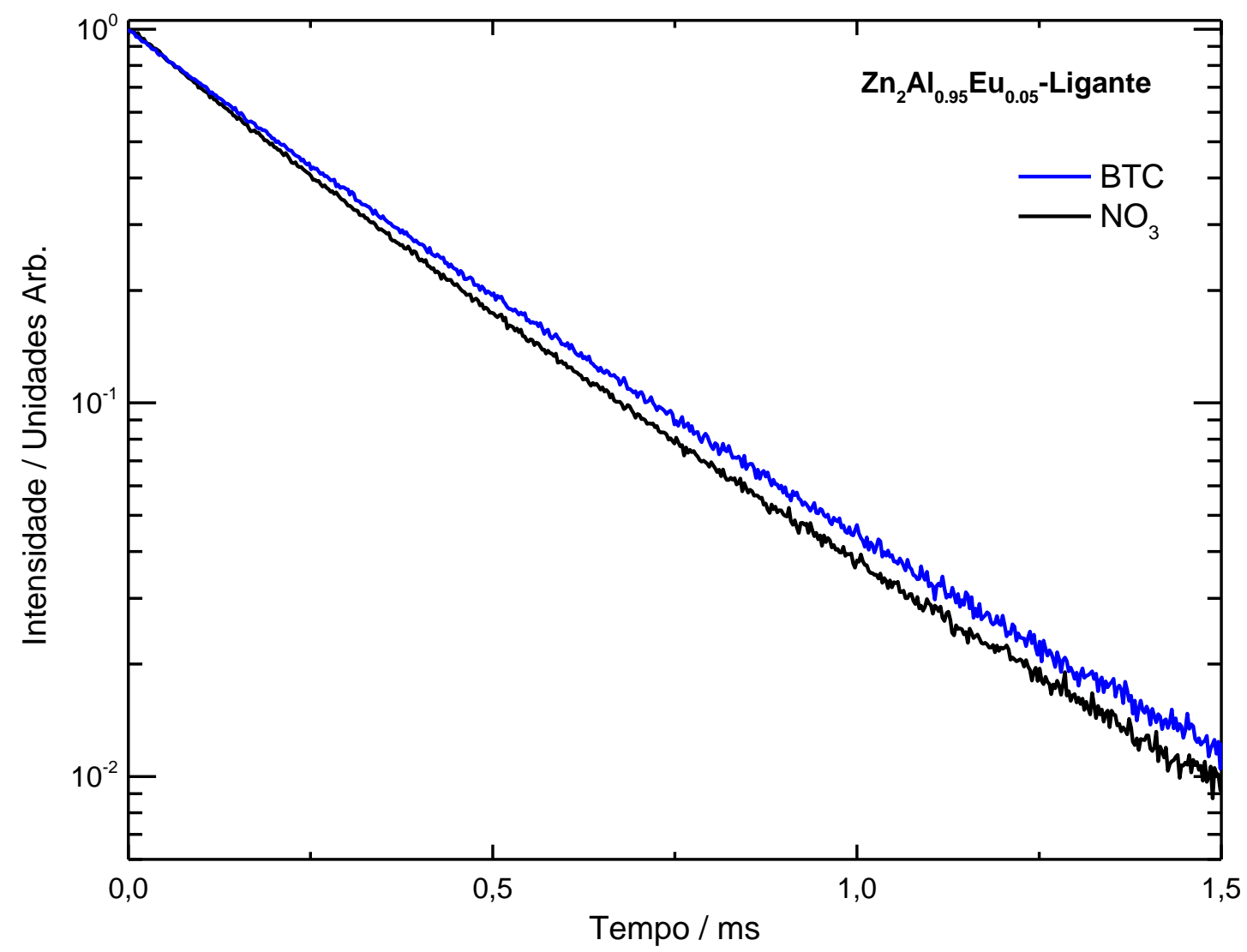

Figura 5.13. Curvas de decaimento da intensidade emitida pela transição $\left(\mathrm{Eu}^{3+}\right)^{5} \mathrm{D}_{0} \rightarrow{ }^{7} \mathrm{~F}_{2}$ após a excitação da amostra na banda do ligante $295 \mathrm{~nm}$ (para a amostra com BTC) e após excitação direta da transição $\left(\mathrm{Eu}^{3+}\right)^{7} \mathrm{~F}_{0,1} \rightarrow{ }^{5} \mathrm{~L}_{6-10}$ em $395 \mathrm{~nm}$ na amostra com $\mathrm{NO}_{3}{ }^{-}$.

O tempo de vida $(\tau)$ do nível emissor $\left(\mathrm{Eu}^{3+}\right)^{5} \mathrm{D}_{0}$ do íon $\mathrm{Eu}^{3+}$ nos LDHs $\mathrm{Zn}_{2} \mathrm{Al}_{0.95} \mathrm{Eu}_{0.05}-\mathrm{NO}_{3}$ e $\mathrm{Zn}_{2} \mathrm{Al}_{0.95} \mathrm{Eu}_{0.05}-\mathrm{BTC}$ foi medido a partir da excitação dos LDHs na banda do ligante (em $295 \mathrm{~nm}$, no caso da amostra com BTC) ou a partir da excitação direta da transição $\left(\mathrm{Eu}^{3+}\right)^{7} \mathrm{~F}_{0,1} \rightarrow{ }^{5} \mathrm{~L}_{6-10}$ em $395 \mathrm{~nm}$ do íon $\mathrm{Eu}^{3+}$ (na amostra com $\mathrm{NO}_{3}{ }^{-}$). O decaimento temporal (Figura 5.13) da intensidade emitida pela transição $\left(\mathrm{Eu}^{3+}\right)^{5} \mathrm{D}_{0} \rightarrow{ }^{7} \mathrm{~F}_{2}$ foi monitorada e o tempo de vida determinado a partir de um modelo exponencial (Tabela 6). A taxa de decaimento do nível emissor $\left(\mathrm{Eu}^{3+}\right)^{5} \mathrm{D}_{0}$ pode ser calculada a partir de $\tau$, como discutido na seção 2.7: $A_{\text {tot }}=1 / \tau$. Com os valores de $\mathrm{A}_{\text {rad }}$ obtidos a partir dos espectros de excitação das amostras, calculamos os valores de $A_{\text {nrad }}=A_{\text {tot }}-A_{\text {rad }}$. Os tempos de relaxação radiativa $\left(\tau_{\text {rad }}\right)$ e não radiativa $\left(\tau_{\text {nrad }}\right)$ do nível $\left(\mathrm{Eu}^{3+}\right)^{5} \mathrm{D}_{0}$ foram então calculados: $\tau_{\text {rad }}=1 / A_{\text {rad }}$ e $\tau_{\text {nrad }}=1 / A_{\text {nrad }}$ (Tabela 6). Para os LDHs investigados, o tempo de vida do nível ${ }^{5} \mathrm{D}_{0}$ é dominado por processos de decaimento não radiativos 
ocorrendo em escalas de tempo muito menores $\left(\tau_{\text {nrad }}=0.31-0.38 \mathrm{~ms}\right)$ que os decaimentos radiativos $\left(\tau_{\text {rad }}=1.71-5.15 \mathrm{~ms}\right)$. Nos hidróxidos duplos lamelares, a presença dos grupos hidroxilas ao redor dos metais induz a desexcitação não radiativa da luminescência através de caminhos de decaimentos mediados por vibrações dos grupos $\mathrm{OH}$ presentes no sistema. A energia elevada dos osciladores $\mathrm{O}-\mathrm{H}$, diminui o número de fônons necessários para promover a desexcitação dos nível $\left(\mathrm{Eu}^{3+}\right)^{5} \mathrm{D}_{0}$, aumentando a probabilidade de decaimento não radiativo. Devido a este efeito, as eficiências quânticas dos íons $\mathrm{Eu}^{3+}$ nos LDHs estudados neste trabalho são muito menores do que aquelas já reportadas para os complexos anidros Eu-BTC, com eficiências quânticas típicas em torno de 50\% [139].

Como mostrado na Tabela 6, a amostra $\mathrm{Zn}_{2} \mathrm{Al}_{0.95} \mathrm{Eu}_{0.05}-\mathrm{NO}_{3}$ tem menor eficiência quântica e maior tempo de relaxação radiativo do nível $\left(\mathrm{Eu}^{3+}\right)^{5} \mathrm{D}_{0}$ que a amostra $\mathrm{Zn}_{2} \mathrm{Al}_{0.95} \mathrm{Eu}_{0.05}$-BTC. Em geral, o tempo de vida de um estado eletrônico é governado pela força do oscilador resultante dos potenciais físicos que levam à transição, de forma que quanto menor a força do oscilador, mais longo é o tempo de vida do estado eletrônico. Nos íons terras raras trivalentes, a força do oscilador para transições $4 \mathrm{f}-4 \mathrm{f}$ são bastante baixas quando eles estão inseridos em ambientes químicos com simetria de inversão, dando origem a tempos de vida bastante longos, como é o caso para a amostra $\mathrm{Zn}_{2} \mathrm{Al}_{0.95} \mathrm{Eu}_{0.05^{-}}$ $\mathrm{NO}_{3}$. Por outro lado, o tempo de vida não radiativo independe da simetria ao redor do $\mathrm{TR}^{3+}$ e é largamente independente dos ligantes intercalados. Isto faz com que o tempo de relaxação não radiativo do nível $\left(\mathrm{Eu}^{3+}\right)^{5} \mathrm{D}_{0}$ seja aproximadamente constante para ambas as amostras estudadas. Ainda, visto que $\tau_{n r a d}$ é usualmente ordens de magnitude menor que $\tau_{\text {rad }}$, uma parte importante da energia é drenada por processo não radiativos antes que o íon $\mathrm{TR}^{3+}$ possa decair radiativamente. Esse fenômeno cria uma barreira importante para o desenvolvimento de LDHs com alta luminescência que somente pode ser ultrapassada a partir da busca por ligantes capazes de criar distorções na simetria ao redor dos íons $\mathrm{TR}^{3+}$, quebrando qualquer tipo de simetria de inversão, mas mantendo intacta a estrutura lamelar desses materiais.

\subsection{Formação de nanotubos de $\mathrm{LDHs:} \mathrm{Zn}_{2} \mathrm{AlEu}_{\mathrm{x} \%}-\mathrm{BTC}-\mathrm{P} 123$}

Diversas amostras foram sintetizadas seguindo o procedimento descrito na seção 4.4, com o gotejamento da solução metálica em solução contendo micelas de P-123. As frações 
$\mathrm{Zn}^{2+}:\left(\mathrm{Al}^{3+}+\mathrm{Eu}^{3+}\right)$ utilizadas foram de 2:1. Mantendo constante a concentração total de cátions trivalentes, a concentração de $\mathrm{Eu}^{3+}$ foi variada, sendo $\mathrm{Eu}^{3+}: \mathrm{Al}^{3+}=\mathrm{x}: 1-\mathrm{x}(\mathrm{x} \mathrm{mol} \%)$. Essas amostras possuem conteúdo metálico da forma $\mathrm{Zn}_{2} \mathrm{Al}_{1-\mathrm{x}} \mathrm{Eu}_{\mathrm{x}}$ e foram denominadas $\mathrm{ZnAlEu}_{\mathrm{x} \%}$-BTC-P123, conforme mostrado na Tabela 7.

\begin{tabular}{c|c}
\hline Tabela 7. Amostras sintetizadas em solução contendo micelas de P-123 \\
\hline Amostra & Amostra \\
$\mathrm{Zn}_{2} \mathrm{AlEu}_{0 \%}$-BTC-P123 & $\mathrm{Zn}_{2} \mathrm{AlEu}_{7 \%}-\mathrm{BTC}-\mathrm{P} 123$ \\
$\mathrm{Zn}_{2} \mathrm{AlEu}_{0.1 \%}-\mathrm{BTC}-\mathrm{P} 123$ & $\mathrm{Zn}_{2} \mathrm{AlEu}_{10 \%}-\mathrm{BTC}-\mathrm{P} 123$ \\
$\mathrm{Zn}_{2} \mathrm{AlEu}_{0.3 \%}-\mathrm{BTC}-\mathrm{P} 123$ & $\mathrm{Zn}_{2} \mathrm{AlEu}_{15 \%}-\mathrm{BTC}-\mathrm{P} 123$ \\
$\mathrm{Zn}_{2} \mathrm{AlEu}_{0.5 \%}-\mathrm{BTC}-\mathrm{P} 123$ & $\mathrm{Zn}_{2} \mathrm{AlEu}_{20 \%}-\mathrm{BTC}-\mathrm{P} 123$ \\
$\mathrm{Zn}_{2} \mathrm{AlEu}_{1 \%}-\mathrm{BTC}-\mathrm{P} 123$ & $\mathrm{Zn}_{2} \mathrm{AlEu}_{80 \%}-\mathrm{BTC}-\mathrm{P} 123$ \\
$\mathrm{Zn}_{2} \mathrm{AlEu}_{3 \%}-\mathrm{BTC}-\mathrm{P} 123$ & $\mathrm{Zn}_{2} \mathrm{AlEu}_{100 \%}-\mathrm{BTC}-\mathrm{P} 123$ \\
$\mathrm{Zn}_{2} \mathrm{AlEu}_{5 \%}-\mathrm{BTC}-\mathrm{P} 123$ & \\
\hline
\end{tabular}

A Figura 5.14 e a Figura 5.15 mostram os difratogramas de raios $\mathrm{X}$ das amostras $\mathrm{Zn}_{2} \mathrm{AlEu}_{\mathrm{x} \%}$-BTC-P123 com diferentes concentrações de $\mathrm{Eu}^{3+}$. Para amostras com até $15 \%$ de $\mathrm{Eu}^{3+}$ em substituição aos íons $\mathrm{Al}^{3+}$, o conjunto das reflexões de Bragg encontradas indicam a formação de duas espécies de LDHs: uma intercalada com BTC $\left(2 \theta=6.61^{\circ}\right)$ e outra intercalada com $\mathrm{CO}_{3}{ }^{2-}\left(2 \theta=11.7^{\circ}\right.$, mais aparente nas amostras com $0 \%$ e $0.3 \%$ de $\left.\mathrm{Eu}^{3+}\right)$. Nessa faixa de concentração de $\mathrm{Eu}^{3+}$, não foi observada a formação de outras fases cristalinas além dos LDHs. Dentre as amostras com 1\%, 3\%, 5\% e $10 \%$ de $\mathrm{Eu}^{3+}$ observa-se na Figura 5.14 que, para concentrações acima de 5\%, ocorre um alargamento brusco da reflexão (003) indicando uma diminuição dos cristalitos das amostras com o aumento da quantidade de $\mathrm{Eu}^{3+}$ no material. Fica claro que a inserção de P-123 no procedimento da síntese induz um alargamento adicional à reflexão (003), como é possível observarmos comparando os difratogramas das amostras $\mathrm{Zn}_{2} \mathrm{Al}_{0.95} \mathrm{Eu}_{0.05}-\mathrm{BTC}$ (Figura 5.9, $\delta\left(2 \theta_{003}\right)=$ $1.72(2)^{\circ}$ ) e $\mathrm{Zn}_{2} \mathrm{AlEu}_{5 \%}-\mathrm{BTC}-\mathrm{P} 123$ (Figura 5.14, $\delta\left(2 \theta_{003}\right)=2.3^{\circ}$ ). Pela equação de Scherrer, essa última amostra deve ter no mínimo, em média, cerca de 3 camadas de hidróxidos empilhadas em cada cristalito (espessura $D=3.6 \mathrm{~nm}$ ). 


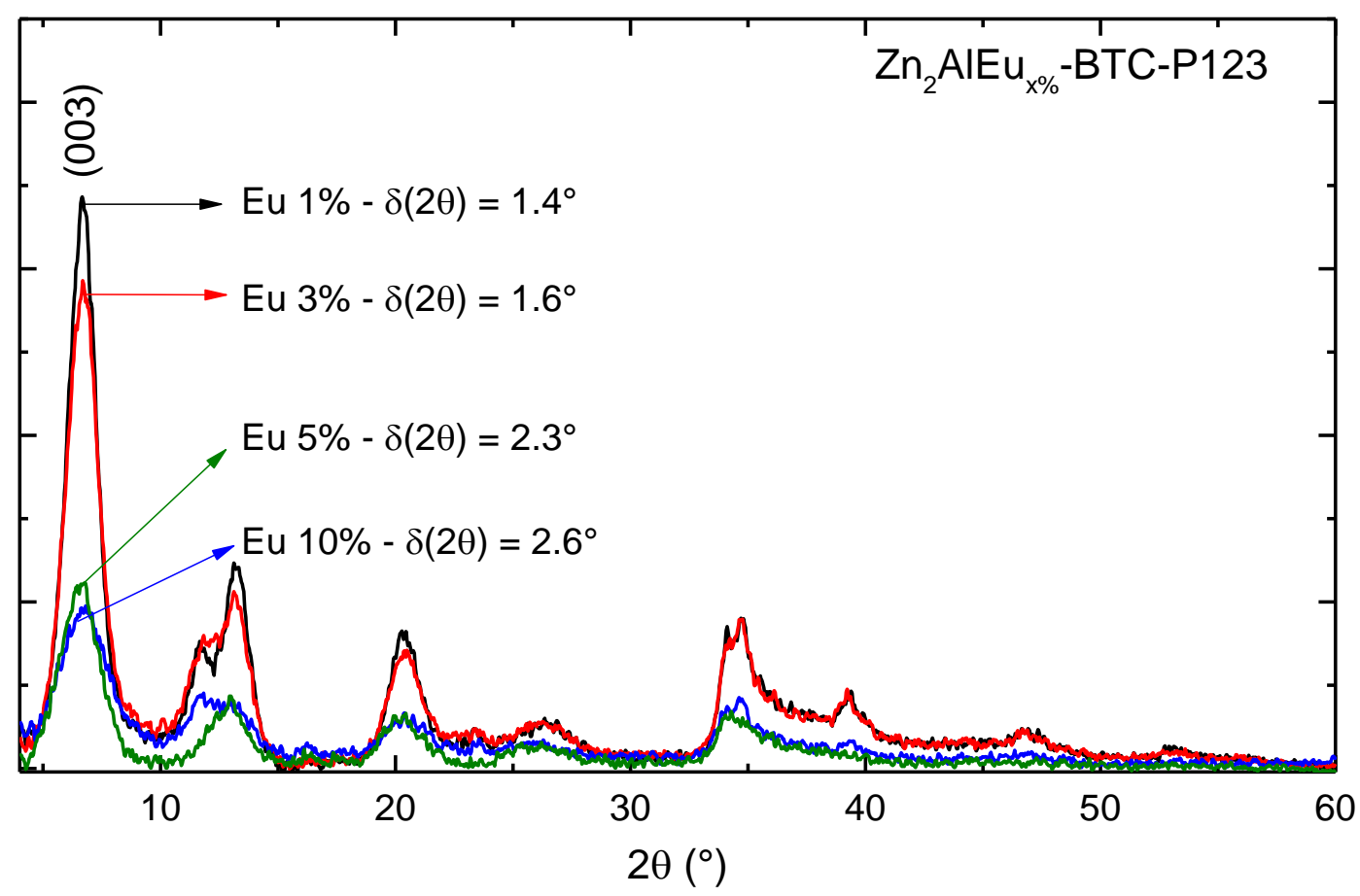

Figura 5.14. Padrões de difração de raios $X$ dos LDHs dopados com diferentes quantidades de $\mathrm{Eu}^{3+}$, intercalados com BTC e sintetizados na presença de micelas de P-123.

$\mathrm{A}$ inserção de $\mathrm{Eu}^{3+}$ nas amostras $\mathrm{Zn}_{2} \mathrm{AlEu}_{\mathrm{x} \%}$-BTC-P123 não altera a estrutura lamelar do material sintetizado até o limite de $15 \mathrm{~mol} \%$ de substituição de $\mathrm{Al}^{3+}$. Para substituições acima de $15 \mathrm{~mol} \%$, novas reflexões foram observadas (Figura 5.15) nos padrões de difração de raios $\mathrm{X}$ das amostras, com o aparecimento de picos finos e bem pronunciados em posições que são características da formação do complexo EuBTC. Para obtermos uma fase puramente lamelar devemos evitar altas concentrações dos terras raras durante a síntese dos LDHs. 


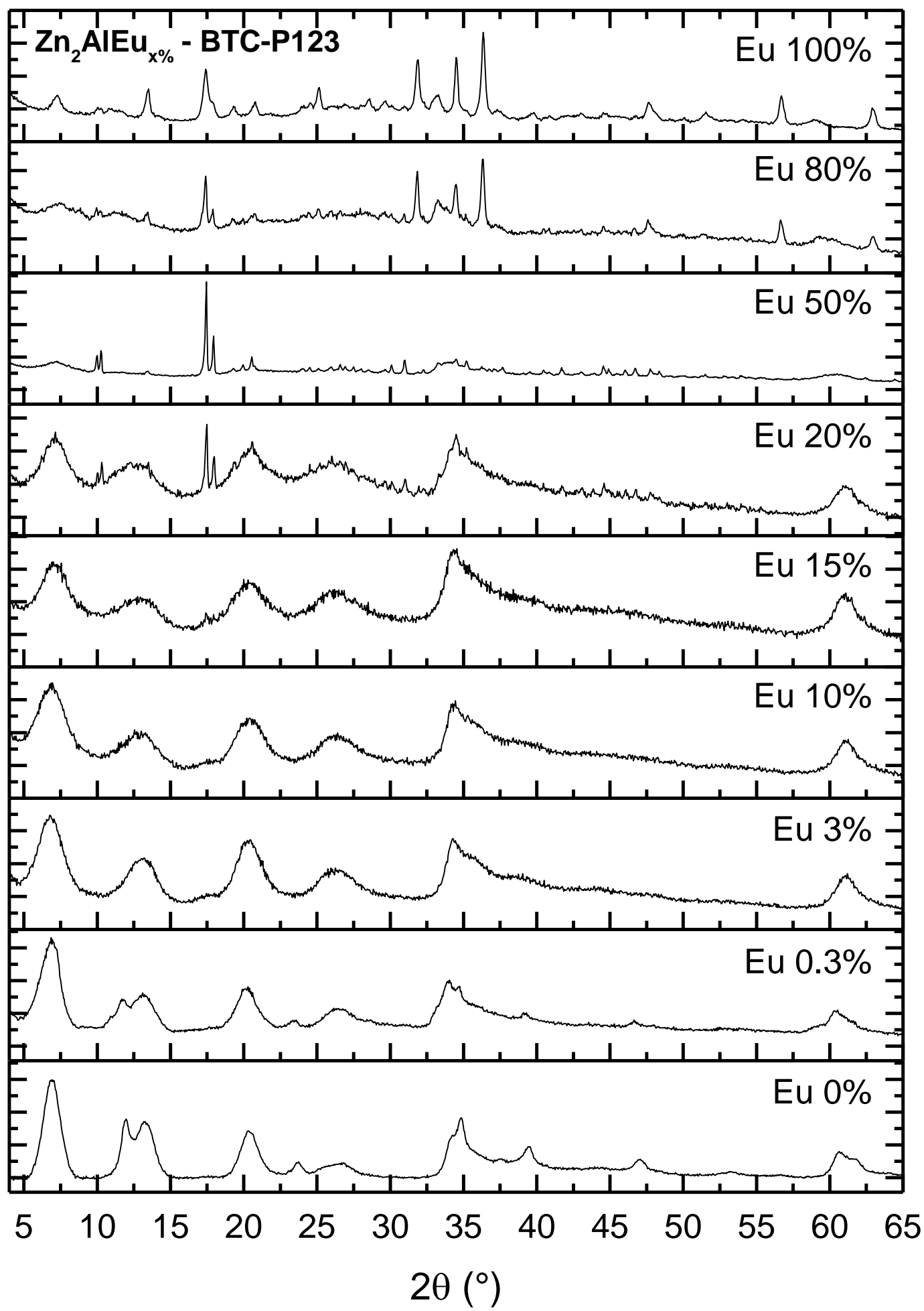

Figura 5.15. Difratogramas de raios $X$ das amostras $\mathrm{ZnAlEu}_{\mathrm{x}}$-BTC-P123 após lavagem com metanol. 
Para uma caracterização inicial da morfologia microscópica das amostras $\mathrm{Zn}_{2} \mathrm{AlEu}_{\mathrm{x} \% \text { - }}$ BTC-P123, foram realizadas medidas de microscopia eletrônica de varredura em alguns espécimes selecionados (Figura 5.16). A presença das micelas de P-123 durante a síntese dos LDHs causa uma diminuição importante no tamanho das partículas, mas, sem a adição de $\mathrm{Eu}^{3+}$, não é capaz de impor uma morfologia tridimensional aos LDHs, como é possível observarmos a partir de a e b da Figura 5.16. No outro extremo, as micrografias das amostras com 100 mol\% de $\mathrm{Eu}^{3+}$ em substituição completa aos cátions $\mathrm{Al}^{3+}$ mostram (g e h da Figura 5.16) que bastões microscópicos identificados como uma fase segregada do complexo EuBTC e de largura $\gtrsim 1 \mu m$ são formados juntamente com a fase planar dos LDHs. Para concentrações intermediárias de $\mathrm{Eu}^{3+}$, as micrografias das amostras com 5\% e $15 \%$ de $\mathrm{Eu}^{3+}$ (c até $\mathbf{f}$ da Figura 5.16, respectivamente) mostram a formação de uma estrutura de fios entrelaçados, diferente daquela encontrada nos LDHs de morfologia plana mostrados anteriormente (Figura 5.4). Sendo assim, imagens de microscopia eletrônica de transmissão das amostras $\mathrm{Zn}_{2} \mathrm{AlEu}_{\mathrm{x} \%}$-BTC-P123 foram obtidas a fim de obter detalhes da sua morfologia. Algumas micrografias selecionadas estão mostradas nas séries das Figuras

\subsection{7-5.19.}

As micrografias de transmissão da série de amostras $\mathrm{Zn}_{2} \mathrm{AlEu}_{\mathrm{x} \%}$-BTC-P123 mostram que, sem a adição de $\mathrm{Eu}^{3+}$, apenas $\mathrm{LDHs}$ de morfologia plana são formados, com a inexistência de curvaturas apreciáveis que indiquem a formação dos materiais sobre a superfície das micelas de P-123 (Figura 5.17a). Apenas a adição conjunta de certas concentrações de $\mathrm{Eu}^{3+}$, BTC e micelas de P-123 induziram a modificação da morfologia do material. Para a menor concentração de $\mathrm{Eu}^{3+}$ considerada $(0.1 \%, \mathbf{b}$ e $\mathbf{c}$ da Figura 5.17) foi possível observar o aparecimento de regiões com curvatura nos flocos dos LDHs, indicando uma tendência de enrolamento desses materiais sobre a superfície das micelas e mostrando que a adição de $\mathrm{Eu}^{3+}$ permite a flexibilização da estrutura das lamelas, permitindo o seu enrolamento. Para concentrações crescentes de $\mathrm{Eu}^{3+}$, um número cada vez maior de regiões com enrolamentos foram encontradas durante as medidas. Em concentrações acima de $1 \%$ (f, $\mathbf{g}$ e $\mathbf{h}$ da Figura 5.17) observamos a formação esparsa de LDHs com paredes densas e galerias menos densas em seu interior indicando a formação de nanotubos de LDHs sobre a superfície das micelas. As micrografias eletrônicas de transmissão das amostras $\mathrm{Zn}_{2} \mathrm{AlEu}_{\mathrm{x} \%}$-BTC-P123 com $5 \%$ (Figura 5.18) e $15 \%$ (Figura 5.19) de $\mathrm{Eu}^{3+}$ mostram a 
formação de uma rede bem formada de nanotubos entrelaçados, com diâmetro externo típico de 11-16 nm e diâmetro interno de 4.6-6 nm. Esses valores, porém, estão em desacordo com o que é esperado para o diâmetro de uma micela cilíndrica de P-123, estimado em cerca de $19 \mathrm{~nm}$ [43, 61]. No entanto, durante as medidas observamos que a interação do feixe de elétrons do microscópio com as partículas causava o seu encolhimento ou até mesmo sua degradação rápida. Dessa forma, as dimensões mostradas pelas micrografias servem apenas como limites inferiores para as dimensões dos nanotubos.

Em c, d e e da Figura 5.18, é possível observarmos claramente a estrutura lamelar

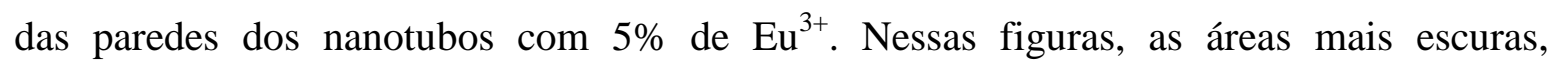
correspondendo às regiões mais densas do material, são as camadas de hidróxidos dos LDHs. Áreas mais claras correspondem a regiões ocas ou contendo matéria orgânica, de baixa densidade eletrônica. A Figura 5.18e mostra a visão quase frontal de um nanotubo. É possível observar que quatro camadas de hidróxidos formam a parede desse nanotubo, em conformidade com o resultado da análise de Scherrer para o tamanho de cristalito dessa amostra. Fazendo um mapa de intensidade dos píxeis ${ }^{16}$ ao longo da linha amarela, como mostrado na Figura 5.18f, é possível obter informações sobre o espaçamento basal $(1,4 \mathrm{~nm})$ e os diâmetros interno $(5,9 \mathrm{~nm})$ e externo $(16 \mathrm{~nm})$ dessas estruturas.

Na Figura 5.18b está mostrado o espectro de EDX da área mostrada na Figura 5.18a, confirmando a fixação do cátion $\mathrm{Eu}^{3+}$ na estrutura dos nanotubos.

\footnotetext{
${ }^{16}$ Áreas claras na figura apresentam píxeis com valores maiores que as áreas escuras. Os vales no gráfico da Figura 5.18f correspondem à posição das camadas de hidróxidos ao longo da linha amarela mostrada na Figura 5.18e.
} 


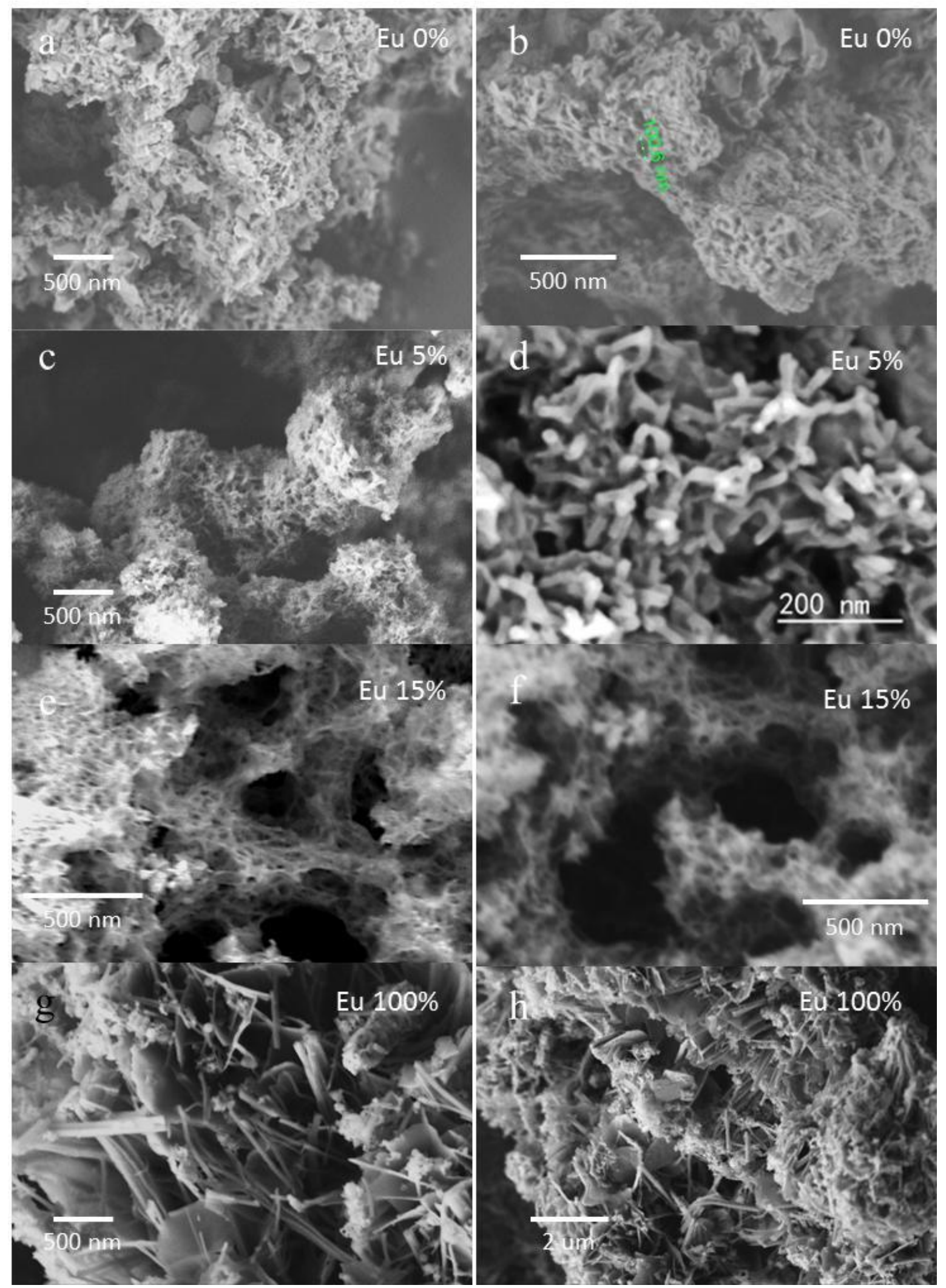

Figura 5.16. Imagens de microscopia eletrônica de varredura das amostras $\mathrm{Zn}_{2} \mathrm{AlEu}_{\mathrm{x}}$ - $\mathrm{BTC}-\mathrm{P} 123$ com (a, b) $0 \%$ de $\mathrm{Eu}^{3+}$, (c, d) $5 \%$ de $\mathrm{Eu}^{3+}$, (e, f) $15 \%$ de $\mathrm{Eu}^{3+}$ e (g, h) $100 \%$ de $\mathrm{Eu}^{3+}$ após lavagem com metanol. 

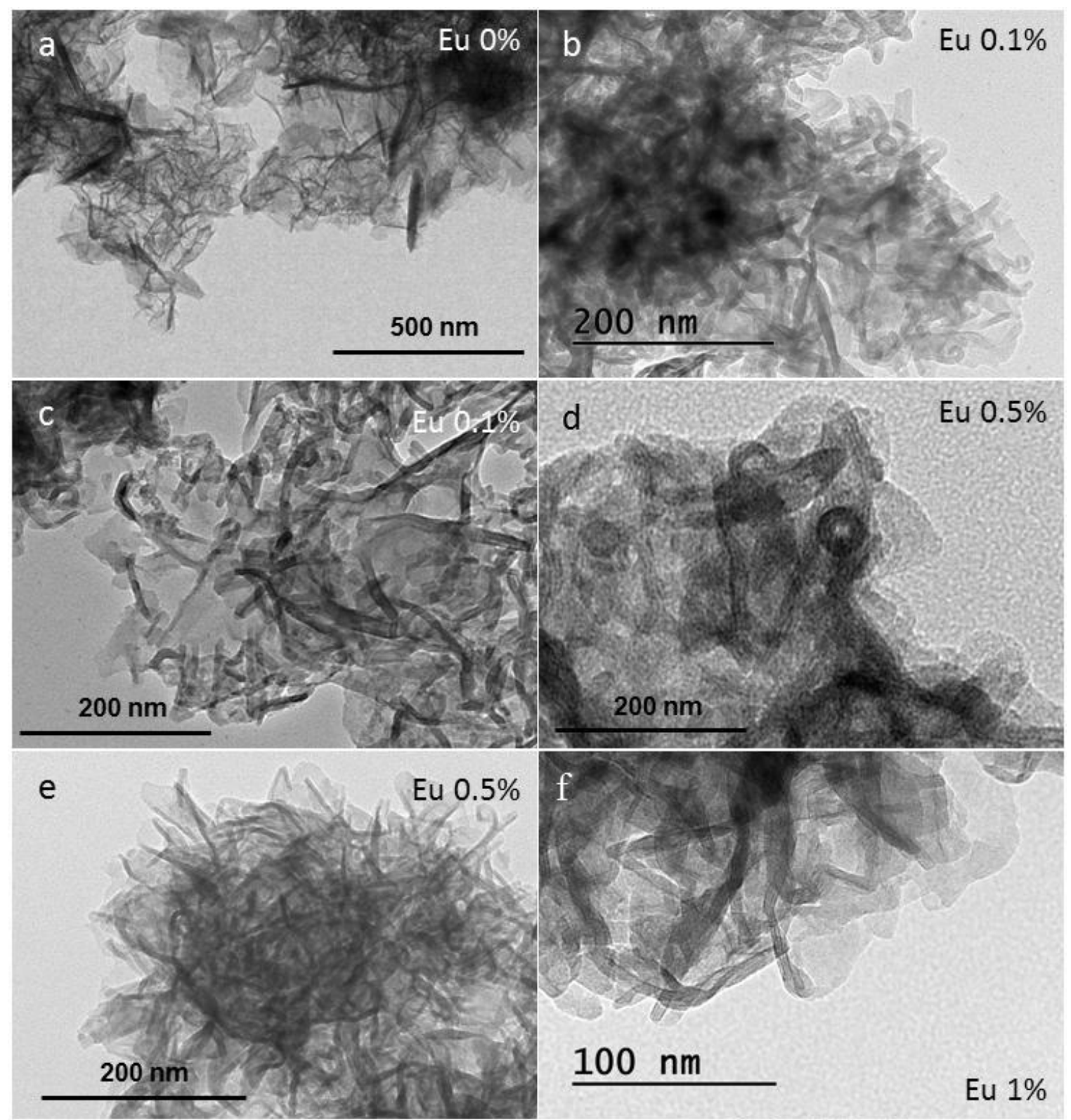

$100 \mathrm{~nm}$

Eu $1 \%$
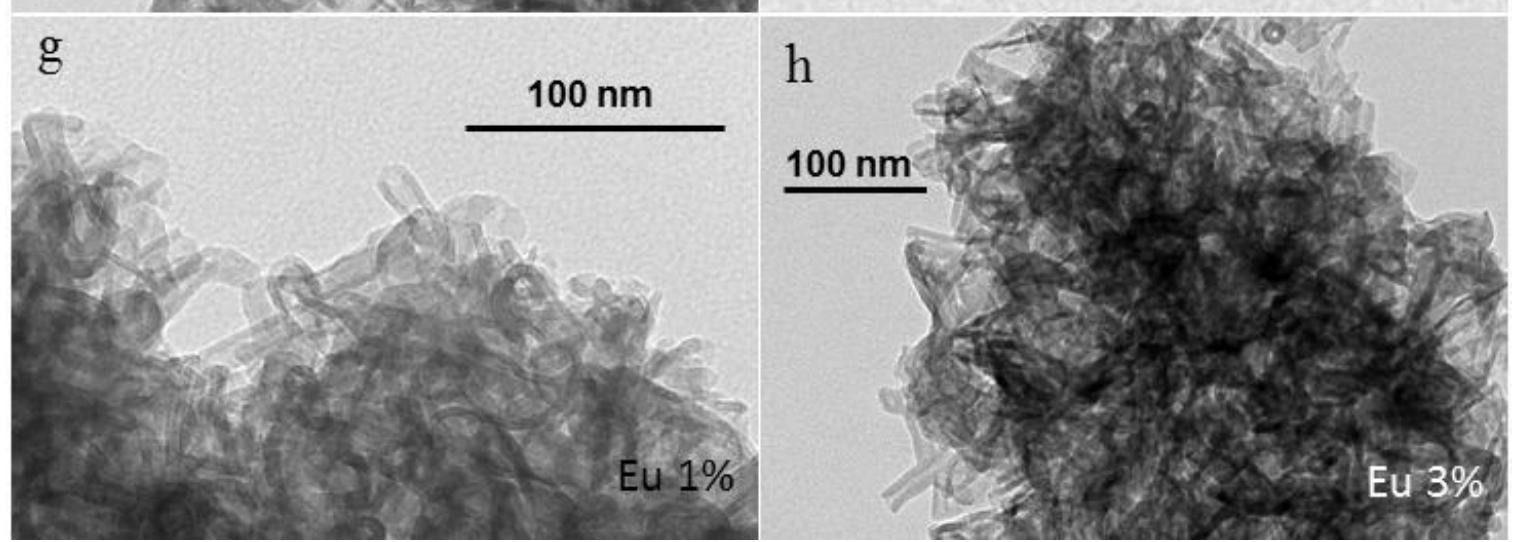

Figura 5.17. Micrografias eletrônicas de transmissão das amostras $\mathrm{Zn}_{2} \mathrm{AlEu}_{\mathrm{x} \%}-\mathrm{BTC}-\mathrm{P} 123$ com (a) $0 \%$, (b) $0.1 \%$, (d, e) $0.5 \%$, (f, g) $1 \%$ e (h) $3 \%$ de $\mathrm{Eu}^{3+}$ após lavagem com metanol. 

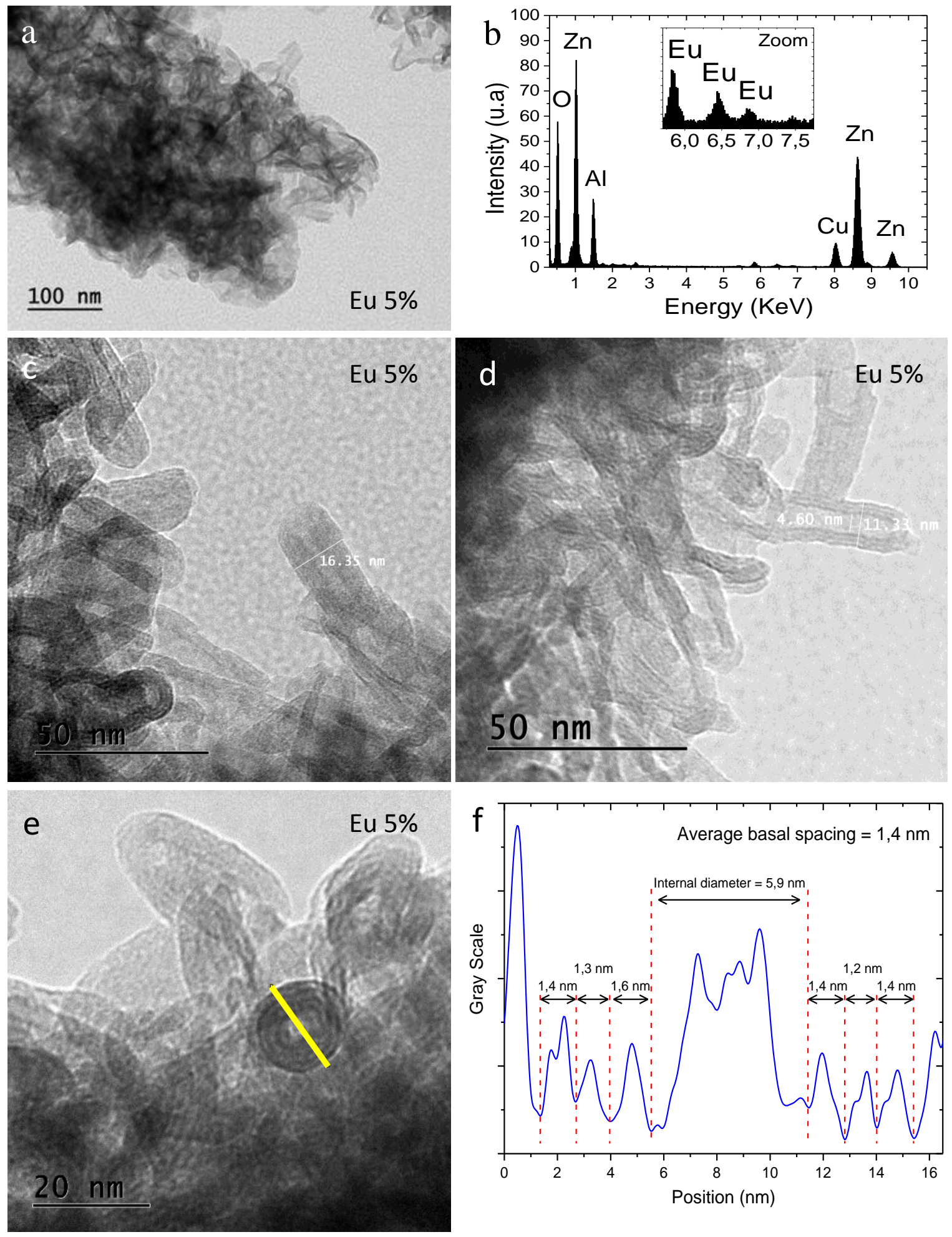

Figura 5.18. (a, c, d, e) Micrografias eletrônicas de transmissão da amostra $\mathrm{Zn}_{2} \mathrm{AlEu}_{5 \%}-\mathrm{BTC}-\mathrm{P} 123$, com $5 \%$ de $\mathrm{Eu}^{3+}$, após lavagem com metanol; (b) espectro EDS da região mostrada em (a); e (f) perfil de píxeis sobre a linha amarela em (e). 


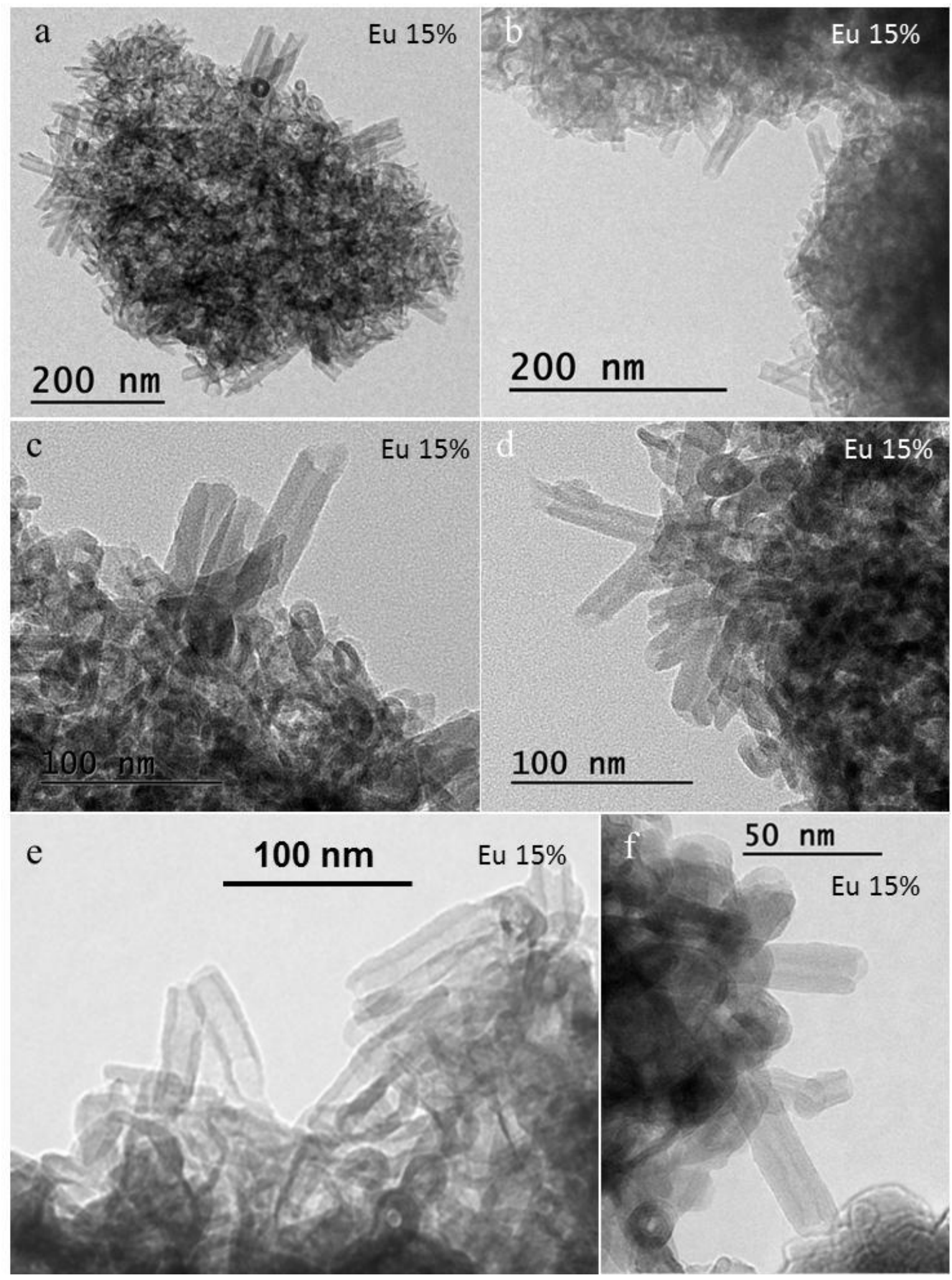

Figura 5.19. Micrografias eletrônicas de transmissão da amostra $\mathrm{Zn}_{2} \mathrm{AlEu}_{15 \%}-\mathrm{BTC}-\mathrm{P} 123$, com $15 \%$ de $\mathrm{Eu}^{3+}$, após lavagem com metanol. 


\subsection{Extração das micelas dos dutos dos nanotubos}

A síntese das nanoestruturas como descrita neste capítulo produz nanotubos com as micelas de P-123 presentes como suporte em seus dutos. Após a formação dos LDHs, no entanto, as micelas podem ser extraídas das cavidades dos tubos através da lavagem da amostra com solventes capazes de dissolver as micelas. Sendo assim, realizamos a lavagem da amostra com metanol anidro em banho ultrassom, como descrito na seção 4.4. Após essa etapa, as amostras são centrifugadas para separar os cristais da solução contendo as micelas retiradas das cavidades dos tubos. Esse processo de lavagem foi repetido por algumas vezes para assegurar uma melhor remoção do polímero. Por fim, a amostra é deixada secar por dois dias novamente em uma estufa a $60^{\circ} \mathrm{C}$.

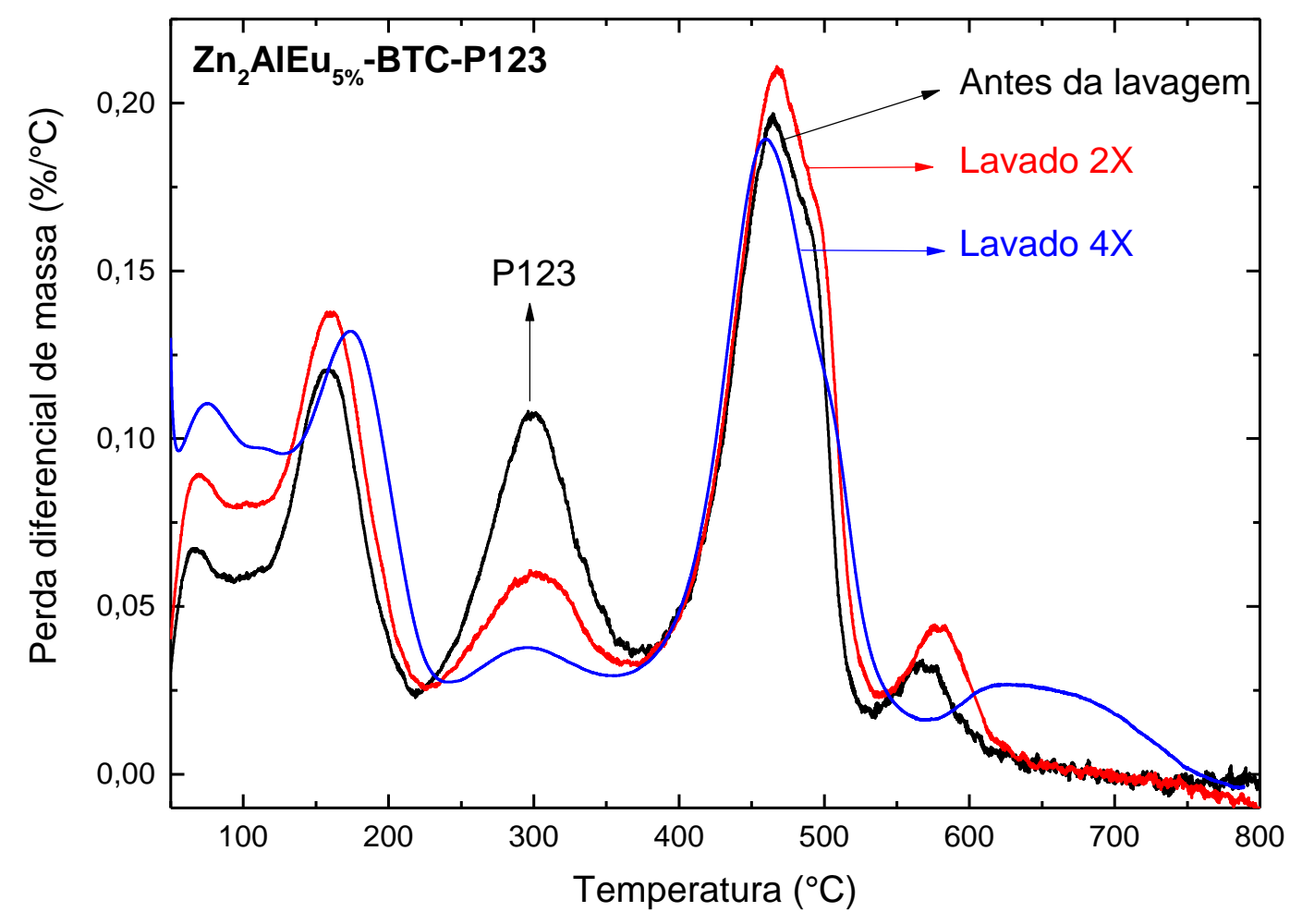

Figura 5.20. Análise termogravimétrica da amostra de nanotubos de LDHs $\mathrm{Zn}_{2} \mathrm{AlEu}_{5 \%}-\mathrm{BTC}-\mathrm{P} 123$ antes e depois da lavagem com metanol.

Para comprovar que a retirada do polímero dos dutos dos nanotubos é realizada de maneira efetiva, as amostras antes e depois da lavagem com metanol foram submetidas à análise termogravimétrica (Figura 5.20). O evento de perda de massa centrado em $460^{\circ} \mathrm{C}$ é atribuído à queima de BTC [137]. Após a lavagem da amostra, observamos a supressão 
gradual do evento de perda de massa ao redor de $300^{\circ} \mathrm{C}$, referente à queima de $\mathrm{P}-123$ presente na amostra [140-142]. Dessa forma, confirmamos que o processo de lavagem com metanol anidro é efetivo na retirada do surfactante, garantindo a acessibilidade dos dutos nos nanotubos.

\subsection{Caracterização da porosidade das amostras sintetizadas com $P-123$}

Para caracterizarmos os poros das amostras $\mathrm{Zn}_{2} \mathrm{AlEu}_{\mathrm{x} \%}$-BTC-P123, isotermas de adsorção-dessorção de Nitrogênio foram medidas e comparadas com a isoterma da amostra $\mathrm{Zn}_{2} \mathrm{Al}_{0.95} \mathrm{Eu}_{0.05}$-BTC, de LDHs planos intercalados com BTC (Figura 5.21).

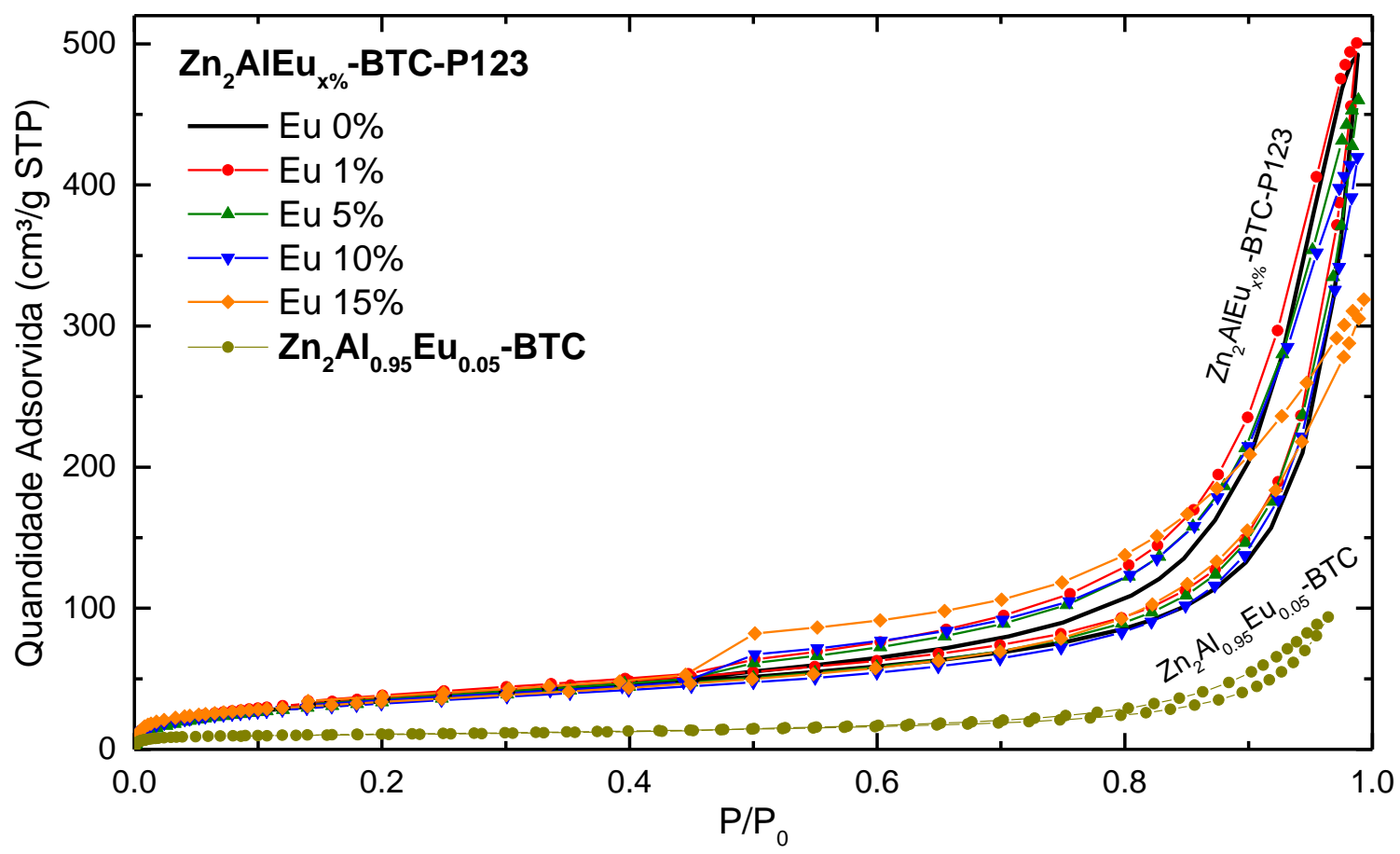

Figura 5.21. Isotermas de adsorção de $\mathrm{N}_{2}$ das amostras $\mathrm{Zn}_{2} \mathrm{AlEu}_{\mathrm{x} \%}$-BTC-P123 após lavagem com metanol e isoterma da amostra de LDHs planos $\mathrm{Zn}_{2} \mathrm{Al}_{0.95} \mathrm{Eu}_{0.05}$-BTC. Todas as isotermas são do tipo IIb, conforme a classificação mostrada na Figura 3.6.

Os poros estreitos e pequenos (microporos) dos LDHs planos estão associados ao espaçamento entre suas lamelas e são capazes de adsorver apenas uma pequena quantidade de gás. A quantidade de gás adsorvida na amostra $\mathrm{Zn}_{2} \mathrm{Al}_{0.95} \mathrm{Eu}_{0.05}-\mathrm{BTC}$ satura rapidamente com o aumento da pressão, com sua isoterma de adsorção apresentando um longo patamar para $0 \lesssim P / P_{0}<0.8$ (Figura 5.21). A elevação da pressão para níveis acima de $P / P_{0} \approx$ 0.8 causa a condensação do gás nos microporos da amostra, com a adsorção de novas 
monocamadas. A condensação causa uma estabilização das moléculas de $\mathrm{N}_{2}$, que, por isso, resistem a sair dos poros no momento da dessorção, causando o formato de histerese da isoterma. A dificuldade de acesso do gás aos microporos da amostra faz com que os LDHs planos possuam baixa área superficial (BET), como mostrado na Tabela 8.

Tabela 8. Dados de porosidade obtidos pela análise das isotermas de adsorção.

\begin{tabular}{|c|c|c|}
\hline Amostra & Área superficial BET $\left(\mathrm{m}^{2} / \mathrm{g}\right)$ & Volume de poros BJH $\left(\mathrm{cm}^{3} / \mathrm{g}\right)$ \\
\hline $\mathrm{Zn}_{2} \mathrm{AlEu}_{5 \%}$-BTC & 24 & 0.14 \\
\hline $\mathrm{Zn}_{2} \mathrm{AlEu}_{0 \%}-\mathrm{BTC}-\mathrm{P} 123$ & 130 & 0.82 \\
\hline $\mathrm{Zn}_{2} \mathrm{AlEu} \mathbf{u}_{1 \%}-\mathrm{BTC}-\mathrm{P} 123$ & 138 & 0.84 \\
\hline $\mathrm{Zn}_{2} \mathrm{AlEu}_{5 \%}-\mathrm{BTC}-\mathrm{P} 123$ & 127 & 0.77 \\
\hline $\mathrm{Zn}_{2} \mathrm{AlEu}_{10 \%}-\mathrm{BTC}-\mathrm{P} 123$ & 120 & 0.70 \\
\hline $\mathrm{Zn}_{2} \mathrm{AlEu}_{15 \%}$-BTC-P123 & 122 & 0.55 \\
\hline
\end{tabular}

Comparando as isotermas das amostras $\mathrm{Zn}_{2} \mathrm{AlEu}_{5 \%}-\mathrm{BTC}-\mathrm{P} 123$ (nanotubos) e $\mathrm{Zn}_{2} \mathrm{AlEu}_{5 \%}$-BTC (LDHs planos), que possuem mesma composição química, mas morfologias diferentes, observamos que, com a formação dos nanotubos de LDHs, há um aumento de cinco vezes na quantidade de gás adsorvido nas amostras (para $P / P_{0}=1$ ), o que é reflexo do aumento de cerca de cinco vezes na área superficial dos LDHs (Tabela 8). Além disso, a histerese nas isotermas das amostras de nanotubos se inicia após $P / P_{0} \approx$ 0.45 , bem abaixo do que foi observado para a amostra de LDHs planos. Visto que os nanotubos, além da microporosidade intrínseca dos LDHs, também apresentam grandes galerias ocas em seu interior (mesoporos), o efeito de condensação do gás nessas estruturas deve ocorrer mais facilmente, já que há espaço suficiente para a deposição de outras monocamadas nessas galerias.

Mesmo para a amostra $\mathrm{Zn}_{2} \mathrm{AlEu}_{0 \%}$-BTC-P123, na qual não foi observada a formação de nanotubos, a área superficial obtida a partir da análise da sua isoterma de adsorçãodessorção é similar àquela das amostras de nanotubos. Observando com cuidado as micrografias eletrônicas de varredura desta amostra, notamos que, apesar de não ter ocorrido a formação de nanotubos, há o aparecimento uma série de fendas nessa amostra cujas dimensões são compatíveis com a aglutinação dos LDHs ao redor das micelas de P123. Algumas dessas fendas estão visíveis na Figura 5.16b. A presença dessas micelas 
funcionariam, portanto, como uma maneira de produzir uma matriz sólida e porosa de LDHs, aumentando sua área superficial mesmo sem a mudança da morfologia das partículas.

A partir da análise das isotermas das amostras $\mathrm{Zn}_{2} \mathrm{AlEu}_{\mathrm{x} \%}$-BTC-P123 é possível obtermos a distribuição de tamanho dos poros em seu interior (Figura 5.22). É possível observarmos que, em todas as amostras analisadas, existe uma grande quantidade de microporos com dimensões da ordem de $2 \mathrm{~nm}$, correspondendo à distância entre as lamelas dos LDHs. Essa característica é independente da morfologia das partículas nas amostras. A análise da região de mesoporosidade $(2 \mathrm{~nm}<$ poro $<50 \mathrm{~nm})$ das amostras é mais complexa e deve ser interpretada em conjunto com os dados de microscopia mostrados nas seções anteriores. A Figura 5.22 mostra que todas as amostras sintetizadas com P-123 apresentam uma fração importante de mesoporos, o que atribuímos estar associados à formação ou agregação dos LDHs ao redor das micelas de P-123. Para concentrações crescentes de $\mathrm{Eu}^{3+}$, no entanto, há uma tendência de crescimento do número de mesoporos nas amostras, sendo claro que, para a amostra com $15 \%$ de $\mathrm{Eu}^{3+}$, existe a formação de mesoporos com dimensões entre 10 e 20 nm, compatíveis com o diâmetro interno esperado dos nanotubos.

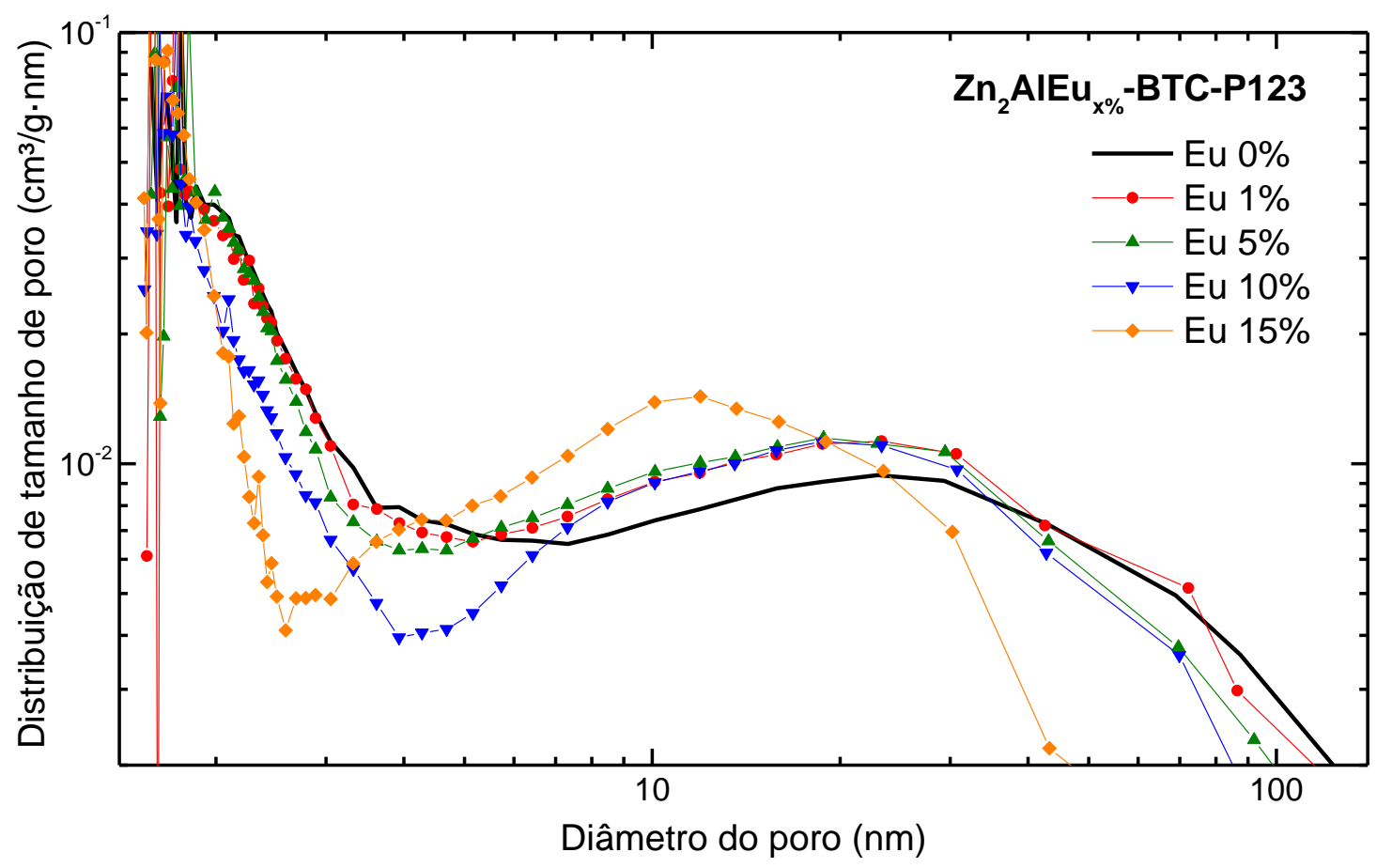

Figura 5.22. Distribuição de tamanho de poros das amostras $\mathrm{Zn}_{2} \mathrm{AlEu}_{\mathrm{x} \%}-\mathrm{BTC}-\mathrm{P} 123$. 


\subsection{Tentativa de síntese de nanotubos com substituição de BTC}

Tentativas de modificação da composição química dos nanotubos de LDHs foram realizadas com a supressão da adição de BTC (amostra $\mathrm{Zn}_{2} \mathrm{AlEu}_{5 \%}-\mathrm{NO}_{3}-\mathrm{P} 123$ ) ou sua substituição equimolar por cloreto a partir da adição de ácido clorídrico (amostra $\mathrm{Zn}_{2} \mathrm{AlEu}_{5 \%}$-Cl-P123). Os difratogramas de raios $\mathrm{X}$ dessas amostras mostram a formação dos LDHs Figura 5.23. Para o material sintetizados após a adição de ácido clorídrico, houve a formação de duas estruturas lamelares distintas, evidenciada pela existência de duas reflexões basais: a primeira, em $2 \theta=10.1^{\circ}(d=8.76 \AA)$, corresponde a LDHs intercalados com $\mathrm{NO}_{3}{ }^{-}$provenientes dos nitratos precursores dos cátions metálicos; a segunda, em $2 \theta=11.5^{\circ}(d=7.69 \AA$ A $)$, corresponde a LDHs contendo íons $\mathrm{Cl}^{-}$adicionados à solução [128]. Com o aumento da concentração de $\mathrm{Cl}^{-}$, verifica-se o aumento da reflexão basal em $2 \theta=11.5^{\circ}$ ante a reflexão em $2 \theta=10.1^{\circ}$. Para o material sintetizado com a supressão da adição de BTC, houve a formação de LDHs intercalados com nitrato $2 \theta=$ $10.1^{\circ}$ e com carbonato proveniente do processo de acidificação da água.

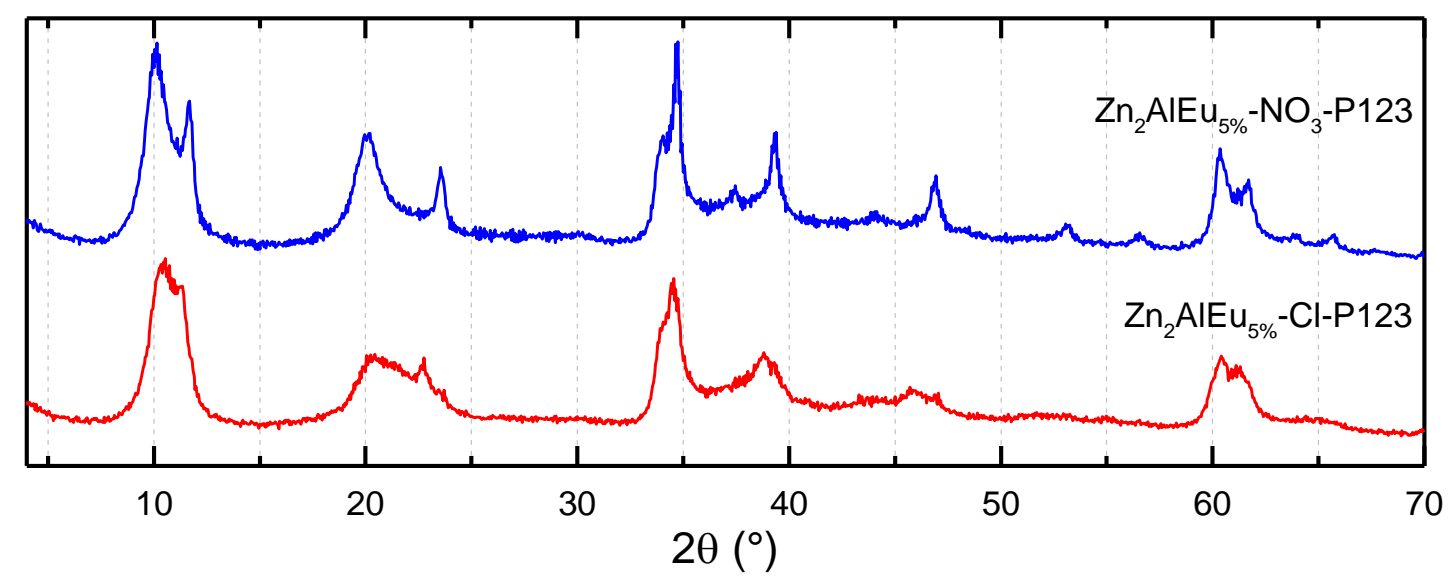

Figura 5.23. Padrões de raios $X$ dos LDHs dopados com $5 \%$ de $\mathrm{Eu}^{3+}$ sintetizados na presença de micelas de P-123 formadas em diferentes pHs pela adição de $\mathrm{HCl}$ em substituição ao BTC.

Apesar da presença de $\mathrm{Eu}^{3+}$ nas amostras $\mathrm{Zn}_{2} \mathrm{AlEu}_{5 \%}-\mathrm{NO}_{3}-\mathrm{P} 123$ e $\mathrm{Zn}_{2} \mathrm{AlEu}_{5 \%}-\mathrm{Cl}-$ P123 e de sua síntese ter ocorrido na presença das micelas de P-123, a análise microscópica dessas amostras (Figura 5.24) mostrou que não foram formados nanotubos, indicando que a presença de BTC é fundamental para a formação dos LDHs na superfície das micelas. 


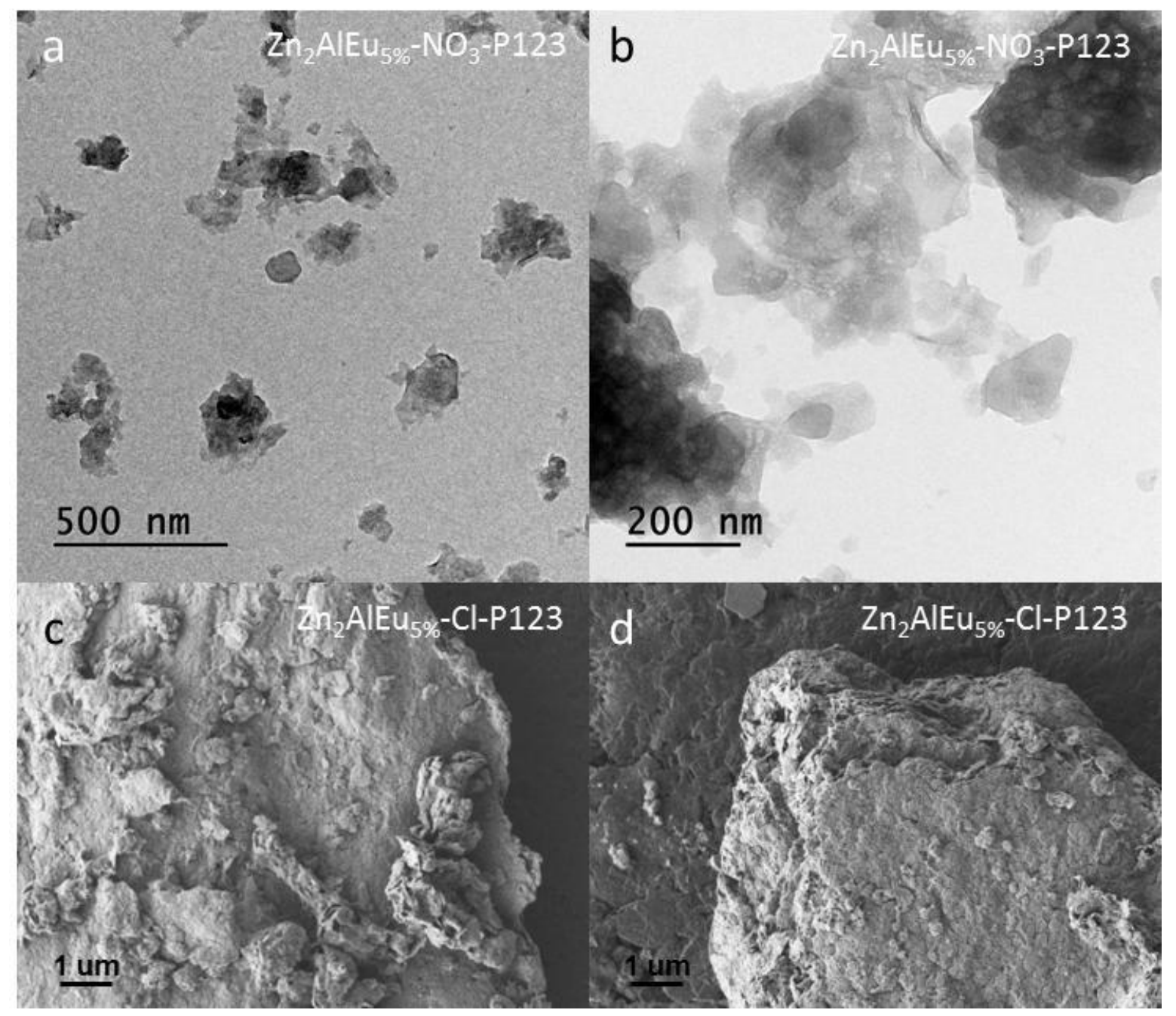

Figura 5.24. (a, b) Micrografias eletrônicas de transmissão da amostra $\mathrm{Zn}_{2} \mathrm{AlEu}_{5} \%-\mathrm{NO}_{3}-\mathrm{P} 123$ e (c, d) micrografias eletrônicas de varredura da amostra $\mathrm{Zn}_{2} \mathrm{AlEu}_{5 \%}-\mathrm{Cl}-\mathrm{P} 123$.

\subsection{O papel do $\mathrm{Eu}^{3+}$ e do BTC na estruturação dos LDHs}

Tentativas de sintetizar nanotubos sem dopagem com íons $\mathrm{Eu}^{3+}$ ou sem a adição de BTC produziram apenas LDHs de morfologia plana, mostrando que a estruturação do material deve ser atribuída a um efeito conjunto da presença de: (i) micelas cilíndricas de P123, (ii) BTC e (iii) $\mathrm{Eu}^{3+}$.

Como discutido na seção 2.1, a adição de solutos em sistemas micelares de P-123 pode causar mudanças no formato das micelas. Ganguly et al. [62] mostraram que, para concentrações de P-123 ligeiramente acima da sua concentração micelar crítica, a adição de sais pode causar a transição das micelas para o formato cilíndrico. No presente trabalho, a formação dos nanotubos de LDHs mostrados nas seções anteriores indica a formação de 
micelas de formato cilíndrico sobre as quais os LDHs são formados. Nesse contexto, a necessidade do BTC para síntese dos nanotubos poderia ser atribuída à indução ou otimização da formação de micelas cilíndricas de P-123 causadas pela adição desse ânion. Um dos papéis do BTC seria, portanto, atuar na própria formação das micelas. Além disso, supomos que a adição de BTC na solução deve formar um conjunto de micelas previamente decoradas com esse ligante, que, por sua afinidade com o íon $\mathrm{Eu}^{3+}$, deve iniciar o processo de formação dos LDHs na superfície daqueles agentes estruturantes. Em um segundo momento, com o crescimento dos LDHs ao redor das micelas, a curvatura das camadas de hidróxidos seria permitida pela presença dos íons $\mathrm{Eu}^{3+}$, que, pelo seu elevado número de coordenação (tipicamente maior que 8) dariam origem a geometrias locais (Figura 5.25) capazes de causar a curvatura das camadas de hidróxidos ao redor das micelas. Sem a presença do íon $\mathrm{Eu}^{3+}$, a curvatura dessas camadas não seria possível, visto que os cátions $\mathrm{Al}^{3+}$ e $\mathrm{Zn}^{2+}$ nos LDHs são hexacoordenantes (número de coordenação 6) com geometria octaédrica ao seu redor. Com o empilhamento compacto (close-packing) dos planos de hidroxilas e de metais nas camadas de hidróxidos, essas unidades octaédricas seriam capazes de formar apenas camadas de morfologia plana, não comportando as curvaturas necessárias para a formação dos nanotubos. Essa interpretação é suportada por observações já reportadas na literatura, nas quais hidróxidos lamelares com fórmula química $\left[\mathrm{TR}^{3+}(\mathrm{OH})_{2.5}\right] \cdot x \mathrm{H}_{2} \mathrm{O} \cdot A_{0.5 / n}^{n-}$ foram sintetizados [143]. Diferentemente dos LDHs planos usuais e como uma consequência da geometria imposta pela coordenação dos íons $\mathrm{TR}^{3+}$, essas estruturas formam camadas de morfologia senoidal, como a mostrada na Figura 5.26B. Esses fatos levam-nos a supor que a morfologia nanotubular dos LDHs deverá também ser conseguida com a substituição do íon $\mathrm{Eu}^{3+}$ por qualquer outro elemento $\mathrm{TR}^{3+}$ da série do Lantânio. 
(a)

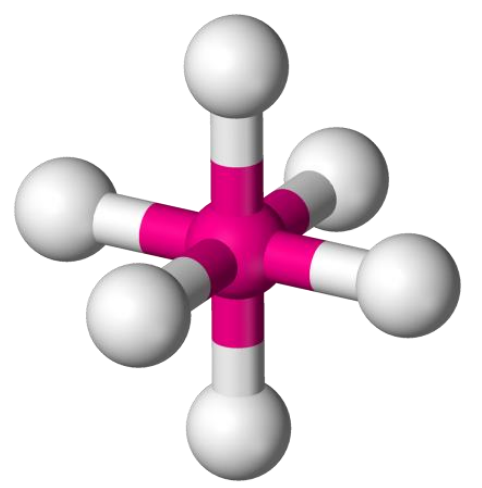

(b)

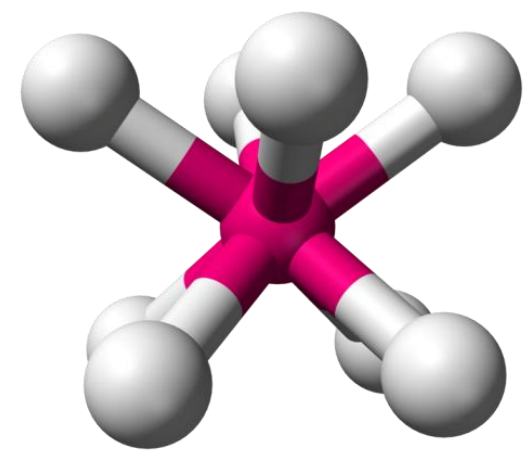

Figura 5.25. Exemplos de geometrias de coordenação permitidas para elementos (em vermelho) com número de coordenação (a) 6 e (b) 8.

Outro fator importante a ser levado em conta na estruturação dos nanotubos é que, como discutimos na seção 5.4, a intercalação de BTC nos LDHs induz uma flexibilização da sequência de empilhamento das camadas de hidróxidos. Devido à curvatura dessas camadas para a formação dos nanotubos, seu empilhamento rígido ao longo da direção radial não seria possível, já que um descompasso entre a posição dos metais ao longo dessa direção seria inevitável devido aos diferentes raios de curvatura em cada camada mais externa na parede dos nanotubos. Como discutido por Duan et al. [124], ânions inorgânicos como o nitrato, o carbonato e o cloreto geram LDHs com sequências de empilhamento muito bem definidas, e, a partir desse entendimento, sua intercalação nos LDHs desfavoreceria a formação dos nanotubos.

A)

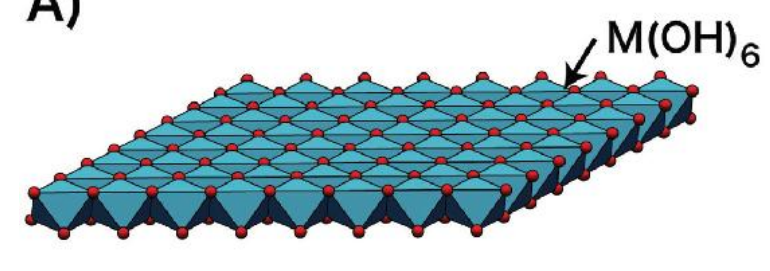

$$
\begin{gathered}
\mathrm{M}^{2+}{ }_{1-\mathrm{x}} \mathrm{M}^{3+}{ }_{\mathrm{x}}(\mathrm{OH})_{2} \mathrm{x+} \\
\mathrm{M}^{2+}=\mathrm{Mg}^{2+}, \mathrm{Co}^{2+}, \mathrm{Ni}^{2+}, \mathrm{Zn}^{2+} \\
\mathrm{M}^{3+}=\mathrm{Al}^{3+}, \mathrm{Co}^{3+}, \mathrm{Fe}^{3+}
\end{gathered}
$$
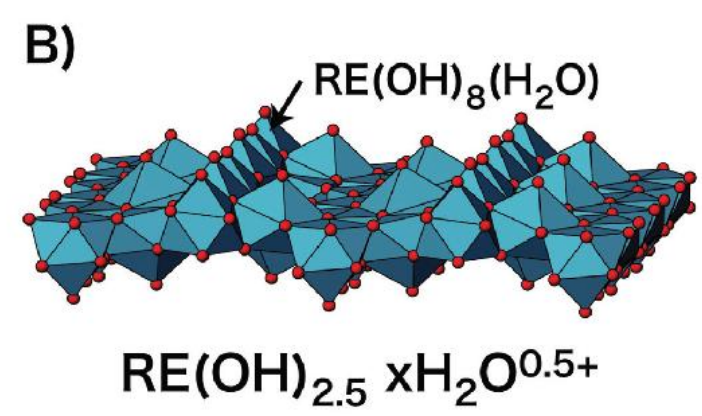

$$
\begin{aligned}
\mathrm{RE}= & \mathrm{Nd}^{3+}, \mathrm{Sm}^{3+}, \mathrm{Eu}^{3+}, \mathrm{Gd}^{3+} \\
& \mathrm{Tb}^{3+}, \mathrm{Dy}^{3+}, \mathrm{Ho}^{3+}, \mathrm{Er}^{3+}
\end{aligned}
$$

Figura 5.26. Camadas de hidróxidos lamelares formados (A) por unidades octaédricas $\left[\mathrm{M}_{1-x}^{2+} M_{x}^{3+}(\mathrm{OH})_{6}\right]$ e (B) por unidades mais coordenantes $\left[\mathrm{TR}^{3+}(\mathrm{OH})_{2.5}\right][143]$. 


\subsection{Propriedades luminescentes dos nanotubos de LDHs}

Para demonstrar as propriedades luminescentes dos nanotubos de LDHs mostrados nas seções anteriores, seus espectros de emissão e excitação foram analisados. Alguns espectros selecionados estão mostrados nas Figuras 5.27, 5.28 e 5.29.

Os espectros de excitação mostrados na Figura $\mathbf{5 . 2 7}$ foram medidos sob monitoramento da transição $\left(\mathrm{Eu}^{3+}\right){ }^{5} D_{0} \rightarrow{ }^{7} F_{2}\left(\lambda_{\mathrm{em}}=614 \mathrm{~nm}\right)$ do íon $\mathrm{Eu}^{3+}$. Assim como no caso dos LDHs de morfologia plana da seção 5.6, esses espectros mostram a banda de excitação do BTC (centrada em $294 \mathrm{~nm}$ ) com posterior transferência de energia para os íons $\mathrm{Eu}^{3+}$ nas camadas de hidróxidos. Com o aumento da quantidade de $\mathrm{Eu}^{3+}$ nos LDHs, ocorre um aumento da intensidade relativa das bandas de excitação direta desse íon.

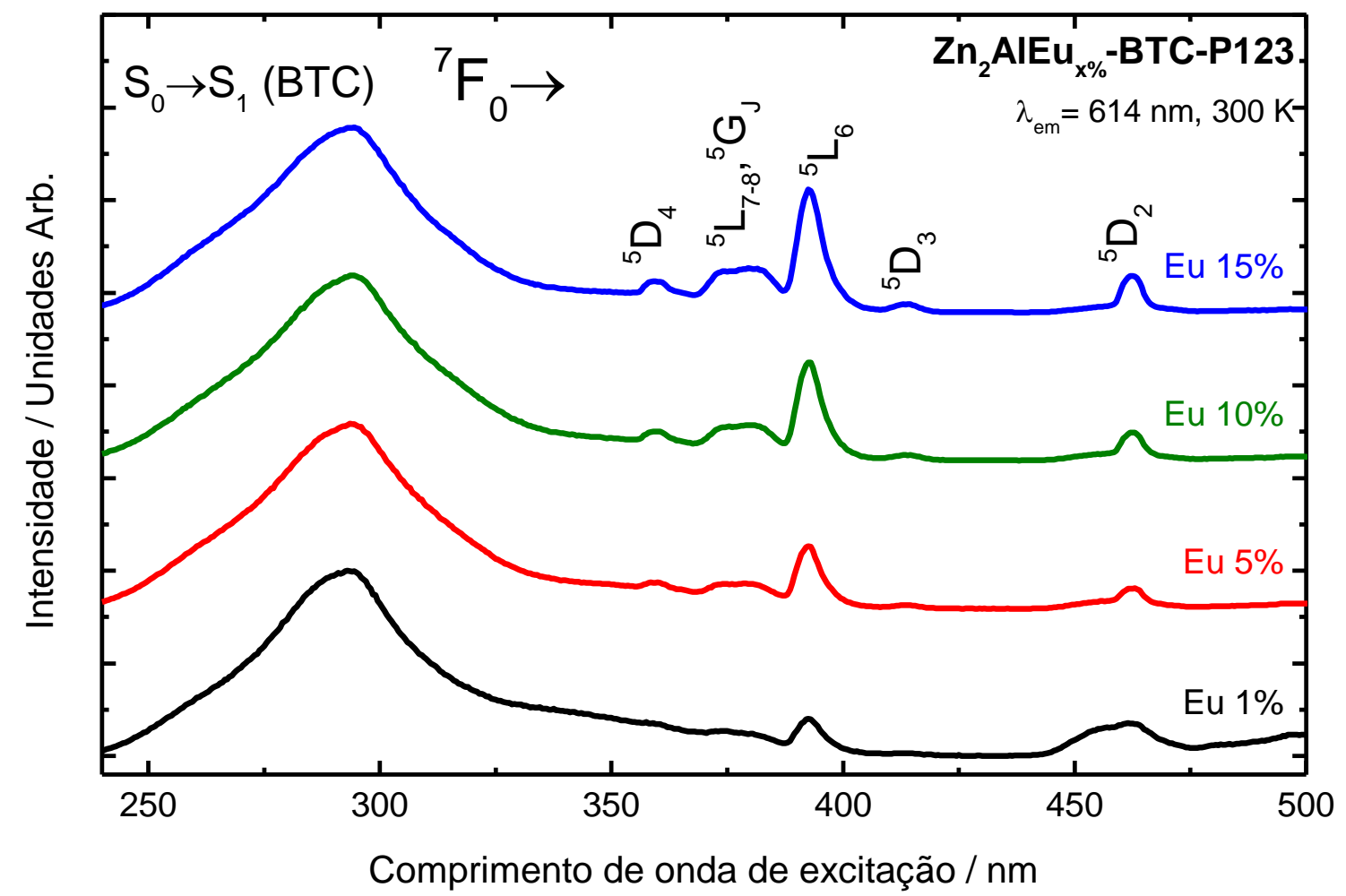

Figura 5.27. Espectros de excitação (normalizados pelo máximo da banda $S_{0} \rightarrow S_{1}$ do BTC) dos nanotubos de LDHs com $1 \%, 5 \%, 10 \%$ e $15 \%$ de Eu ${ }^{3+}$ sob monitoramento da transição $\left(\mathrm{Eu}^{3+}\right)^{5} D_{0} \rightarrow{ }^{7} F_{2}\left(\lambda_{\text {em }}=614 \mathrm{~nm}\right)$ e com a identificação dos níveis eletrônicos envolvidos nas transições.

A emissão dos nanotubos após a excitação do BTC em 294 nm (Figura 5.28) foi analisada. Com a excitação do ligante e seu relaxamento para o nível tripleto $\mathrm{T}_{1}$ (Figura 2.12 e Figura 5.11), a energia do sistema é transferida para os cátions $\mathrm{Eu}^{3+}$, que, relaxando 
até o nível emissor ${ }^{5} \mathrm{D}_{0}$, emite nos comprimentos de onda correspondentes às transições $\left(\mathrm{Eu}^{3+}\right){ }^{5} D_{0} \rightarrow{ }^{7} F_{J}(\mathrm{~J}=0-6)$, como observado no espectro da Figura 5.28. A elevada intensidade de ambas as transições $\left(\mathrm{Eu}^{3+}\right){ }^{5} D_{0} \rightarrow{ }^{7} F_{2}$ e $\left(\mathrm{Eu}^{3+}\right){ }^{5} D_{0} \rightarrow{ }^{7} F_{4}$ quando comparadas com a intensidade da transição de dipolo magnético $\left(\mathrm{Eu}^{3+}\right){ }^{5} D_{0} \rightarrow{ }^{7} F_{1}$ indica que o íon $\mathrm{Eu}^{3+}$ está localizado em sítios sem simetria de inversão, como é descrito pela teoria de Judd-Ofelt. A inexistência de emissão do ligante mostra que a transferência de energia $\mathrm{BTC} \rightarrow \mathrm{Eu}^{3+}$ nesse sistema é bastante eficiente. Independentemente da concentração de $\mathrm{Eu}^{3+}$ nos nanotubos de LDHs, esse cátion exibe perfis de emissão bastante similares, indicando que, em todos esses materiais, o íon $\mathrm{Eu}^{3+}$ se encontra em ambientes químicos similares. Além disso, é interessante notar que, mesmo sob excitação direta do íon $\mathrm{Eu}^{3+} \mathrm{em}$ uma de suas transições 4f-4f, o perfil de emissão desse íon (Figura 5.29) é praticamente idêntico àquele observado sob excitação do ligante, demonstrando uma característica notável dos íons terras raras trivalentes. Como descrito pela teoria de Judd-Ofelt: a emissão desses cátions apenas depende da simetria e do ambiente químico ao qual eles estão expostos.

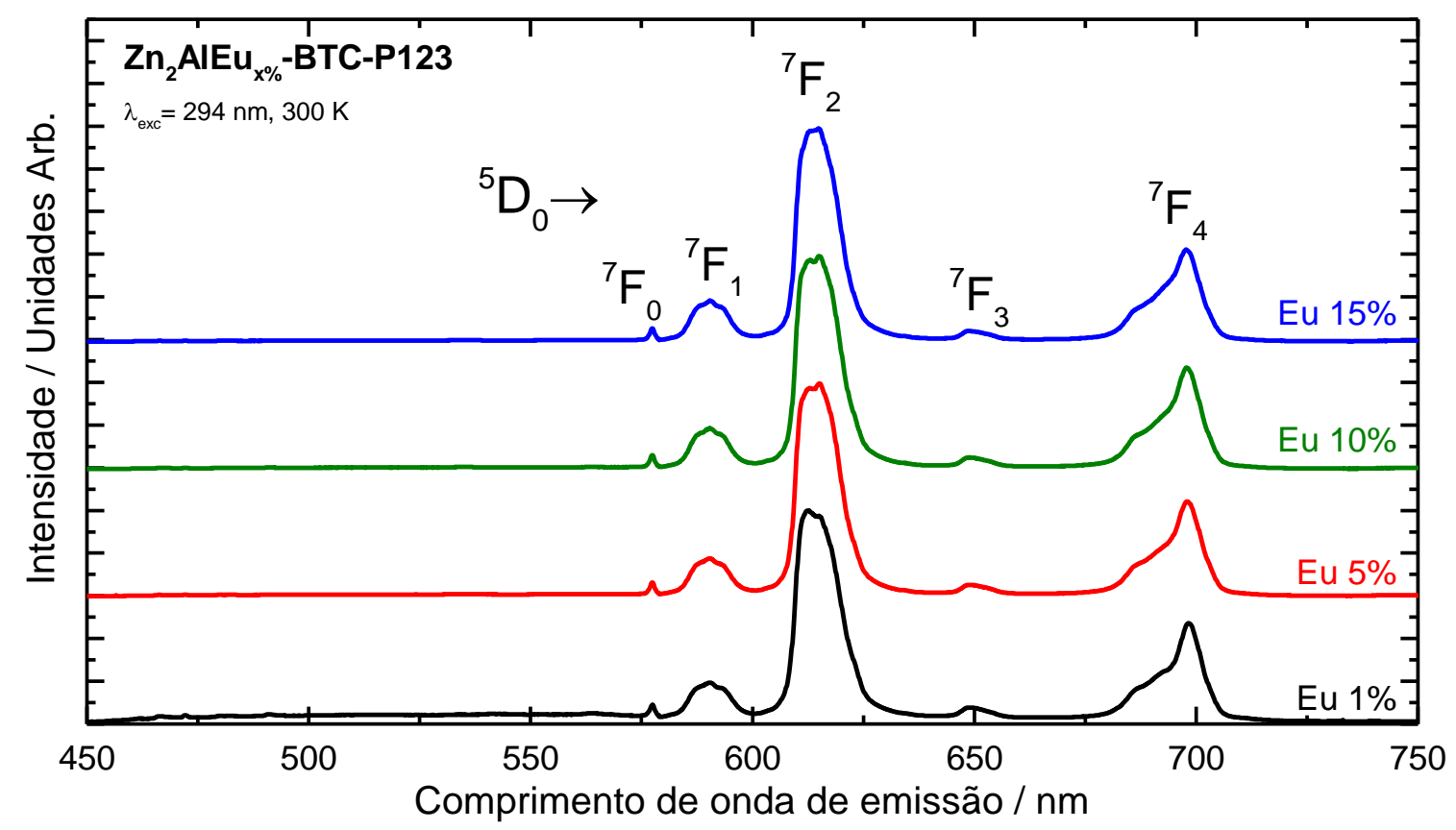

Figura 5.28. Emissão dos nanotubos de LDHs para excitação no centro da banda de excitação do BTC (294 $\mathrm{nm})$. Os picos de emissão são característicos das transições $4 \mathrm{f}-4 \mathrm{f}$ do íon $\mathrm{Eu}^{3+}$. A inexistência de emissão do ligante mostra que a transferência de energia $\mathrm{BTC} \rightarrow \mathrm{Eu}^{3+}$ é bastante eficiente. Os espectros foram normalizados pelo máximo da banda $\left(\mathrm{Eu}^{3+}\right)^{5} D_{0} \rightarrow{ }^{7} F_{2}$. 
Os espectros de emissão dos LDHs mostrados na Figura 5.28 não apresentam a emissão do próprio BTC (entre $450 \mathrm{~nm}$ e $550 \mathrm{~nm}$ ), mostrando que a energia absorvida pela molécula fotossensibilizadora é transferida para o íon $\mathrm{Eu}^{3+}$ de maneira eficiente, comprovando que o BTC possui um bom desempenho como molécula antena nesse sistema. Sob excitação direta do íon $\mathrm{Eu}^{3+}$ (Figura 5.29), no entanto, é possível observarmos uma banda de emissão de baixa intensidade na região de fosforescência do ligante, contrastando com o que é observado sob a excitação direta do BTC. Esse fato já foi observado em outros sistemas, mas ainda não foi bem explicado pela literatura.

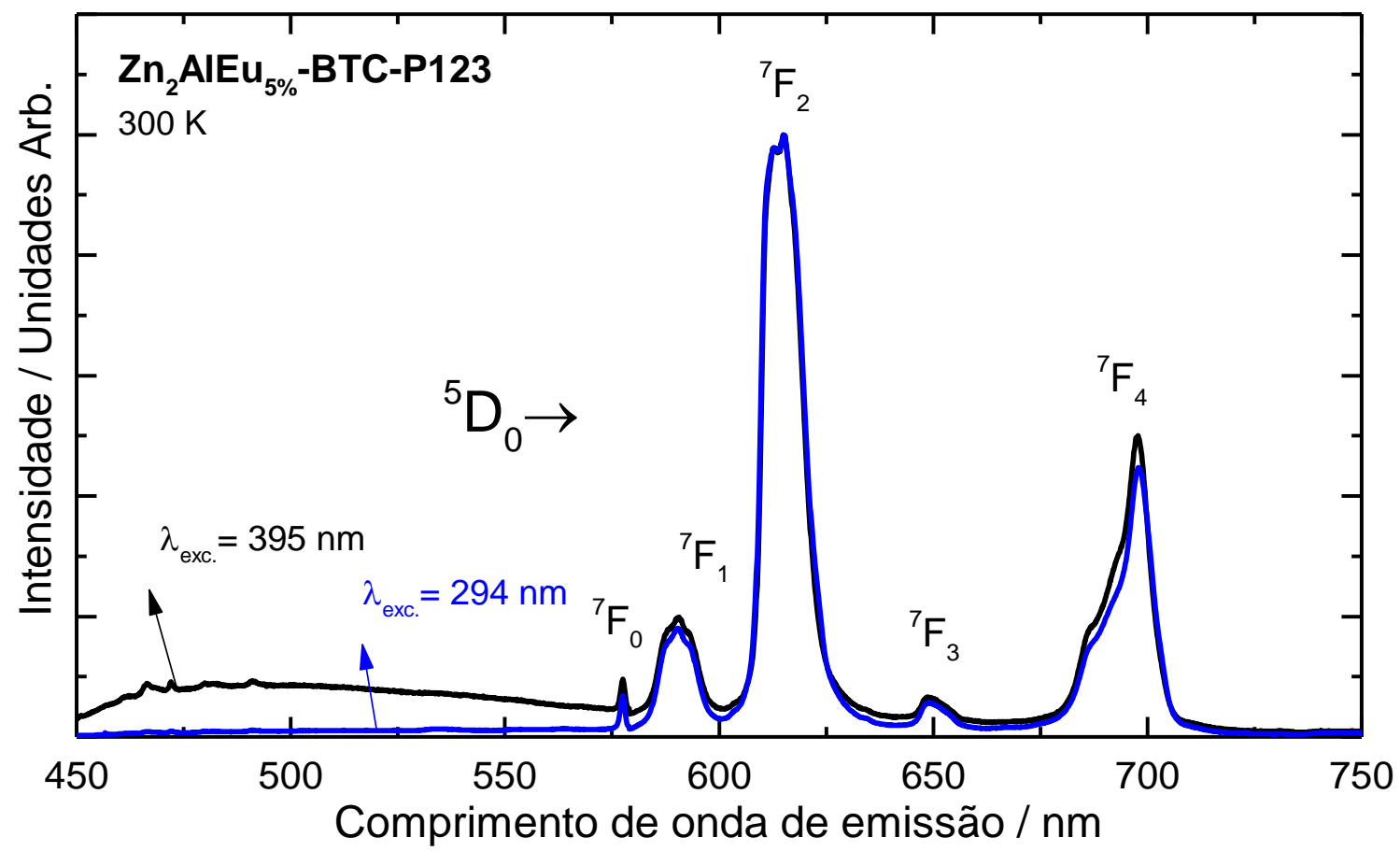

Figura 5.29. Comparação entre os espectros de emissão da amostra de nanotubos $\mathrm{Zn}_{2} \mathrm{AlEu}_{5 \%}$-BTC-P123 após excitação na banda do BTC (294 nm) e excitação direta da transição $\left(\mathrm{Eu}^{3+}\right)^{7} F_{0} \rightarrow{ }^{5} L_{6}(395 \mathrm{~nm})$ do íon $\mathrm{Eu}^{3+}$. Os espectros foram normalizados pelo máximo da banda $\left(\mathrm{Eu}^{3+}\right)^{5} D_{0} \rightarrow{ }^{7} F_{2}$.

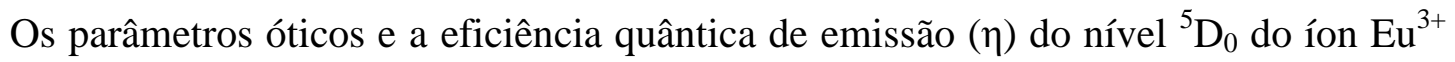
nas amostras $\mathrm{Zn}_{2} \mathrm{AlEu}_{\mathrm{x} \%}$-BTC-P123 foram analisados à luz da teoria de Judd-Ofelt (Tabela 9). Os resultados são similares aos obtidos para LDHs de morfologia plana intercalados com BTC (vide seção 5.6). O valor elevado dos parâmetros $\Omega_{2}$ e $\Omega_{4}$ em todas as amostras de nanotubos analisadas indica que a intercalação do BTC nos LDHs causa distorções importantes na simetria ao redor do íon $\mathrm{Eu}^{3+}$, o que relaxa a proibição das suas transições 4f-4f, diminuindo o tempo de vida radiativo do nível emissor ${ }^{5} \mathrm{D}_{0}$. Esse efeito é responsável 
por aumentar em três vezes a eficiência quântica de emissão desse nível. Atribuímos a distorção da simetria ao redor do íon $\mathrm{Eu}^{3+}$ à forte atração eletrostática entre esse íon e o BTC, que deve causar simultaneamente: (i) um deslocamento do centro metálico na direção do ligante e (ii) a repulsão dos grupos hidroxilas ao redor do $\mathrm{Eu}^{3+}$. Em tese, essas deformações seriam capazes de remover a simetria de inversão ao redor do íon emissor, elevando $\Omega_{2}$ e $\Omega_{4}$ da maneira observada. Não observamos nenhum efeito nas propriedades luminescentes do material após sua estruturação na forma de nanotubos. Também não observamos mudanças na eficiência quântica com o aumento da concentração de $\mathrm{Eu}^{3+}$ nas amostras, indicando que a inserção deste elemento terra rara nos LDHs causa apenas distorções locais na rede cristalina do material, em consonância com o que já foi observado a partir de seus difratogramas de raios $\mathrm{X}$.

Tabela 9. Parâmetros óticos das amostras de nanotubos $\mathrm{Zn}_{2} \mathrm{AlEu} \mathrm{u}_{\mathrm{x}}-\mathrm{BTC}-\mathrm{P123}$

\begin{tabular}{|c|c|c|c|c|c|c|c|c|c|}
\hline $\mathbf{E} \mathbf{u}^{3+}$ & $\begin{array}{c}\Omega_{2} \\
\left(10^{-20} \mathrm{~cm}^{2}\right)\end{array}$ & $\begin{array}{c}\Omega_{4} \\
\left(10^{-20} \mathrm{~cm}^{2}\right)\end{array}$ & $\begin{array}{l}A_{\text {rad }} \\
\left(s^{-1}\right)\end{array}$ & $\begin{array}{c}A_{\text {nrad }} \\
\left(s^{-1}\right)\end{array}$ & $\begin{array}{l}\mathbf{A}_{\text {tot }} \\
\left(\mathbf{s}^{-1}\right)\end{array}$ & $\begin{array}{l}\tau_{\text {rad }} \\
(\mathbf{m s})\end{array}$ & $\begin{array}{l}\tau_{\text {nrad }} \\
(\mathbf{m s})\end{array}$ & $\begin{array}{c}\tau \\
(\mathrm{ms})\end{array}$ & $\begin{array}{c}\eta \\
(\%)\end{array}$ \\
\hline $1 \%$ & 13.9 & 13.9 & 675 & 2896 & 3571 & 1.48 & 0.35 & 0.28 & 18.9 \\
\hline $5 \%$ & 13.9 & 13.8 & 675 & 2773 & 3448 & 1.48 & 0.36 & 0.29 & 19.6 \\
\hline $10 \%$ & 13.0 & 13.8 & 648 & 2924 & 3571 & 1.54 & 0.34 & 0.28 & 18.1 \\
\hline $15 \%$ & 12.4 & 12.9 & 616 & 2831 & 3448 & 1.62 & 0.35 & 0.29 & 17.9 \\
\hline
\end{tabular}




\section{Conclusões}

Modificações químicas e morfológicas nos hidróxidos duplos lamelares podem levar ao remodelamento das suas propriedades físico-químicas. No presente trabalho, utilizamonos da versatilidade de composição química desses materiais para produzir uma série de amostras com propriedades diferenciadas. Enquanto a inclusão de cátions $\mathrm{Eu}^{3+}$ nas camadas de hidróxidos produziu LDHs com propriedades luminescentes, a utilização da estrutura lamelar para promover a intercalação da molécula fotossensibilizadora ácido benzeno1,3,5-tricarboxílico (BTC) foi capaz de melhorar sensivelmente a luminescência desses materiais. A absorção da radiação eletromagnética pelo ligante, mais eficiente que a absorção direta pelo íon terra rara, é capaz de popular os níveis excitados do $\mathrm{Eu}^{3+}$ através da transferência de energia $\mathrm{BTC} \rightarrow \mathrm{Eu}^{3+}$. Esse bombeamento inicial se beneficia, em seguida, da distorção da simetria ao redor do sítio do terra rara, causada pela presença do ligante em sua vizinhança.

A análise dos parâmetros de Judd-Ofelt de LDHs contendo $\mathrm{Eu}^{3+}$ e intercalados com BTC mostrou que a presença dessa molécula aumenta em mais de três vezes a eficiência quântica de emissão do terra rara. Atribuímos esse efeito à atração eletrostática com a qual os grupos carboxílicos do BTC atraem (deslocam) os sítios metálicos nas camadas de hidróxidos ao mesmo tempo em que repelem os grupos hidroxilas ao seu redor. Essas distorções seriam capazes de adicionar termos ímpares ao campo cristalino ao qual o cátion $\mathrm{Eu}^{3+}$ está sujeito, criando misturas de paridade em seus estados quânticos, o que tornariam algumas transições $4 \mathrm{f}-4 \mathrm{f}$ deste íon permitidas por dipolo elétrico forçado, diminuindo a drenagem da energia por rotas não radiativas. Este estudo produziu os LDHs contendo $\mathrm{Eu}^{3+}$ com a maior eficiência quântica já demonstrada até o presente momento. Um artigo com os resultados foi submetido para publicação.

Além de produzir propriedades luminescentes interessantes nos LDHs, a presença de $\mathrm{Eu}^{3+}$ e BTC nesses materiais também causou mudanças estruturais bastante intrigantes. A intercalação de BTC alterou o formato das reflexões de Bragg (10l) e (01l) dos LDHs, produzindo um formato de "barbatana de tubarão", atribuído na literatura como sendo originado por incompatibilidades geométricas entre a posição dos cátions nas camadas de hidróxidos e a posição das cargas negativas dos ânions intercalados. Essa incompatibilidade 
seria responsável por forçar o empilhamento turbostrático das camadas dos LDHs, com deslocamentos e rotações (torções) entre camadas adjacentes, causando uma diminuição do ordenamento dos cátions na direção $\vec{c}$. A inserção de $\mathrm{Eu}^{3+}$, por sua vez, causa distorções adicionais na rede cristalina dos LDHs devido a sua alta capacidade de coordenação se

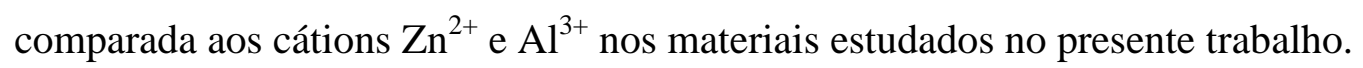

A síntese de LDHs contendo $\mathrm{Eu}^{3+}$ e BTC na presença de micelas cilíndricas do surfactante P-123 causou uma mudança brusca na morfologia dos LDHs. A utilização simultânea desses três ingredientes causou a formação de nanotubos sobre as micelas de P123, uma morfologia inédita na literatura de hidróxidos lamelares. Após a lavagem com metanol em banho ultrassom para a retirada das micelas, a caracterização das amostras através de técnicas de microscopia eletrônica mostrou a formação de uma rede de nanotubos cilíndricos, ocos e interconectados, com diâmetro $\emptyset 20 \mathrm{~nm}$, espessura de $5 \mathrm{~nm}$ e comprimentos $\gtrsim 100 \mathrm{~nm}$, formados pela deposição de multicamadas de hidróxidos duplos intercalados com BTC. A formação desses nanotubos elevou em cerca de cinco vezes a área superficial dos LDHs, quando comparamos com o mesmo material em sua morfologia plana. A formação dessas estruturas foi discutida por nós em um artigo publicado recentemente no periódico Chemical Communications ${ }^{17}$. Recentemente, também submetemos, através da Agência USP de Inovação (AUSPIN), um pedido de patente dos nanotubos e do seu processo de síntese. O pedido está sob análise do Instituto Nacional da Propriedade Industrial (INPI) sob o número BR 1020180092669.

Alguns comentários extras sobre a estruturação dos LDHs na forma de nanotubos são pertinentes. Tentativas de sintetizar nanotubos sem a presença de $\mathrm{Eu}^{3+}$ ou sem a adição de BTC produziram apenas LDHs de morfologia plana, mostrando que a estruturação do material deve ser atribuída a um efeito conjunto da presença de: (i) micelas cilíndricas de P123, (ii) $\mathrm{BTC}$ e (iii) $\mathrm{Eu}^{3+}$. Com base nos resultados mostrados no presente trabalho, apontamos quatro hipóteses que, em conjunto, podem ajudar a explicar o papel desses ingredientes na formação dos nanotubos:

(I) como discutido, a própria formação das micelas cilíndricas de P-123 é possivelmente otimizado pela adição de BTC, que deve acelerar o processo de

\footnotetext{
${ }^{17}$ Morais et al. Chem. Commun., 2017, 53,7341. DOI: 10.1039/c7cc02097j.
} 
transição de micelas esféricas para micelas cilíndricas, analogamente com o que já foi relatado na literatura para outros ânions;

(II) supomos que a adição de BTC na solução deve formar um conjunto de micelas previamente decoradas com esse ligante, que, por sua afinidade com o íon $\mathrm{Eu}^{3+}$, deve iniciar o processo de formação dos LDHs na superfície daqueles agentes estruturantes;

(III) o crescimento dos LDHs ao redor das micelas seria permitido pela presença dos íons $\mathrm{Eu}^{3+}$, que, pelo seu elevado número de coordenação (tipicamente maior que 8) dariam origem a geometrias locais capazes de causar a curvatura das camadas de hidróxidos ao seu redor; e

(IV) a flexibilização da sequência de empilhamento das camadas de hidróxidos causada pela intercalação com BTC seria capaz de acomodar o descompasso entre a posição dos metais ao longo da direção radial dos nanotubos, fato que seria inevitável frente aos diferentes raios de curvatura em cada camada mais externa na parede dos nanotubos.

Desvendar o mecanismo de formação dos nanotubos certamente não é uma tarefa fácil, mas acreditamos que os desenvolvimentos e interpretações que fizemos até agora possam ser melhoradas e/ou refinadas por experimentos que realizaremos no futuro. Além disso, esperamos que a divulgação desse trabalho possa levantar a discussão sobre as aplicações que possam seguir dessa nova morfologia de LDHs. Possivelmente, outras morfologias possam ser conseguidas com a combinação de cátions $\mathrm{TR}^{3+}$ com outros ligantes e micelas de outros formatos. Visto que os íons terras raras trivalentes possuem propriedades químicas semelhantes, acreditamos que ao menos a estrutura nanotubular deve ser mantida com a substituição de $\mathrm{Eu}^{3+}$ por outros elementos dessa série. 


\section{Referências Bibliográficas}

[1]. M. Ochs, J. R. Nyengaard, A. Jung, L. Knudsen, M. Voigt et al. The Number of Alveoli in the Human Lung. American Journal of Respiratory and Critical Care Medicine, 169(1), 120-124. (2004) DOI:10.1164/rccm.200308-1107OC

[2]. G. J. Tortora and B. H. Derrickson. Principles of anatomy and physiology (15th ed.). John Wiley \& Sons. (2017)

[3]. E. T. C. Vogt and B. M. Weckhuysen. Fluid catalytic cracking: recent developments on the grand old lady of zeolite catalysis. Chemical Society Reviews, 44(20), 7342-7370. (2015) DOI:10.1039/C5CS00376H

[4]. B. M. Weckhuysen and J. Yu. Recent advances in zeolite chemistry and catalysis. Chemical Society Reviews, 44(20), 7022-7024. (2015) DOI:10.1039/C5CS90100F

[5]. T. Ennaert, J. Van Aelst, J. Dijkmans, R. De Clercq, W. Schutyser et al. Potential and challenges of zeolite chemistry in the catalytic conversion of biomass. Chemical Society Reviews, 45(3), 584-611. (2016) DOI:10.1039/C5CS00859J

[6]. J. Shi, Y. Wang, W. Yang, Y. Tang and Z. Xie. Recent advances of pore system construction in zeolite-catalyzed chemical industry processes. Chemical Society Reviews, 44(24), 8877-8903. (2015) DOI:10.1039/C5CS00626K

[7]. N. Rangnekar, N. Mittal, B. Elyassi, J. Caro and M. Tsapatsis. Zeolite membranes a review and comparison with MOFs. Chemical Society Reviews, 44(20), 71287154. (2015) DOI:10.1039/C5CS00292C

[8]. C. Gomes Silva, Y. Bouizi, V. Fornés and H. García. Layered double hydroxides as highly efficient photocatalysts for visible light oxygen generation from water. Journal of the American Chemical Society, 131(38), 13833-13839. (2009) DOI: $10.1021 / \mathrm{ja} 905467 \mathrm{v}$

[9]. J. Liu, Y. Li, X. Huang, G. Li and Z. Li. Layered Double Hydroxide Nano- and Microstructures Grown Directly on Metal Substrates and Their Calcined Products for Application as Li-Ion Battery Electrodes. Advanced Functional Materials, 18(9), 1448-1458. (2008) DOI:10.1002/adfm.200701383

[10]. D. Kubo, K. Tadanaga, A. Hayashi and M. Tatsumisago. Improvement of electrochemical performance in alkaline fuel cell by hydroxide ion conducting Ni-Al layered double hydroxide. Journal of Power Sources, 222, 493-497. (2013) DOI:10.1016/jjpowsour.2012.08.093

[11]. X. Liu, R. Ma, Y. Bando and T. Sasaki. A general strategy to layered transitionmetal hydroxide nanocones: tuning the composition for high electrochemical performance. Advanced Materials, 24(16), 2148-2153. (2012) DOI:10.1002/adma.201104753

[12]. J. H. Lee, J. Chang, J. H. Cha, D. Y. Jung, S. S. Kim et al. Anthraquinone sulfonate modified, layered double hydroxide nanosheets for dye-sensitized solar cells. Chemistry - A European Journal, 16, 8296-8299. (2010) DOI:10.1002/chem.201000703

[13]. L. Zhang, J. Liu, H. Xiao, D. Liu, Y. Qin et al. Preparation and properties of mixed metal oxides based layered double hydroxide as anode materials for dyesensitized solar cell. Chemical Engineering Journal, 250, 1-5. (2014) DOI:10.1016/j.cej.2014.03.098

[14]. K. H. Goh, T. T. Lim and Z. Dong. Application of layered double hydroxides for 
removal of oxyanions: A review. Water Research, 42(6-7), 1343-1368. (2008) DOI:10.1016/j.watres.2007.10.043

[15]. V. R. L. Constantino and T. J. Pinnavaia. Basic Properties of $\mathbf{M g}^{2+}{ }_{1-x} \mathbf{A l}^{3+}{ }_{\mathbf{x}}$ Layered Double Hydroxides Intercalated by Carbonate, Hydroxide, Chloride, and Sulfate Anions. Inorganic Chemistry, 34(4), 883-892. (1995) DOI:10.1021/ic00108a020

[16]. E. L. Crepaldi and J. B. Valim. Hidróxidos duplos lamelares: Síntese, estrutura, propriedades e aplicações. Quimica Nova, 21(3), 300-311. (1998) DOI:10.1590/S0100-40421998000300011

[17]. V. R. R. Cunha, A. M. Ana, V. R. L. Constantino, J. Tronto and J. B. Valim. Hidróxidos duplos lamelares: Nanopartículas inorgânicas para armazenamento e liberação de espécies de interesse biológico e terapêutico. Quimica Nova, 33(1), 159-171. (2010) DOI:10.1590/S0100-40422010000100029

[18]. T. Kameda, T. Shimmyo and T. Yoshioka. Preparation of Zn-Al layered double hydroxide intercalated with triethylenetetramine-hexaacetic acid by coprecipitation: uptake of rare-earth metal ions from aqueous solutions. $R S C$ Adv., 4(86), 45995-46001. (2014) DOI:10.1039/C4RA06795A

[19]. P. Gunawan and R. Xu. Lanthanide-doped layered double hydroxides intercalated with sensitizing anions: Efficient energy transfer between host and guest layers. Journal of Physical Chemistry C, 113(39), 17206-17214. (2009) DOI:10.1021/jp905884n

[20]. A. W. Musumeci, Z. P. Xu, S. V Smith, R. F. Minchin and D. J. Martin. Layered double hydroxide nanoparticles incorporating terbium: applicability as a fluorescent probe and morphology modifier. Journal of Nanoparticle Research, 12(1), 111-120. (2010) DOI:10.1007/s11051-008-9583-9

[21]. N. G. Zhuravleva, A. A. Eliseev, A. V Lukashin, U. Kynast and Y. D. Tret'yakov. Luminescent Materials Based on Tb- and Eu-Containing Layered Double Hydroxides. Doklady Chemistry, 396(1), 87-91. (2004) DOI:10.1023/B:DOCH.0000029538.18156.62

[22]. J. Wang, Q. Pan, Q. Liu, Y. He, T. Mann et al. Synthesis and photoluminescence properties of europium doped $\mathrm{Mg}-\mathrm{Al}$ layered double hydroxides intercalated with $\mathrm{MoO}_{4}{ }^{2-}$ anions. Solid State Sciences, 14(5), 562-566. (2012) DOI:https://doi.org/10.1016/j.solidstatesciences.2012.01.004

[23]. X. Gao, J. Xie, Y. Yin, Y. Hao and Y. Lian. Study of the Structure and Luminescent Properties of Terbium Complex Intercalated Zn/Al Layered Double Hydroxide. Russian Journal of Physical Chemistry A, 90(1), 36-244. (2016) DOI:10.1134/S0036024415120328

[24]. L. Sarakha, C. Forano and P. Boutinaud. Intercalation of luminescent Europium(III) complexes in layered double hydroxides. Optical Materials, 31(3), 562-566. (2009) DOI:10.1016/j.optmat.2007.10.018

[25]. X. Gao, M. Hu, L. Lei, D. O'Hare, C. Markland et al. Enhanced luminescence of europium-doped layered double hydroxides intercalated by sensitiser anions. Chem. Commun., 47(7), 2104-2106. (2011) DOI:10.1039/C0CC04123H

[26]. S. Gago, M. Pillinger, R. A. Sá Ferreira, L. D. Carlos, T. M. Santos et al. Immobilization of Lanthanide Ions in a Pillared Layered Double Hydroxide. Chemistry of Materials, 17(23), 5803-5809. (2005) DOI:10.1021/cm051431p

[27]. X. Chen, F. Mi, H. Zhang and H. Zhang. Facile synthesis of a novel magnetic core- 
shell hierarchical composite submicrospheres $\mathrm{Fe}_{3} \mathrm{O}_{4} @ \mathrm{CuNiAl-LDH}$ under ambient conditions. Materials Letters, 69, 48-51. (2012) DOI:10.1016/J.MATLET.2011.11.052

[28]. L. Li, Y. Feng, Y. Li, W. Zhao and J. Shi. $\mathrm{Fe}_{3} \mathrm{O}_{4}$ Core/Layered Double Hydroxide Shell Nanocomposite: Versatile Magnetic Matrix for Anionic Functional Materials. Angewandte Chemie International Edition, 48(32), 5888-5892. (2009) DOI: 10.1002/anie.200901730

[29]. Z. Gu, J. J. Atherton and Z. P. Xu. Hierarchical layered double hydroxide nanocomposites: structure, synthesis and applications. Chemical Communications, 51(15), 3024-3036. (2015) DOI:10.1039/C4CC07715F

[30]. L. Huang, D. Chen, Y. Ding, S. Feng, Z. L. Wang et al. Nickel-Cobalt Hydroxide Nanosheets Coated on $\mathrm{NiCo}_{2} \mathrm{O}_{4}$ Nanowires Grown on Carbon Fiber Paper for High-Performance Pseudocapacitors. Nano Letters, 13(7), 3135-3139. (2013) DOI: $10.1021 / \mathrm{nl} 401086 \mathrm{t}$

[31]. J. Zhao, J. Chen, S. Xu, M. Shao, Q. Zhang et al. Hierarchical NiMn Layered Double Hydroxide/Carbon Nanotubes Architecture with Superb Energy Density for Flexible Supercapacitors. Advanced Functional Materials, 24(20), 2938-2946. (2014) DOI:10.1002/adfm.201303638

[32]. M. Shao, F. Ning, Y. Zhao, J. Zhao, M. Wei et al. Core-Shell Layered Double Hydroxide Microspheres with Tunable Interior Architecture for Supercapacitors. Chemistry of Materials, 24(6), 1192-1197. (2012) DOI: $10.1021 / \mathrm{cm} 203831 \mathrm{p}$

[33]. Q. Liu, J. Yu, X. Zhang, J. Wang, Z. Li et al. Hierarchically porous MgAl mixed metal oxide synthesized by sudden decomposition of MgAl layered double hydroxide gel. New Journal of Chemistry, 37(7), 2128-2132. (2013) DOI:10.1039/c3nj41177j

[34]. Y. Kuang, L. Zhao, S. Zhang, F. Zhang, M. Dong et al. Morphologies, Preparations and Applications of Layered Double Hydroxide Micro/Nanostructures. Materials, 3(12), 5220-5235. (2010) DOI: $10.3390 / \mathrm{ma} 3125220$

[35]. Y. Li, L. Zhang, X. Xiang, D. Yan and F. Li. Engineering of ZnCo-layered double hydroxide nanowalls toward high-efficiency electrochemical water oxidation. Journal of Materials Chemistry A, 2(33), 13250-13258. (2014) DOI:10.1039/C4TA01275E

[36]. L. Li, R. Ma, N. Iyi, Y. Ebina, K. Takada et al. Hollow nanoshell of layered double hydroxide. Chemical Communications, (29), 3125-3127. (2006) DOI: $10.1039 / \mathrm{b} 605889 \mathrm{~b}$

[37]. M. A. Rocha, P. A. D. Petersen, E. Teixeira-Neto, H. M. Petrilli, F. Leroux et al. Layered double hydroxide and sulindac coiled and scrolled nanoassemblies for storage and drug release. RSC Advances, 6(20), 16419-16436. (2016) DOI:10.1039/C5RA25814F

[38]. A. F. Morais, I. G. N. Silva, S. P. Sree, F. M. de Melo, G. Brabants et al. Hierarchical self-supported ZnAlEu LDH nanotubes hosting luminescent CdTe quantum dots. Chem. Commun., 53(53), 7341-7344. (2017) DOI: $10.1039 / C 7 C C 02097 \mathrm{~J}$

[39]. D. F. Evans and H. Wennerström. The colloidal domain : where physics, chemistry, biology, and technology meet (2nd ed.). Weinheim, Germany: VCH 
Publishers. (1994)

[40]. G. J. de A. A. G. Soler-Illia, C. Sanchez, B. Lebeau and J. Patarin. Chemical strategies to design textured materials: from microporous and mesoporous oxides to nanonetworks and hierarchical structures. Chemical Reviews, 102(11), 4093-4138. (2002) DOI:10.1021/cr0200062

[41]. R. Hadgiivanova, H. Diamant, D. Andelman Raymond and B. Sackler. Kinetics of Surfactant Micellization: A Free Energy Approach. J. Phys. Chem. B, 115, 72687280. (2011) DOI:10.1021/jp1073335

[42]. S. D. Singh-Joy and V. C. McLain. Safety assessment of poloxamers 101, 105, $108,122,123,124,181,182,183,184,185,188,212,215,217,231,234,235,237$, 238, 282, 284, 288, 331, 333, 334, 335, 338, 401, 402, 403, and 407, poloxamer 105 benzoate, and poloxamer 182 dibenzoate as use. International Journal of Toxicology, 27(Suppl. 2), 93-128. (2008) DOI:10.1080/10915810802244595

[43]. P. Petrov, J. Yuan, K. Yoncheva, A. H. E. Müller and C. B. Tsvetanov. Wormlike morphology formation and stabilization of "pluronic P123" micelles by solubilization of pentaerythritol tetraacrylate. Journal of Physical Chemistry B, 112(30), 8879-8883. (2008) DOI:10.1021/jp8008767

[44]. G. Wanka, H. Hoffmann and W. Ulbricht. Phase Diagrams and Aggregation Behavior of Poly(oxyethylene)-Poly(oxypropylene)-Poly(oxyethylene) Triblock Copolymers in Aqueous Solutions. Macromolecules, 27, 4145-4159. (1994)

[45]. P. Alexandridis, V. Athanassiou, S. Fukuda and T. A. Hatton. Surface Activity of Poly(ethylene oxide)-block-Poly(propylene oxide)-block-Poly(ethylene oxide) Copolymers. Langmuir, 10(8), 2604-2612. (1994) DOI:10.1021/la00020a019

[46]. R. Ganguly, V. K. Aswal, P. A. Hassan, I. K. Gopalakrishnan and J. V. Yakhmi. Sodium chloride and ethanol induced sphere to rod transition of triblock copolymer micelles. Journal of Physical Chemistry B, 109(12), 5653-5658. (2005) DOI:10.1021/jp0468408

[47]. M. Malmsten and B. Lindman. Self-assembly in aqueous block copolymer solutions. Macromolecules, 25(20), 5440-5445. (1992) DOI:10.1021/ma00046a049

[48]. P. Bahadur, P. Li, M. Almgren and W. Brown. Effect of Potassium Fluoride on the Micellar Behavior of Pluronic F-68 in Aqueous Solution. Langmuir, 8(8), 19031907. (1992) DOI:10.1021/la00044a005

[49]. N. Pandit, T. Trygstad, S. Croy, M. Bohorquez and C. Koch. Effect of Salts on the Micellization, Clouding, and Solubilization Behavior of Pluronic F127 Solutions. Journal of Colloid and Interface Science, 222(2), 213-220. (2000) DOI:10.1006/JCIS.1999.6628

[50]. N. K. Pandit and J. Kisaka. Loss of gelation ability of Pluronic $®$ F127 in the presence of some salts. International Journal of Pharmaceutics, 145(1-2), 129136. (1996) DOI:10.1016/S0378-5173(96)04748-5

[51]. W. Brown, K. Schillen, M. Almgren, S. Hvidt and P. Bahadur. Micelle and gel formation in a poly(ethylene oxide)/poly(propylene oxide)/poly(ethylene oxide) triblock copolymer in water solution: dynamic and static light scattering and oscillatory shear measurements. The Journal of Physical Chemistry, 95(4), 18501858. (1991) DOI:10.1021/j100157a064

[52]. W. Brown, K. Schillen and S. Hvidt. Triblock copolymers in aqueous solution studied by static and dynamic light scattering and oscillatory shear measurements: influence of relative block sizes. The Journal of Physical 
Chemistry, 96(14), 6038-6044. (1992) DOI:10.1021/j100193a072

[53]. V. K. Aswal, P. S. Goyal, J. Kohlbrecher and P. Bahadur. SANS study of salt induced micellization in PEO-PPO-PEO block copolymers. Chemical Physics Letters, 349(5-6), 458-462. (2001) DOI:10.1016/S0009-2614(01)01249-0

[54]. P. Thiyagarajan, D. J. Chaiko and R. P. Hjelm. A Neutron Scattering Study of Poly(ethylene glycol) in Electrolyte Solutions. Macromolecules, 28(23), 77307736. (1995) DOI:10.1021/ma00127a020

[55]. R. Ivanova, B. Lindman and P. Alexandridis. Effect of Glycols on the SelfAssembly of Amphiphilic Block Copolymers in Water. 1. Phase Diagrams and Structure Identification. Langmuir, 16(8), 3660-3675. (2000) DOI:10.1021/LA991235V

[56]. P. Alexandridis, R. Ivanova and B. Lindman. Effect of Glycols on the SelfAssembly of Amphiphilic Block Copolymers in Water. 2. Glycol Location in the Microstructure. Langmuir, 16(8), 3676-3689. (2000) DOI:10.1021/LA9912343

[57]. J. Armstrong, B. Chowdhry, J. Mitchell, A. Beezer and S. Leharne. Effect of Cosolvents and Cosolutes upon Aggregation Transitions in Aqueous Solutions of the Poloxamer F87 (Poloxamer P237): A High Sensitivity Differential Scanning Calorimetry Study. The Journal of Physical Chemistry, 100(5), 17381745. (1996) DOI:10.1021/jp951390s

[58]. R. Ivanova, B. Lindman and P. Alexandridis. Modification of the lyotropic liquid crystalline microstructure of amphiphilic block copolymers in the presence of cosolvents. Advances in Colloid and Interface Science, 89-90, 351-382. (2001) DOI:10.1016/S0001-8686(00)00049-X

[59]. F. Yan and J. Texter. Polymerization of and in mesophases. Advances in Colloid and Interface Science, 128-130, 27-35. (2006) DOI:10.1016/j.cis.2006.11.014

[60]. C. J. Brinker, Y. Lu, A. Sellinger and H. Fan. Evaporation-Induced SelfAssembly: Nanostructures Made Easy. Advanced Materials, 11(7), 579-585. (1999) DOI:10.1002/(SICI)1521-4095(199905)11:7<579::AIDADMA579>3.0.CO;2-R

[61]. Y. Kadam, R. Ganguly, M. Kumbhakar, V. K. Aswal, P. A. Hassan et al. Time dependent sphere-to-rod growth of the pluronic micelles: Investigating the role of core and corona solvation in determining the micellar growth rate. Journal of Physical Chemistry B, 113(51), 16296-16302. (2009) DOI:10.1021/jp9036974

[62]. R. Ganguly, M. Kumbhakar and V. K. Aswal. Time dependent growth of the block copolymer P123 micelles near cloud point: Employing heat cycling as a tool to form kinetically stable wormlike micelles. Journal of Physical Chemistry B, 113(28), 9441-9446. (2009) DOI:10.1021/jp900535f

[63]. A. J. Freeman and R. E. Watson. Theoretical investigation of some magnetic and spectroscopic properties of rare-earth ions. Physical Review, 127(6), 2058-2075. (1962) DOI:10.1103/PhysRev.127.2058

[64]. R. K. Ray. Investigations into the Origin of the Crystalline Electric Field Effects on Rare Earth Ions: II . Contributions from the Rare Earth Orbitals. Proceedings of the Physical Society, 82(1), 47-57. (1963)

[65]. M. N. Ghatikar, a K. Raychaudhuri and D. K. Ray. Electronic shielding of the crystalline electric field in rare earth ions. Proceedings of the Physical Society, 86(1), 1235-1238. (1965) DOI:10.1088/0370-1328/86/6/309

[66]. T. Jüstel, H. Nikol and C. Ronda. New developments in the field of luminescent 
materials for lighting and displays. Angewandte Chemie International Edition, 37, 3084-3103. (1998) DOI:/10.1002/(SICI)15213773(19981204)37:22\%3C3084::AID-ANIE3084\%3E3.0.CO;2-W

[67]. P. Caravan, J. J. Ellison, T. J. McMurry and R. B. Lauffer. Gadolinium(III) chelates as MRI contrast agents: Structure, dynamics, and applications. Chemical Reviews, 99(9), 2293-2352. (1999) DOI:10.1021/cr980440x

[68]. D. Parker. Luminescent lanthanide sensors for $\mathbf{p H}, \mathbf{p O}_{2}$ and selected anions. Coordination Chemistry Reviews, 205(1), 109-130. (2000) DOI:10.1016/S00108545(00)00241-1

[69]. V. W. W. Yam and K. K. W. Lo. Recent advances in utilization of transition metal complexes and lanthanides as diagnostic tools. Coordination Chemistry Reviews, 184(1), 157-240. (1999) DOI:10.1016/S0010-8545(98)00262-8

[70]. S. Capecchi, O. Renault, D. G. Moon, M. Halim, M. Etchells et al. High-efficiency organic electroluminescent devices using an organoterbium emitter. Advanced Materials, 12(21), 1591-1594. (2000) DOI:10.1002/15214095(200011)12:21<1591::AID-ADMA1591>3.0.CO;2-P

[71]. K. Binnemans. Interpretation of europium(III) spectra. Coordination Chemistry Reviews, 295, 1-45. (2015) DOI:10.1016/j.ccr.2015.02.015

[72]. H. G. Friedman, G. R. Choppin and D. G. Feuerbacher. The shapes of the f orbitals. Journal of Chemical Education, 41(7), 354. (1964) DOI:10.1021/ed041p354

[73]. B. Wybourne. Spectroscopic properties of rare earths (1st ed.). New York: Interscience Publishers (Wiley). (1965)

[74]. V. A. G. Rivera, F. A. Ferri and E. Marega. Localized Surface Plasmon Resonances: Noble Metal Nanoparticle Interaction with Rare-Earth Ions. In K. Y. Kim (Ed.), Plasmonics - Principles and Applications (1st ed., pp. 283-312). InTech. (2012) DOI:10.5772/50753

[75]. H. Felinto Brito, O. Manoel Loureiro Malta, M. Claudia França Cunha Felinto and E. Epaminondas de Sousa Teotonio. Luminescence Phenomena Involving Metal Enolates. In PATAI'S Chemistry of Functional Groups (pp. 131-184). Chichester, UK: John Wiley \& Sons, Ltd. (2010) DOI:10.1002/9780470682531.pat0419

[76]. P. S. P. Peijzel, A. Meijerink, R. T. R. Wegh, M. M. F. Reid and G. W. Burdick. A complete $4 \mathrm{fn}$ energy level diagram for all trivalent lanthanide ions. Journal of Solid State Chemistry, 178(2), 448-453. (2005) DOI:10.1016/j.jssc.2004.07.046

[77]. B. R. Judd. Optical absorption intensities of rare-earth ions. Physical Review, 127(3), 750-761. (1962) DOI:10.1103/PhysRev.127.750

[78]. G. S. Ofelt. Intensities of Crystal Spectra of Rare-Earth Ions. The Journal of Chemical Physics, 37(3), 511-520. (1962) DOI:10.1063/1.1701366

[79]. B. M. Walsh. Judd-Ofelt theory: principles and practices. International School of Atomic and Molecular Spectroscopy, (June), 403-433. (2006) DOI:10.1007/1-40204789-4_21

[80]. W. T. Carnall, P. R. Fields and K. Rajnak. Electronic Energy Levels in the Trivalent Lanthanide Aquo Ions. I. $\mathrm{Pr}^{3+}, \mathrm{Nd}^{3+}, \mathrm{Pm}^{3+}, \mathrm{Sm}^{3+}, \mathrm{Dy}^{3+}, \mathrm{Ho}^{3+}, \mathrm{Er}^{3+}$, and $\mathbf{T m}^{3+}$. The Journal of Chemical Physics, 49(10), 4424-4442. (1968) DOI:10.1063/1.1669893

[81]. W. T. Carnall, P. R. Fields and K. Rajnak. Electronic Energy Levels of the Trivalent Lanthanide Aquo Ions. II. Gd ${ }^{3+}$. The Journal of Chemical Physics, 
49(10), 4443-4446. (1968) DOI:10.1063/1.1669894

[82]. W. T. Carnall, P. R. Fields and K. Rajnak. Electronic Energy Levels of the Trivalent Lanthanide Aquo Ions. III. Tb $^{3+}$. The Journal of Chemical Physics, 49(10), 4447-4449. (1968) DOI:10.1063/1.1669895

[83]. W. T. Carnall, P. R. Fields and K. Rajnak. Electronic Energy Levels of the Trivalent Lanthanide Aquo Ions. IV. $\mathbf{E u}^{3+}$. The Journal of Chemical Physics, 49(10), 4450-4455. (1968) DOI:10.1063/1.1669896

[84]. W. Carnall, H. Crosswhite and H. Crosswhite. Energy level structure and transition probabilities in the spectra of the trivalent lanthanides in $\mathbf{L a F}_{3}$. Argone, IL, USA: Technical Report ANL-78-XX-95. (1978)

[85]. K. Binnemans, K. Van Herck and C. Görller-Walrand. Influence of dipicolinate ligands on the spectroscopic properties of europium(III) in solution. Chemical Physics Letters, 266(3-4), 297-302. (1997) DOI:10.1016/S0009-2614(97)00012-2

[86]. R. T. Moura, A. N. Carneiro Neto, R. L. Longo and O. L. Malta. On the calculation and interpretation of covalency in the intensity parameters of $4 \mathrm{f}-4 \mathrm{f}$ transitions in $\mathrm{Eu}^{3+}$ complexes based on the chemical bond overlap polarizability. Journal of Luminescence, 170, 420-430. (2016) DOI:10.1016/j.jlumin.2015.08.016

[87]. R. M. Martin and R. S. Quimby. Reciprocity between Emission and Absorption for Rare Earth Ions in Glass (PhD Thesis). Worcester Polytechnic Institute. (2006)

[88]. W. H. Melhuish. Absolute spectrofluorometry. Journal of Research of the National Bureau of Standards Section A: Physics and Chemistry, 76A(6), 547. (1972) DOI:10.6028/jres.076A.049

[89]. J. Zabicky (Ed.). The Chemistry of Metal Enolates, Part 1. Group (1st ed.). West Sussex, England: WILEY. (2009) DOI:10.1002/9780470682531.pat0419

[90]. S. I. Weissman. Intramolecular energy transfer. The fluorescence of complexes of europium. The Journal of Chemical Physics, 10(4), 214-217. (1942) DOI:10.1063/1.1723709

[91]. J. O. Hill and R. J. Irving. The heat of formation of aluminium acetylacetonate. Journal of the Chemical Society A: Inorganic, Physical, Theoretical, 0, 971-974. (1966) DOI:10.1039/j19660000971

[92]. G. A. Crosby. Luminescent Organic Complexes of the Rare Earths. Molecular Crystals, 1(1), 37-81. (1966) DOI:10.1080/15421406608083261

[93]. G. A. Crosby, R. E. Whan and R. M. Alire. Intramolecular energy transfer in rare earth chelates. Role of the triplet state. The Journal of Chemical Physics, 34(3), 743-748. (1961) DOI:10.1063/1.1731670

[94]. M. L. Bhaumik and M. A. El-Sayed. Mechanism and Rate of the Intramolecular Energy Transfer Process in Rare-Earth Chelates. The Journal of Chemical Physics, 42(2), 787-788. (1965) DOI:10.1063/1.1696007

[95]. R. E. Whan and G. A. Crosby. Luminescence studies of rare earth complexes: benzoylacetonate and dibenzoylmethide chelates. Journal of Molecular Spectroscopy, 8(1-6), 315-327. (1962)

[96]. F. R. Gonçalves e Silva, O. L. Malta, C. Reinhard, H.-U. Güdel, C. Piguet et al. Visible and Near-Infrared Luminescence of Lanthanide-Containing Dimetallic Triple-Stranded Helicates: Energy Transfer Mechanisms in the Sm III and Yb III Molecular Edifices. The Journal of Physical Chemistry A, 106(9), 1670-1677. (2002) DOI:10.1021/jp012884u

[97]. M. Kleinerman. Energy migration in lanthanide chelates. The Journal of 
Chemical Physics, 51(6), 2370-2381. (1969) DOI:10.1063/1.1672355

[98]. G. E. Buono-Core, H. Li and B. Marciniak. Quenching of excited states by lanthanide ions and chelates in solutionOriginal Research Article. Coord. Chem. Rev., 99, 55-87. (1990)

[99]. I. G. N. Silva, D. Mustafa, M. C. F. C. Felinto, W. M. Faustino, E. E. S. Teotonio et al. Low Temperature Synthesis of Luminescent $\mathrm{RE}_{2} \mathrm{O}_{3}: \mathrm{Eu}^{3+}$ Nanomaterials Using Trimellitic Acid Precursors. Journal of the Brazilian Chemical Society, 26(12), 2629-2639. (2015) DOI:10.5935/0103-5053.20150314

[100]. K. Okada, Y. Wang, T. Chen, M. Kitamura, T. Nakaya et al. Bright red lightemitting organic electroluminescent devices based on a novel thiophenecontaining europium complex as an emitting layer. Journal of Materials Chemistry, 9(12), 3023-3026. (1999) DOI:10.1039/a906215g

[101]. T. Sano, M. Fujita, T. Fujii, Y. Hamada, K. Shibata et al. Novel Europium Complex for Electroluminescencent Devices with Sharp red Emission. Jpn. J. Appl. Phys., 34, 1883-1887. (1995)

[102]. R. Reyes, M. Cremona, E. E. S. Teotonio, H. F. Brito and O. L. Malta. Voltage

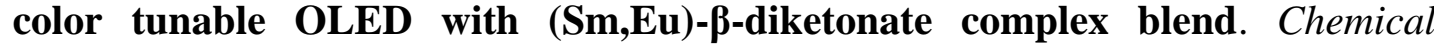
Physics Letters, 396(1-3), 54-58. (2004) DOI:10.1016/j.cplett.2004.07.074

[103]. G. L. Law, K. L. Wong, H. L. Tam, K. W. Cheah and W. T. Wong. White OLED with a Single-Component Europium Complex. Inorganic Chemistry, 48(22), 10492-10494. (2009) DOI:10.1021/ic9018037

[104]. J. Atteberry. The Key Components of a Scanning Electron Microscope - How Scanning Electron Microscopes Work | HowStuffWorks. (n.d.) Retrieved October 18, 2016, from http://science.howstuffworks.com/scanning-electronmicroscope $2 . h t m$

[105]. L. Reimer. Scanning Electron Microscopy. An Introduction to Microscopy by Means of Light, Electrons, X-Rays, or Ultrasound (Vol. 45). Berlin, Heidelberg: Springer Berlin Heidelberg. (1998) DOI:10.1007/978-3-540-38967-5

[106]. B. Fultz and J. Howe. Transmission Electron Microscopy and Diffractometry of Materials. Berlin, Heidelberg: Springer Berlin Heidelberg. (2013) DOI:10.1007/978-3-642-29761-8

[107]. Wikimedia Commons. (2011) Retrieved October 18, 2016, from https://commons.wikimedia.org/wiki/File:Inductively_Coupled_Plasma.jpg

[108]. D. A. Skoog, F. J. Holler and S. R. Crouch. Principles of instrumental analysis (6th ed.). Thomson Brooks/Cole. (2007)

[109]. D. A. Skoog, D. M. West, F. J. Holler and S. R. Crouch. Fundamentals of analytical chemistry (9th ed.). Brooks Cole. (2013)

[110]. V. A. Fassel. Quantitative Elemental Analyses by Plasma Emission Spectroscopy. $\quad$ Science, 202(4364), 183-191. DOI: $10.1126 /$ science.202.4364.183

[111]. PerkinElmer. 2400 Series II CHNS/O Elemental Analysis Award-Winning Results. Waltham, MA, USA: Perkin Elmer. (n.d.) Retrieved October 18, 2016, from http://www.perkinelmer.com/labsolutions/resources/docs/BRO_2400_SeriesII_CHNSO_Elemental_Analysis.pdf

[112]. Michael Thompson (Ed.). CHNS Elemental Analysers - AMC Technical Briefs. Royal Society of Chemistry. (2008)

[113]. PerkinElmer. 2400 Series II CHNS/O Analyzer. (n.d.) Retrieved October 18, 2016, 
from http://www.perkinelmer.co.uk/CMSResources/Images/4474656PRD_2400SeriesIICHNSOAnalyzer.pdf

[114]. F. Rouquerol, J. Rouquerol and K. Sing. Interpretation of Physisorption Isotherms at the Gas-Solid Interface. In Adsorption by Powders and Porous Solids (pp. 93-115). Elsevier. (1999)

[115]. D. C. Harris. Quantitative Chemical Analysis (7th ed.). New York: W. H. Freeman. (2006)

[116]. Lecture 22: Thermal methods. (2005) Retrieved October 18, 2016, from http://radchem.nevada.edu/classes/chem455/lecture_22_thermal_methods.htm

[117]. P. Nalawade, B. Aware, V. Kadam and R. Hirlekar. Layered double hydroxides: A review. J. Sci. Ind. Res, 68, 267-272. (2009)

[118]. S. V Krivovichev, V. N. Yakovenchuk, E. S. Zhitova, A. A. Zolotarev, Y. A. Pakhomovsky et al. Crystal chemistry of natural layered double hydroxides. 2. Quintinite-1M: first evidence of a monoclinic polytype in $\mathbf{M}^{2+}-\mathbf{M}^{3+}$ layered double hydroxides. Mineralogical Magazine, 74(5), 833-840. (2010) DOI:10.1180/minmag.2010.074.5.833

[119]. P. J. Sideris, U. G. Nielsen, Z. Gan and C. P. Grey. Mg/Al ordering in layered double hydroxides revealed by multinuclear NMR spectroscopy. Science (New York, N.Y.), 321(5885), 113-7. (2008) DOI:10.1126/science.1157581

[120]. A. Di Bitetto, E. André, C. Carteret, P. Durand and G. Kervern. Probing the Dynamics of Layered Double Hydroxides by Solid-State ${ }^{27} \mathrm{Al}$ NMR Spectroscopy. The Journal of Physical Chemistry C, 121(13), 7276-7281. (2017) DOI:10.1021/acs.jpcc.6b13106

[121]. M. Vucelic, W. Jones and G. D. Moggridge. Cation ordering in synthetic layered double hydroxides. Clays and Clay Minerals, 45(6), 803-813. (1997) DOI:10.1346/CCMN.1997.0450604

[122]. G. Bourrié, F. Trolard, P. Refait and F. Feder. A Solid-Solution Model for Fe(II)Fe(III)-Mg(II) Green Rusts and Fougerite and Estimation of Their Gibbs Free Energies of Formation. Clays and Clay Minerals, 52(3), 382-394. (2004) DOI:10.1346/CCMN.2004.0520313

[123]. Maurizio Bellotto, B. Rebours, A. Olivier Clause, J. Lynch, D. B. And et al. A Reexamination of Hydrotalcite Crystal Chemistry. J. Phys. Chem., 100(20), 8527-8534. (1996) DOI:10.1021/JP960039J

[124]. X. Duan, D. G. Evans, J. He, Y. Kang, A. I. Khan et al. Structure and Bonding Layered Double Hydroxides. (D. G. Duan, X. Evans, Ed.) (1st ed., Vol. 119). Springer Berlin Heidelberg. (2005) DOI:10.1007/b100426

[125]. S. Miyata. Physico-Chemical Properties of Synthetic Hydrotalcites in Relation to Composition. Clays and Clay Minerals, 28(1), 50-56. (1980) DOI:10.1346/CCMN.1980.0280107

[126]. E. Conterosito, L. Palin, D. Antonioli, D. Viterbo, E. Mugnaioli et al. Structural Characterisation of Complex Layered Double Hydroxides and TGA-GC-MS Study on Thermal Response and Carbonate Contamination in Nitrate- and Organic-Exchanged Hydrotalcites. Chemistry - A European Journal, 21(42), 14975-14986. (2015) DOI:10.1002/chem.201500450

[127]. J. T. Kloprogge, D. Wharton, L. Hickey and R. L. Frost. Infrared and Raman study of interlayer anions $\mathrm{CO}_{3}{ }^{2-}, \mathrm{NO}_{3}{ }^{-}, \mathrm{SO}_{4}{ }^{2-}$ and $\mathrm{ClO}_{4}{ }^{-}$in $\mathrm{Mg} / \mathrm{Al}-\mathrm{hydrotalcite}$. American Mineralogist, 87(5-6), 623-629. (2002) DOI:0003-004X/02/0506- 
$623 \$ 05.00$

[128]. S. Miyata. Anion-Exchange Properties of Hydrotalcite-Like Compounds. Clays and Clay Minerals, 31(4), 305-311. (1983) DOI:10.1346/CCMN.1983.0310409

[129]. A. S. Bookin and V. A. Drits. Polytype diversity of the hydrotalcite-like minerals I. possible polytypes and their diffraction features. Clays and Clay Minerals, 41(5), 551-557. (1993) DOI:10.1346/CCMN.1993.0410504

[130]. S. A. Solin, D. Hines, S. K. Yun, T. J. Pinnavaia and M. F. Thorpe. Layer rigidity in 2D disordered NiAl layer double hydroxides. Journal of Non-Crystalline Solids, 182(1-2), 212-220. (1995) DOI:10.1016/0022-3093(94)00541-9

[131]. S. Marappa and P. V. Kamath. Structure of the Carbonate-Intercalated Layered Double Hydroxides: A Reappraisal. Industrial and Engineering Chemistry Research, 54(44), 11075-11079. (2015) DOI:10.1021/acs.iecr.5b03207

[132]. S. Marappa, S. Radha and P. V. Kamath. Nitrate-intercalated layered double hydroxides - Structure model, order, and disorder. European Journal of Inorganic Chemistry, (12), 2122-2128. (2013) DOI:10.1002/ejic.201201405

[133]. C. Vaysse, L. Guerlou-Demourgues, A. Demourgues, F. Lazartigues, D. Fertier et al. New ( $\mathrm{Ni}, \mathrm{Co}$ )-based layered double hydroxides with intercalated oxometalate (Mo, W) species, obtained by chimie douce reactions. Journal of Materials Chemistry, 12(4), 1035-1043. (2002) DOI:10.1039/b107791k

[134]. D. R. Consoni. Morfologia e Estrutura dos Nódulos de Grafite Gerados pela Dissociação de SiC na Sinterização (Tese de Doutorado). Universidade Federal de Santa Catarina. (2014)

[135]. M.-A. Kim, D. Jang, S. Tejima, R. Cruz-Silva, H.-I. Joh et al. Strengthened PANbased carbon fibers obtained by slow heating rate carbonization. Scientific Reports, 6(1), 22988. (2016) DOI:10.1038/srep22988

[136]. ISO. ISO/TS 80004-13:2017 - Nanotechnologies -- Vocabulary -- Part 13: Graphene and related two-dimensional (2D) materials. (ISO/TC 229, Ed.) (1st ed.). International Organization for Standardzation. (2017)

[137]. E. R. Souza, I. G. N. Silva, E. E. S. Teotonio, M. C. F. C. Felinto and H. F. Brito. Optical properties of red, green and blue emitting rare earth benzenetricarboxylate compounds. Journal of Luminescence, 130(2), 283-291. (2010) DOI:10.1016/j.jlumin.2009.09.004

[138]. W. T. Carnall, P. R. Fields and K. Rajnak. Spectral Intensities of the Trivalent Lanthanides and Actinides in Solution. II $\mathbf{P m}^{3+}, \mathrm{Sm}^{3+}, \mathbf{E u}^{3+}, \mathbf{G d}^{3+}, \mathrm{Tb}^{3+}, \mathrm{Dy}^{3+}$ and $\mathbf{H o}^{3+}$. The Journal of Chemical Physics, 49(10), 4412-4423. (1968) DOI: $10.1063 / 1.1669892$

[139]. I. G. N. Silva, D. Mustafa, B. Andreoli, M. C. F. C. Felinto, O. L. Malta et al. Highly luminescent Eu3+-doped benzenetricarboxylate based materials. Journal of Luminescence, $\quad 170, \quad 364-368 . \quad$ (2016) DOI:https://doi.org/10.1016/j.jlumin.2015.04.047

[140]. A. A. S. Gonçalves, M. J. F. Costa, L. Zhang, F. Ciesielczyk and M. Jaroniec. OnePot Synthesis of $\mathrm{MeAl}_{2} \mathrm{O}_{4}(\mathrm{Me}=\mathrm{Ni}, \mathrm{Co}$, or $\mathrm{Cu})$ Supported on $\gamma$-Al2O3 with Ultralarge Mesopores: Enhancing Interfacial Defects in $\gamma$-Al2O3 to Facilitate the Formation of Spinel Structures at Lower Temperatures. Chemistry of Materials, 30(2), 436-446. (2018) DOI:10.1021/acs.chemmater.7b04353

[141]. F. Bérubé and S. Kaliaguine. Calcination and thermal degradation mechanisms of triblock copolymer template in SBA-15 materials. Microporous and 
Mesoporous Materials, $\quad$ 115(3), 469-479. (2008) DOI:10.1016/j.micromeso.2008.02.028

[142]. S. G. de Ávila, L. C. C. Silva and J. R. Matos. Optimisation of SBA-15 properties using Soxhlet solvent extraction for template removal. Microporous and Mesoporous $\quad$ Materials, $\quad 234, \quad 277-286 . \quad$ (2016) DOI:10.1016/j.micromeso.2016.07.027

[143]. R. Ma and T. Sasaki. Nanosheets of oxides and hydroxides: Ultimate 2D chargebearing functional crystallites. Advanced Materials, 22(45), 5082-104. (2010) DOI:10.1002/adma.201001722 